\title{
Untersuchungen der Funktion des Kleinhirns mit Hilfe von Mausmutanten
}

\author{
Dissertation \\ zur Erlangung des mathematisch-naturwissenschaftlichen Doktorgrades \\ „Doctor rerum naturalium“ \\ der Georg-August-Universität Göttingen
}

\author{
vorgelegt von \\ Diplom-Biologe \\ Alexander Pieper
}

aus Leipzig, Deutschland

Göttingen 2010 
Referent:

Korreferent:

Tag der mündlichen Prüfung:
Prof. Dr. Nils Brose

Prof. Dr. Reinhold Hustert 08.11.2010 
Die vorliegende Arbeit wurde in der Zeit von Oktober 2006 bis September 2010 am MaxPlanck-Institut für Experimentelle Medizin (Göttingen) in der Abteilung Neurogenetik (Leiter: Prof. Dr. Klaus-Armin Nave) durchgeführt. 
Meinen Eltern, Großeltern und Svenja 


\begin{tabular}{|c|c|}
\hline Abb. & Abbildung \\
\hline ANK3 & Ankyrin3 \\
\hline ATP & Adensosintriphosphat \\
\hline BCIP & 5-Brom-4-Chlor-3-Indolylphosphat, Toluidin-Salz \\
\hline$\beta-G a l$ & $\beta$-Galaktosidase \\
\hline bp & Basenpaare \\
\hline BSA & Rinder-Serum-Albumin (bovine serum albumin) \\
\hline $\mathrm{Bp}$ & Basenpaare (base pairs) \\
\hline cDNA & komplementäre Desoxyribonukleinsäure \\
\hline${ }^{\circ} \mathrm{C}$ & Grad Celsius \\
\hline CMV & humanes Zytomegalievirus \\
\hline bzw. & beziehungsweise \\
\hline $\mathrm{H} 2 \mathrm{O}_{\mathrm{dd}}$ & entsalztes destilliertes Wasser \\
\hline DAPI & 4,6-Diamino-2-phenylindol \\
\hline DEPC & Diethylpyrocarbonat \\
\hline DMSO & Dimethylsulfoxid \\
\hline DNA & Desoxyribonukleinsäure \\
\hline dNTP & Desoxynukleosidtriphosphat \\
\hline DTT & 1,4-Dithiotreitol \\
\hline $\mathrm{E}$ & Embryonaltag \\
\hline E.coli & Escherichia coli \\
\hline EDTA & Ethylendiamintetraessigsäure \\
\hline EKS & Externe Körnerzellschicht \\
\hline EM & Elektronenmikroskopie \\
\hline EPSC & excitatory postsynaptic current \\
\hline $\mathrm{EtOH}$ & Ethanol \\
\hline FCS & fötales Kälberserum (fetal calf serum) \\
\hline GABA & $\gamma$-Aminobuttersäure (gamma-Aminobutiric acid) \\
\hline GABRA1 & gamma-aminobutyric acid receptor alpha 1 \\
\hline GAD $1 / 2$ & glutamic acid $\underline{\text { decarboxylase } 1 / 2}$ \\
\hline $\mathrm{h}$ & Stunden (hours) \\
\hline HBSS & Hank's gepufferte Salzlösung \\
\hline HCN1 & hyperpolarization activated cyclic nucleotide-gated potassium chanel 1 \\
\hline HRP & Meerrettich Peroxidase (horseradish peroxidase) \\
\hline HS & Pferdeserum (horse serum) \\
\hline IHC & Immunhistochemie \\
\hline IKS & Interne Körnerzellschicht \\
\hline IN & Interneurone \\
\hline IPSC & inhibitory postsynaptic current \\
\hline ISH & in situ Hybridisierung \\
\hline KZ & Körnerzellen \\
\hline $\mathrm{KS}$ & Körnerzellschicht \\
\hline KS-IN & Körnerzellschicht-Interneurone \\
\hline loxP & locus of crossover aus dem Bakteriophagen $\mathrm{P}$ \\
\hline $\mathrm{mm}$ & Millimeter \\
\hline $\mathrm{mV}$ & Millivolt \\
\hline M & Molar $=\mathrm{mol} / 1$ \\
\hline MAP2 & microtubule-associated protein 2 \\
\hline$\mu \mathrm{m}$ & $\bar{M}$ ikrometer \\
\hline$\mu 1$ & Mikroliter \\
\hline MS & Molekularschicht \\
\hline
\end{tabular}




\begin{tabular}{|c|c|}
\hline MS-IN & Molekularschicht-Interneurone \\
\hline $\mathrm{n}$ & Stichprobenumfang \\
\hline NBT & Nitroblautetrazoliumchlorid \\
\hline NDRF & NeuroD $\underline{\text { related factor }}$ \\
\hline NEPH3 & Nephrin 3 \\
\hline NeuroD & neurogenic differentiation \\
\hline NEFH & neurofilament heavy \\
\hline NEX & neuronal helix-loop-helix protein \\
\hline OD & optische Dichte \\
\hline $\mathrm{P}$ & Postnataltag \\
\hline pA & Pico-Ampere \\
\hline PAX2 & paired box gene 2 \\
\hline PBS & Phosphat-gepufferte Salzlösung (phosphat-buffered saline) \\
\hline PCR & Polymerase-Kettenreaktion (polymerase chain reaction) \\
\hline PS & Purkinje-Zellschicht \\
\hline PSD95 & postsynaptic density protein 95 \\
\hline PTF1A & pancreas transcription factor 1 \\
\hline $\mathrm{PZ}$ & Purkinje-Zellen \\
\hline PFA & Paraformaldehyd \\
\hline $\mathrm{pH}$ & negativer dekadischer Logarithmus der Protonenkonzentration \\
\hline PVALB & Parvalbumin \\
\hline RL & Rhombische Lippe \\
\hline RNA & Ribonukleinsäure \\
\hline RNAse & Ribonuklease \\
\hline RNasin & Ribonuklease Inhibitor \\
\hline RT & Raumtemperatur \\
\hline RT-PCR & Reverse Transkriptase Polymerase-Kettenreaktion \\
\hline SDS & Natriumdodecylsulfat \\
\hline SSC & Standard-Zitratpuffer \\
\hline TAE & Tris-Acetat/EDTA-Puffer \\
\hline TE & Tris/EDTA-Puffer \\
\hline $\mathrm{TF}$ & Transkriptionsfaktor \\
\hline Tris & Tris-(hydroxymethyl)-aminomethan \\
\hline Tween20 & Polyoxyethylenmonosorbitanlaurinsäure \\
\hline $\mathrm{TZK}$ & Tiefe zerebelläre Kerne \\
\hline $\mathrm{U}$ & Einheit der Enzymaktivität (unit) \\
\hline UV & ultraviolettes Licht \\
\hline VGAT & vesicular GABA transporter \\
\hline $\mathrm{VZ}$ & Ventrikularzone \\
\hline WS & Weiße Substanz \\
\hline $\mathrm{ZS}$ & Ziegenserum \\
\hline ZNS & Zentrales Nervensystem \\
\hline
\end{tabular}


1 EINLEITUNG. 1

$1.1 \quad$ Das zentrale Nervensystem .............................................................................................................................. 1

1.2 Molekulare Programme zur Steuerung der Zerebellumentwicklung .............................................. 3

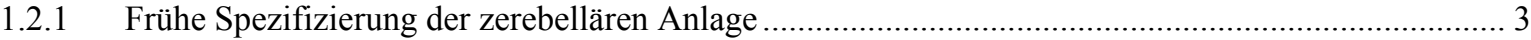

1.2.2 Ontogenese, Wanderungsrouten, Differenzierung und Reifung zerebellärer Zelltypen .................... 5

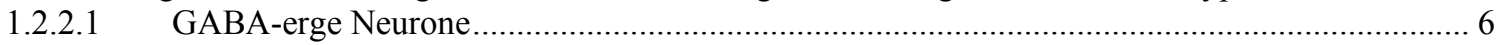

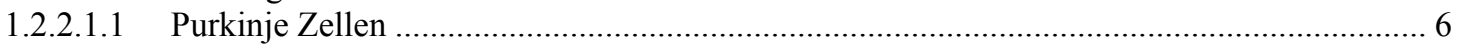

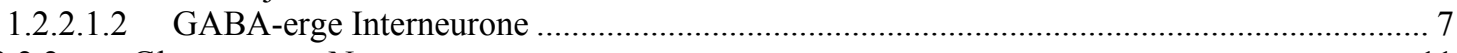

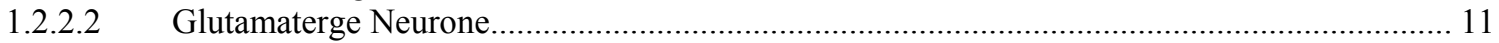

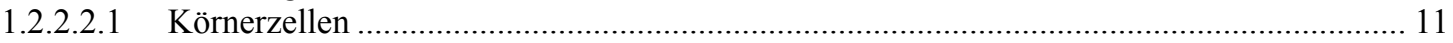

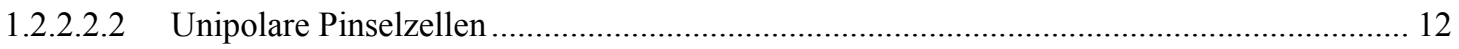

1.3 Molekulare Programme zur Steuerung der Axon- und Dendritenentwicklung............................... 13

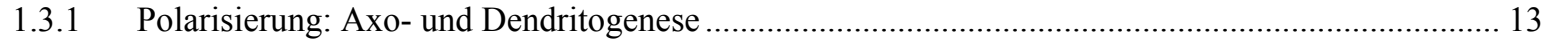

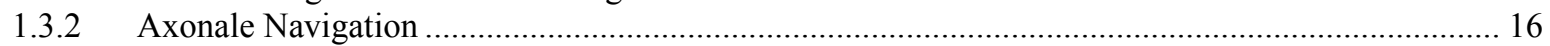

1.3.2.1 Wachstumsfaktoren und Signaltransduktionswege zur Steuerung der axonalen Navigation ... 16

1.3.2.2 Transkriptionelle Mechanismen zur Steuerung der axonalen Navigation ............................ 18

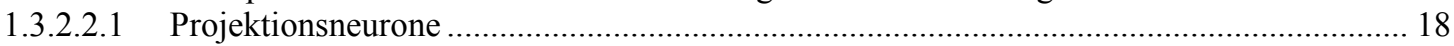

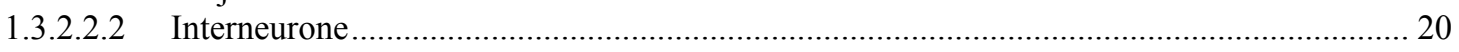

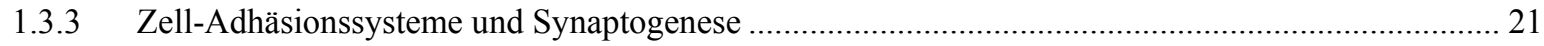

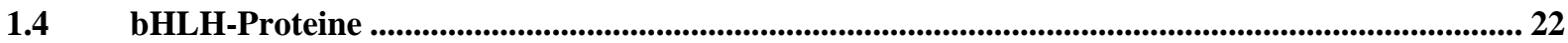

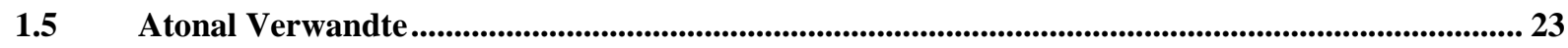

1.6 Konditionale Inaktivierung von Genen mittels Cre loxP-System.............................................. 25

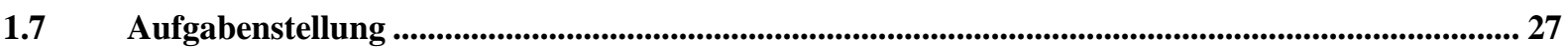

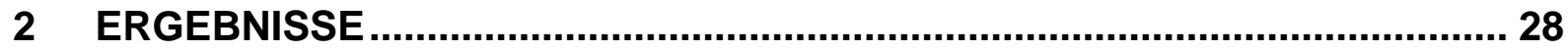

$2.1 \quad$ Erzeugung NDRF-nullmutanter Mäuse................................................................................................28

2.2 Rückkreuzung auf Sv129 genetischen Hintergrund ................................................................... 28

2.3 Reduzierte zerebelläre Größe in NDRF-Nullmutanten ....................................................................29

$2.4 \quad$ Normale Körnerzellentwicklung in NDRF-Nullmutanten .........................................................30

2.5 Reife und normal entwickelte Kletterfasern in NDRF-Nullmutanten .............................................. 33

2.6 Die Anzahl von Korb- und Sternzellen ist in NDRF-Nullmutanten reduziert ................................ 34

2.7 Gestörte terminalen Differenzierung von Korb- und Sternzellen in NDRF-Nullmutanten........... 36

2.8 Verzögerte Differenzierung von Korb- und Sternzellen in NDRF-Nullmutanten ........................ 37

2.9 Dendrito- und Axogenese von Korb- und Sternzellen in NDRF-Nullmutanten.............................. 39

2.10 Sekundäre Effekte des NDRF-Verlustes............................................................................................ 43

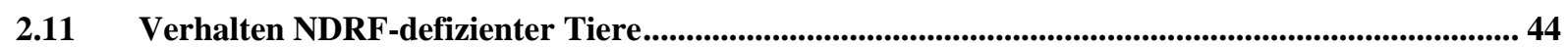

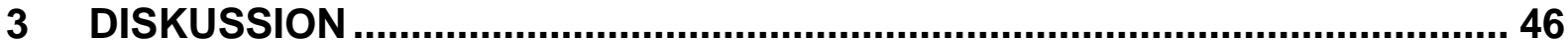


Die Funktion von NDRF in zerebellären Körnerzellen .................................................................4 47

3.2.1 NDRF sichert das Überleben von Körnerzellen während früher Entwicklungsphasen.................... 47

3.2.2 NDRF besitzt in vivo keine essentielle Funktion als transkriptioneller Regulator der Dendrito- Axo-

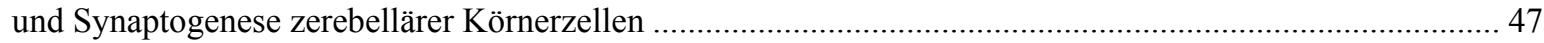

3.2.3 Partielle Redundanz der bHLH-Proteine NeuroD und NDRF in zerebellären Körnerzellen ............ 49

3.3 Die Funktion von NDRF in zerebellären Interneuronen..........................................................5 50

3.3.1 NDRF reguliert die terminale Differenzierung von Interneuronen der Molekularschicht ................50

3.3.2 NDRF als transkriptioneller Regulator der Axonentwicklung in Korbzellen ...............................51

3.4 Motorische Defizite bei fehlender synaptischer Korbzelltransmission ..........................................56

3.5 Neuropathologische Veränderungen durch gestörte GABA-erge synaptische Transmission im

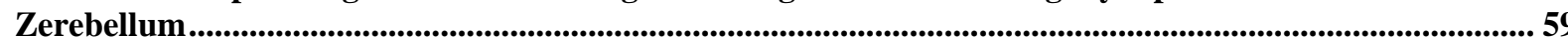

4 MATERIAL

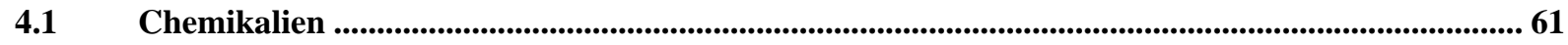

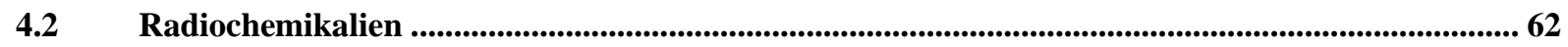

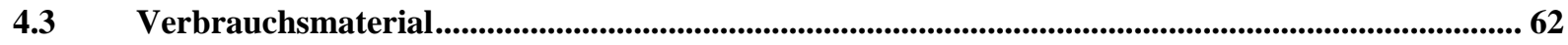

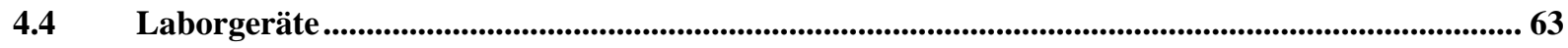

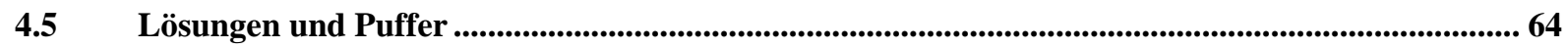

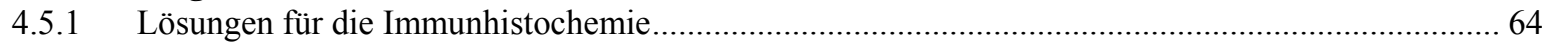

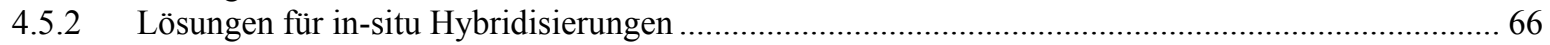

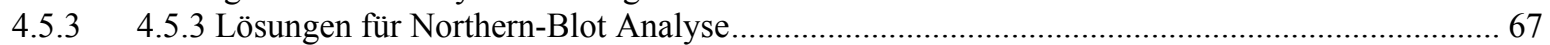

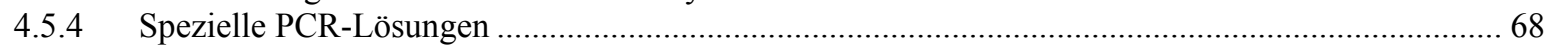

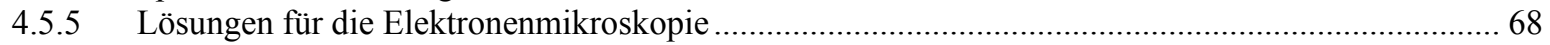

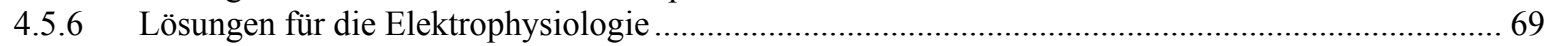

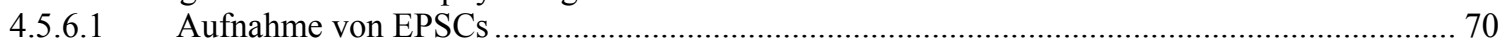

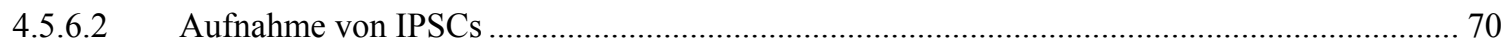

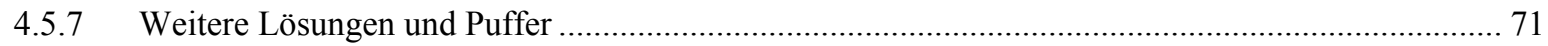

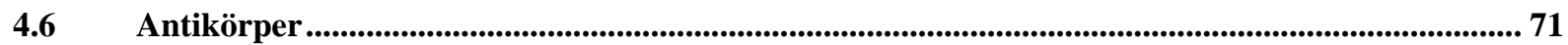

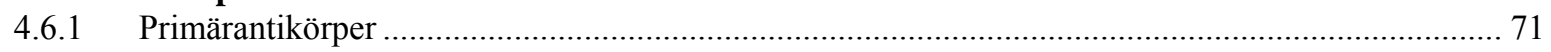

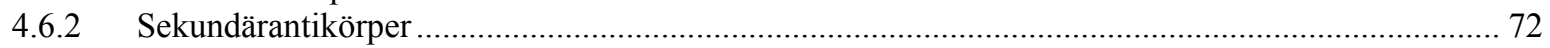

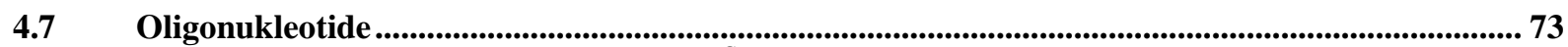

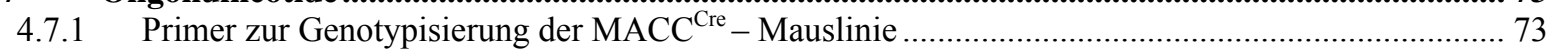

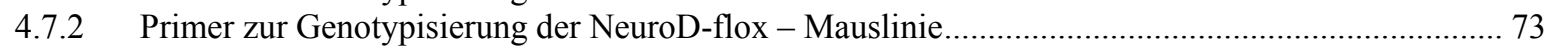

4.7.3 Primer zur Genotypisierung der NDRF mutanten Mauslinie............................................... 73

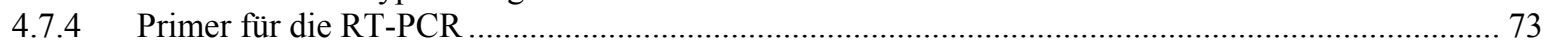

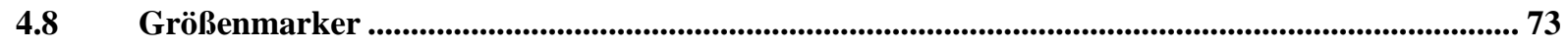

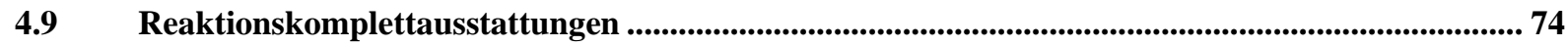

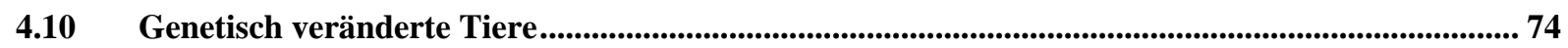

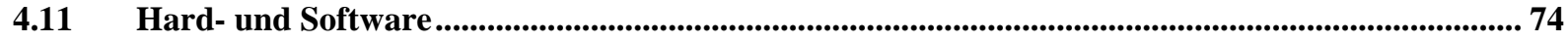

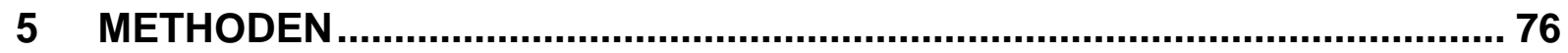

Histologische und immunhistochemische Methoden ................................................................. 76 
5.1.1 Ganzkörperfixierung von Mäusen durch Perfusion ...................................................... 76

5.1.2 Herstellung von Paraffinschnitten für die Lichtmikroskopie ............................................... 76

5.1.3 Herstellung von Vibratomschnitten für die Lichtmikroskopie.................................................. 77

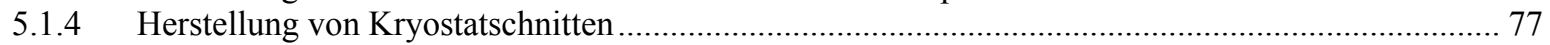

5.1.5 Semidünn- und Ultradünnschnitte für die Elektronenmikroskopie ............................................ 77

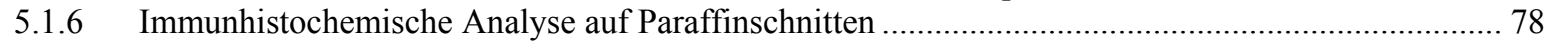

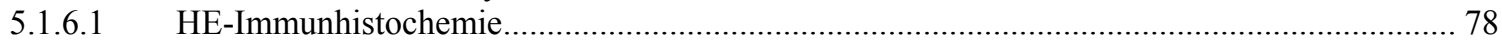

5.1.6.2 Fluoreszente Immunhistochemie auf Paraffinschnitten ....................................................... 78

5.1.7 Immunhistochemische Analyse auf Vibratomschnitten ...................................................... 79

5.1.8 Methylen-Azur II-Färbung (Richardson, 1969) von Semidünnschnitten..................................... 79

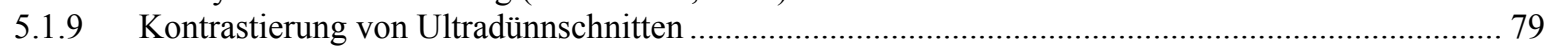

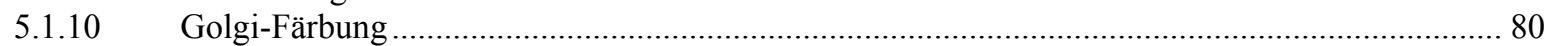

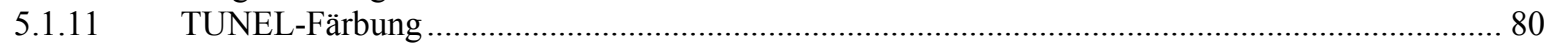

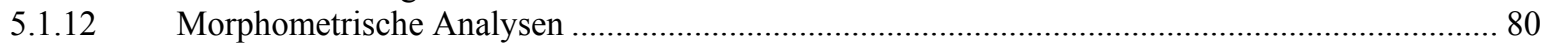

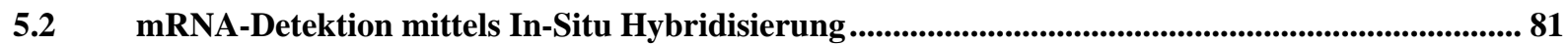

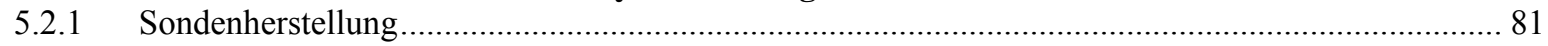

5.2.2 Restriktionsverdau zur Linearisierung der Plasmide....................................................... 81

5.2.3 In vitro Transkription zur Sondenmarkierung..................................................................... 81

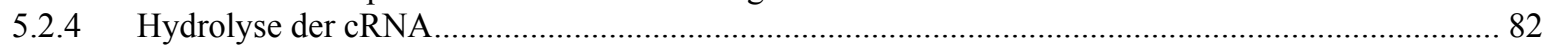

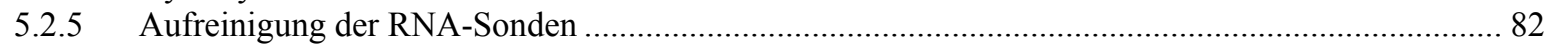

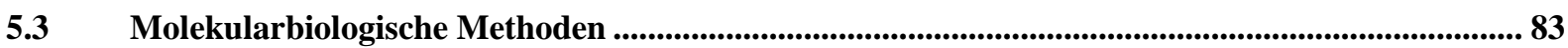

5.3.1 Präparation von genomischer DNA aus Mausschwanzgeweben .............................................. 83

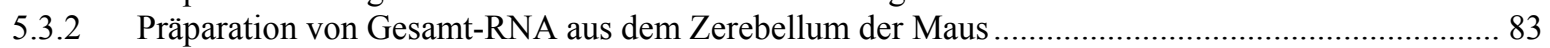

5.3.3 Konzentrationsbestimmung von Nukleinsäuren mittels Photometer ........................................ 84

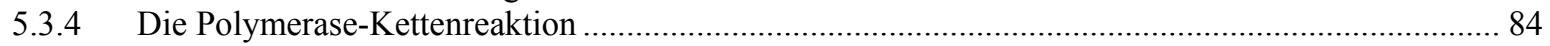

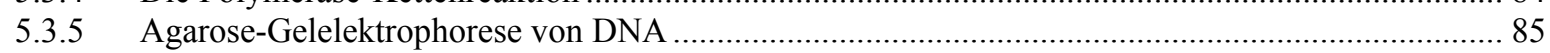

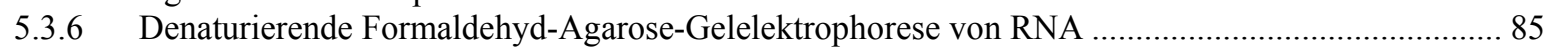

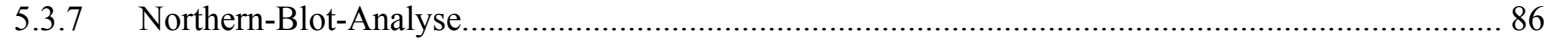

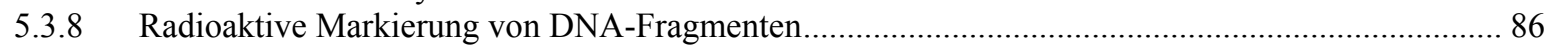

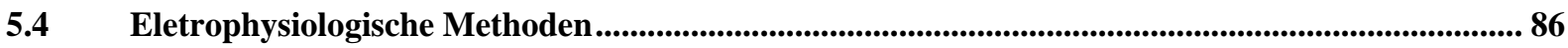

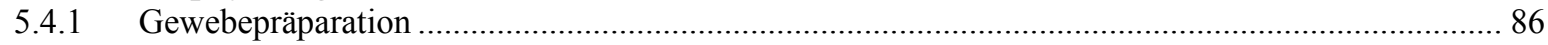

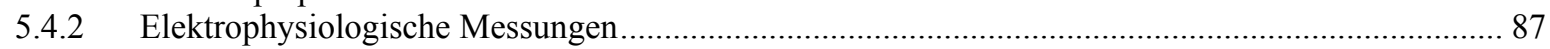

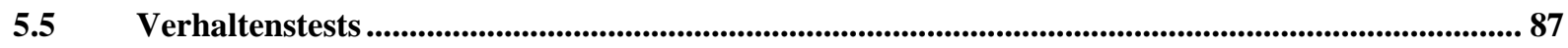

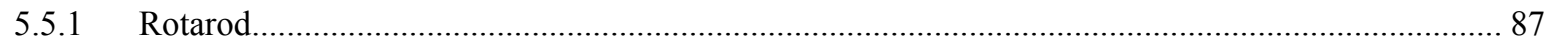

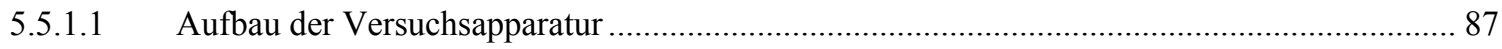

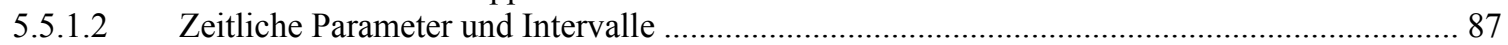

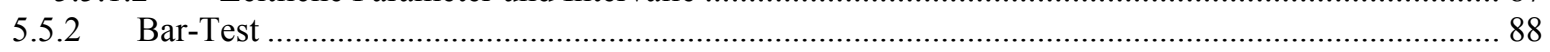

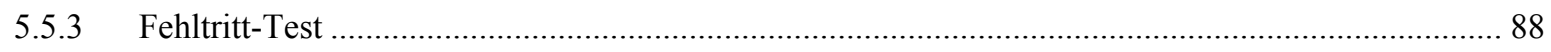

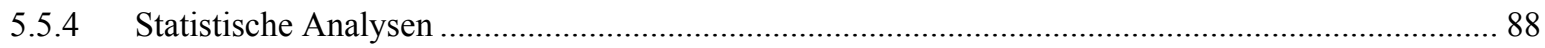

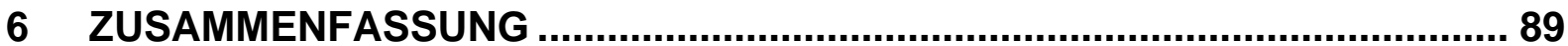

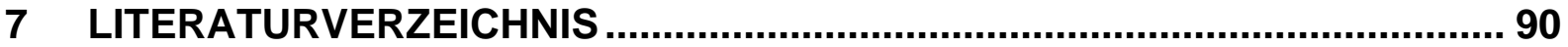

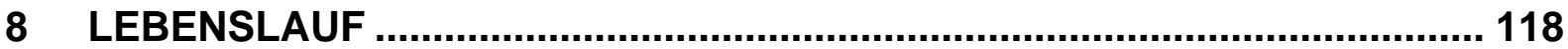

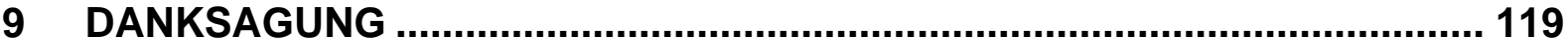




\section{Einleitung}

\subsection{Das zentrale Nervensystem}

Das Nervensystem koordiniert die Rezeption, Prozessierung und Weiterleitung sensibler extrinsischer sowie intrinsischer, im Organismus selbst generierter Reize. Es ermöglicht eine effektive Kommunikation zwischen den Organen des Körpers und erzeugt lokal und temporal spezifische Aktivierungsmuster zur Kontrolle diverser Verhaltensweisen.

Säugetiere besitzen ein stark zentralisiertes Nervensystem. Es wird in das Zentrale Nervensystem (ZNS), bestehend aus Gehirn und Rückenmark und in das periphere Nervensystem (PNS), das Ganglien (Nervenknoten) und periphere Nerven umfasst, untergliedert. Innerhalb des PNS können somatisches und vegetatives Nervensystem unterschieden werden.

Anatomisch lässt sich das adulte ZNS in sechs Bereiche gliedern: Telencephalon (Großhirn), Diencephalon (Zwischenhirn), Mesencephalon (Mittelhirn), Pons und Cerebellum (Brücke und Kleinhirn), Medulla oblongata (verlängertes Mark) und Rückenmark. Auf zellulärer Ebene besteht das ZNS aus zwei Hauptkomponenten, den Neuronen und neuroglialen Zelltypen.

Das menschliche Gehirn besteht aus ca. $10^{11}$ Neuronen, die in neuronalen Netzwerken organisiert sind und über $10^{14}$ bis $10^{15}$ Synapsen miteinander kommunizieren (Brose, 1999).

Für das auf höheren Hirnleistungen basierende komplexe Verhalten von Säugetieren ist neben der Spezialisierung der jeweiligen Neurone vor allem ihre synaptische Verschaltung zu Netzwerken entscheidend. Während der Entwicklung und Regeneration sowie durch Erfahrungen und Lernen können synaptische Eigenschaften durch neuronale Aktivität modifiziert werden.

Trotz der großen Vielfalt von Neuronen können sie, basierend auf morphologischen Charakteristika, in drei funktionelle Hauptgruppen untergliedert werden. Primäre sensorische afferente Neurone versorgen das ZNS mit Informationen von sensorischen Instanzen der Körperperipherie wie etwa den Mechanorezeptoren der Haut oder Photorezeptoren der Retina. Motorneurone werden hingegen als efferente Neurone bezeichnet, da sie instruktive Informationen zu Muskeln oder Drüsen weiterleiten. Die Mehrheit der Neurone sind jedoch solche, die ausschließlich Kontakte mit anderen Neuronen eingehen, die sog. Interneurone. Sie werden in lokale Interneurone mit kurzen Axonen und Projektions-Interneurone, die Informationen über längere Distanzen vermitteln, unterschieden. 
Auf einzelzellulärer Ebene liegt allen Neuronen ein gemeinsamer Grundbauplan zugrunde: Neurone bestehen aus einem Zellkörper mit Zellkern (Neurosmoma) und einem, meist breitbasig am Zellkörper entspringenden und fein verzweigten Zytoplasmafortsatz, dem Dendriten. Dieser dient der Aufnahme synaptisch übertragener Information. Das Ergebnis der Informationsverarbeitung wird über das Axon, einen weiteren, am Zellkörper entspringenden, meist wenig oder unverzweigten, achsenförmigen und bis zu $1 \mathrm{~m}$ langen Zytoplasmafortsatz, in einer Reihe von Aktionspotentialen an die Effektorzellen weitergeleitet.

Das Netzwerk der Neurone wird durch die Neuroglia komplettiert, die in Makro- und Mikroglia untergliedert werden können. $\mathrm{Zu}$ den Makroglia gehören Oligodendrozyten, Schwannzellen und Astrozyten. Die aus der Subventrikularzone stammenden Oligodendrozyten sind die myelinbildenden Zellen des ZNS, die aus der Neuralleiste hervorgehenden Schwannzellen synthetisieren das Myelin des PNS (Arroyo und Scherer, 2000; Baumann und Pham-Dinh, 2001; Sherman und Brophy, 2005; Jessen et al., 2008).

Das Myelin umgibt die Axone von Vertebraten in Form einer isolierenden, den elektrischen Widerstand erhöhenden, segmentierten Myelinscheide. An den nicht myelinisierten Bereichen dieser Isolationsschicht, den Nodien bzw. Ranvier`schen Schnürringen, befinden sich die für die Generierung von Aktionspotentialen nötigen Ionenkanäle. Der segmentierte Aufbau der Myelinscheide gewährleistet, dass Aktionspotentiale nur an den nicht myelinisierten Bereichen des Axons entstehen, was die schnelle, sich sprunghaft fortsetzende, saltatorische Erregungsleitung ermöglicht (Hartline und Colman, 2007). Verglichen mit unmyelinisierten Axonen gleicher Dicke, vollzieht sich die saltatorische Erregungsleitung in myelinisierten Axonen mit bis zu 100-facher Geschwindigkeit (Lemke, 1988).

Den häufigsten Gliazelltyp im ZNS bilden die sternförmigen Astrozyten. Mit den breiten Endfüßchen ihrer Fortsätze bedecken sie die Pia mater und tragen so zur Bildung der BlutHirn-Schranke bei (Ballabh et al., 2004). Sie versorgen das Gehirn mit Nährstoffen und Wachstumsfaktoren und sind maßgeblich am Metabolismus von Neurotransmittern sowie der Entsorgung potentiell toxischer Komponenten beteiligt (Vannucci et al., 1997; Tamai und Tsuji, 2000; Cui et al., 2001). Während die Makroglia des ZNS aus dem Neuroektoderm hervorgehen, stammen die Mikrogliazellen von mesodermalen Monozyten ab, die früh in der Entwicklung in das Gehirn einwandern (Sorokin et al., 1992; Nakajima K.[1] und Kohsaka S.[1], 2004). Im passiven Zustand besitzen Mikroglia eine bipolare oder vielfältig verzweigte Morphologie (Lawson et al., 1990). Treten pathologische Veränderungen, wie Verletzungen oder Infektionen auf, verändern sich die Mikroglia zu motilen, amöboiden Zellen, die phagozytotische Funktionen übernehmen (Bruce-Keller, 1999). 


\subsection{Molekulare Programme zur Steuerung der Zerebellumentwicklung}

\subsubsection{Frühe Spezifizierung der zerebellären Anlage}

Im frühembryonalen Entwicklungsstadium der Gastrula sind drei Keimblätter differenzierbar. Aus dem inneren Keimblatt (Endoderm) entwickeln sich die inneren Organe, aus dem mittleren Keimblatt (Mesoderm) gehen Knochen und Muskeln hervor. Die Zellen des äußeren Keimblattes (Ektoderm) sind Ursprung der Haut und des Nervensystems.

Die Induktion der Neuralplatte im dorsalen Ektoderm stellt den ersten grundlegenden Entwicklungsschritt während der Bildung des ZNS dar (Jessell und Sanes, 2000). An diesem Entwicklungsschritt ist Chordin masgeblich beteiligt (Sasai et al., 1994; Piccolo et al., 1996). Während des darauffolgenden, als Neurulation bezeichneten Entwicklungsprozess, schließt sich die Neuralplatte zum Neuralrohr. Von der dorsalen Hälfte des Neuralrohrs schnüren sich Neuralleistenzellen ab und wandern in die Peripherie. Aus ihnen gehen die sensorischen Neurone des PNS sowie das autonome Nervensystem hervor. Die Regionalisierung des Neuralrohres vollzieht sich entlang der anterior-posterioren und der dorso-ventralen Achse.

Die Expression von Transkriptionsfaktoren entlang der anterior-posterioren Achse markiert hierbei Domänen, die sich zum Prosencephalon (Rubenstein et al., 1998), Mesencephalon (Joyner, 1996), Met- und Myelencephalon (Guthrie, 1996) und Rückenmark (Lee et al., 1998) entwickeln. Das Mesencephalons ist durch eine klare morphologische Grenze, den isthmischen Organisator (ISO), vom dorsalen Rhombomer 1 des Metenencephalons abgegrenzt (Zervas et al., 2004). Die korrekte Formation des Mesencephalons entlang der anterior-posterioren Achse ist hierbei von Signalen abhängig, die von der ISO-Region abgegeben werden (Brand et al., 1996; Liu und Joyner, 2001a; Wurst und Bally-Cuif, 2001; Zervas et al., 2004; Nakamura et al., 2005). Das erste vom ISO sezernierte Organisationsmolekül ist FGF8 (fibroblast growth factor 8; Liu und Joyner, 2001a; Wurst und Bally-Cuif, 2001; Nakamura et al., 2005). So führt die Inaktivierung der FGF8Expression zum Fehlen des kompletten Tectums und Zerebellums in Zebrafischen (Meyers et al., 1998; Reifers et al., 1998; Chi et al., 2003). Umgekehrt induziert die ektopische Expression von FGF8 bzw. das Einbringen von Isthmus-Gewebstransplantaten in Maus- und Hühnerembryos die Ausbildung ektopischer Tecta und Zerebelli (Crossley et al., 1996; Martinez et al., 1999; Hidalgo-Sánchez et al., 1999; Liu et al., 1999; Sato et al., 2001). Das anterior zur FGF8-Expressionsdomäne sezernierte Molekül WNT1 (wingless homolog1) besitzt im Gegensatz zu FGF8 nicht die Fähigkeit ektopischer Tecta- oder Zerebellum- 
Induktion, ist aber trotzdem essentiell für die Zerebellumentwicklung, da es die Expression von FGF8 bedingt (Bradley et al., 1984; McMahon und Bradley, 1990; Lee et al., 1997).

Als wichtige Interaktionspartner der Schlüsselmoleküle FGF8 und WNT1 fungieren die Transkriptionsfaktoren EN1/2 (engrailed 1/2) und PAX2 (paired box 2) (Crossley \& Martin 1995; Liu \& Joyner 2001a). Letzterer induziert die Expression von FGF8, während EN1/2 für den Erhalt von dessen Expression nötig ist (Liu und Joyner, 2001b; Ye et al., 2001). Weiterhin gehören die homeobox-Gene OTX2 und GBX2 zu den am frühesten im ZNS exprimierten Genen. OTX2-Expression markiert den anterioren, GBX2-Expression den posterioren Epiblasten (Simeone, 2000; Joyner et al., 2000; Liu und Joyner, 2001b; Wurst und Bally-Cuif, 2001; Simeone et al., 2002). Ab E 8.5 markiert die Expressionsgrenze zwischen OTX2 und GBX2 die spätere posteriore Abgrenzungslinie des Mesencephalons (Abb. 1). OTX2 und GBX2 agieren antagonistisch und markieren so die Position der FGF8 und WNT1Expression (Millet et al., 1996; Rhinn et al., 1998, 1999; Broccoli et al., 1999; Li und Joyner, 2001). Das präzise räumliche und zeitliche Zusammenspiel exprimierter Transkriptionsfaktoren und sezernierter Signalmoleküle ist notwendig, um die bilaterale zerebelläre Anlage der Säugetiere zu erzeugen.

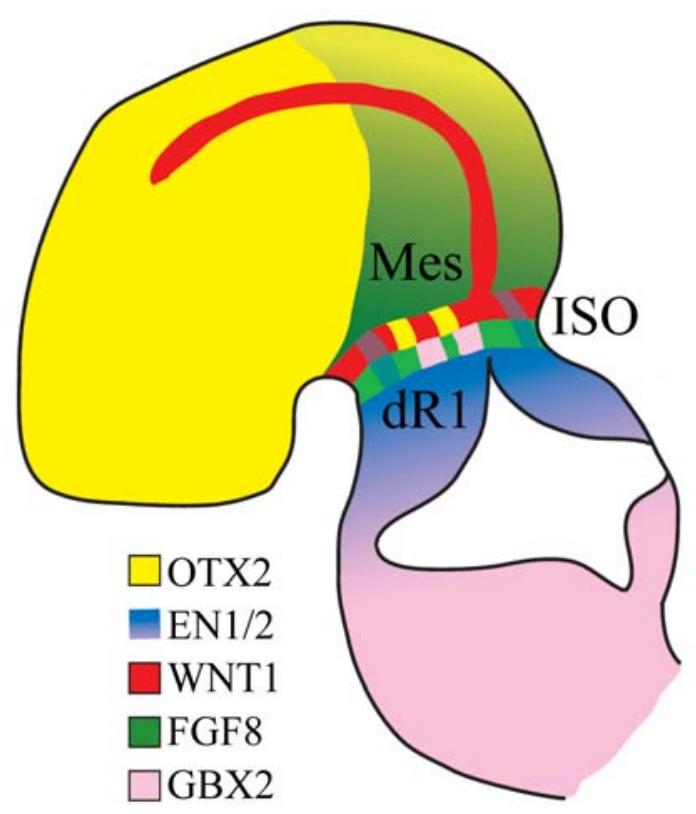

Abb. 1 Genetische Interaktionen zur Steuerung der zerebellären Morphogenese (mod. nach Silitoe und Joyner, 2007).

Illustriert ist ein Mausembryo an E 9,5 und die komplexen genetischen Interaktionen, die für die Spezifizierung der zerebellären Anlage nötig sind. Mes, Mesencephalon; ISO, Isthmischer Organisator; dR1, dorsales Rhombomer 1 des Metencephalons. 


\subsubsection{Ontogenese, Wanderungsrouten, Differenzierung und Reifung zerebellärer Zelltypen}

Als einzigartige Besonderheit innerhalb der ZNS Entwicklung verfügt die zerebelläre Anlage über zwei germinale Zonen, aus denen die späteren zerebellären Zelltypen hervorgehen (Abb. 2). So ist ein transientes Neuroepithelium, das als Rhombische Lippe (RL) bezeichnet wird, Quelle glutamaterger zerebellärer Neurone (Machold und Fishell, 2005; Wang et al., 2005; Englund et al., 2006). Hierzu zählen die Körnerzellen, die großen Neurone der tiefen zerebellären Kerne (TZK) sowie die unipolaren Pinselzellen. An der apikalen Grenze des vierten Ventrikels in ventraler Orientierung zur RL befindet sich eine zweite germinale Zone, die Ventrikularzone (VZ). Aus ihr gehen die GABA-ergen Purkinje-, Golgi-, Korb-, und Sternzellen sowie die kleinen GABA-ergen Neurone der TZK hervor (Altman und Bayer, 1985a; Machold und Fishell, 2005; Mizuhara et al., 2010).

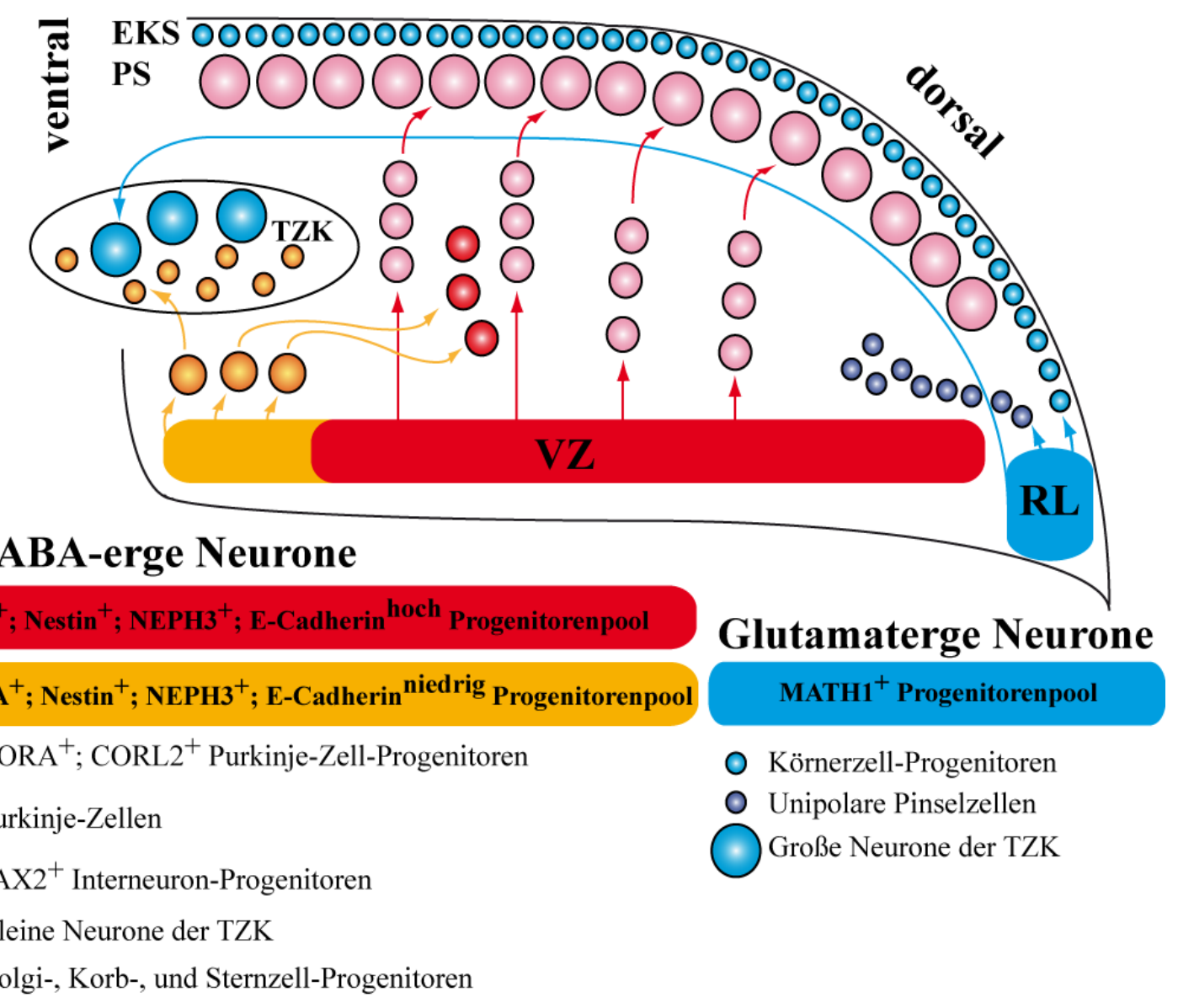

Abb. 2 Ontogenese und Wanderungsrouten zerebellärer Progenitoren im Überblick (mod. nach Mizuhara et al., 2010, 2005; Minaki et al., 2008; Hoshino, 2006a; Hoshino et al., 2005; Nishida et al., 2010; Ben-Arie et al., 1997b; Maricich und Herrup, 1999)

Dargestellt sind die beiden germinalen Zonen des Zerebellums, die Ventrikularzone (VZ) und die Rhombische Lippe (RL) sowie die daraus hervorgehenden Progenitoren samt deren genetischen Expressionsprofilen. Progenitoren der VZ schlagen ein GABA-erges Zellschicksal ein und differenzieren sich zu Interneuronen der tiefen zerebellären Kerne (TZK) und des zerebellären Kortex (Golgi-, Korb- und Sternzellen) sowie zu Purkinje-Zellen. Die RL ist Quelle glutamaterger Körnerzellen und Unipolarer Pinselzellen. 


\subsubsection{GABA-erge Neurone}

Die Produktion und Migration GABA-erger Neurone beginnt vor der aller übrigen Neurone des zerebellären Kortex (um E 11 in der VZ der Maus; Altman und Bayer, 1985b; Yuasa et al., 1991). Die Gesamtheit aller GABA-ergen VZ-Progenitoren ist durch die Expression des basischen Helix-loop-Helix-Transkriptionsfaktors PTF1a, Nestin sowie des Zelloberflächenmarkers NEPH3 (KIRREL2) charakterisiert (Hoshino, 2006a; Pascual et al., 2007; Mizuhara et al., 2010). Mizuhara et al. konnten 2010 in Zellsortierungsexperimenten mit dissoziierten zerebellären Anlagen an E 12,5 zeigen, dass alle NEPH3-positiven Progenitoren der VZ nach zwei Tagen in vitro auch LHX1 (LIM homeoboxil) und GAD1 (Glutamatdecarboxylase1) exprimierten, also ein GABA-erges Differenzierungsschicksal einschlugen. Etwa 90\% der NEPH3-positiven Progenitoren zeigten eine starke E-CadherinExpression, während die restlichen ca. $10 \%$ eine geringere E-Cadherin-Expressionsrate aufwiesen. Der erste Progenitoren-Pool $\left(\mathrm{NEPH}^{+}{ }^{+}\right.$, E-Cadherin $\left.{ }^{\text {hoch }}\right)$ war Quelle von PurkinjeZellen, während aus dem zweiten kleineren Pool $\left(\mathrm{NEPH}^{+}{ }^{+}\right.$E-Cadherin $\left.{ }^{\text {niedrig }}\right)$ die GABAergen Interneurone der TZK und des zerebellären Kortex hervorgingen (Mizuhara et al., 2010). Nach vier Tagen in vitro wurden von den meisten Purkinje-Zell-Progenitoren (>90\%) auch die frühen Purkinje-Zell-Marker CORL2 (Transkriptioneller Korepressor des Homeodomänen Transkriptionsfaktors LBX1) und RORA ( $\underline{R} A R$ related orphan receptor $\underline{A})$, sowie der reifere Marker Calbindin (> 69 \%) exprimiert (Mizuhara et al., 2005, 2010; Minaki et al., 2008). CORL2-positive Progenitoren epremierten dabei nie den frühen interneuronalen Marker PAX2 (Minaki et al., 2008). PAX2 als Marker aller GABA-ergen zerebellären Interneurone wurde nur in $7 \%$ aller NEPH $3^{+}$Progenitoren exprimiert (Maricich und Herrup, 1999; Weisheit et al., 2006; Mizuhara et al., 2010).

\subsection{Purkinje Zellen}

Ab E 14 - E 17 wandern die Purkinje-Zell-Progenitoren der VZ entlang radialer Gliafasern über die sich entwickelnden TZK hin zu den pialen Mantelschichten der zerebellären Anlage aus (Edwards et al., 1990; Yuasa et al., 1991; Hatten und Heintz, 1995; Morales und Hatten, 2006). Die Terminierung der Migrationsbewegung sowie die korrekte Positionierung der Purkinjezell-Progenitoren unterhalb der externen Körnerzellschicht (EKS) wird hierbei durch das extrazelluläre Matrix- und Signalmolekül Reelin vermittelt, welches von den KörnerzellProgenitoren sezerniert wird (Miyata et al., 1997; Hatten, 1999; Rice und Curran, 2001).

Die Axone der Purkinje-Zellen entwickeln sich um den Zeitpunkt der Geburt, AxonKollaterale und apikale, wenig verzweigte Dendriten werden früh postnatal gebildet. Letztere erstrecken sich bis in den mittleren Bereich der EKS (Inouye und Murakami, 1980a). 
Purkinje-Zell-Axone und -Dendriten verlassen den Zellkörper am jeweils gegenüberliegenden Pol der Zelle (Ramon und Cajal 1911; Armengol und Sotelo, 1991). Früh postnatal (P 1 - P 6) verkürzt sich der primäre apikale Dendrit und multiple dendritische Prozesse entspringen nun dem Zellkörper (Ramon und Cajal, 1911). Während der gesamten Phase dendritischer Remodelierung empfangen Purkinje-Zellen perisomatische synaptische Kontakte von Kletterfasern, die schon ab E 19 vorhanden sind (Mason et al., 1990a; Morara et al., 2001).

Die weitere Differenzierung von Purkinje-Zellen wird zwischen P 6 und P 20 durch die Einwanderung von Körnerzellprogenitoren aus der EKS in die interne Körnerzellschicht (IKS) und die Entwicklung von Parallelfasern initiiert (Inouye und Murakami, 1980b). Diese Phase ist durch starke dendritische Elongation und Synaptogenese zwischen Purkinje-ZellDendrit und Parallelfasern geprägt (Ramon und Cajal, 1929).

Zusammengefaßt wird die Transformation des buschigen apikalen Purkinje-Zell-Fortsatzes in einen breit aufgefächerten, komplexen, translobularen Dendritenbaum durch die sich entwickelnden Parallelfasern vermittelt (Altman, 1972a; Altman und Bayer, 1978, 1985c; Goldowitz und Hamre, 1998). Weiterhin verlagern sich die perisomatischen KletterfaserSynapsen hin zu peridendritischen Bereichen und multiple Kletterfaser-Innervationen an Purkinje-Zellen werden eliminiert (Mason et al., 1990b).

Mit zunehmendem Wachstum der Purkinje-Zell-Dendriten nimmt auch die Dicke der Molekularschicht (MS) zu. Adulte Purkinje-Zellen exprimieren eine Reihe charakteristischer Markerantigene, so z.B. spezifische intrazelluläre kalziumbindende Proteine, die sich in Kalziumsensoren und -puffer untergliedern lassen (Schwaller et al., 2002). Aufgrund seiner hohen Affinität zu Kalziumionen wird Calbindin zu den schnellen Kalziumpuffern gezählt (Cheung et al., 1993). Im Gegensatz dazu gehört Parvalbumin zur Klasse langsamer Kalziumpuffer (Haiech et al., 1979; Lee et al., 2000). Die korrekte Funktion kalziumbindender Proteine ist essentiell für den Erhalt intra- und extrazelluläre Kalziumhomöostase in Purkinje-Zellen sowie in anderen Neuronen, wie z.B. den Korb- und Sternzellen der MS (Airaksinen et al., 1997; Schmidt et al., 2003).

\subsection{GABA-erge Interneurone}

Das gesamte Repertoire zerebellärer GABA-erger Interneurone geht ab E 12,5 aus einer Subpopulation PTF1A-positiver Progenitoren im ventralen Bereich der Ventrikularzone hervor, die durch die transiente Expression von PAX2 gekennzeichnet ist (Abb. 2; Maricich und Herrup, 1999; Hoshino, 2006b; Weisheit et al., 2006; Mizuhara et al., 2010). Diese Progenitoren bleiben bis in früh-postnatale Stadien mitotisch aktiv (Zhang und Goldman, 1996) und generieren auf Ihrer Wanderung durch die sich bildende weiße Substanz (WS) 
sequenziell verschiedene GABA-erge Interneuronentypen nach einem von innen nach außen verlaufenden Muster (Schilling, 2000). Zunächst werden die kleinen Neurone der TZK generiert, dann die Interneurone der Körnerzellschicht (KS; Golgi-, Lugaro-, und Globulare Zellen) und zuletzt die Interneurone der Molekularschicht (MS; Stern- und Korbzellen). Der Großteil des Pools GABA-erger interneuronaler Progenitoren ist durch die Expression von GAD1 ab P 0 gekennzeichnet sowie durch die Expression einer Reihe spezifischer transkriptioneller Regulatoren, zu denen u. a. TCFAP2 $\alpha / \beta$ (transcription factor ap $2 \alpha / \beta)$, LBX1 (Maus Homolog zum Drosophila Gen lady bird late), der LBX1 Korepressor LBXCOR1, LHX5 (IM homeobox protein 5), NANOS1 (Maus Homolog zum Drosophila Gen NANOS1) und PBX3 (pre-ba-cell leukemia transcription factor 3) gehören (Schüller et al., 2006; Simat et al., 2007; Glassmann et al., 2009). Keiner dieser Faktoren ist jedoch korboder sternzellspezifisch innerhalb der MS exprimiert (Glassmann et al., 2009). Erst jüngste Untersuchungen auf Basis der öffentlichen Genexpressionsdatenbank „The Allen Brain Atlas“ konnten eine Reihe von über 20, bisher unbekannter, innerhalb der MS korbzellspezifisch exprimierter Gene identifizieren, zu denen u. a. NEFH (neurofilament heavy), NEF3 (Neurofilament 3), PENK1 (Proenkephalin1), CHST1 (ㅁarbohydrate sulfotransferase 1) und GRM8 (glutamate receptor metabotropic 8) gehören (Schilling und Oberdick, 2009.).

Kontrollierte Apoptose überflüssiger neuronaler Vorläufer spielt eine wichtige Rolle für die korrekte Ausbildung neuronaler Netzwerke (Oppenheim et al., 1991; Lossi und Merighi, 2003). So werden beispielsweise überflüssige Korb- und Sternzellprogenitoren in der WS und der MS durch kontrollierte Apoptose in den ersten beiden postnatalen Wochen eliminiert (Yamanaka et al., 2004).

\section{Golgi-, Lugaro- und Globulare Zellen:}

Die IN-Progenitoren der IKZ werden kurz nach der Geburt postmitotisch und beginnen sich in Golgi-, Lugaro- und Globulare Zellen zu differenzieren. Adulte Golgi-Zellen haben große polygonale Zellkörper, die über die ganze KS verteilt sind. Ihre Dendriten erstrecken sich in die MS, wo sie von Parallelfasern kontaktiert werden sowie in die KS, wo sie synaptische Kontakte von Moosfasern empfangen (Chan-Palay und Palay, 1971; Ito, 1984; Dieudonne, 1998; Vos et al., 1999). Das Axon der Golgi-Zellen erstreckt sich in der KS, wo es einen komplexen axonalen Plexus bildet, der tausende von Körnerzellen kontaktiert und zur Ausprägung der sog. Glomeruli (Moosfaser-, Körnerzelldendrit-, Golgi-Zell-Synapse), beiträgt (Hámori und Szentágothai, 1966; Chan-Palay und Palay, 1971; Dieudonne, 1998). Auch Unipolare Pinselzellen werden von Golgi-Zellen inhibiert (Mugnaini et al., 1994). Die 
Dendriten der direkt unterhalb der Purkinje-Zellschicht (PS) lokalisierten Lugaro-Zellen erstrecken sich nur innerhalb der KS und werden ausschließlich von Purkinje-Zell-AxonKollateralen kontaktiert (Larramendi und Lemkey-Johnston, 1970; McCrea et al., 1976). Lugaro-Zellen ihrerseits kontaktieren ausschließlich Korb-, Stern- und Golgi-Zellen (Lainé und Axelrad, 1998; Dumoulin et al., 2001). Die erst kürzlich beschriebenen Globularen Zellen werden von Purkinje-Zell-Kollateralen und Lugaro-Zellen kontaktiert. Ihre Dendriten und Axone erstrecken sich in die MS, wo letztere synaptische Kontakte mit Golgi-, Korb- und Sternzelldendriten bilden (Simat et al., 2007). Die meisten KS-IN sind GABA- und glycinerg, nur ein kleiner Anteil ist ausschließlich GABA-erg (ca. $15 \%$ ) oder ausschließlich Glycin-erg (ca. $5 \%$;) (Simat et al., 2007).

\section{Korb- und Sternzellen:}

Der Beginn der Differenzierung von MS-Interneuronen ist durch die Bildung VIAAT-

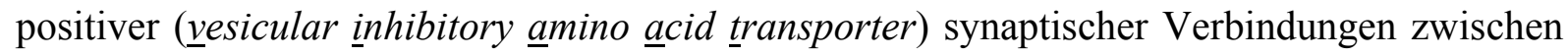
den interneuronalen Vorläufern ab P 4 charakterisiert (Simat et al., 2007). Die Progenitoren sind am Ende der ersten postnatalen Woche an einer Position unterhalb der PS angelangt und differenzieren sich bei Ihrer Einwanderung in die MS in Stern- oder Korbzellen (Ango et al., 2004a). Die PAX2-positiven interneuronalen Vorläufer behalten bis zu diesem Zeitpunkt das volle Potential zur Entwicklung jeder der beiden Interneuronen-Typen bei. Die terminale Differenzierung in Korb- oder Sternzelle ist abhängig von extrazellulären instruktiven Signalen der jeweiligen Zieldomäne (Leto et al., 2006, 2008, 2009).

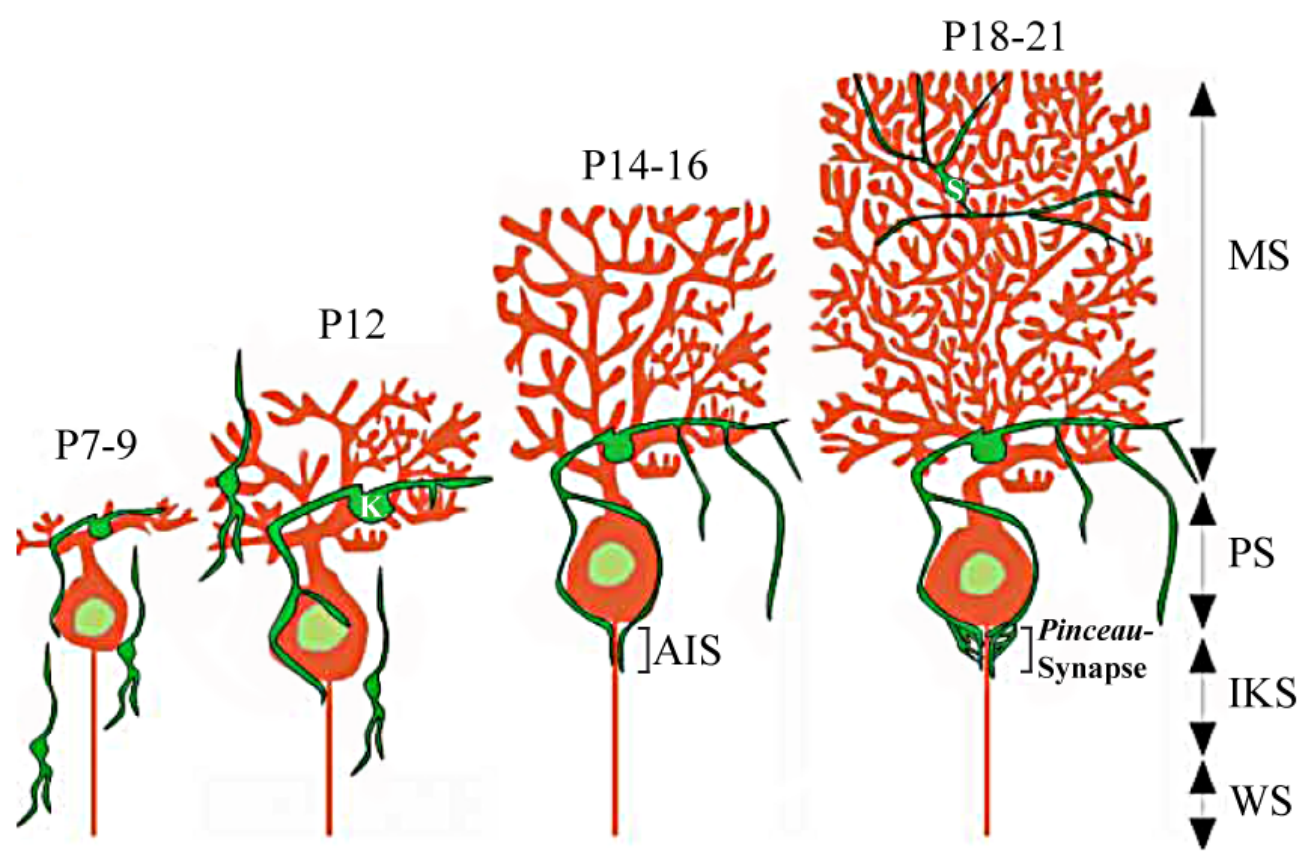


Abb. 3 Schematische Zusammenfassung der Korbzellreifung (mod. nach Ango et al. 2004)

Stern- und Korbzellprogenitoren wandern durch die Weiße Substanz (WS) und die Interne Körnerzellschicht (IKS). Letztere gelangen um P 7 an ihrer Position oberhalb der Purkinje-Zellschicht (PS) an. Von hier aus bilden Korbzellen (K) axonale Vorläufer, die ihrerseits Kollaterale ausbilden, welche entlang des Purkinje-Zellsomas in Richtung axonales initiales Segment (AIS) einwachsen. Am Ende der dritten postnatalen Woche (P 18 - P 21) umschließen mehrere Kollaterale die Purkinje-ZellAIS und bilden die sog. Pinceau-Synapse. Die Entwicklung der im oberen Drittel der Molekularschicht (MS) lokalisierten und auf den Purkinje-Zelldendriten synapsierenden Sternzellen (S) ist in der Maus ebenfalls um P 21 abgeschlossen.

Erste determinierte Korbzellen erscheinen ab P 5 im unteren Drittel der MS oberhalb der PS (Yamanaka et al., 2004). Von hier aus bilden sie einen axonalen Fortsatz, der sich in der translobularen Eben erstreckt und Kollateralen entwickelt, sobald eine Purkinje-Zelle kontaktiert wird. Die Kollateralen verlaufen dicht am Purkinje-Zellkörper entlang und kontaktieren deren axonales initiales Segment (AIS) mit Hilfe eines dichten terminalen synaptischen Plexus. Dieser wird aufgrund seiner Pinzetten-Form als Pinceau-Synapse bezeichnet (Bobik et al., 2004). Im reifen Zustand besitzt eine Korbzelle ein langes, horizontal orientiertes Axon, von dem in gleichmäßigem Abstand rechtwinklig Gruppen von Axon-Kollateralen abzweigen. Über diese steht die Zelle mit zahlreichen, in der gleichen translobularen Ebene lokalisierten Purkinje-Zellen in Kontakt (Pouzat und Hestrin, 1997). Der Dendritenbaum einer Korbzelle ist wie ihr Axon translobular ausgerichtet, im Vergleich zu diesem jedoch abgeflacht und unregelmäßig verzweigt. Er ist, ähnlich wie der Dendritenbaum von Purkinje-Zellen, zur Zerebellum-Oberfläche hin orientiert und steht mit zahlreichen Parallelfasern in synaptischer Verbindung (Altman, 1972a, 1972b).

Sternzellen wandern in die oberen zwei Drittel der MS ein und entwickeln ab P 12 erste afferente Synapsen mit Parallelfasern im Bereich des Perikaryons. Um P 15 weitet sich das Geflecht synaptischer Kontakte auf das Soma und die Dendriten aus und erreicht seine ausgereifte Form am Ende der dritten postnatalen Woche (Altman, 1972a, 1972b, 1972). Wie Korbzellen, bilden Sternzellen inhibitorische Synapsen mit Purkinje-Zellen. Im Vergleich zu diesen bilden sie aber asymmetrische Synapsen mit dem Purkinje-Zelldendriten. Die GABAergen und GAD1-positiven Stern- und Korbzellen beginnen ab P 14 den Kalziumpuffer Parvalbumin zu exprimieren (Solbach und Celio, 1991). Um P 21 ist die Entwicklung von Korb- und Sternzellen abgeschlossen (Yamanaka et al., 2004). Die Bildung der hochspezifischen dendritischen und axonalen Kontaktierungsmuster zerebellärer Interneurone erfordert die sequenzielle Exekution spezieller genetischer Programme und molekularer Mechanismen. So konnten z.B. die postsynaptischen Mechanismen, die die korrekte synaptische Zielfindung von Korb- und Stern-Zellen vermitteln, bereits detailiert beschrieben werden (Ango et al., 2004a, 2008a). Im Falle von Korb-Zellen wird die synaptische 
Zielfindung der Axon-Kollateralen durch Neurofascin186, ein Zelladhäsionsmolekül der L1 Immunoglobulin-Familie (L1CAM), vermittelt. Ein Ankyrin3-gekoppelter Gradient von Neurofascin186 rekrutiert die Axon-Kollateralen zu ihrer korrekten synaptischen Destination am axonalen initialen Segment (AIS) der Purkinje-Zelle. Sternzellaxone interagieren ebenfalls mit einem Immunoglobulin der L1-Familie, sie nutzen einen auf Bergmann-Glia exponierten Gradienten von CHL1 (ㄷlose homologue of $\underline{L} 1$ ), um an deren Schnittpunkt mit PurkinjeZelldendriten inhibitorische Synapsen zu bilden (Ango et al., 2008a).

Insgesamt konnten die Mechanismen der synaptischen Zielfindung von Korb- und Sternzellen auf postynaptischer Ebene sehr detailiert beschrieben werden (Ango et al., 2004a, 2008a). Zellintrinsische Programme und transkriptionelle Regulationsmechanismen zur Steuerung der Axo- und Synaptogenese von Korb- und Sternzellen sind bisher jedoch weitgehend unbekannt.

\subsubsection{Glutamaterge Neurone}

\subsection{Körnerzellen}

Körnerzellprogenitoren leiten sich zwischen E 13 und E 15 aus einem Pool MATH1-positiver germinaler Zellen im rostralen Teil der Rhombischen Lippe (RL) ab (Altman und Bayer, 1978; Ben-Arie et al., 1997a). Von hier wandern sie rostral über die gesamte Oberfläche der zerebellären Anlage aus und bilden eine neue, zunächst einzellschichtige germinale Zone, die EKS. Die Proliferation weiterer Körnerzellprogenitoren führt zur Ausdehnung der EKS, die um P 7 mit etwa 6 bis 8 Zelllagen ihre größte Dicke erreicht. Von hier aus beginnen die Körnerzellen durch die MS und PS hindurch zu wandern und bilden so die IKS. Die Migrationsbewegung der Körnerzellen führt zur Ausbildung zweier Phasen in der EKS, die bereits durch Ramon und Cajal (1909-1911) beschrieben wurden: eine äußere Schicht, in der die Zellen noch undifferenziert und in verschiedenen Generations-Zyklen vorliegen und eine tiefer liegende Schicht postmitotischer Zellen. Letztere bilden zwei parallel zur Pia ausgerichtete Axonvorläufer aus, die innerhalb der parlobularen Ebene auswachsen und dabei hauptsächlich synaptische Kontakte mit Purkinje-Zellen bilden (Pichitpornchai et al., 1994). Jedes einzelne Körnerzell-Axon kontaktiert dabei bis zu 750 Purkinje-Zellen (Brand et al., 1976; Heck und Sultan, 2002). Während die Körnerzellen entlang der radialen Bergmann Glia (Mugnaini und Forstronen, 1967) einwandern, wächst ein dritter zytoplasmatischer Fortsatz aus. Dieser durchquert spezielle, parasagittal abgegrenzte Zwischenräume (,granule cell raphes" $^{\text {") }}$ zwischen Purkinje-Zell-,,clustern“, wodurch die charackteristische T-Form der Körnerzell-Axone entsteht (Luckner et al., 2001; Karam et al., 2001; Redies et al., 2002). Der 
Körnerzellkern wandert in diesen Fortsatz ein, bis er seine Endposition in der IKS erreicht hat. Hier bilden die Körnerzellen, einige kurze Dendriten mit klauenartigen „Endfüßchen“ (Telodenria). Die molekulare Basis der Körnerzellentwicklung konnte schon lange vor der Ära gezielter Geninaktivierung mit Hilfe natürlich vorkommender Mausmutanten analysiert werden. So liegt bei der 1951 erstmals beschrieben spontanen reeler-Mausmutante beispielsweise ein Defekt im Reelin-Gen vor. Da die korrekte Migration von Purkinje-Zellen von deren Interaktion mit extrazellulärem Reelin abhängig ist, ist in der reeler-Mutante ein Großteil der Purkinje-Zellen delokalisiert und als sekundärer Effekt auch die Anzahl der Körnerzellen reduziert (Falconer, 1951; Hamburgh, 1960; Meier und Hoag, 1962). Bei der erstmals 1965 beschriebenen weaver-Mutante liegt eine Punkt-Mutation des Genes GIRK2 vor, das für einen G-Protein-gekoppelten Kaliumkanal kodiert (Goldowitz und Smeyne, 1995; Patil et al., 1995). Die Umwandlung premigratorischer Körnerzell-Progenitoren in wanderungs- und differenzierungsfähige Körnerzellvorläufer hängt von deren Fähigkeit ab, auf Kaliumionen zu reagieren. Durch den Verlust der Kaliumkanäle in weaver-Mutanten, ist die Umwandlung der Progenitoren in migrationsfähige Vorläufer gestört und ein Großteil der Zellen stirbt bereits im premigratorischen Stadium, was zum früh-postnatalen Tod der meisten Mutanten führt. Die gezielte Mutagenese identifizierter Gene führte zu weitreichenden Einblicken in die genetischen Steuerungsmechanismen der Körnerzellentwicklung. So konnten diverse Signalmoleküle, Transkriptionsfaktoren und Zelladhäsionssysteme identifiziert werden, die die Auswanderung MATH1-positiver Progenitoren, deren Proliferation in der EKS und spätere Differenzierungsprozesse steuern (review in Millen et al., 1999).

\subsection{Unipolare Pinselzellen}

Unipolare Pinselzellen (UPZ) gehen wie Körnerzellen ab E 13,5 aus Progenitoren der RL hervor (Englund et al., 2006) und gehören zum Typ lokaler exzitatorischer Interneurone. Sie sind neben den Körnerzellen Hauptrezepienten von Moosfaser-input. Sie synapsieren ihrerseits auf Dendriten anderer UPZ und Körnerzellen und sind neurochemisch et al. durch Calretinin- und Glutamat-Immunoreaktivität charackterisiert (review in Kalinichenko und Okhotin, 2005). 


\subsection{Molekulare Programme zur Steuerung der Axon- und Dendritenentwicklung}

\subsubsection{Polarisierung: Axo- und Dendritogenese}

Die Entwicklung der Axone und Dendriten eines Neurons in vivo ist mit dem Verlauf der Axo- und Dendritogenese kultivierter Neurone vergleichbar (Leclerc et al., 1988; Armstrong und Hawkes, 2000; Armstrong et al., 2001; Larouche und Hawkes, 2006; Larouche et al., 2006). So wurde schon 1988 von Dotti et al. ein Model entwickelt, nach dem sich die Reifung kultivierter hippocampaler Neurone in fünf Stufen unterteilt (Dotti et al., 1988). Kurz nach dem Ausplattieren bilden die Neurone sog. Lamellopodien um das Soma herum aus (Stufe 1), die sich nach zwei Tagen in vitro zu primären Neuriten mit Wachstumskegeln differenzieren (Stufe 2). Beim Übergang der zweiten zur dritten Stufe bilden die Zellen ein Axon aus. Dieser, als Polarisierung bezeichnete Prozess, wird durch eine Reihe extra- und intrazellulärer molekularer Programme und Signalmoleküle gesteuert. Während kultivierte hippocampale Neurone auch ohne extrazelluäre Signale polarisieren (Craig und Banker, 1994a), orientiert sich ihr Axonwachstum in vivo an extrazellulär präsentierten Substraten, wie NGCAM (neuron-glia cell adhesion molecule) und Laminin (Esch et al., 1999; Ménager et al., 2004). So konnte auch für das in Caenorhabditis elegans (C. elegans) sezernierte Protein UNC-6 (Netrin in Säugetrieren) eine Funktion für die Ausbildung asymmetrischer Axone gezeigt werden (Hedgecock et al., 1990; Serafini et al., 1994; Wadsworth et al., 1996; Hong et al., 1999; Adler et al., 2006). Weiterhin fungiert das in C. elegans sezernierte Protein WNT (wingless und INT1) als essentieller Regulator neuronaler Polarität entlang der anteriorposterioren Körperachse (Hilliard und Bargmann, 2006; Prasad und Clark, 2006). NGF (ñerve growth factor), BDNF ( braind derived neurotrophic factor) und NT3 (Neutrophin3) gehören ebenfalls zu diskutierten sezernierten Polarisierungsinitiatoren. Dieser relativ kurzen Liste, extrazellulärer Polarisationskomponenten steht eine größere Bandbreite, bekannter intrazellulärer downstream-Mechanismen gegenüber (Yoshimura et al., 2006; Arimura und Kaibuchi, 2007). So konnte für die Phosphatidylinositol 3-Kinase (PI3-Kinase) und deren Lipid-Produkt Phosphatidylinositol 3,4,5-Triphosphat (PIP3) (PtdIns(3,4,5)P3) eine determinierende und erhaltende Rolle für neuronale Polarisierung nachgewiesen werden (Iijima et al., 2002; Shi et al., 2003a; Ménager et al., 2004; Schwamborn und Püschel, 2004; Da Silva et al., 2005; Adler et al., 2006; Horiguchi et al., 2006). Verschiedene Gruppen konnten zeigen, dass lokale Aktivierung von PI3-Kinase und Akkumulation von PIP3 im Wachstumskegel eines unreifen Neuriten für dessen Spezifizierung zum Axon und Elongation sorgt (Shi et al., 2003a; Ménager et al., 2004; Yoshimura et al., 2006). Die Stimulation sich 
entwickelnder Neurone mit neutrophen Faktoren, wie BDNF oder NT3 aktiviert den PI3KPTDINS(3,4,5)P3-AKT-GSK-3 $\beta$-Signaltransduktionsweg. PI3-Kinase aktiviert PDK1 (phosphoinositide-dependent kinase 1) (Alessi et al., 1997) und stimuliert zusammen mit anderen Kinasen, z.B. der Integrin-linked Kinase die Proteinkinase AKT. AKT wiederum phosphoriliert und inaktiviert GSK-3 $\beta$ in Wachstumskegeln (Yamada et al., 1997; Jiang et al., 2005). GSK-3 $\beta$ phosphoriliert MAP1B ( microtubule-associated protein 1B) und APC (Polyposis coli gene product) (Goold et al., 1999; Zumbrunn et al., 2001; Trivedi et al., 2005), worüber die Anzahl stabiler Microtubuli reguliert wird. Überexpression konstitutiv aktiven

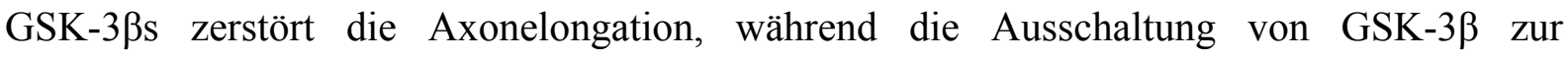
Ausbildung multipler Axone führt. Die Inaktivierung von GSK3 $\beta$ zu späteren Entwicklungszeitpunkten, vermag sogar Dendriten in Axone zu transformieren, was eine essentielle Funktion von AKT und GSK3 $\beta$ in der Regulation neuronaler Polarität impliziert (Jiang et al., 2005). Inhibition des Ubiquitin-Proteasom-Systems führt zu symmetrischer AKT-Verteilung und Ausbildung multipler Axone in kultivierten hippocampalen Neuronen (Yan et al., 2006). Dies zeigt, dass lokal spezifische Proteindegradation ebenfalls zur Steuerung neuronaler Polarität beiträgt. Die Anreicherung weiterer spezifischer Proteine im Wachstumskegel des Axon-Vorläufers führt zur Manifestierung dessen Polarität und Stimulation der Axon-Entwicklung (Shi et al., 2003b; Dotti und Poo, 2003). Zu diesen Proteinen zählt RAP1b (rhho-GTP-asen Ras related protein 1b), das von PI3K über CDC42 (cell devision cycle42) aktiviert wird und sich im Wachstumskegel des zukünftigen Axons einlagert. Hier rekrutiert es zur Axonspezifizierung essentielle Proteine und trägt zur Polarisierungsentescheidung bei. Überexpression von RAP1b induziert multiple Axone, RAP1b-Supression dagegen Axonverlust, was die wichtige Rolle dieses Proteins für die Axonentwicklung unterstreicht (Arimura und Kaibuchi, 2007). Der downstream von PI3K liegende, durch KIF3a (kinesin family member 3a) regulierte PAR3-PAR6-aPKC (átypical protein kinase C) Protein Komplex, der in C. elegans asymmetrische Zellteilung während der Entwicklung induziert (Cowan und Hyman, 2004), wird in hippocampalen Neuronen beim Übergang der Phase2 zu Phase3 in der Spitze des axonalen Vorläufers angereichert (Shi et al., 2003a; Nishimura et al., 2004). Als zentraler Regulator der Polarisierung, wird er durch CDC42 korrekt in der Axonspitze positioniert. Hier überträgt er die CDC-42-vermittelten

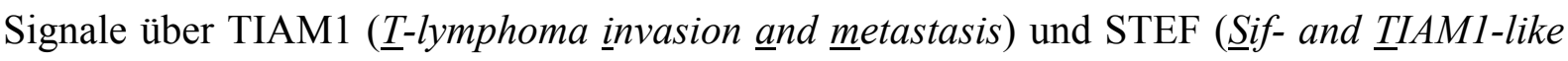
exchange factor) auf RAC1. RAC1 wiederum aktiviert PI3K. Die von PI3K initiierten Signale propagieren also auf selbige zurück und bilden eine positive Rückkopplungsschleife, die als wichtiger Aktivator des Axonwachstums diskutiert wird (Govek et al., 2005). Eine weitere 
Funktion des PAR-Komplexes besteht in der Phosphorilierung und AktivitätsAntagonisierung von MAP2 ( microtubule-associated protein 2) (Hurov et al., 2004; Suzuki et al., 2004; Kusakabe und Nishida, 2004). MAP2 vermittelt seinerseits Tau-Phosphorilierung und verhindert die Axon-Formation, MAP2-Inaktivierung im Wachstumskegel durch den PAR-Komplex ist daher ein wichtiger Regulator axonalen Wachstums. Ein weiterer zentraler Regulator der Axon-Formation und Elongation stellt das durch GSK-3 $\beta$ regulierte CRMP-2 (collapsin response mediator protein) dar (Goshima et al., 1995; Inagaki et al., 2001; Arimura et al., 2004). CRMP-2 verbindet Tubulin-Heterodimere oder SRA-1 mit Kinesin und transportiert diese in den distalen Bereich des wachsenden Axons (Kimura et al., 2005; Kawano et al., 2005). CRMP-2 vermittelt die Axon-Spezifizierung und -Elongation also zum einen über die Regulation der Tubulin-Organisation. Zum anderen reguliert CRMP-2 die Endozytose von Adhesionsmolekülen, wie L1, über Interaktion mit Numb sowie die Reorganisation von Aktinfilamenten über Interaktion mit SRA-1 (steroid receptor RNA activator 1) (Nishimura et al., 2003; Kawano et al., 2005; Yoshimura et al., 2006).

Externe Faktoren initiieren demnach komplexe intrazelluläre Signaltransduktionskaskaden, die die Axonentwicklung mittels mehrerer zytologischer Hauptprozesse vermitteln. Zu diesen zählen erhöhte Aktinfilament-Dynamik, beschleunigte Microtubuli-Formation und lokale Konzentration von Signalmolekülen (Arimura und Kaibuchi, 2007).

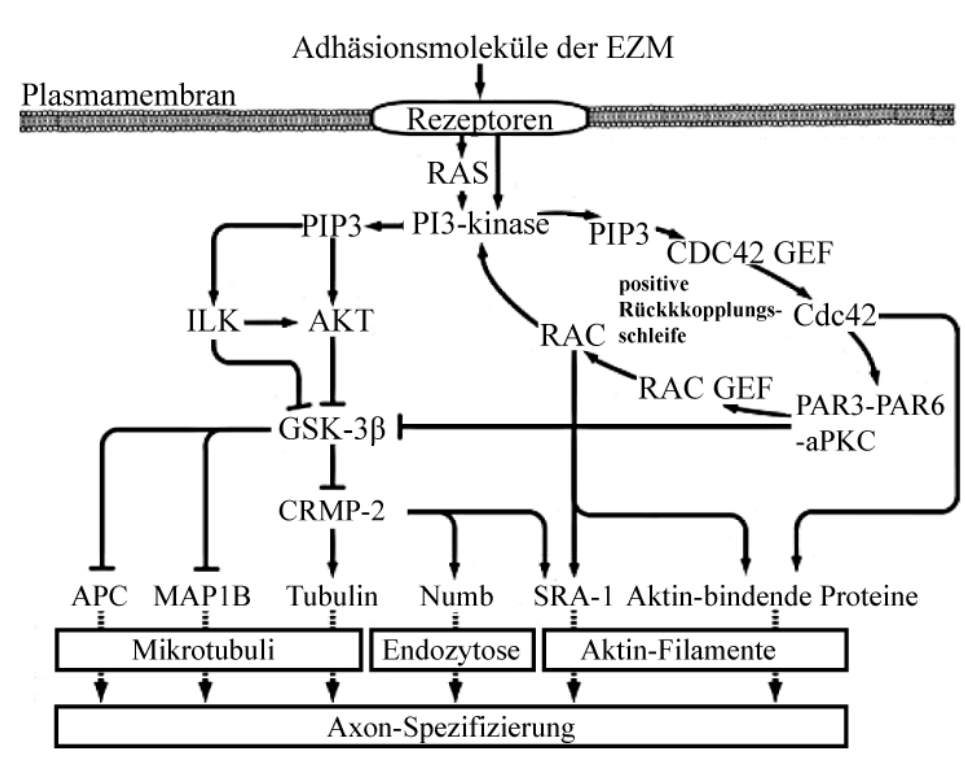

Abb. 4 Model der Regulation der Axon-Formation (mod. nach Yoshimura et al., 2006)

Im unreifen Neuriten (dem zukünftigen Axon) aktivieren die Rezeptoren und Adhäsionsmoleküle der extrazellulären Matrix (EZM) PI3-kinase, was zur Akkumulation von PIP3 führt. PIP3 aktiviert den GSK-3 $\beta / C R M P-2-$ Signaltransduktionsweg und die positive Rückkopplungsschleife des PAR-Komplexes. Diese molekularen Mechanismen regulieren die Dynamik des Zytoskeletts, die Endozytose, den Proteintransport und die Transkription zur Steuerung der Neuritenextension und deren zukünftiges Schicksal (Axon/Dendrit).

Stufe 3 - die Ausbildung eines Axons - wird gefolgt von Stufe 4, der Ausbildung primärer Dendriten aus den übrigen Neuriten. Dendriten höherer Ordnung zweigen von Dendriten niedrigerer Ordnung ab und sind somit weiter vom Zellkörper entfernt in der Zellperipherie lokalisiert (Dotti et al., 1988). Ein Dendrit kann sich apikal Y-förmig verzweigen oder es 
bildet sich seitlich an einem bereits existierenden Dendritenstamm ein neuer Dendrit aus (Scott und Luo, 2001). Auch die Entwicklung von Dendriten wird durch extrazelluläre Stimuli, wie Neurotrophine, Semaphorine und Ephrine (Miller und Kaplan, 2003; Van Aelst und Cline, 2004; Hoogenraad et al., 2005) und daran gekoppelte intrinsische Signaltransduktionskomponenten wie c-ABL (zelluläre Ábelson Tyrosinkinase), RAC, CDC42 und RHO gesteuert (Jones et al., 2004; Govek et al., 2005). Weiterhin können Proteine der postsynaptischen Dichte (post-synaptic density-95; PSD-95), Densin-180 und GRIP1 (glucocorticoid receptor interacting protein 1) die Dendritogenese beeinflussen (Quitsch et al., 2005; Charych et al., 2006; Vessey und Karra, 2007).

Phase 5 der Axon- und Dendritenentwicklung ist gekennzeichnet durch das Vorhandensein reifer Axone und funktionalen Synapsen sowie Dendriten mit dendritischen Dornfortsätzen (Dotti et al., 1988; Craig und Banker, 1994b; Bradke und Dotti, 2000)

\subsubsection{Axonale Navigation}

\subsubsection{Wachstumsfaktoren und Signaltransduktionswege zur Steuerung der axonalen Navigation}

Um das hoch geordnete und komplexe Netzwerk von Effektor- und Zielzellen des Nervensystems (im Menschen ca. 1 Milliarde) zu verknüpfen, bedarf es präziser Mechanismen, die die auswachsenden Axone korrekt zur jeweiligen postsynaptischen Destination an der Zielzelle leiten. Um topographisch korrekte Verknüpfungen benachbarter Nervenzellen mit benachbarten Zielregionen zu gewährleisten, müssen Axone zum Teil über weite Strecken, präzise navigiert werden, was am Beispiel von Projektionsneuronen besonders deutlich wird. Hierzu zählen die benachbarten Ganglienzellen der Retina und ihre Verbindungen mit benachbarten Zielneuronen des optischen Tectums, deren Entwicklung von Sperry und Anderen ausführlich beschrieben wurden (SPERRY, 1963; Kaprielian und Patterson, 1994; Meyer, 1998; Ruthazer und Cline, 2004; Scicolone et al., 2009). Pyramidale kortikale Projektionsneurone bilden ebenfalls lange Axone aus, die pyramidale Neurone der gegenüberliegenden Hemisphäre kontaktieren. Sie bilden dabei dichte Faserbündel, die die „midline“ des Nervensystems überqueren und sich zu drei kommisuralen Faserpfaden konsolidieren, die hippocampale und anteriore Kommisur sowie das Corpus Callosum, die Archi- und Neocortex, Amygdala, olfaktoruschen Bulbus und andere Gehirnregionen verbinden (Katz 1983; Mihrshahi 2006). Die Entwicklung dieser Projektionsneurone kann in vier Phasen untergliedert werden: initiale Axonausbildung/Polarisierung, Faserbündelung, Navigation zur Zielregion und Zielkontaktierung. Der axonale Wachstumskegel reagiert dabei auf verschiedene Orientierungssignale und formt transiente Kontakte mit umliegenden Zellen 
und der extrazellularen Matrix (go Kater und Rehder, 1995; Gordon-Weeks und Fischer, 2000).

Insgesamt wird jedwede axonale Navigation durch vier Hauptkräfte vermittelt. Dies sind wachstumsfördernde oder hemmende Signale, die lokal oder über weite Distanzen wirken können. Eine Vielzahl solcher Effektoren wurde bisher schon identifiziert (Tessier-Lavigne und Goodman, 1996). So gehören die Immunglobuline (IG) und Cadherine zur Gruppe lokal wirkender Regulatoren innerhalb der Superfamilie der Zelladhäsionsmoleküle (CAMs; cell adhesion molecules) (Rutishauser, 1989; Fredette et al., 1993; Skaper et al., 2001; Johnson et al., 2005). Viele Mitglieder dieser beiden Familien vermitteln homophile Adhäsion, dass heißt fungieren auf einem Zelltyp als Ligand, auf anderen Zelltypen als Rezeptor, wie etwa die NCAMs (ㅁeuronal cell a dhesion molecules) (Cunningham et al., 1987). Andere Mitglieder der CAMs, wie Axonin-1 und NG-CAMs (ㅁeuron-glia cell adhesion molecules) können als heterophile Liganden, oder Rezeptoren für distinkte Zelloberflächen agieren (Kuhn et al., 1991; Grumet et al., 1993). Weitere wichtige Zelladhäsionsmoleküle stellen Mitglieder der leucin-rich repeat- und Fascilin1-Familie sowie Mitglieder der IG-CAM-Familie, wie LAMP (lysosome-associated membrane protein) und IRREC (irregular chiasm $\underline{C}$ ) dar (Cunningham et al., 1987; Zinn et al., 1988; Snow et al., 1988; Elkins et al., 1990; Krantz und Zipursky, 1990; Nose et al., 1992; Jouet et al., 1993; Grumet et al., 1993; Bellosta et al., 1995; Pimenta et al., 1995; Buchstaller et al., 1996). Rezeptor Protein Tyrosin Kinasen (RPTKs) modulieren Axonwachstum und Zielregionfindung. Wichtige RPTKs sind FGF-Rezeptoren (fibroblast growth factor) und die TRK Familie der Neutrophin-Rezeptoren, die jeweils als Rezeptoren für sezernierter Faktoren fungieren (Basilico und Moscatelli, 1992; Hoyle et al., 1993; McFarlane et al., 1995, 1996; ElShamy et al., 1996).

Extrazelluläre Matrixmoleküle (EZM) fungieren als lokale Stimulatoren oder Inhibitoren axonalen Wachstums und beinhalten die Laminin-, Tenascin-, Collagen- und Thrombospondin-Familie sowie Fibronectin, Vitronectin und Proteoglycane (Bixby und Harris, 1991; Hynes und Lander, 1992; Tessier-Lavigne und Goodman, 1996). Im Gegensatz dazu sind Netrine diffusiv und wirken über weite Distanzen wachstumsstimulierend oder hemmend (Kennedy et al., 1994; Mitchell et al., 1996; Harris et al., 1996). Sie besitzen eine evolutionär konservierte Rolle bei der Axonnavigation über die ventrale „midline“ in Nematoden, Fruchtfliegen und Vertebraten. Jede Organismengruppe exprimiert dabei mindestens ein Netrin-Familienmitglied (Hedgecock et al., 1987; Kennedy et al., 1994; Harris et al., 1996; Mitchell et al., 1996; Bradford et al., 2009). Mitglieder der DCC-Subfamilie (deleted in $\underline{\text { colorectal }} \underline{\text { cancer}) ~ d e r ~ I G-S u p e r f a m i l i e ~ s i n d ~ K o m p o n e n t e n ~ v o n ~ R e z e p t o r e n, ~ d i e ~}$ 
wachstumsstimulierende Aktivitäten von Netrinen vermitteln (Keino-Masu et al., 1996; Kolodziej et al., 1996; Chan et al., 1996), während das IG-Superfamilienmitglied Unc-5 die wachstumshemmende (reppelent) Wirkung des Netrins über UNC-6 vermittelt (Hedgecock et al., 1990; Ishii et al., 1992; Wadsworth et al., 1996).

Semaphorine sind eine große Familie membranassoziierter oder sezernierter Proteine, die durch eine aminoterminale Semaphorin-Domäne und eine Plexin-Semaphorin-IntegrinDomäne (PSI) charackterisiert sind (Pasterkamp und Giger, 2009). Die phylogenetisch konservierten Plexine sind die prominentesten Semaphorin-Rezeptoren und können ihrerseits in vier Klassen - Plexin A bis D - subgruppiert werden (Franco und Tamagnone, 2008). Die hoch konservierten zytoplasmatischen Domänen dieser kanonischen Rezeptoren verfügen über GTP-ase-aktivierende Motive, binden und inaktivieren das Protein RAS (Negishi et al., 2005). Reduzierte RAS-Aktivität führt zu verringerter PI3-K-Aktivität und Inhibition des Integrin- $\beta 1$ Signalweges, was wiederum die Wachstumskegel-Adhäsion verringert (Pasterkamp und Giger, 2009). Zusätzlich zu ihrer Funktion als lokale chemoadhäsive oder repulsive Axon-Navigatoren spielen Semaphorine eine wichtige Rolle für die Reifung dendritischer spines.

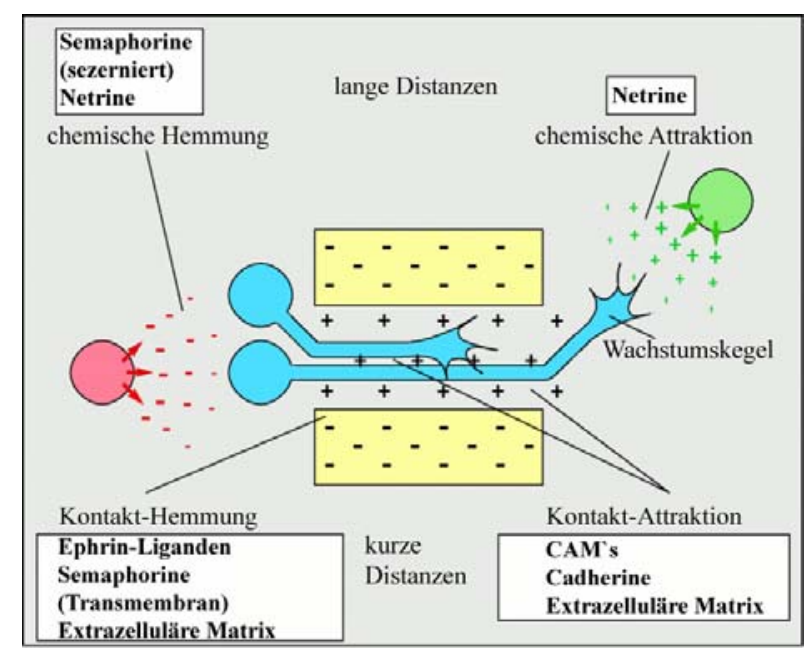

Abb. 5 Steuerung der axonalen Navigation (mod. nach Tessier-Lavigne $M$ und Goodman CS, 1996)

Vier verschiedene Mechanismen tragen zur Steuerung der Navigation des axonalen Wachstumskegels bei: die über lange Distanzen wirkende chemische Hemmung oder Attraktion durch diffusive Signale, wie z.B. Netrine und Semaphorine sowie die bei Kontakt eintretende repulsive (Kontakt-Hemmung) oder Wachstumsstimulierende Wirkung (KontaktAttraktion) verschiedener Ephrin-Liganden, Semaphorine, Cadherine, Signale der Extrazellulären Matrix und Mitgliedern der CAMs (cell adhesion molecules).

\subsubsection{Transkriptionelle Mechanismen zur Steuerung der axonalen Navigation}

\subsection{Projektionsneurone}

Im Verhältnis zur Vielzahl bekannter, das Axonwachstum regulierender Rezeptoren und sezernierter Faktoren sind bisher relativ wenige, intrinsische transkriptionelle Regulationsmechanismen der axonalen Navigation bekannt. Hier sind jedoch die atonalVerwandten bHLH-Transkriptionsfaktoren zu nennen, zu denen u. a. NEX, Neurogenin2 und 
NDRF gehören (Neuro므 related factor). Die Projektionen thalamischer Nuclei in topographisch exakt organisierte Bereiche des somatosensorischen Kortex bilden einen der komplexesten, in Säugetieren vorhandenen Projektionspfade, die sog. thalamokortikalen Projektionen. Neurogenin2 (NGN2) ist ein bHLH-Transkriptionsfaktor (bHLH-TF), der im rostralen Teil des sich entwickelnden Thalamus exprimiert wird und die Ausbildung von Projektionen der ventrolateralen und anterioren thalamischen Kerne in den somatosenorischen Kortex durch Modulation deren Ansprechverhalten auf intermediäre Wachstumssignale, wie Ephrin A5, kontrolliert (Caviness und Frost, 1980; Crandall und Caviness, 1984; HöhlAbrahão und Creutzfeldt, 1991; Seibt et al., 2003). Für die „downstream“ von Neurogenin 1 und 2 liegenden, aktivitätsabhängigen bHLH-TF NDRF und LMO4 (transcriptional coactivator lim domain only 4) konnte eine Rolle in der Regulation thalamokortikaler Projektionen in das „,barrel-field“ der Schicht IV des somatosensorischen Kortex gezeigt werden (Sommer et al., 1996a; Ma et al., 1996a; Ince-Dunn et al., 2006; Kashani et al., 2006). NDRF und LMO4 induzieren Genexpression in Folge von Kalziumeinstrom über spannungsempfindliche Kalziumkanäle (Aizawa et al., 2004). In NDRF- und LMO4Mausmutanten entwickeln sich thalamokortikale Projektionen in Schicht IV des somatosensorischen Kortex, deren Organisation in kortikale „barrels“ ist aber gestört, was eine essentielle, aktivitätsabhängige Rolle von NDRF und LMO4 in der Justierung präsynaptischer Axonterminale des somatosensorischen „barrel-fields“ impliziert (Ince-Dunn et al., 2006; Kashani et al., 2006). Weitere hochspezifische Projektionen stellen die Efferenzen kortikaler Pyramidenneurone dar. Pyramidale Neurone, der Schicht 6a projezieren beispielsweise in den Thalamus, während Schicht-5-Neurone ausschließlich subkortikale Ziele, wie Striatum, Colliculus Superior, Pons und Rückenmarck kontaktieren. Pyramidenneurone, die hauptsächlich in die kontralaterale Hemisphäre projezieren und damit den prominentesten von drei kommissuralen Faserpfaden - das Corpus Callosum - bilden, befinden sich hauptsächlich in Schicht 2, 3 und 5 des Neokortex (Katz et al., 1983; Mihrshahi, 2006). Retrograde Markierung von Pyramidenneuronen verschiedener Projektionszielregionen wurde genutzt, um distinkte Zellpopulationen mittels FACS (fluoreszens-activated cell sorting) $\mathrm{zu}$ isolieren, die dann auf zelltypspezifische transkriptionelle Regulatoren untersucht wurden (Arlotta et al., 2005). Hierbei konnte CTIP2 (ein DNA-bindendes Protein mit Zinkfinger-Motiv; auch BCL11B genannt) identifiziert werden, das an der Spezifizierung kortikospinaler Projektionen beteiligt ist (Arlotta et al., 2005). Ebenfalls an der Spezifizierung kortikospinaler Projektionen beteiligt ist ein weiterer

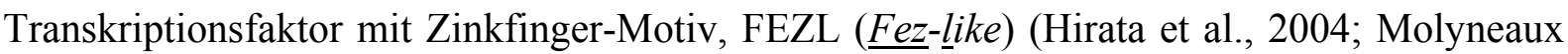


et al., 2005; Chen et al., 2005a, 2005b). Die intrinsische Spezifizierung von neokortikalen Projektionsneuronen wird u. a. durch die TF NDRF und NEX (neuronal helix-loop-helix protein) reguliert. Die Axone neokortikal projezierender Pyramidenzellen sind in Nex-NDRFDoppelmutanten in der Anzahl reduziert oder fehlen ganz. Die am stärksten betroffenen callosalen Axone defaszikulieren in der Subventrikularzone, folgen zufälligen Auswachsrichtungen im ipsilateralen Kortex, überqueren nicht die ventrale „midline“ und zeigen Verlust der Expression des IG-Cams Contactin-2 (Bormuth et al., persönliche Kommunikation). Dies unterstreicht die Rolle von NDRF und NEX als transkriptionelle Schlüsselregulatoren neokortikaler Projektionspfadentwicklung.

Erste intrinsiche transkriptionelle Mechanismen, die die Reaktion auswachsender Axone auf extrinsische Reize vermitteln und somit die korrekte axonaler Zielfindung gewährleisten, konnten in jüngerer Zeit also am Beispiel neo- und thalamokortikaler Projektionsneurone, spinaler Motoneurone sowie retinotectaler Projektionen entschlüsselt werden (review in Polleux et al., 2007). Neben Netzwerken prinzipaler Projektionsneurone spielen lokale inhibitorische Interneurone eine essentielle Rolle als Taktgeber und Modulator der Netzwerkaktivität (Traub et al., 1996; Hormuzdi et al., 2001; Buhl et al., 2003; Cardin et al., 2009; Sohal et al., 2009).

\subsection{Interneurone}

Die Palette bekannter TF erstreckt sich bisher jedoch im Vorderhirn als auch im Zerebellum hauptsächlich auf solche, die während der Determinierung und frühen Differenzierung von Interneuronen eine Rolle spielen. Transkriptionelle Regulationsmechanismen späterer INEntwicklungsstadien, wie etwa der axonalen Navigation sind weitgehend unerforscht. Eine der wenigen Ausnahme bilden hier die Transkriptionsfaktoren DLX 1 und 2 (Cobos et al., 2005, 2007). Diese kontrollieren und inhibieren das Axon- und Dendritenwachstum unreifer Interneurone subpallialen Ursprungs temporär und ermöglichen so deren korrekte tangentiale Migration und Positionierung im Neokortex (Cobos et al., 2007). Eine weitere Familie von $\mathrm{TF}$, die in diesem Zusammenhang genannt werden kann, bildet die große Molekülfamilie der TF mit ETS-DNA-Bindedomäne (E74-like transforming sequence). Zu den ETS-TF, mit einer transkriptionellen Regulationsfunktion der Axonentwicklung in Interneuronen gehören AST-1 und ZAG-1, die in C. elegans die axonale Navigation von Kommandointerneuronen des motorischen Schalkreises kontrollieren (Hart et al., 2000; Sharrocks, 2001; Wacker et al., 2003; Schmid et al., 2006). Zwei Mitglieder der ETS-TF-Familie, ER81 und PEA3 sind in propiozeptiven sensorischen Neuronen und Motoneuronen im Rückenmarck von Vertebraten exprimiert (Lin et al., 1998; Arber et al., 2000; Livet et al., 2002). Inaktivierung von ER81 
oder PEA3 bewirkt den Verlust korrekter axonaler Kontakte der propiozeptiven Afferenzen mit Motonueronen, was eine wichtige Funktion der beiden ETS-TF für die Axonentwicklung im Rückenmarck impliziert (Arber et al., 2000; Livet et al., 2002).

\subsubsection{Zell-Adhäsionssysteme und Synaptogenese}

Die initiale Kontaktaufnahme zwischen axonalem Wachstumskegel und Dendrit erfolgt meist durch ein vom Dendriten ausgebildetes Filopodium (Fiala et al., 1998; Saito et al., 1992). Dessen auf Aktin basierendes Zytoskellet ist sehr beweglich und ermöglicht es, die nähere Umgebung zu „sondieren“ (Gupton und Gertler, 2007). Nach erfolgter axo-dendritischer Kontaktaufnahme werden präsynaptisch mehrere dense core vesicle inseriert, die vorgefertigte präsynaptische Elemente, wie z.B. Gerüstmoleküle (bassoon, piccolo) und an der Transmitterfreisetzung beteiligte Proteine, enthalten (Zhai et al., 2001). Die Interaktion zwischen prä- und postsynaptischer Seite wird dabei durch mehrere Superfamilien von Zelladhäsionsmolekülen (CAMs; cell $\underline{\text { adhesion }}$ molecules) vermittelt. Hierzu zählt u. a. die Superfamilie der Cadherine, IG-CAMs, das Neuroligin/Neurexin- und das Ephrin/EphrinRezeptor-System (Togashi et al., 2009). Cadherine sind kalziumabhängige Zell-Zell Adhäsionsmoleküle, die über 100 Mitglieder in Vertebraten umfassen und in Cadherine und Protocadherine subgruppiert werden können (Takeichi, 2007). Alle klassischen Cadherine sind homophile Einzelpass-Transmembranproteine, die mit ihren zytoplasmatischen Partnern, den Cateninen, interagieren (Wheelock und Johnson, 2003). Im Gegensatz zu den Cadherinen haben Protocadherine eine variierende Zahl extrazellulärer cadherin-repeat-domains (EC domains) und variierende zytoplasmatische Interaktionspartner (Yagi und Takeichi, 2000; Hirano et al., 2003). Die zu den IG-CAMs gehörenden kalziumunabhängigen Nectine formen homo- oder hetero-trans-Dimere, wobei Heterodimerisierung zu stärkerer Bindung führt als Homodimerisierung (Fabre et al., 2002; Yasumi et al., 2003; Martinez-Rico et al., 2005). Eine weitere Familie von IG-CAMs bilden neural cell adhesion molecules (NCAMs), die mit einer Vielzahl von Liganden, wie FGFR (fibroblast growth factor), TAG-1/Axonin-1 und Heparan Sulfat Proteoglycan interagieren und homo- und heterophile Bindungen eingehen (Walsh und Doherty, 1997; Kiss und Muller, 2001). CHL1 und Neurofascin (çlose homologue of L1), beides IG-Cams der L1-Familie, spielen eine essentielle Rolle für die subzelluläre Organisation von Sternzell-Purkinje-Zell-, bzw. Korbzell-Purkinje-Zell-Synapsen (Ango et al., 2004b, 2008b). SYG1/SYG2 und Sidekicks gehören ebenfalls zu den IG-CAMs und besitzen wichtige Funktionen für die Synapsenspezifizierung (Yamagata et al., 2002; Shen und Bargmann, 2003; Shen et al., 2004). 
Neuroligine sind postsynaptische esterase-like-domains enthaltende Proteine, die mit präsynaptisch präsentierten Neurexinen interagieren und vor allem für die Synapsenreifung und synaptische Transmission unabdingbar sind (Ushkaryov et al., 1992; Ichtchenko et al., 1995; Missler et al., 1998; Graf et al., 2004; Chih et al., 2005; Varoqueaux et al., 2006).

Die Ephrine und Ephrin-Rezeptor-Tyrosinkinasen werden in zwei Gruppen unterteilt: EphrinA-Liganden sind via GPI-Bindung (Glycosylphosphatidylinositol) membranassoziiert und binden EphrinA-Rezeptoren, während EphrinB-Liganden Transmembranproteine sind, die vorwiegend an EphrinB-Rezeptoren binden (Flanagan und Vanderhaeghen, 1998). Synaptische EphrinB-Rezeptoren binden die NMDA-Glutamat-Rezeptor-Untereinheit NR1 (Dalva et al., 2000), vermitteln Kalziumeinstrom und spezifische Genexpression (Takasu et al., 2002).

NECL-2 (nectin-like molecule 2) ist ein homophil bindendes Adhäsionsmolekül, das auch heterophile Bindungen mit NECL-1 und Nectin-3 eingeht (Sakisaka und Takai, 2004). NECL-2 ist synaptisch lokalisiert und induziert präsynaptische Differenzierung und Stabilisierung (Biederer et al., 2002).

Integrine sind Zelloberflächenrezeptoren, die mit der extrazellulären Matrix interagieren und deren Signale in die Zelle weiterleiten. An Kontaktstellen zwischen Neuronen und Astrozyten induzieren sie Protein-KinaseC-Aktivität und Synaptogenese (Hama et al., 2004).

\section{4 bHLH-Proteine}

Die Generierung, Proliferation, Determinierung und Differenzierung neuronaler und glialer Progenitoren erfordert das Vorhandensein präziser Regulationsmechanismen, die die räumlich und zeitlich korrekte Exekution instruktiver genetischer Informationen steuern. Ermöglicht wird dies durch das Zusammenwirken basaler Proteine des Transkriptionskomplexes (RNAPolymerase II und Hilfsfaktoren) mit Transkriptionsfaktoren (TF). Diese binden sequenzspezifisch an cis-Elemente von Zielgenen und regulieren deren Expression (Greenblatt, 1997). Helix-loop-Helix-Proteine bilden eine der mindestens 12 bisher identifizierten Familien von TF und umfassen über 240 Kandidaten in verschiedensten Organismengruppen, die vom Einzeller bis zu Säugetieren reichen (Atchley und Fitch, 1997). bHLH-Proteine bestehen aus zwei amphipatischen Alpha-Helices von 15-20 Aminosäureresten, die über eine variable loop-Domäne miteinander verbunden sind. Die loop-Domäne vermittelt Homo- oder Heterodimerisierung mit anderen bHLH-Proteinen, die 5' zur HLH-Region gelegene basische Domäne hingegen die Bindung der Homo- oder Heterodimere an regulatorischen Elemente der Zielgene, sogenannte E-Boxen, mit der Erkennungssequenz CANNTG (Voronova und Baltimore, 1990). E-Boxen wurden in den 
Promotor- und Enhancer-Elementen vieler verschiedener Gen-Klassen identifiziert (Buskin und Hauschka, 1989; Whelan et al., 1990; Bessis et al., 1995; Ahmad, 1995; Grant et al., 1996; Pepitoni et al., 1997)

\subsection{Atonal Verwandte}

Die Funktion der bHLH-Proteine für die Neurogenese wurde zuerst in Drosphila analysiert. Hier werden sie in undifferenzierten Zellen des Ektoderms exprimiert, die sich dadurch zu neuronalen Progenitoren entwickeln (Jan und Jan, 1993). Proteine des AS-Komplexes (achate-scute) steuern hierbei die Entwicklung sensorischer Organe, wobei eine einzige neuronale Vorläuferzelle des „proneuronalen clusters“ Startpunkt dieser Entwicklung ist, während die umliegenden Zellen durch laterale Inhibition an der Differenzierung gehindert werden (Campos-Ortega, 1993). Das Protein atonal steuert die Entwicklung des Chordotonalorgans, ektopische atonal-Expression führt zur Ausbildung ektopischer sensorischer Organe (Jarman et al., 1993). Insgesamt wird das neurogene Programm durch Heterodimerisierung von atonal und Proteinen des AS-Komplexes mit dem ubiquitär exprimierten bHLH-Protein daughterless initiiert (Cabrera und Alonso, 1991). Hierbei fungieren achate und scute als positive, hairy, enhancer of split [E(SPL)] und extramacrochaetae (EMC) als negative Regulatoren der Neurogenese (Ellis et al., 1990; Oellers et al., 1994; Nakajima K.[1] und Kohsaka S.[1], 2004).

Homologe der Drosophila bHLH-Gene wurden ebenfalls in Säugetieren identifiziert und ihre regulatorische Funktion für die neurale Entwicklung charackterisiert. So heterodimerisiert MASH1 ( mammalian achaete-ścute homolg 1) mit dem daughterless-Homolog E2A und wirkt als Aktivator neuronaler Differenzierung (Johnson et al., 1990; Guillemot und Joyner, 1993).

Eine weitere Familie positiver Regulatoren der Neurogenese bilden die atonal-Homologe MATH1; NEX (MATH2); NeuroD; NDRF (KW8; NeuroD2) und die Neurogenine (Bartholomä und Nave, 1994; Shimizu et al., 1995; Akazawa et al., 1995; Naya et al., 1995; Lee et al., 1995; Kume et al., 1996; Yasunami et al., 1996; McCormick et al., 1996; Gradwohl et al., 1996; Takebayashi et al., 1997).

$\mathrm{Zu}$ den in neuronalen Progenitoren des PNS und ZNS exprimierten Determinierungsfaktoren gehören die Neurogenine NGN1/NeuroD3, NGN2/MATH-4A und NGN3 (Sommer et al., 1996b; McCormick et al., 1996). Sie werden in der Maus ab E 9 im Rückenmark, Mittel- und Hinterhirn, olfaktorischen Neuroepithelium sowie der Retina exprimiert, wo sie die neurale Induktion multipitenter Vorläuferzellen initiieren und verschiedene neuronale Subtypen spezifizieren (McCormick et al., 1996; Ma et al., 1996b). 
Im Gegensatz zu den Neurogeninen werden atonal-Homologe vorwiegend während späterer Entwicklungs- und adulter Stadien exprimiert, was für sie eher eine Rolle in der Differenzierung und im Erhalt von Neuronen als Determinierungsfunktionen impliziert. So wird das neuronale bHLH-Protein NEX ab P 11.5 in postmitotischen Neuronen des Rückenmarks, des Telenzephalons und eines Bereiches des vierten Ventrikels exprimiert (Bartholomä und Nave, 1994; Shimizu et al., 1995). Adulte Expressionsdomänen des NEX Gens sind der zerebrale Kortex, die Amygdala und die CA 1 - 4 Region des Hippocampus (Bartholomä und Nave, 1994; Shimizu et al., 1995; Schwab et al., 1998a). Inaktivierung der NEX-Genexpression allein zieht keine phänotypischen Veränderungen nach sich.

Zusätzliche Inaktivierung eines weiteren, mit NEX räumlich und zeitlich stark überlappend exprimierten atonal-Homologs, dem NDRF-Gen, führt jedoch zu einem axonalen Phänotyp neokortikaler Projektionsneurone, was für ein hohes kompensatorische Potential innerhalb dieser Gruppe spricht (Kume et al., 1996; Yasunami et al., 1996; McCormick et al., 1996).

NDRF wird ab E 14 im Neuroepithelium des vierten Ventrikels, dem Rückenmark und den dorsalen Wurzelganglien und ab E 18 zusätzlich im olfaktorischen Neuroepithelium und der EKS des Zerebellums exprimiert (Schwab et al., 1998b). In frühen postnatalen Stadien (P5) ist NDRF-Expression auch in der CA 1- CA 3 Region des Hippocampus und im Gyrus dentatus nachweisbar. Die adulten Expressionsdomänen erstrecken sich über Neurone des Neokortex, piriformen Kortex, Hippocampus, Induseum griseum, des medialen habenularen Nukleus und der KS des Zerebellums sowie über die inhibitorischen Korb- und Sternzellen der zerebellären MS. In Purkinje-Zellen ist keine NDRF-Expression nachweisbar (Bartholomae \& Nave, 1994; Yasunami et al., 1996; Schwab et al., 1998b). Im Gegensatz zu NEX führt die Inaktivierung des NDRF-Gens in der Maus nach unauffälliger Embryonalentwicklung ab P 14 zu erhöhter Apoptose in der zerebellären KS und somit zur Reduktion ihrer Dicke und der Größe des gesamten Zerebellums. Diese zellulären Defekte führen äußerlich zu ataktischem Gang, Wachstumsstörungen und postnatalem Tod zwischen P 14 und P 35 auf (Olson et al., 2001).

Um die adulte Funktion von NDRF für zerebelläre Körnerzellen und Interneurone analysieren zu können, wurde eine davon unabhängig in der Abteilung Nave hergestellte NDRF Nullmutante (T. Yonemasu, unveröffentlicht) auf einen SV129 genetischen Stammeshintergrund zurück gekreuzt. Tiere der auf diese Weise modifizierten knockoutMauslinie überlebten zum großen Teil bis in hohe Altersstadien.

Das dritte, mit NDRF räumlich und zeitlich stark üperlappend exprimierte atonal-Homolog ist

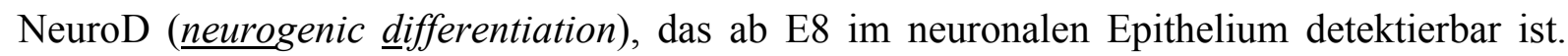


AB E10 erstrecken sich dessen Expressiondomänen über Vorderhirn- und Hinterhirn, Rückenmark und die cranialen und dorsalen Wurzelganglien, die Retina, das olfaktorischen Epithelium und den Bulbus olfaktorius (Lee et al., 1995, 2000; Schwab et al., 1998a). Früh postnatal ist die NeuroD-Expression fast ausschließlich auf den olfaktorischen Bulbus, den primordialen Hippocampus und die mitotisch aktiven Bereiche der premigratorischen EKS des sich entwickelnden Kleinhirns beschränkt. Mit fortschreitender Einwanderung der Körnerzellprogenitoren in die IKS verlagert sich auch die Expression hier hin. Wie bei NDRF bleibt die Expression von NeuroD in den Körnerzellen des Hippocampus und des Kleinhirns bis ihn hohe Altersstadien konstant. Im Gegensatz zu NDRF zeigen zerebelläre Molekularschichtinterneurone aber keine NeuroD-Expression (Schwab et al., 1998a; Uittenbogaard und Chiaramello, 2000; Lee et al., 2000).

Außerhalb des Nervensystems wird NeuroD im Darm und Pankreas exprimiert. Hier hat es eine essentielle Rolle für die Entwicklung pankreatischer B-Zellen sowie für die Regulation des Insulin- bzw. Sekretin Gens (Chae et al., 2004; Habener et al., 2005). Da Mäuse mit inaktiviertem NeuroD-Gen schwere Defekte in der Differenzierung pankreatischer ß-Zellen aufweisen und kurz nach der Geburt aufgrund von Hyperglykämie sterben, muss ein konditionales Geninaktivierungssystem verwendet werden, um adulte neuronale Funktionen von NeuroD analysieren zu können (Naya et al., 1995, 1997; Goebbels et al., 2005).

Zusammengefaßt weisen die bHLH-Gene NeuroD, NDRF und NEX während der Entwicklung des ZNS ähnliche Expressionszeitpunkte und hauptsächlich stark überlappende, teilweise aber auch strikt voneinander getrennte Expressionsdomänen auf. Im Kleinhirn stellen die Körnerzellen die Hauptexpressionsdomäne von NeuroD und NDRF dar, während NDRF noch zusätzlich in den Interneuronen der Molekularschicht exprimiert wird.

\subsection{Konditionale Inaktivierung von Genen mittels Cre loxP-System}

Die Inaktivierung von Genen durch homologe Rekombination in embryonalen Stammzellen (knockout) bewirkt, dass das betreffende Gen in allen Körperzellen des Organismus ausgeschaltet ist (KLEINSMITH und PIERCE, 1964; Martin und Evans, 1975; Mintz und Illmensee, 1975; Evans und Kaufman, 1981; Bradley et al., 1984; Smithies et al., 1985; Thomas et al., 1986; Robertson et al., 1986; Kuehn et al., 1987; Evans, 2001).

Um bestimmte Aspekte der Funktion von Genen analysieren zu können, kann es erforderlich sein, dieses Gen nicht in allen Körperzellen sondern nur in spezifischen Zelltypen und zu definierten Zeitpunkten auszuschalten. So erfordert etwa die Analyse der adulten neuronalen Funktion des NeuroD-Gens dessen spezifische Inaktivierung im ZNS ohne die pankreatischen Expression zu beeinträchtigen (Goebbels et al., 2005). 
Die zelltypspezifische Inaktivierung von Genen ist mit Hilfe des Cre/LoxP-Systems möglich. Dieses Verfahren basiert auf dem Zusammenwirken von positionsspezifischen DNARekombinationsstellen, die als LoxP-Sequenzen bezeichnet werden und der CreRekombinase des Bakteriophagen P1 (Abremski et al., 1983, 1986; Sauer und Henderson, 1988; Gu et al., 1994; Tsien et al., 1996). Eine LoxP-Sequenz besteht aus zwei palindromen 13 Basenpaare langen Erkennungssequenzen, die durch eine 8 Basenpaare lange spacerRegion getrennt sind (Sternberg und Hamilton, 1981; Hamilton und Abremski, 1984). Die Cre-Rekombinase katalysiert die Rekombination zwischen zwei LoxP-Sequenzen nach der spezifischen Bindung je eines Monomers an eine Erkennungssequenz (Van Duyne, 2001; Lewandoski, 2001).

Um ein Gen konditional zu inaktivieren bedarf es zweier Mauslinien. In den Tieren der ersten Mauslinie müssen zwei, das zu eliminierende Gen flankierende LoxP-Sequenzen inseriert werden, ohne dessen Funktion zu beeinträchtigen. In der zweiten Mauslinie wird Cre unter der Kontrolle eines Zelltyp-spezifischen Promotors exprimiert. Kreuzt man diese beiden Mauslinien, entstehen zunächst doppeltransgene Nachkommen und in weiteren Verpaarungen Tiere, die für das gefloxte Allel homozygot und für das Cre-Allel heterozygot sind. Bei diesen Mäusen werden also in allen Cre-exprimierenden Zellen essentielle Bereiche des gefloxten NeuroD-Gens, durch Cre-vermittelte Rekombination ausgeschnitten und es bleibt lediglich eine der beiden loxP-sites zurück. In den Cre-exprimierenden Zellen ist das betreffende Gen demzufolge inaktiviert. 


\subsection{Aufgabenstellung}

Bisher konnten zahlreiche molekulare Programme und Mechanismen zur Steuerung der Axon- und Dendritenentwicklung identifiziert werden. Vor allem die biochemischen Prozesse während früher Phasen der Axo- und Denritogenese konnten durch Experimente mit kultivierten hippocampalen Neuronen gut analysiert werden. In vivo und in vitro konnten weiterhin zahlreiche Wachstumsfaktoren, Zell-Adhäsionssysteme und zellintrinsische Signaltransduktionswege zur Steuerung der axonalen Navigation und synaptischen Zielfindung beschrieben werden. Zellintrinsische transkriptionelle Regulationsmechanismen, die diese Prozesse steuern, sind bisher jedoch wenig erforscht. Erste Erkenntnisse konnten hier u. a. an hippocampalen Projektionsneuronen des Vorderhirns (z.B. thalamokortikale und neokortikale Projektionen) gewonnen werden. So konnten mit den bHLH-Proteinen NEX und NDRF erste transkriptionelle Kandidaten indentifiziert werden, die die Exekution zellintrinsischer Programme zur Spezifizierung von Langstreckenprojektionsneuronen vermitteln.

Im Gegensatz dazu sind transkriptionelle Regulationsmechanismen zur Steuerung der Axound Synaptogenese inhibitorischer zerebellärer Interneurone weitestgehend unbekannt, was unter anderem an der geringen Anzahl bisher bekannter, adult in diesen Zelltypen exprimierter Markerantigene liegt. So wurde beispielsweise erst 2009 eine Reihe von Genen identifiziert, die Korb- und Sternzellen des Zerebellums eindeutig als genetisch unterschiedliche Interneuronenpopulationen darstellten.

Im Rahmen dieser Arbeit sollte untersucht werden, ob die axonale Spezifizierungsfunktion von NDRF bei Vorderhirnneuronen auch in zerebellären Körner-, Korb- und Sternzellen konserviert ist. Sollte NDRF tatsächlich einen Einfluss auf die axonale und synaptische Entwicklung dieser Neurone haben, so sollte weiterhin untersucht werden, ob die Programme zur Steuerung der Axon- und Dendritenentwicklung gleichermaßen reguliert sind. Weiterhin sollte der sekundäre Effekt des Verlustes der NDRF-Expression in Körner-, Korb- und Sternzellen auf deren Zielzellen (Purkinje-Zellen) analysiert werden. Die Durchführung von Verhaltenstests sollte Aufschluss darüber geben, inwieweit sich potentielle, durch den Verlust der NDRF-Expression erzeugte Defekte, in motorische Defizite übersetzen. 


\section{Ergebnisse}

\subsection{Erzeugung NDRF-nullmutanter Mäuse}

Um NDRF-nullmutante Mäuse zu generieren, wurde die kodierende Sequenz auf Exon 2 durch eine Neomycin-Resistenzkassette ausgetauscht (T. Yonemasu, unveröffentlicht; Abb. 6 A). Ein homolog rekombinierter ES-Zellklon wurde in die Blastozysten von C57BL/6JMäusen mikroinjeziert. Der nachfolgende Embryotransfer in pseudoträchtige (Foster-) Weibchen des Stammes B6/CBF1(agouti) erzeugte hochchimäre Männchen deren Verpaarung mit C57BL/6J-Weibchen heterozygote F1-Tiere lieferte. Inzuchtverpaarungen von Tieren der F1-Generation lieferte NDRF-nullmutante Mäuse in der erwarteten Mendelschen Verteilung. Durch weitere Inzuchtverpaarungen von NDRF-Nullmutanten mit heterozygoten Mäusen wurden konstant NDRF-Nullmutanten und heterozygote Kontrolltiere erzeugt, die im Folgenden als Kontrolle bezeichnet werden.

Northern-Blot-Analysen zerebellärer Gesamt-RNA von drei Monate alten Tieren verifizierte die Abwesenheit jeglicher NDRF-Genexpression in NDRF-Nullmutanten (Abb. 6 B). Genotypisierungs-PCRs wurden mittels der in Abb. 6 A skizzierten Primer durchgeführt. Primer \#1 und \#3 amplifizierten hierbei ein 970 bp langes DNA-Fragment vom Wildtyp-Allel und Primer \#2 und \#3 ein 680 bp langes DNA-Produkt vom NDRF-Null-Allel (Abb. 6 C).

\subsection{Rückkreuzung auf Sv129 genetischen Hintergrund}

Die durch weitere Verpaarungen erzeugten NDRF-Nullmutanten zeigten starke Wachstumsdefizite. Etwa 2/3 der Mutanten starben bevor sie das Alter von vier Wochen erreichten, ein Drittel überlebte jedoch bis in höhere Altersstadien, was darauf hin deutete, dass der genetischen Hintergrundes die Lebenserwartung der Tiere beeinflusst. Daher wurden die NDRF-Nullmutanten auf einen Sv129-genetischen Stammeshintergrund zurück gekreuzt, eine Strategie, die zuvor schon von (Liu et al., 2000) angewendet wurde, um die postnatale Letalität NeuroD-nullmutanter Mäuse zu umgehen. Alle in dieser Arbeit verwendeten Tiere wurden über mindestens vier Generationen zurück gekreuzt, was zum Überleben der meisten Mutanten bis in hohe Altersstadien führte. So sollten Verpaarungen (heterozygoter) Kontrollen mit NDRF-Nullmutanten zu Nachkommen in einer Mendelschen Verteilung von $50 \%$ Kontrollen und $50 \%$ Mutanten führen. Unter 113, aus solchen Verpaarungen hervor gegangenen Nachkommen, befanden sich im Alter von 2 Monaten 53 Mutanten. Dies entsprach $47 \%$ der gesamten Nachkommenschaft und zeigte, dass der größte Teil der NDRFNullmutanten bis zum Alter von mindestens zwei Monaten überlebte. Trotz der optimierten 
Überlebensrate zeigten Mutanten aber verzögerte Gewichtszunahme bis zum Alter von vier Wochen, die sich danach an das Wildtypniveau anglich (Abb. 6 D).

\subsection{Reduzierte zerebelläre Größe in NDRF-Nullmutanten}

Die Analyse HE-gefärbter sagittaler Schnitte an P 25 zeigte eine um 20,4 \% reduzierte zerebelläre Größe in Mutanten (Abb. 6 E, F; Mutanten, 5,84 $\pm 0,02 \mathrm{~mm}^{2}$; Kontrollen, 7,34 \pm $0,19 \mathrm{~mm}^{2}, \mathrm{p}=0,0015 ; \mathrm{n}=3$ / Genotyp). Die Organisation der Lobuli (1 - 10) und zerebellären Zellschichten war jedoch nicht gestört. Die Größenreduktion des Zerebellums wirkte sich auf alle Zellschichten gleichermaßen aus (Abb. 6 G).

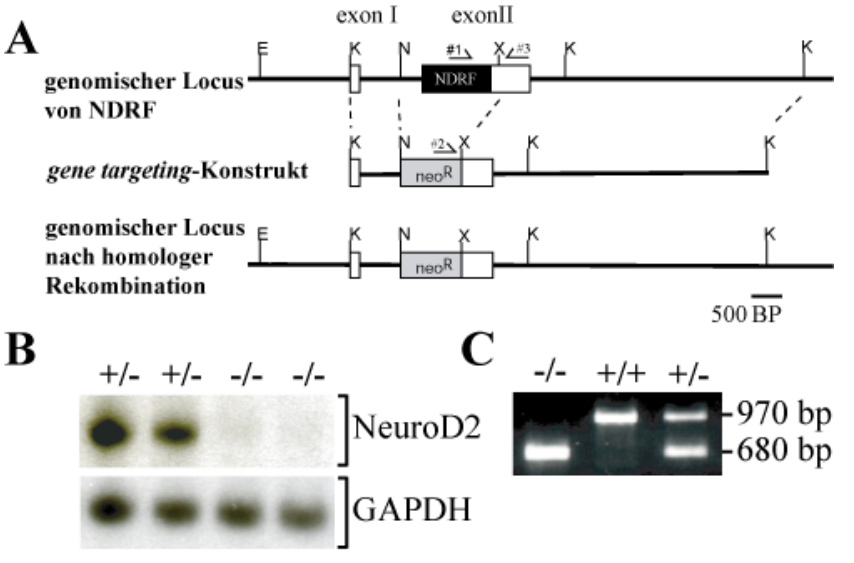

D

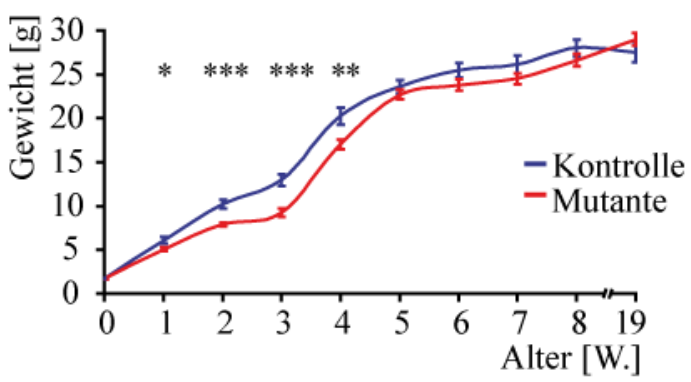

$\mathbf{E}$

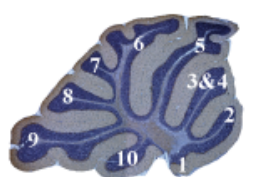

Kontrolle

$\mathbf{G}$

\begin{tabular}{|cc|cc|c|}
\hline $37,8+/-0,6 \%$ & $37,8+/-0,9 \%$ & IKS \\
\hline $44,8+1-1,3 \%$ & $46,4+/-0,7 \%$ & MS \\
\hline $8,9+/-0,4 \%$ & $8,2+/-0,7 \%$ & WS \\
\hline
\end{tabular}

Abb. 6 Inaktivierung des NDRF-Gens in der Maus

A, Struktur des wildtypischen NDRF-Gens (oben), des gene targeting-Konstrukts (mitte) und des rekombinierten genomischen Locus (unten). Das NDRF-Gen besitzt zwei Exone (weiße Boxen) und der kodierende Bereich ist auf Exon 2 lokalisiert (schwarze Box). Nach der homolgen Rekombination ist der für NDRF kodierende Bereich durch eine antisense orientierte NeomycinResistenzkassette ersetzt $\left(\right.$ neo $\left.^{\mathrm{R}}\right)$. Die Positionen verschiedener Restriktionsenzymschnittstellen (E, EcoRI; K, KpnI; N, NotI; X, XhoI) sowie die Ansatzstellen verschiedener Primer sind indiziert (\#1 - 3) B, Northern-Blot-Analyse zerebellärer Gesamt-RNA drei Monate alter Tiere verifizierte die Abwesenheit von NDRFRNA in zerebellären Lysaten von NDRFNullmutanten (-/-) verglichen mit heterozygoten Kontrollen (+/-). Als interner Ladestandard diente GAPDH. C, Genotypisierungs-PCR mit Primern \#1 - 3 auf genomischer Mausschwanz-DNA von Nullmutanten (-/-), Wildtypen $(+/+)$ und heterozygoten Kontrollen (+/-) sowie die Größen der zugehörigen PCR-Produkte. D, Wachstumskurve für männliche NDRFMutanten und heterozygote Kontrollen $(\mathrm{n}=9$ / Genotyp und Alter). Trotz gleichem Erscheinungsbild an P 0 liegen die Mutanten bezogen auf die Gewichtszunahme hinter den Kontrollen zurück, gleichen sich aber nach dem ersten Monat wieder an. E, HE-Färbung

sagittaler zerebellärer Schnitte verdeutlicht die Größenreduktion des Zerebellums in Mutanten verglichen mit Kontrollen an P $25(1-10=$ zerebelläre Lobuli). Maßstab $=1 \mathrm{~mm}$. F, In sagittaler Ebene beträgt die Größenreduktion des Zerebellums in Mutanten 20,4 \% verglichen mit Kontrollen. G, Die Größenreduktion des Zerebellums vollzieht sich gleichmäßig in allen zerebellären Schichten (IKS, Interne Körnerzellschicht; MS, Molekularschicht; WS, Weiße Substanz). 


\subsection{Normale Körnerzellentwicklung in NDRF-Nullmutanten}

Übereinstimmend mit den früheren Resultaten von (Olson et al., 2001), dass NDRF essentiell für das Überleben zerebellärer Körnerzellen ist, starben auch bei den im Rahmen dieser Arbeit verwendeten Tieren (Abb. 7) eine größere Zahl von Körnerzellen innerhalb der ersten drei postnatalen Wochen

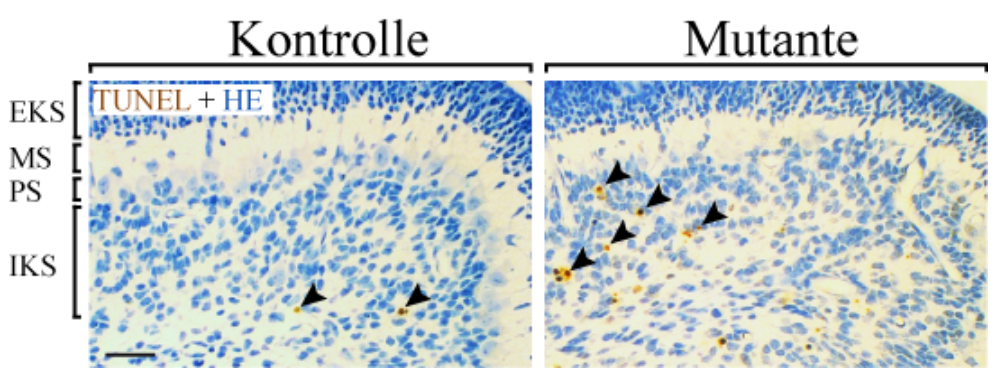

\section{Abb. 7 Apoptose in der Körnerzellschicht von NDRF-Nullmutanten}

Detektion zahlreicher apoptotischer Körnerzellen an P 5 mittels TUNEL-Färbung in Mutanten. EKS = Externe Körnerzellschicht; MS = Molekularschicht; PS = Purkinje-Zellschicht; IKS = Interne Körnerzellschicht. Maßstab $=50 \mu \mathrm{m}$.

Nach dieser kritischen Phase kam es jedoch zu keinem weiteren apoptotischen Zelltod zerebellärer Körnerzellen in den Mutanten. Die Körnerzellen, welche nicht innerhalb des kritischen postnatalen Zeitraums apoptotisch zugrunde gingen, zeigten keine Anzeichen einer weiteren Schädigung bis zu einem Alter von über einem Jahr (Abb. 8). So wurde durch die Analyse $0,5 \mu \mathrm{m}$ dicker Methylenblau-gefärbter Semidünnschnitte ermittelt, dass die Körnerzelldichte in Mutanten im Alter von einem Jahr der von Kontrollen entsprach (Kontrollen: $20833 \pm 1820 / \mathrm{mm}^{2}$; Mutanten: $20058 \pm 886 / \mathrm{mm}^{2} ; \mathrm{p}=0,988 ; \mathrm{n}=3 /$ Genotyp;Abb. 8 A). Die mittels Golgi-Silberimprägnierung visualisierten Somata, Axone, Dendriten und dendritischen Endigungen (Telodendria) waren in Mutanten im Vergleich zu Wildtypen ebenfalls unverändert (Abb. 8 B). Mittels immunhistochemischer Analyse konnte gezeigt werden, dass Körnerzellen in Mutanten GABRA6 (gamma-aminobutyric acid receptor, $\underline{\alpha} 6$ ) expremierten, einen Marker für terminale Differenzierung und postsynaptische Funktionen (Hatten et al., 1997). Mit Hilfe doppelimmunfluoreszenter Detektion von CALR (Calretinin), einem Marker für Parallelfasern (Körnerzellaxone und deren T-förmige Verzweigungen) und PVALB (Parvalbumin), einem Marker für Purkinje-Zellen und deren Dendriten, konnte gezeigt werden, dass Parallelfasern in Mutanten normal entwickelt und angeordnet waren (Abb. $8 \mathrm{C}$, Mitte). Doppelimmunfluoreszente Analyse von PVALB mit VGLUT1 (esicular glutamate transporter 1), einem Marker für die synaptischen Endigungen von Parallelfasern verdeutlichte, dass selbige ebenfalls normal in Mutanten entwickelt waren (Abb. $8 \mathrm{C}$, unten). Auch in der ultrastrukturellen 
elektronenmikroskopischen Analyse waren Morphologie und Anzahl der ParallelfaserPurkinje-Zellsynapsen in ein Jahr alten Mutanten verglichen mit Wildtypen unverändert (Abb. 8 D; Kontrollen: 37,8 Synapsen / $100 \mu \mathrm{m}^{2}$; Mutanten: 31,27 Synapsen / $100 \mu \mathrm{m}^{2}$; $\mathrm{p}=$ 0,$12 ; \mathrm{n}=3$ / Genotyp).

Zusammengefasst deuten diese Ergebnisse darauf hin, dass alle NDRF-defizienten Körnerzellen, die die kritische Phase der ersten drei postnatalen Wochen und den Übergang vom späten Progenitorstadium zur voll differenzierten Körnerzelle überlebten, auch funktionell in das zerebelläre Netzwerk integriert werden konnten.

Untermauert wird diese Beobachtung durch elektrophysiologische whole-cell patch-clamp Untersuchungen an Purkinje-Zellen (Abb. 8 E).

Hierbei wurden Parallelfasern mit zwei Stromimpulsen im Abstand von 50 ms stimuliert und die Amplituden der zugehörigen EPSCs (excitatory posts ynaptic çurrents) auf den PurkinjeZellen und die darüber zugänglichen Werte für die PPF (paired pulse fascilitation), einem Maß für die Wahrscheinlichkeit der Vesikelfreisetzung und synaptische Kurzzeitplastizität, ermittelt. Weder die jeweiligen EPSC-Amplituden noch die daraus resultierenden Werte für die PPF unterschieden sich in Mutanten im Vergleich zu Kontrollen (Kontrollen: 1,51 \pm 0,13; Mutanten: $1,56 \pm 0,04 ; \mathrm{p}=0,61 ; \mathrm{n}=5$ / Genotyp). Die Funktionalität der ParallefaserPurkinje-Zellsynapse in Mutanten war also auch auf elektrophysiologischem Niveau unverändert.

Um zu überprüfen, ob das Fehlen von Defekten in integrierten Körnerzellen NDRFdefizienter Mäuse durch die kompensatorische Wirkung des verwandten bHLHTranskriptionsfaktors NeuroD erklärt werden kann, wurden als nächstes phänotypisch unauffällige konditionale NeuroD-Mutanten in die NDRF-knockout Mauslinie eingekreuzt und analysiert. Die konditionale Inaktivierung des NeuroD-Gens in postmitotischen, postmigratorischen Körnerzellen ab ca. P 6 wurde mit Hilfe des Cre/loxP-Systems erzielt (Goebbels et al., 2005). Alle Analysen wurden hierbei auf flox/- genetischem Hintergrund durchgeführt. Der Phänotyp von Tieren mit zur Hälfte reduzierter NDRF- und NeuroDGendosis und konditional inaktivierter NeuroD-Expression ab P $6\left(\mathrm{NDRF}^{+/-}, \mathrm{NeuroD}{ }^{\mathrm{fl} /-}, \mathrm{Cre}\right)$ entsprach dem von $\left(\mathrm{NDRF}^{+/}\right)$-Kontrollen (Abb. 8 F, links). Tiere mit inaktvierter NDRFExpression und zur Hälfte reduzierter NeuroD-Gendosis entsprachen phänotypisch den NDRF-Einzelmutanten (Abb. 8 F, Mitte). Wurde in Tieren mit inaktvierter NDRF-Expression und zur Hälfte reduzierter NeuroD-Gendosis, letztere noch zusätzlich komplett konditional inaktiviert, so verschlechterte sich der Phänotyp in diesen Tieren stark (Abb. 8 F, rechts). Es kam zu starker Apoptose von Körnerzellen an P 21 und reduzierter Zerebellumgröße im 
Vergleich zu NDRF-Einzelmutanten, was eine zumindest teilweise kompensatorische Funktion von NeuroD für den NDRF-Verlust implizierte. Ein Allel von NeuroD war also ausreichend, um NDRF-defiziente postmitotische und postmigratorische Körnerzellen der IKS vor apoptotischem Zelltod zu bewahren.
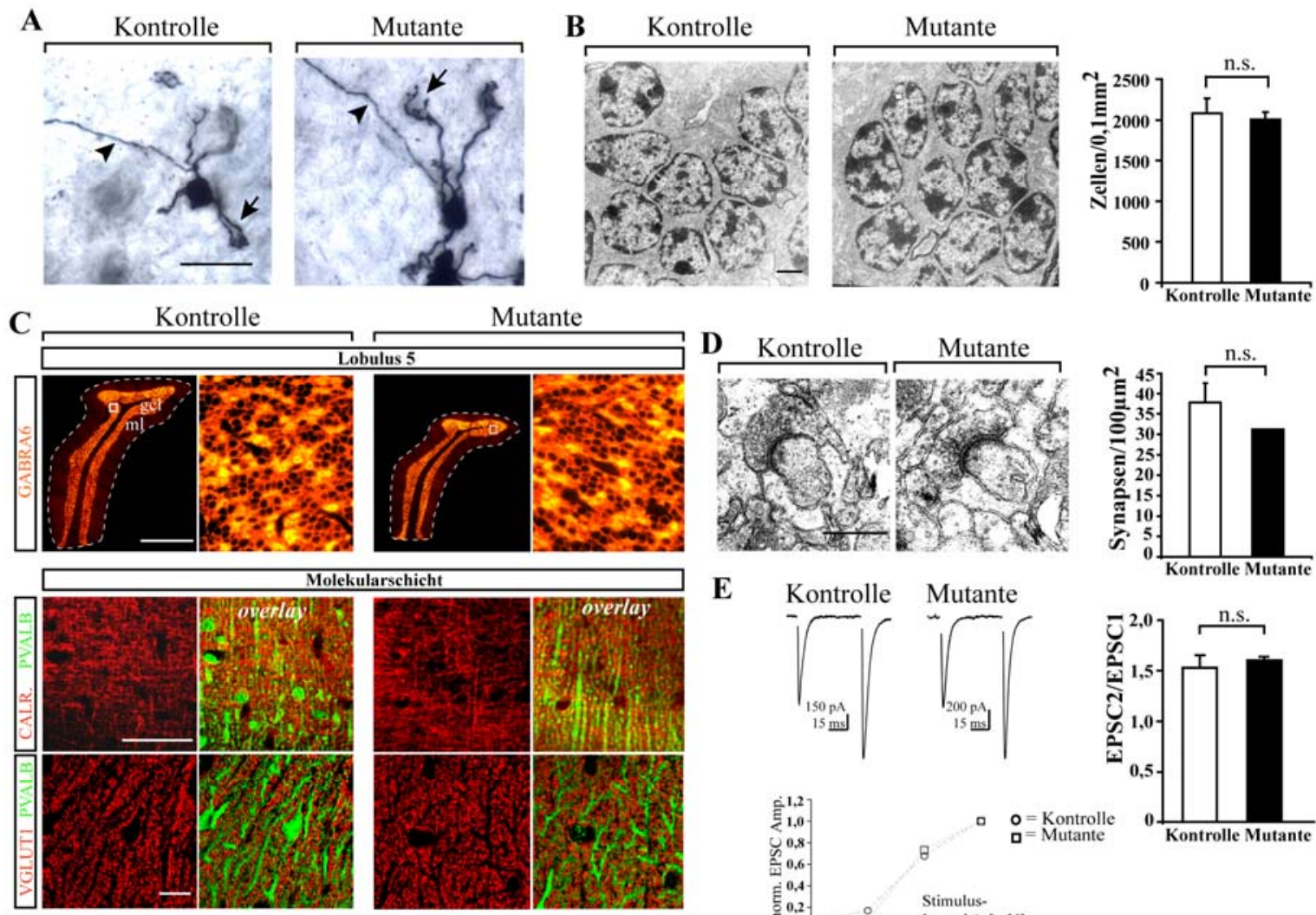

F
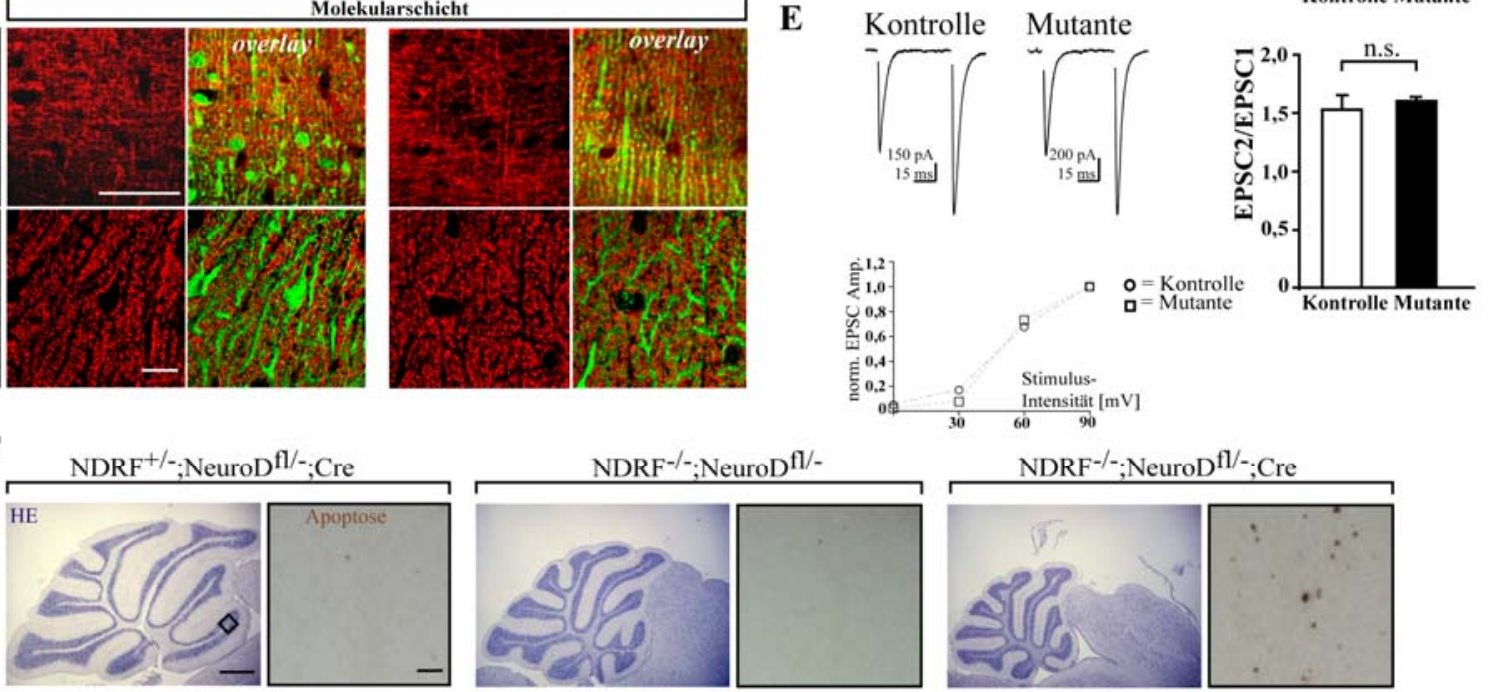

Abb. 8 Körnerzelldifferenzierung und Funktion in NDRF-Nullmutanten

A, Golgi-Silberimprägnierung an P 25 verdeutlichte, dass Mutanten und Kontrollen gleichermaßen für reife Körnerzellen typische Klauenartige dendritische Endigungen (Telondria) und Axone besitzen, die die Körnerzellschicht in Richtung Molekularschicht verlassen. Maßstab $=20 \mu \mathrm{m}$.

B, Quantifizierung der Körnerzelldichte auf zerebellären Semidünnschnitten im Alter von einem Jahr zeigte keine Unterschiede zwischen Mutanten und Kontrollen.

C, Die Körnerzellen, die nicht apoptotisch zugrunde gegangen sind, expremieren reife Marker in NDRF-Nullmutanten. Die obere Spalte zeigt die GABRA6-Expression in Lobulus 5 im Überblick und im Detail. Die coimmunhistochemische Detektion von CALR und PVALB (mittlere Spalte) sowie VGLUT und PVALB (untere Spalte) zeigt eine normale Verteilung und Anordnung von Körnerzellaxonen und synaptischen Endigungen in Mutanten verglichen mit Kontrollen. Maßstab von oben nach unten $=600,50,10 \mu \mathrm{m}$.

D, Die Anzahl und Ultrastruktur von Parallelfaser-Purkinje-Zell-Synapsen waren in Mutanten verglichen mit Kontrollen unverändert $(\mathrm{PF}=$ Parallelfaser; $\mathrm{s}=$ Purkinje-Zell-spine; $\mathrm{BG}=$ Bergman Glia). Maßstab $=25 \mu \mathrm{m}$. 
E, Die synaptische Transmission von Parallelfasern auf Purkinje-Zellen in Mutanten ist normal und vergleichbar mit der in Kontrollen (links oben). Die Applikation zweier kurz aufeinander folgender Stimuli im zeitlichen Abstand von 50 ms erzeugt in Mutanten und Kontrollen gleichermaßen zwei EPSCs (extrasynaptic postsynaptic currents), wobei die Amplitude des jeweils zweiten EPSCs in Mutanten und Kontrollen gleichermaßen erhöht ist (paired pulse fascilitation). Daher ergeben sich auch gleiche Quotienten für EPSC2/EPSC1 (paired pulse ration; rechts oben). Darüber hinaus ist die Amplitude der EPSCs abhängig von der Intensität des applizierten Stimulus (unten). Eine schrittweise Erhöhung der Stimulusspannung führt in Kontrollen und Mutanten $\mathrm{zu}$ einem vergleichbaren graduellen Anstieg der EPSCs auf Purkinje-Zellen, da eine steigende Anzahl von Parallelfasern rekrutiert wird.

F, Funktionelle Redundanz von NeuroD und NDRF detektiert mittels HE- und TUNEL-Färbung sagittaler Schnitte an P 21. Konditionale NeuroD Nullmutanten mit einem verbliebenen Allel NDRF $\left(\mathrm{NDRF}^{+/} ; \mathrm{NeuroD}{ }^{\mathrm{fl} /} ; \mathrm{Cre}\right)$ besitzen ein Zerebellum unveränderter Größe ohne apoptotische Körnerzellen, während NDRF-Nullmutanten mit einer verbliebenen Kopie des NeuroD-Gens (NDRF ${ }^{-/}$ ;NeuroD ${ }^{\mathrm{fl} /}$ ) ein Zerebellum besitzen, dass auf die Größe von NDRF-Nullmutanten reduziert ist und ebenfalls keine apoptotischen Körnerzellen zeigt. Im Gegensatz dazu ist die Größe des Zerebellums in NDRF-Nullmutanten mit zusätzlicher kompletter Inaktivierung des NeuroD-Gens in postmigratorischen Körnerzellen $\left(\mathrm{NDRF}^{-/} ; \mathrm{NeuroD}^{\mathrm{fl} /-}\right.$; Cre) nochmals reduziert und weist eine große Anzahl apoptotischer Zellen auf, hier dargestellt in Lobulus 2 des Zerebellums. Ein Allel von NeuroD in postmigratorischen Körnerzellen kann den kompletten Verlust von NDRF also kompensieren. Maßstab für HE-Färbung: $500 \mu \mathrm{m}$; Maßstab für TUNEL-Färbung: $30 \mu \mathrm{m}$.

\subsection{Reife und normal entwickelte Kletterfasern in NDRF- Nullmutanten}

Um die Funktionalität der zweiten exzitatorischen Eingangsinstanz des Zerebellums, den Kletterfasern, zu überprüfen wurden diese ebenfalls im Abstand von 50 ms stimuliert und die Purkinje-Zell-EPSCs bestimmt (Abb. 9). Bei allen Stimulationen ergab sich in Mutanten eine reguläre „Alles-oder-Nichts“-Antwort. Diese zeigte an, dass eine Purkinje-Zelle von jeweils nur einer einzigen Kletterfaser kontaktiert wurde und während der Entwicklung (bis P 14) auftretende multiple Kletterfasern in den Mutanten korrekt eleminiert wurden (Hashimoto und Kano, 2005). Zudem waren die Werte für die PPD (paired pulse depression) der Kletterfasern in Mutanten identisch mit denen in Wildtypen (Kontrollen: 0,49 $\pm 0,03 ; n=11$; Mutanten: $0,44 \pm 0,03 ; n=7 ; p=0,2)$, was impliziert, dass diese reif und funktional sind.

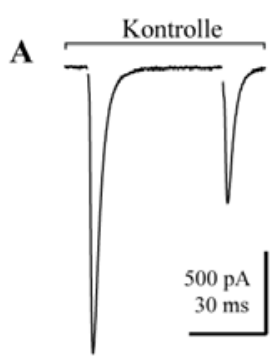

C

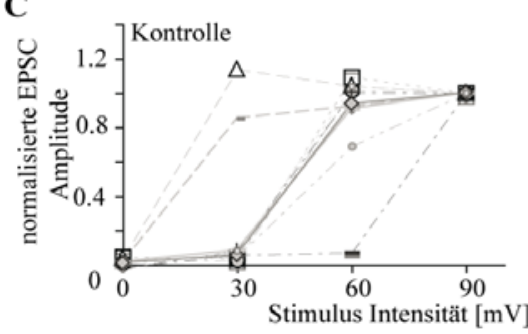

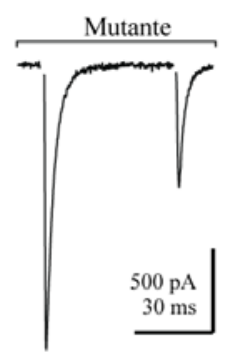
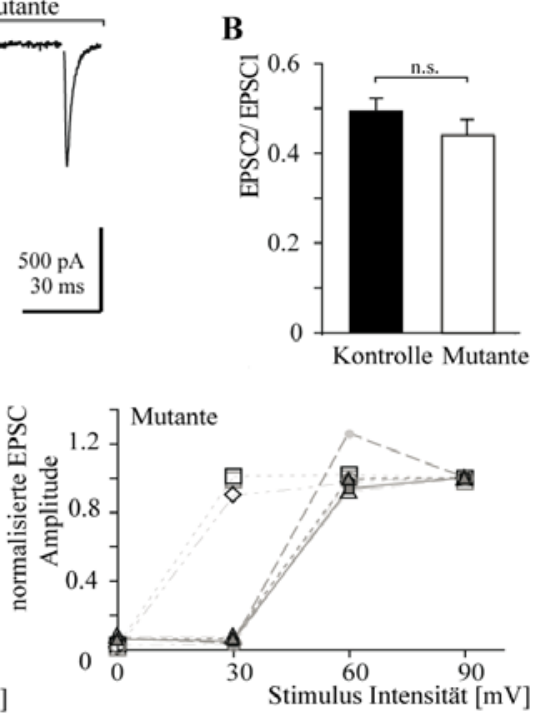
Abb. 9 Normaler synaptischer Kletterfaser-input in NDRF-Nullmutanten

A, Dargestellt sind repräsentative Kletterfaser-EPSCs auf Purkinje-Zellen, die durch Stimulation im Abstand von $50 \mathrm{~ms}$ evoziert wurden. In Mutanten und Kontrollen ist die Amplitude des zweiten EPSC jeweils gleichermaßen reduziert (PPD). B, Der Quotient aus EPSC2 und EPSC1 in Mutanten ist vergleichbar mit dem in Kontrollen. C, In Kontrollen und Mutanten führt Erhöhung der Stimulationsintensität nur zu einer Alles-oder-Nichts-Antwort und nicht zu graduellen Antworten, was für die Schrittweise Rekrutierung multipler (unreifer) Kletterfasern sprechen würde. Die Symbole repräsentieren $6-7$ individuelle stimulierte Zellen.

\subsection{Die Anzahl von Korb- und Sternzellen ist in NDRF- Nullmutanten reduziert}

Da die zweite zerebelläre Hauptexpressionsdomäne von NDRF die MolekularschichtInterneurone (MS-IN) des Zerebellums sind, wurde als nächstes der inhibitorische Einfluss auf Purkinje- und Sternzellen elektrophysiologisch untersucht. Die Frequenz von mIPSCs (miniature inhibitory postsynaptic çurrents) auf Purkinje-Zellen war in Mutanten im Vergleich zu Kontrollen signifikant reduziert (Abb. 10 A; Kontrollen: 26,87 \pm 1,71 Hz; n = 15; Mutanten: 15,39 $\pm 1,44 \mathrm{~Hz} ; \mathrm{n}=16, \mathrm{p}<0,0001)$ während ihre Amplitude in Mutanten jedoch unverändert war (Kontrollen: 223,81 \pm 9.46 pA; $n=15$; Mutanten: 249,75 $\pm 14,33$ $\mathrm{pA} ; \mathrm{n}=16 ; \mathrm{p}=0,14)$. Da MS-IN auf sich selbst synapsieren (feed forward inhibition) wurden ebenfalls mIPSCs auf Sternzellen gemessen. Hier ergab sich die gleiche Tendenz, wie bei Purkinje-Zellen: Die Frequenz der mIPSCs war reduziert (Abb. 10 B; Kontrollen: 3,28 \pm 1,18 $\mathrm{Hz} ; \mathrm{n}=8$; Mutanten: $0,51 \pm 0,23 \mathrm{~Hz} ; \mathrm{n}=9 ; \mathrm{p}=0,03)$ nicht jedoch ihre Amplitude (Kontrollen 86,67 $\pm 16,08 ; \mathrm{n}=8$; Mutanten: 80,69 $\pm 18,93 \mathrm{pA} ; \mathrm{n}=9 ; \mathrm{p}=0,82$ ).

Zusammengefasst deuten diese Resultate auf eine reduzierte Dichte funktionaler Synapsen von MS-IN hin.

Zur Überprüfung des elektrophysiologischen Befundes reduzierter inhibitorischer synaptischer Transmission, wurde die Anzahl von MS-IN an P 25 histologisch auf $5 \mu \mathrm{m}$ dicken Paraffinschnitten bestimmt. So war die Anzahl durch HE-Färbung detektierter Nuclei in der Molekularschicht in Mutanten verglichen mit Kontrollen auf $37 \%$ reduziert (Abb. 10 C, D) Kontrollen: 148,9 \pm 9,9 / 0,1 mm²; Mutanten: 54,4 $\pm 4,4 / 0,1 \mathrm{~mm}^{2} ; \mathrm{p}=0,001, \mathrm{n}=3 /$ Genotyp).

Die Quantifizierung der Dichte GAD1 (glutamate decarboxylase 1)-expremierender Zellen (Abb. 10 D) ergab in Mutanten eine auf 31,4 \% reduzierte Zellzahl im Vergleich zur Kontrolle (Kontrollen: $119 \pm 9 / 0,1 \mathrm{~mm}^{2}$; Mutanten: $37 \pm 3 / 0,1 \mathrm{~mm}^{2} ; \mathrm{p}=0,0009 ; \mathrm{n}=3 /$ Genotyp), was bestätigte, dass es sich bei den fehlenden Zellen in der Molekularschicht hauptsächlich um MS-IN handelt. 
A

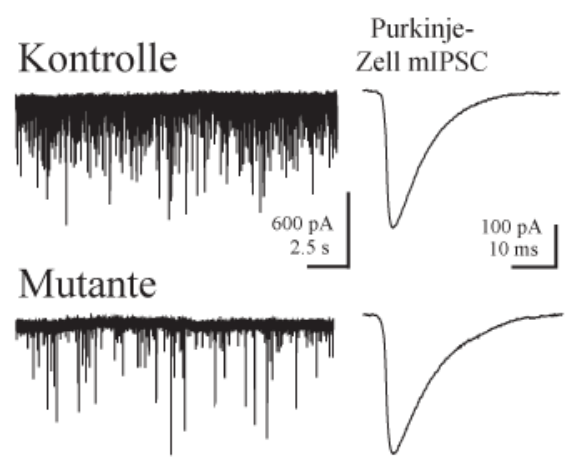

B

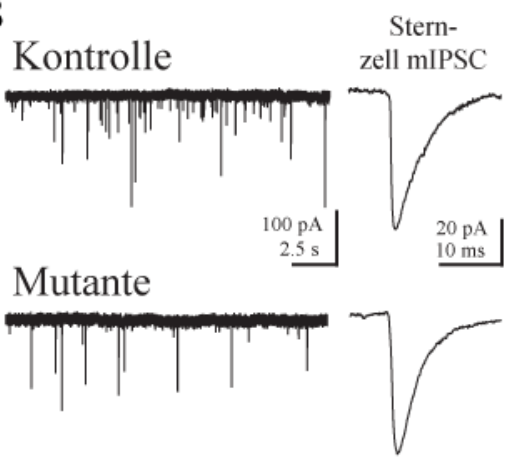

C

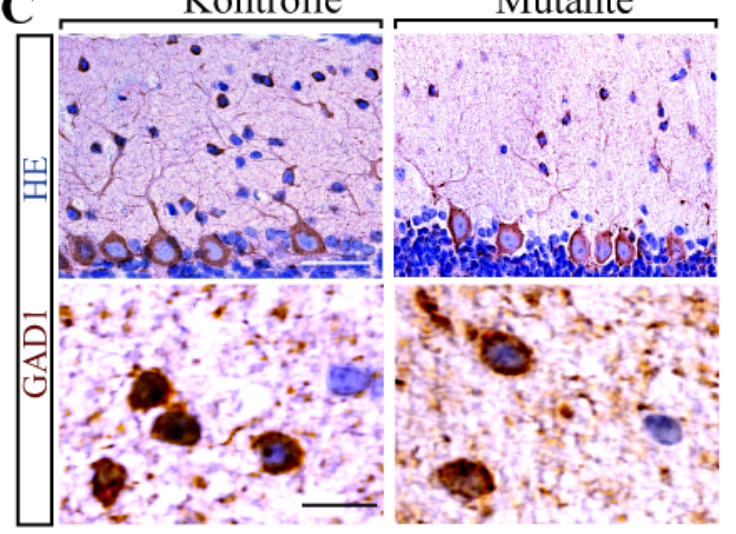

D

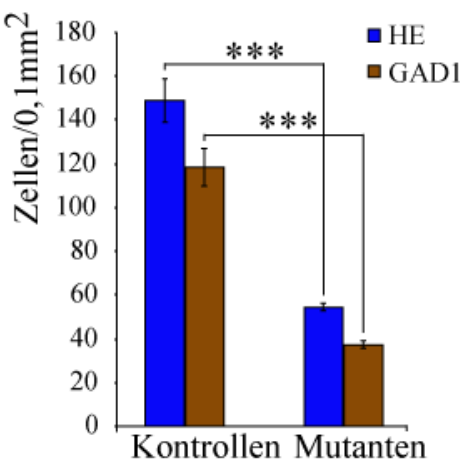

Abb. 10 Reduzierte Anzahl von Interneuronen der Molekularschicht (MS-IN) in NDRFNullmutanten

A, Inhibitorische synaptische Transmission auf Purkinje-Zellen bei 15 - 19 Tage alten Tieren. Die Frequenz der mIPSCs auf Purkinje-Zellen war in Mutanten verglichen mit Kontrollen signifikant reduziert. B, Inhibitorische synaptische Transmission auf Sternzellen bei 15 - 19 Tage alten Tieren. Die Frequenz der mIPSCs auf Sternzellen war in Mutanten verglichen mit Kontrollen ebenfalls signifikant reduziert.C, HE-Färbung und immunhistochemische Detektion von GAD1 auf sagittalen zerebellären Schnitten an P 25 offenbart eine stark reduzierte Anzahl von MS-IN in Mutanten. Dargestellt ist ein Ausschnitt aus der Molekularschicht $(\mathrm{Maßstab}=50 \mu \mathrm{m})$ und darunter eine Detailansicht (Maßstab $=10 \mu \mathrm{m})$. D, Quantifizierung der HE-Färbung und der GAD1immunhistochemischen Detektion. GABAerge Interneurone sind in Mutanten auf 31,4 \% reduziert.

In Übereinstimmung mit diesem Resultat wiesen Mutanten an P10 erhöhte Apoptose in der Molekularschicht auf, was eine Funktion von NDRF für den Erhalt dieser Interneurone impliziert (Abb. 11).
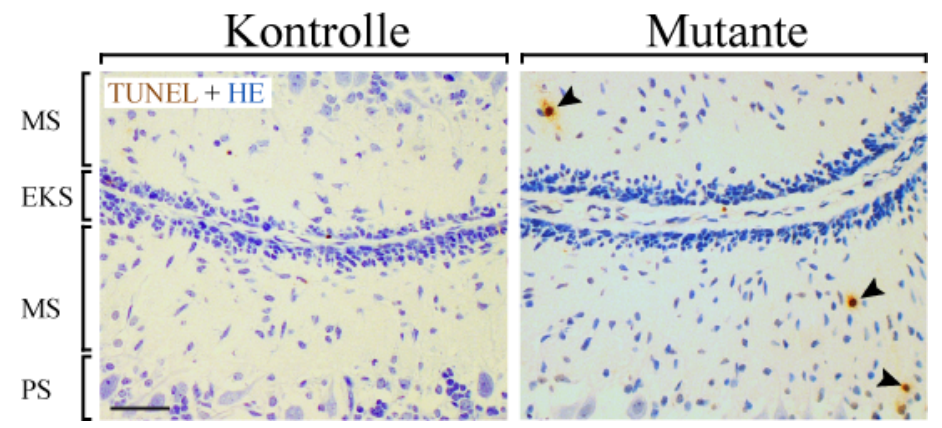

\section{Abb. 11 Erhöhte Anzahl apoptotischer MS-IN in NDRF-Nullmutanten}

TUNEL-Färbung verdeutlicht, dass einige ML-IN in NDRF-Nullmutanten an P 10 apoptotisch sterben. EKS = Externe Körnerzellschicht; MS = Molekularschicht; PS = PurkinjeZellschicht; Maßstab $=50 \mu \mathrm{m}$. 


\subsection{Gestörte terminalen Differenzierung von Korb- und Sternzellen in NDRF-Nullmutanten}

Weiterhin stellte sich die Frage, ob die verbliebenen Interneurone den NDRF-Verlust, wie Körnerzellen, überstehen und funktionell integriert werden können. Dabei stellte sich heraus, dass alle überlebenden GAD1-positiven Interneurone in Mutanten an P 25 den

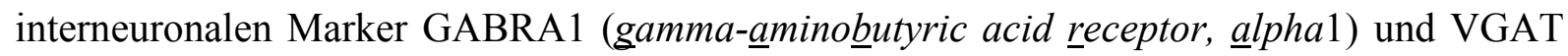
(vesicular GABA transporter) exprimierten (Abb. 12 A). Während alle GABRA1-positiven Zellen in Kontrollen auch den reifen interneuronalen Marker PVALB exprimierten, fehlte dessen Expression in nahezu allen verblieben MS-IN der Mutante (Abb. 12 B, C, D; Kontrollen: $110 \pm 8$ PVALB $^{+}$Zellen $/ 0,1 \mathrm{~mm}^{2}$; Mutante: $4 \pm 1$ PVALB $^{+}$Zellen $/ 0,1 \mathrm{~mm}^{2}$; $\mathrm{n}=$ 3 / Genotyp; $\mathrm{p}=0,0002$ ).

A
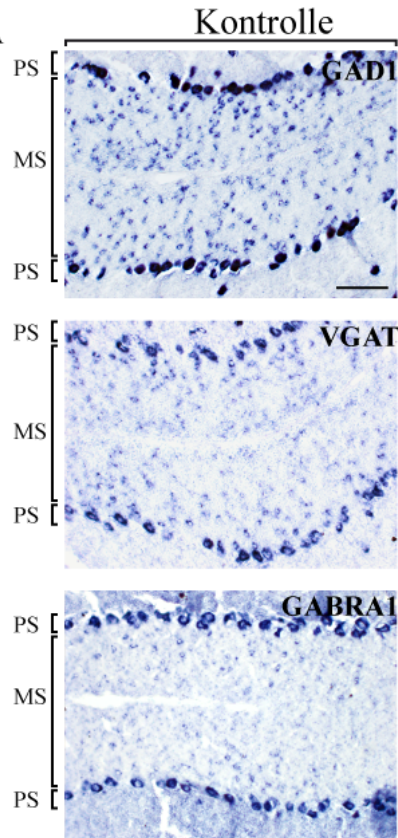

B

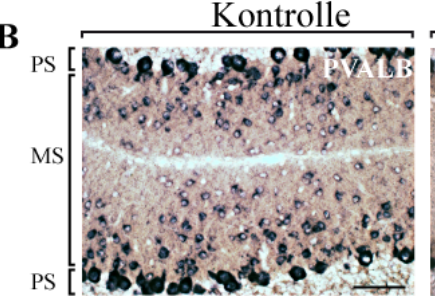

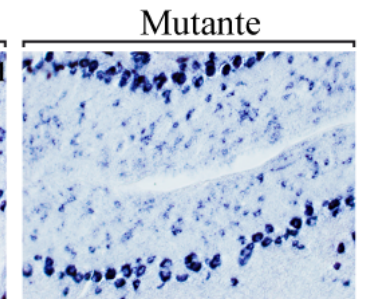
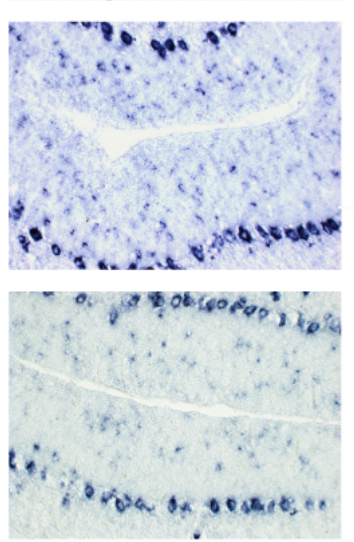

Mutante

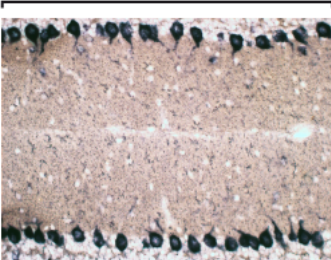

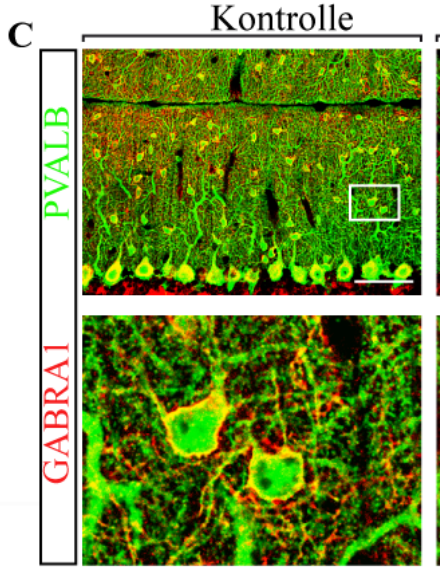

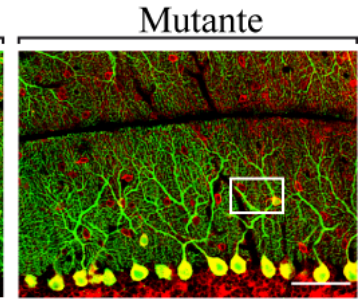

D
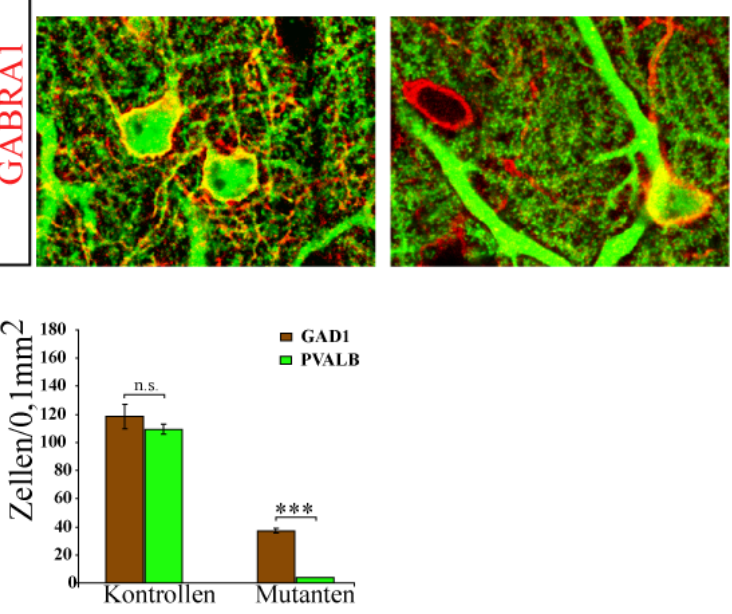

Abb. 12 Überlebende ML-IN in NDRF-Nullmutanten exprimieren kein PVALB

A, In situ Hybridisierung auf zerebellären Schnitten an P17 zeigt, dass die überlebenden ML-IN GAD1 (oben), VGAT (mitte) und GABRA1 (unten) exprimieren. Maßstab $=100 \mu \mathrm{m}$. B, Im Gegensatz dazu fehlt PVALB-Expression nahezu gänzlich in NDRF-Nullmutanten, was ebenfalls mittels In Situ Hybridisierung auf zerebellären Schnitten an P 17 gezeigt wurde. Maßstab $=100 \mu \mathrm{m}$.C, Die immunhistochemische Analyse auf sagittalen zerebellären Schnitten an P 25 zeigt, dass alle GABRA1-exprimierenden ML-IN in Kontrollen auch PVALB exprimieren, während PVALBExpression in fast allen überlebenden GABRA1-postiven ML-IN in der Mutante fehlt. Maßstab = 50 $\mu \mathrm{m}$. D, Quantifizierung aller GAD $1^{+}$und $\mathrm{PVALB}^{+}$Zellen in Lobulus 5 sagittaler zerebellärer Schnitte. Nur $11 \%$ der verbliebenen GAD $1^{+}$ML-IN in Mutanten exprimieren PVALB. 
Im Gegensatz zu den MS-IN waren die die Parvalbumin-positiven Interneurone des Vorderhirns nicht vom NDRF-Verlust betroffen (Abb. 13 B).

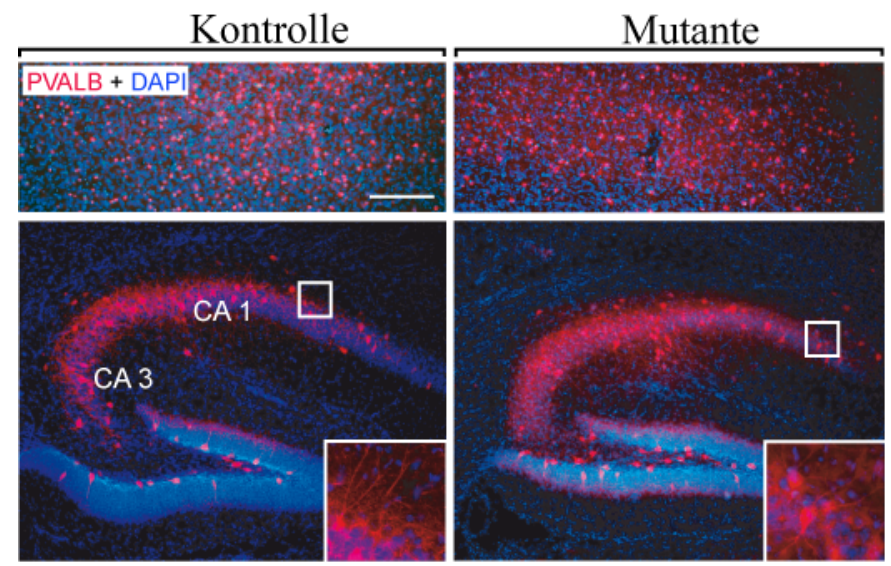

Abb. 13 PVALB-Expression in Interneuronen des Vorderhirns ist in NDRF-Nullmutanten nicht gestört Immunhistochemische Detektion von PVALB und DAPI zeigt eine normale Verteilung und Morphologie PVALB ${ }^{+}$ Interneurone in Mutanten verglichen mit Kontrollen. Maßstab $=200 \mu \mathrm{m}$.

\subsection{Verzögerte Differenzierung von Korb- und Sternzellen in NDRF- Nullmutanten}

Um genauer zu untersuchen, inwieweit die Differenzierung der verbliebenen Interneurone in NDRF-Nullmutanten gestört war wurde die Expression von GAD1 sowie PAX2 (paired box gene 2), ein Marker für interneuronale Progenitoren, in $5 \mu \mathrm{m}$ dicken zerebellären Schnitten im Alter von 5, 10, 50 Tagen und 6 Monaten coimmunhistochemisch detektiert.

An P 5 zeigten Kontrollen und Mutanten eine ähnliche Verteilung der durch die weiße Substanz (WS), interne Körnerzellschicht (IKS) und die sich entwickelnde Molekularschicht (MS) migrierenden interneuronalen Progenitoren (Abb. 14 A). Dies wies darauf hin, dass die Produktion und Migration von MS-IN-Progenitoren in NDRF-Nullmutanten nicht gestört war. An P 10 hatte die Dicke der Molekularschicht sowie die Anzahl der sich darin befindlichen PAX2-positiven Progenitoren in Kontrollen und Mutanten stark zugenommen (Abb. 14 B). In Kontrollen kam es zu diesem Zeitpunkt zum allmählichen Verlust der PAX2-Expression, die von steigender GAD1-Expression begleitet wurde. Diese Expressionsveränderung vollzog sich entlang eines von innen nach außen verlaufenden Gradienten, mit den meisten PAX2defizienten Zellen in der inneren Hälfte der MS. Im Gegensatz dazu zeigte in diesem Alter keines der MS-IN der Mutanten beginnende GAD1-Expression oder Verlust der PAX2Expression. An P 50 haben alle Interneurone der Kontrolle jegliche PAX2-Expression verloren, während in Mutanten ein großer Teil der MS-IN immer noch PAX2, zusätzlich nun aber auch GAD1, expremiert. Das gleiche Expressionsmuster konnte im Alter von 6 Monaten beobachtet werden. 
Zusammengefasst deuten diese Beobachtungen darauf hin, dass NDRF-Expression an der Vermittlung der terminalen neurochemischen Differenzierungsschritte der GABAergen MSIN beteiligt ist.

A

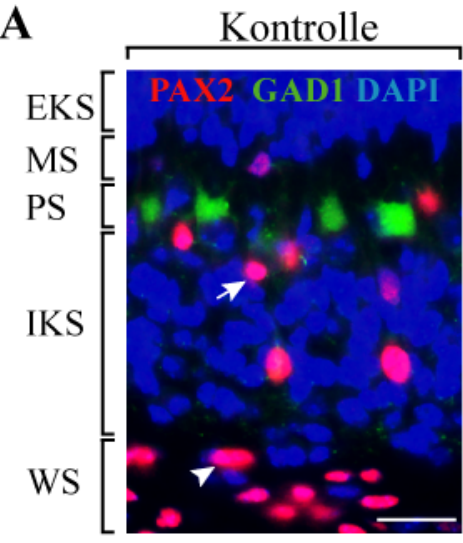

B

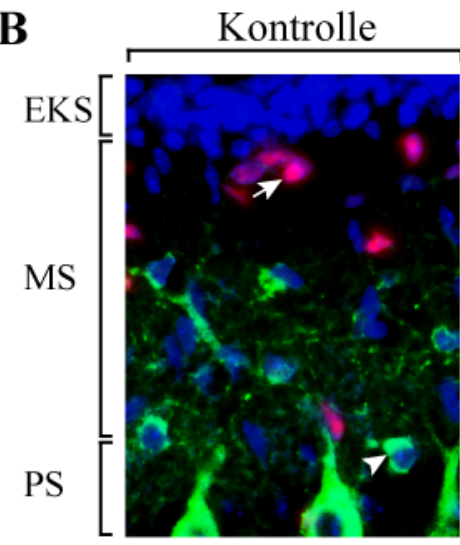

C
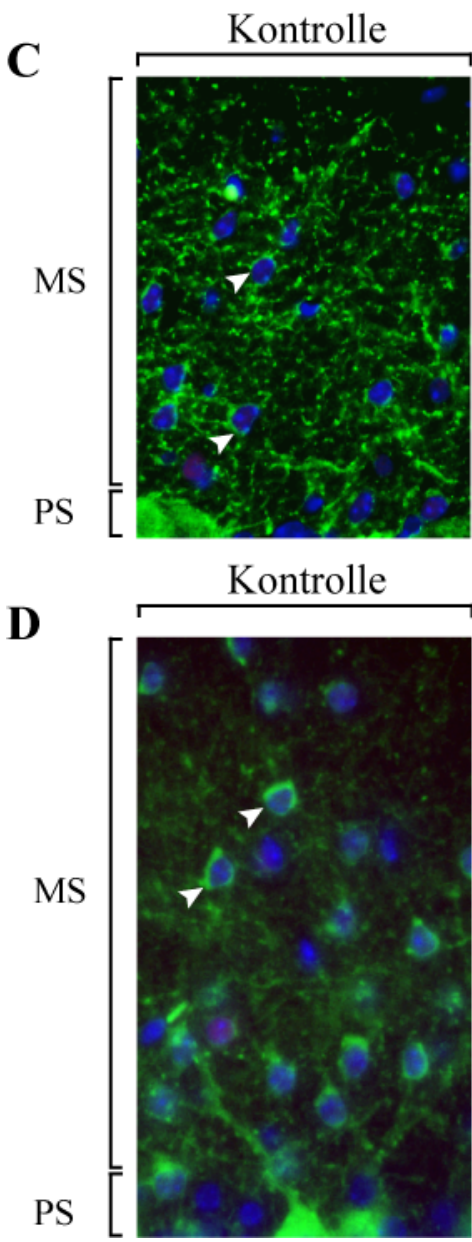

Mutante

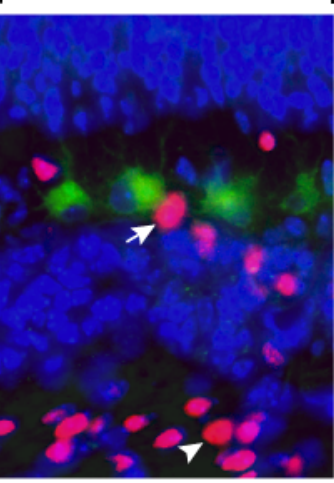

Mutante

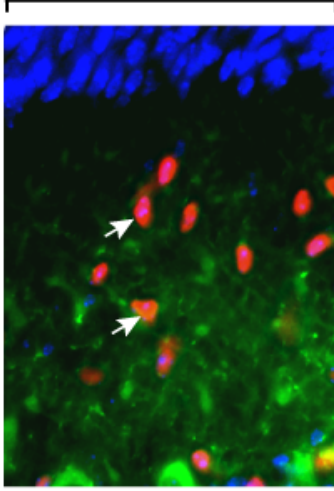

Mutante

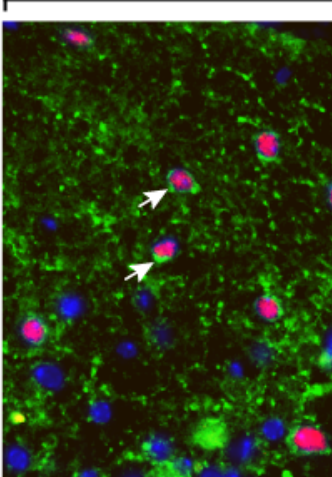

Mutante

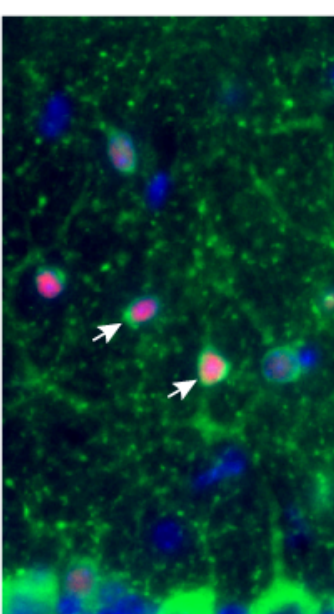

Abb. 14 Gestörte Terminale Differenzierung von ML-IN in NDRF-Nullmutanten

A, Immunhistochemische Detektion von GAD1 und PAX2 auf $5 \mu \mathrm{m}$ dicken zerebellären sagittalen Schnitten an P 5 zeigt in Mutanten und Kontrollen interneuronale Progenitoren, die aus der WS durch die IKS in Richtung sich entwickelnder MS wandern. Pfeile: INProgenitoren. EKS $=$ Externe Körnerzellschicht; MS = Molekularschicht; PS $=$ Purkinje-Zellschicht; IKS = Interne Körnerzellschicht; WS $=$ Weiße Substanz. Maßstab $=20 \mu \mathrm{m}$. B, An P 10 sind in der Kontrolle $\mathrm{PAX}^{+}$IN-Progenitoren in der äußeren Hälfte der MS, vermutlich Sternzellvorläufer, detektierbar (Pfeil) sowie IN-Progenitoren mit beginnender GAD1Expression und allmählichem Verlust der PAX2-Expression in der inneren Hälfte der MS. Im Gegensatz dazu exprimieren alle MLIN der Mutante noch PAX2 und kein GAD1 (Pfeile). C, D, An P 50 und im Alter von 6 Monaten haben die ML-IN der Kontrollen jegliche PAX2-Expression verloren (Pfeilspitzen). Im Gegensatz dazu expremiert in Mutanten ein Grossteil der GAD1 positiven Interneurone noch PAX2 (Pfeile). 
Im Gegensatz dazu waren die Interneurone der Körnerzellschicht (KS-IN) nicht vom NDRFVerlust betroffen. Ihre in Lobulus 5 quantifizierte Anzahl war unverändert (Kontrolle: 35,22 \pm 0,87; Mutante: $32,56 \pm 0,78 ; \quad \mathrm{p}=0,08 ; \mathrm{n}=3$ /Genotyp) und auch die immunhistochemisch ermittelte Expression von PAX2 im Alter von 6 Monaten (Abb. 15 A), sowie die durch insitu-Hybridisierung an P 17 detektierte Expression der reifen inhibitorischen Marker VGAT und GAD1 (Abb. 15 B) war in der Mutante normal.

A

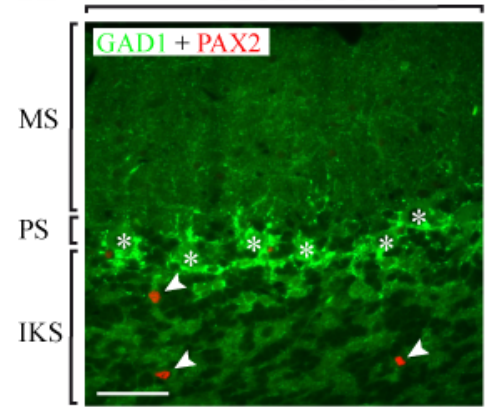

B
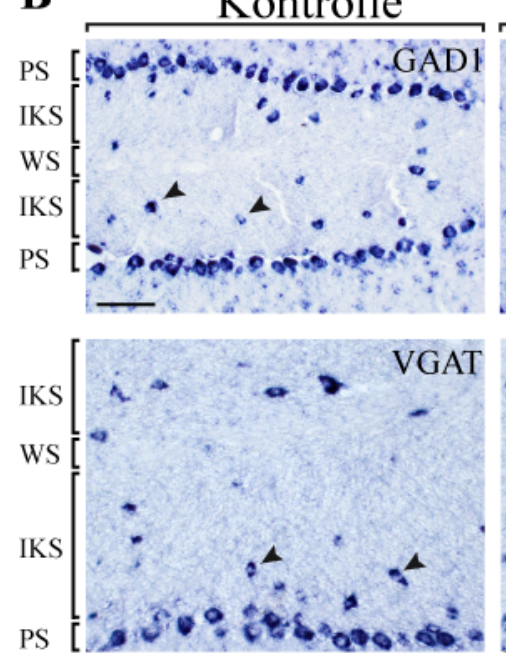

Mutante

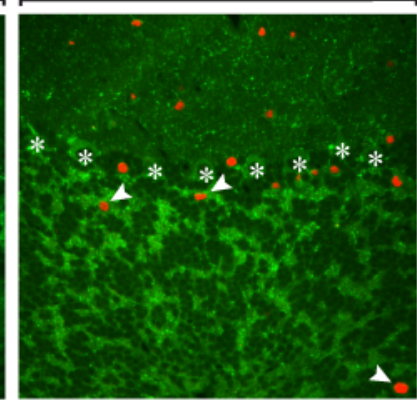

Mutante
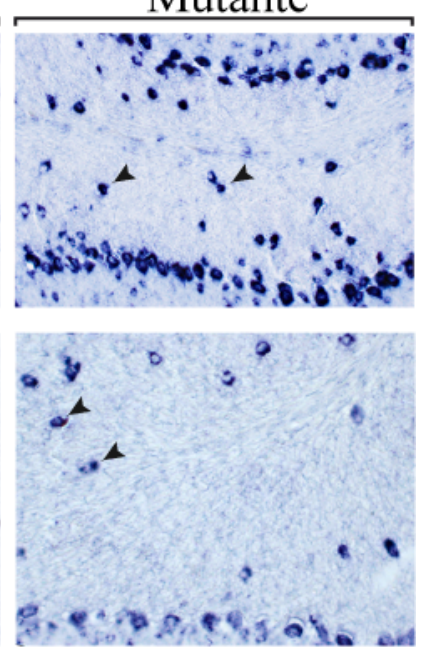

Abb. 15 KS-IN sind normal entwickelt

Bezüglich Anzahl und Position sind KS-IN in Mutanten verglichen mit Kontrollen normal entwickelt (MS = Molekularschicht; PS $=$ PurkinjeZellschicht; IKS $=$ Externe Körnerzellschicht; WS = Weiße Substanz; Sternchen $=$ Position der Purkinje-Zellen; Pfeilspitzen $\quad=\quad$ KS-IN). A, Immunhistochemische Detektion von GAD1 und PAX2 in KS-IN von Kontrollen und Mutanten im Alter von 6 Monaten. Maßstab $=50 \mu \mathrm{m} \mathbf{B}$, In situ Hybridisierung auf zerebellären Schnitten an P 17 zeigt, dass KS-IN in Kontrollen und Mutanten die reifen inhibitorischen Marker GAD1 und VGAT exprimieren. $\mathrm{Maßstab}=100 \mu \mathrm{m}$.

\subsection{Dendrito- und Axogenese von Korb- und Sternzellen in NDRF- Nullmutanten}

Mitglieder der NeuroD-Familie von Transkriptionsfaktoren wurden als wichtige Regulatoren der Axo- und Dendritogenese prinzipaler Neurone identifiziert. Um zu analysieren, ob die Axo- oder Dendritogenese auch in MS-IN von der Expression von NDRF abhängig ist wurde die morphologische Differenzierung dieser Zellen im Bereich des Lobulus 5 detailierter untersucht. Golgi-Silberimprägnierung zeigte in Mutanten, verglichen mit der Kontrolle, eine normale basale Morphologie der in den äußeren zwei Dritteln der Molekularschicht lokalisierten Sternzellen (Chan-Palay und Palay, 1972; Abb. 16 A oben, jeweils links). Immunhistochemische Detektion von MAP2 zeigte, dass auch deren dendritische Strukturen 
in Mutanten normal und mit der Kontrolle vergleichbar entwickelt waren (Abb. 16 A oben, jeweils rechts).

Zur Visualisierung von synaptischen Sternzellendigungen wurden GAD1-positive synaptische Boutons in den oberen zwei Dritteln der Molekularschicht immunhistochemisch visualisiert, da sich diese hier fast ausschließlich von Sternzellen ableiten (Ango et al., 2008a). So konnten in der Mutante deutlich GAD1-positive GABA-erge synaptische Endingungen immunhistichemisch detektiert werden, die entlang dendritischer Purkinje-Zellprofile verliefen (Abb. $16 \mathrm{~B})$.

Obwohl NDRF also wichtig für das Überleben und die Vermittlung der PVALB-Expression ist, ist es für eine korrekte Axo- und Dendritogenese in Sternzellen entbehrlich.

A

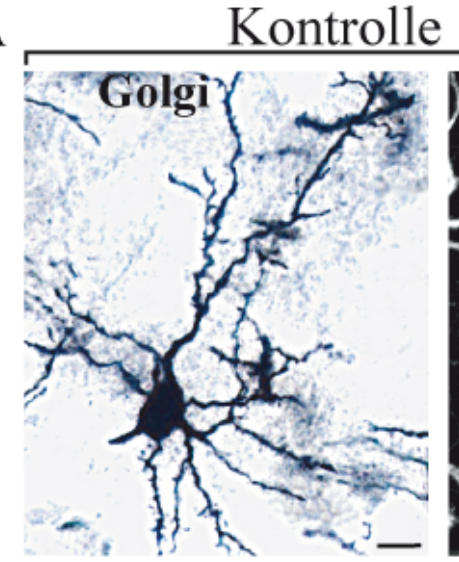

B

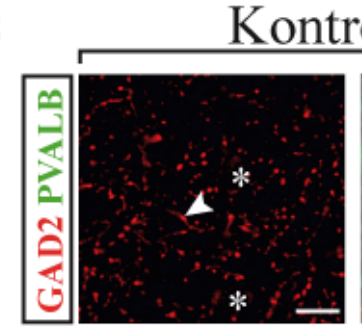

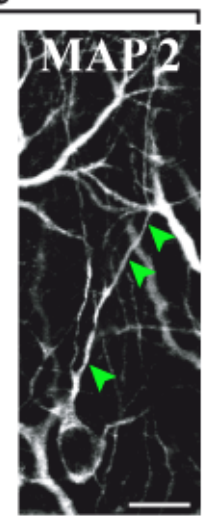

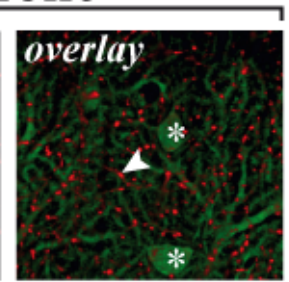

Mutante
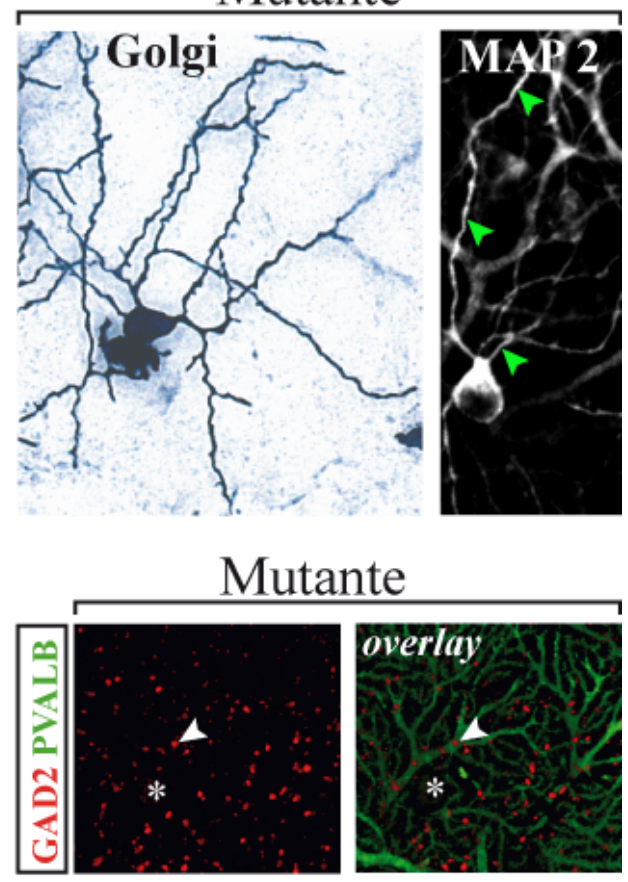

Abb. 16 Sternzellen in NDRF-Nullmutanten entwickeln normale Dendriten, Axone und Synapsen

A, Golgi-Silberimprägnierung (jeweils links) $60 \mu \mathrm{m}$ dicker zerebellärer Schnitte an P 25 zeigte eine normale basale Sternzellmorphologie mit einem ovalen Zellkörper und in alle Richtungen entspringenden Neuriten in Mutanten verglichen mit Kontrollen. Maßstab $=20 \mu \mathrm{m}$. Die immunhistochemische Detektion von MAP2 (jeweils rechts) bestätigte, dass Mutanten im Vergleich zu Kontrollen normal entwickelte Dendriten besaßen (Pfeilspitzen). Maßstab $=10 \mu \mathrm{m}$. B, Sternzellen (Sternchen) von Mutanten besitzen GAD2-positive präsynaptische Endigungen (Pfeilspitzen), die eine normale Verteilung und gering reduzierte Dichte verglichen mit Kontrollen aufweisen. Diese inhibitorischen Synapsen orientieren sich in Mutanten und Kontrollen dicht entlang (PVALB ${ }^{+}$) dendritischer Purkinje-Zellprofile. Maßstab $=10 \mu \mathrm{m}$.

Mit Hilfe der Golgi-Silberimprägnierung konnte gezeigt werden, dass die im unteren Drittel der Molekularschicht lokalisierten Korbzellen (Rakic, 1973) ebenfalls über Neuriten verfügen (Abb. 17 A). Mittels 3D-Rekonstruktion immunhistochemisch detektierter MAP2-positiver 
Dendriten an P 25 konnte nachgewiesen werden, dass die Korbzellen der Mutanten eine mit den Korbzellen der Kontrollen vergleichbare Gesamtlänge und ähnliche Verzweigungsmuster aufwiesen (Abb. 17 B; Kontrollen: $351 \pm 18 \mu \mathrm{m}$; $\mathrm{n}=2$; 10 Zellen / Tier; Mutanten 421,8 \pm $31,3 ; \mathrm{n}=3 ; 10$ Zellen / Tier; $\mathrm{p}=0,086)$.

Im Gegensatz dazu waren die synaptischen Endigungen von Korbzellen in Mutanten stark betroffen. Während die charakteristischen präsynaptischen Pinceau-Synapsen in Kontrollen klar durch die Expression von GAD1, HCN1 (hyperpolarization activated cyclic nucleotidegated potassium chanel 1), PVALB und PSD95 (postsynaptic density protein 95) immunhistochemisch detektiert werden konnten, fehlten diese Strukturen in Mutanten gänzlich (Bobik et al., 2004; Luján et al., 2005a; Abb. 17 C, D). Um zu überprüfen, ob in den Korbzellsynapsen lediglich die Expression dieser Marker herunter reguliert war, die PinceauSynapsen gänzlich fehlten oder die komplette Axogenese vom NDRF-Verlust betroffen war, wurden als nächstes NEFH-positive (neurofilament heavy) Korbzellaxone immunhistochemisch visualisiert und mit Hilfe des Programmes Neuromantic dreidimensional rekonstruiert. Wie aufgrund der reduzierten Korbzellzahl in Mutanten zu erwarten war, waren hier auch wesentlich weniger NEFH-markierte Axone vorhanden, als in der Kontrolle. Interessanterweise zeigten die verbliebenen Axone der Mutante eine stark veränderte Morphologie verglichen mit den Kontrollen. Die Axone der Kontrollen verliefen geordnet oberhalb der Purkinje-Zellschicht in der translobularen Ebene und brachten Kollaterale hervor, die stets in Richtung Purkinje-Zellen orientiert waren. Die Axone der Mutanten wiesen hingegen eine stark komprimierte, desorientierte Morphologie auf und besaßen Axonkollaterale, die nur in seltenen Fällen Richtung Purkinje-Zellen, in vielen Fällen aber völlig zufällig, zum Teil sogar zur Pia hin orientiert waren (Abb. 17 E). Selbst an P 75 konnten in der Mutante durch PSD95-Expression immuhistochemisch detektierte axonale Wachstumskegel identifiziert werden, die in der Molekularschicht umher wuchsen, ohne dabei ihr synaptisches Ziel, die Purkinje-Zellen, zu erreichen (Abb. 17 F).

Ankyrin3 (ANK3) konnte als wichtiges postsynaptisches scaffolding-Protein identifiziert werden, dass die axonale Zielfindung von Korbzellen zur Purkinje-Zell-AIS vermittelt (Ango et al., 2004a).

Das Vorhandensein von ANK3 an der AIS von Purkinje-Zellen in Mutanten sprach daher dafür, dass hier die axonalen Defizite und die Abwesenheit von Mutanten nicht durch postsynaptische Defekte begründet waren (Abb. $17 \mathrm{G})$.

Zusammengefasst deuteten alle immunhistochemischen Analysen und Rekonstruktionen darauf hin, dass NDRF essentiellen Einfluss auf die Exekution eines zellintrinsischen 
Programms zur Steuerung der Axogenese von Korbzellen hat, die Dendritogenese aber nicht von NDRF abhängig ist.
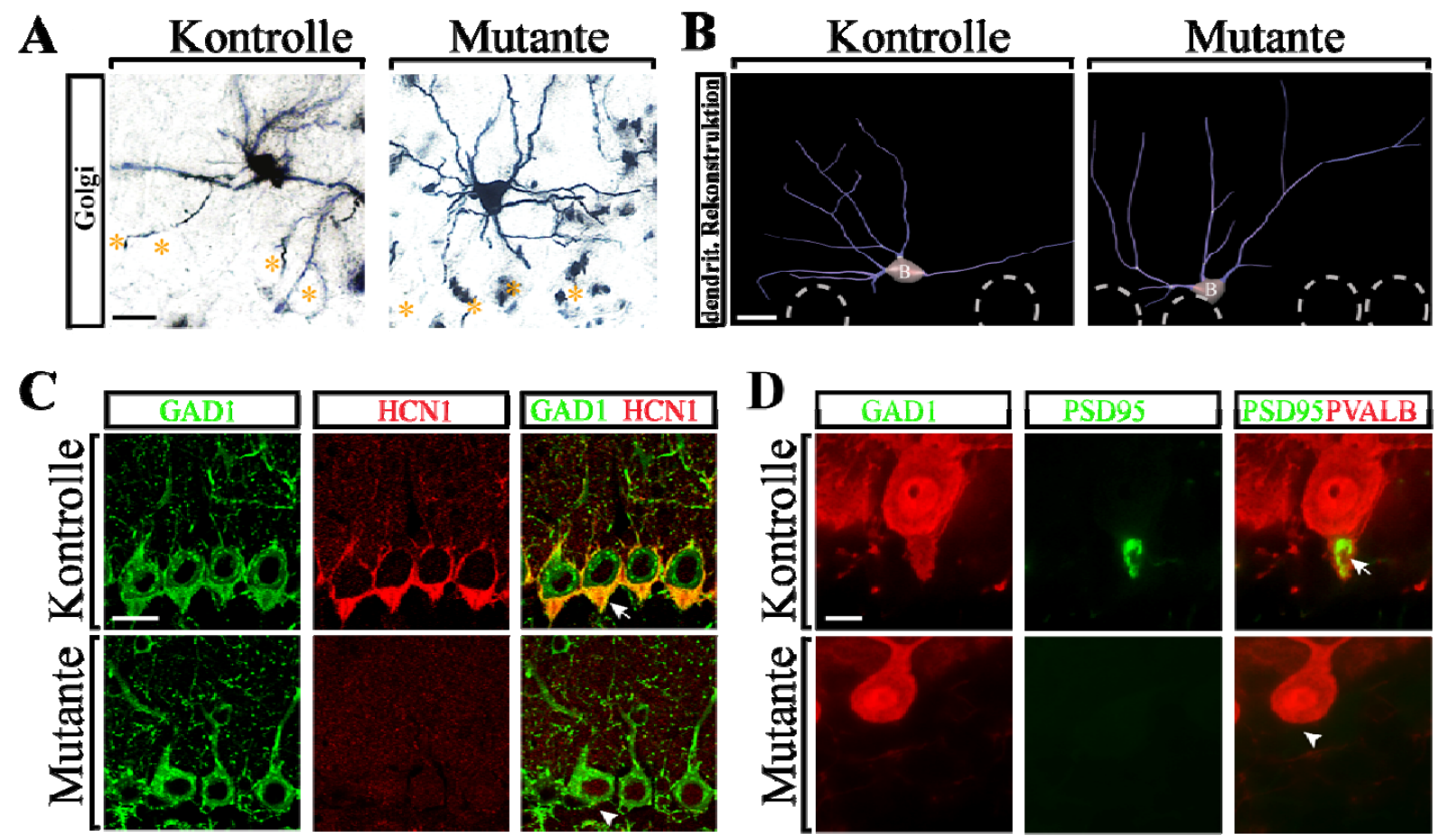

$\mathbf{E}$

Kontrolle

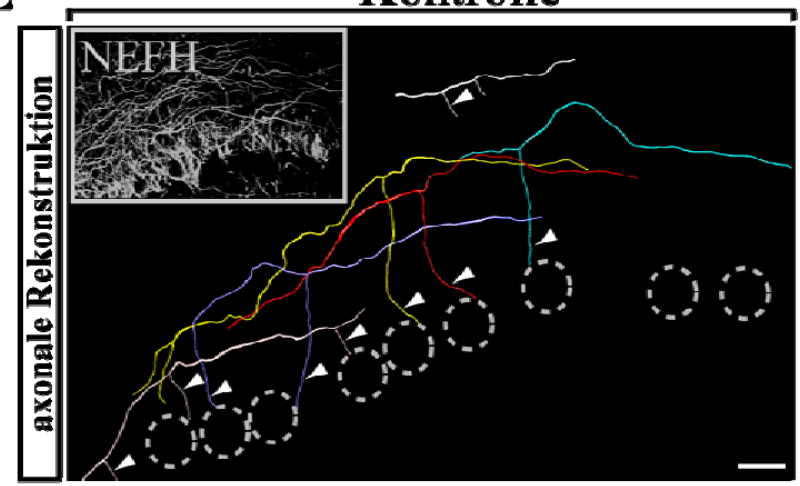

Mutante
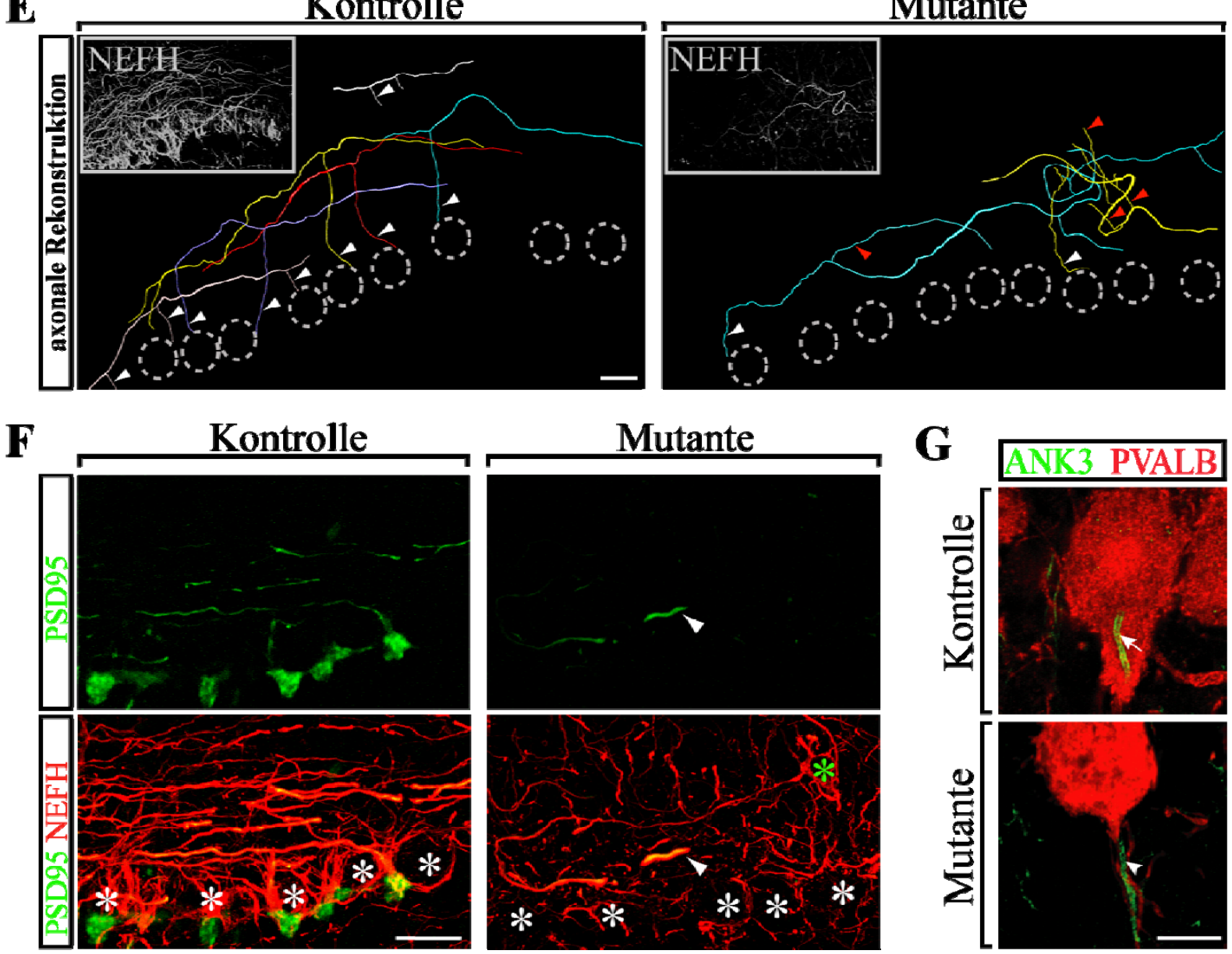
Abb. 17 Korbzellen in NDRF-Nullmutanten entwickeln normale Dendriten, zeigen aber starke Defizite in der Axon- und Synapsenentwicklung

A, Die Golgi-Silberimprägnierung (jeweils links) $60 \mu \mathrm{m}$ dicker zerebellärer Schnitte an P 25 zeigte eine normale basale bipolare Korbzellmorphologie bei Mutanten verglichen mit Kontrollen. Maßstab $=20 \mu \mathrm{m}$. B, Dreidimensionale morphometrische Rekonstruktion MAP2-immunodetektierter Dendriten an P 25. Verglichen mit Kontrollen, war die Morphologie und Gesamtlänge der Dendriten von Korbzellen in Mutanten unverändert. Maßstab $=10 \mu \mathrm{m}$. C, An P 25 fehlen die immunhistochemisch detektierten GAD1- und HCN1-positiven Korbzellsynapsen in NDRFNullmutanten (Pfeilspitze) gänzlich im Vergleich zur Kontrolle (Pfeil). Maßstab $=20 \mu \mathrm{m}$. D, Die Region um die Purkinje-Zell-AIS war in Mutanten an P 25 frei von jeglicher PSD95- oder PVALBImmunoreaktivität (Pfeilspitze) im Gegensatz zur Kontrolle (Pfeil), was das komplette Fehlen der Pinceau-Synapsen in Mutanten bestätigte. Maßstab $=10 \mu \mathrm{m}$. E, Dreidimensionale morphometrische Rekonstruktion NEFH-immunodetektierter Axone an P 25. Zur Rekonstruktion wurden in der Kontrolle aus der großen Zahl von Korbzellaxonen fünf verschiedene repräsentative Axone von fünf verschiedenen Korbzellen ausgewählt (dargestellt in fünf verschiedenen Farben). Korbzellaxone von Kontrollen verliefen in der sagittalen Ebene oberhalb der Purkinje-Zellschicht und sendeten in regelmäßigen Abständen Axonkollaterale, die sich direkt in Richtung Purkinje-Zell-AIS erstreckten (weiße Pfeilspitzen). Korbzellaxone der Mutante hingegen besaßen eine komprimierte und deformierte Struktur. Ihre Kollaterale erstreckten sich in alle Richtungen der Molekularschicht (rote Pfeilspitzen), zum Teil sogar in Richtung Pia und erreichten die Purkinje-Zellen nur in seltenen Fällen (weiße Pfeilspitzen). Die eingefügten mikroskopischen Übersichten illustrieren die zusammen gefügten konfokalen Bilder, die zur Rekonstruktion verwendet wurden. Das NEFH-Signal in Mutanten war hierbei aufgrund der reduzierten Anzahl von Korbzellen verglichen mit der Kontrolle wesentlich geringer. Maßstab $=20 \mu \mathrm{m}$. F, Co-immunhistochemische Detektion von PSD95 und NEFH bestätigte, dass Korbzellaxone sogar an P 75 noch ziellos in der Molekularschicht umher irrten und nicht ihr synaptisches Ziel, die Purkinje-Zell-AIS erreichten (grünes Sternchen = Korbzellsoma; weiße Sternchen $=$ Purkinje-Zellkörper; weiße Pfeilspitze $=$ Korbzellaxonspitze). Maßstab $=20 \mu \mathrm{m}$. G, ANK3 konnte an der Postsynapse von Purkinje-Zellen in der Mutante (Pfeilspitze) wie in der Kontrolle (Pfeil) immunhistochemisch lokalisiert werden, was für einen präsynaptischen Defekt in Korbzellen von NDRF-Nullmutanten sprach. Maßstab $=10 \mu \mathrm{m}$.

\subsection{Sekundäre Effekte des NDRF-Verlustes}

Das komplette Fehlen GABA-ergen synaptischen inputs an der Purkinje-Zell AIS zog Veränderungen der Zytoarchitektur von Purkinje-Zellen nach sich (Abb. 18). Deren Quantifizierung in sagittaler Ebene des Lobulus 5 im Alter von einem Jahr ergab keine reduzierte Anzahl in Mutanten (Kontrollen: 178,5 \pm 9,5; Mutanten: 177,2 $\pm 11,3 \mathrm{n}=3$; $\mathrm{p}=$ 0,9325), jedoch wiesen diese klar detektierbare PVALB-positive axonale Schwellungen auf.
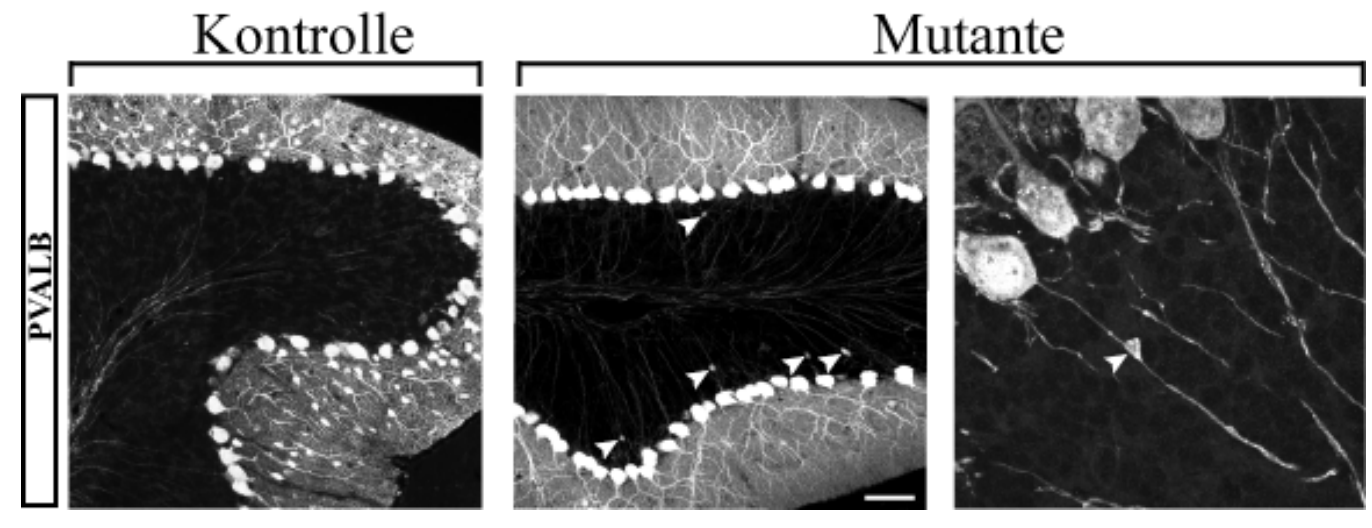

Abb. 18 Sekundäre Purkinje-Zelldefekte

$\mathrm{PZ}$ von Mutanten entwickelten verglichen mit Konrollen zahlreiche, immunhistochemisch detektierbare PVALB-positive axonale Schwellungen (Pfeilspitzen). Maßstab $=50 \mu \mathrm{m}$. 


\subsection{Verhalten NDRF-defizienter Tiere}

Trotz der schwerwiegenden morphologischen Veränderungen in NDRF-Nullmutanten waren die Tiere bei Betrachtung ihres Explorationsverhaltens im Käfig nicht augenscheinlich motorisch betroffen. Weder ataktische Anzeichen, Tremor noch andere motorische Auffälligkeiten waren bei Mutanten zu beobachten.

Wurden die Mutanten jedoch am Schwanz für eine Minute angehoben, so zeigten die meisten Tiere einen eindeutigen multiplen clasping-Phänotyp (Abb. 19 A). Dieser, für motorische Dysfunktionen charakteristische Phänotyp, wurde bereits in anderen Mausmutanten mit zerebellären Neurodegenerationen (Lalonde, 1987a, 1987b) aber auch mit zerebralen (Ramaswamy et al., 2009) als auch PNS-Defekten (Gillespie et al., 2000) beschrieben, sodass dieser nicht ausschließlich auf zerebelläre Probleme zurück geführt werden konnte.

Um die vom Zerebellum abhängigen motorischen Fähigkeiten der Mutanten genauer zu analysieren, wurden als nächstes zerebellumassoziierte Verhaltenstets durchgeführt. So zeigten die Mutanten zunächst eine unveränderte Ausdauer auf einem bei $5 \mathrm{U} / \mathrm{min}$ konstant rotierenden Rotarod-Zylinder vergleichen mit Kontrollen (Abb. 19 B; Kontrollen: 42,02 \pm 2,58 min; $\mathrm{n}=4$; Mutanten: 42,39 $\pm 2,33 \mathrm{~min} ; \mathrm{n}=5 ; \mathrm{p}=0,93$ ). Auch auf einem konstant beschleunigenden Rotarod mit niedrigen Beschleunigungsraten $(3,3 \mathrm{U} / \mathrm{min}$ bis $12 \mathrm{U} / \mathrm{min}$ innerhalb von $2 \mathrm{~min} ; 10 \mathrm{~min}$. Pause zw. den Durchgängen) zeigten die Mutanten keine Defizite verglichen mit Kontrolle (Abb. 19 C; Tag 1 - Habituation; Durchgang 1: Kontrollen: $74,8 \pm 9,5$ s; Mutanten: 77,4 \pm 8,4 s; $\mathrm{p}=0,84$; Durchgang 2: Kontrollen: 96,3 \pm 5,9 s; Mutanten: 97,0 \pm 6,7 s; $\mathrm{p}=$ 0,93; Durchgang3 Kontrollen: 114,7 \pm 3,9 s; Mutanten: 109,9 \pm 5,4 s; $\mathrm{p}=0,46 ; \mathrm{n}=32$ Kontrollen/ 24 Mutanten). Dies ließ den Schluss zu, dass fehlender inhibitorischer Korbzell-input auf Purkinje-Zellen in NDRF-Nullmutanten nicht essentiell für den Erhalt basaler motorischer Fähigkeiten ist. Im Gegensatz dazu offenbarte ein anspruchsvolleres Testprotokoll, mit fünf aufeinander folgenden Testdurchläufen und höherer Beschleunigungsrate (4,1 bis $41 \mathrm{U} / \mathrm{min}$ in $6 \mathrm{~min} ; 10 \mathrm{~min}$. Pause zw. Durchgängen) motorische Defizite bei den Mutanten. Diese zeigten nur eine sehr langsame Verbesserung der Fähigkeit, sich auf dem beschleunigenden Rotarod zu halten (Abb. 19 C; Tag 2 -Herausforderung; Durchgang 1: Kontrollen: 138,7 $\pm 10,1 \mathrm{~s}$; Mutanten: 112,4 $\pm 12,7 \mathrm{~s} ; \mathrm{p}=0,11$; Durchgang 2: Kontrollen: 178,8 $\pm 13,7$ s; Mutanten: 134,8 $\pm 11,6 \mathrm{~s} ; \mathrm{p}=0,02$; Durchgang 3: Kontrollen: $201,7 \pm 2,3$ s; Mutanten: 145,4 $\pm 12,8 \mathrm{~s} ; \mathrm{p}=0,0026$; Durchgang 4: Kontrollen: 227,5 $\pm 11,5$ s; Mutanten: 146,0 \pm 14,0 s; p < 0,0001; Durchgang 5: Kontrollen: 240,1 \pm 11,6 s Mutanten: $151,0 \pm 15,6 \mathrm{~s} ; \mathrm{p}<0,0001 ; \mathrm{n}=32$ Kontrollen/ 24 Mutanten). Weiterhin zeigten Mutanten ein signifikant schlechteres Balanciervermögen auf einem Stab mit 1,8 cm Durchmesser, das sich, 
verglichen mit Kontrollen, in drei aufeinanderfolgenden Durchgängen wesentlich weniger verbesserte (Abb. 19 D; Durchgang 1: Kontrollen: 28,7 \pm 7,8 s; $\mathrm{n}=6$; Mutanten: 2,0 0 0,9; $\mathrm{n}$ $=8 ; \mathrm{p}<0,002 ;$ Durchgang 2: Kontrollen: 37,2 $\pm 10,8 \mathrm{~s}$; Mutanten: 10,3 $\pm 3,9 \mathrm{~s} ; \mathrm{p}<0,023$; Durchgang 3: Kontrollen: 52,5 \pm 4,8 s; Mutanten: 19,6 \pm 7,9 s; $\mathrm{p}<0,023$; $\mathrm{n}=6$ Kontrollen/ 8 Mutanten). Weiterhin zeigten Mutanten, die frei ein erhöhtes Drahtgitter mit dem Durchmesser von $30 \times 30 \mathrm{~cm}$ und $1,5 \mathrm{~cm}$ Gitterlochgröße explorierten, signifikant mehr Fehltritte mit Vorder- und Hinterpfoten, als Kontrollen (Vorderpfoten Kontrollen: 2,3 \pm 0,5 Fehltritte; Mutanten: 8,4 \pm 1,8 Fehltritte; $\mathrm{p}<0,02$; Hinterpfoten Kontrollen: 2,8 $\pm 0,9$ Fehltritte; Mutanten: 19,8 \pm 2,6 Fehltritte; $\mathrm{p}<0,0007 ; \mathrm{n}=4$ Kontrollen/ 8Mutanten). Zusammengefasst implizieren diese Resultate, dass NDRF-Expression für höhere motorische Leistungen, wie Balancieren oder motorisches Lernen unabdingbar ist. Da NDRF aber auch im Vorderhirn expremiert wird, können die motorischen Defizite in Mutanten nicht eindeutig auf fehlende NDRF-Expression im Zerebellum zurück geführt werden.

A

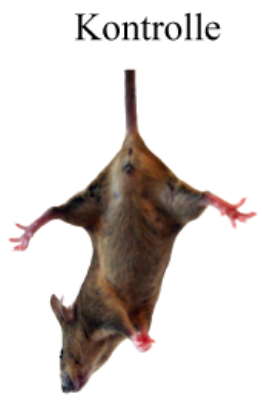

B

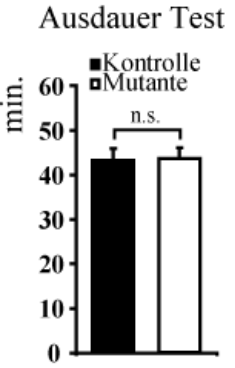

C Beschleunigter Rotarod Test

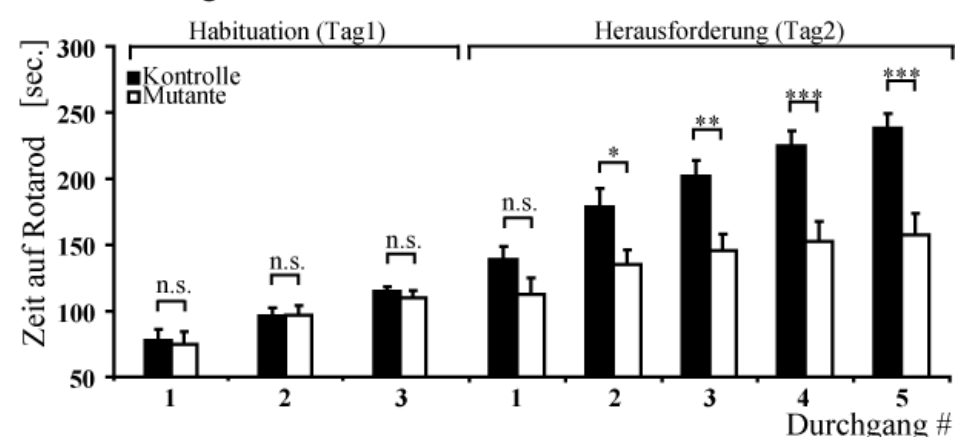

D Stabtest

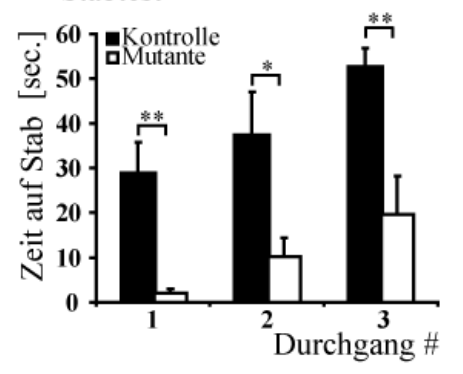

E Fehltritttest

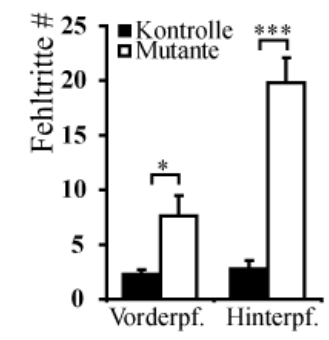

Abb. 19 Motorische Defizite in NDRF-Nullmutanten

A, Die meisten Mutanten zeigen einen clasping-Phänotyp der Hinterbeine. B, Die Ausdauer 5 Monate alter Mutanten auf einem bei $5 \mathrm{U} / \mathrm{min}$ rotierenden Rotarod ist im Vergleich zu Kontrollen nicht beeinträchtigt.

C, Habituation (Tag1): 5 Monate alte Mutanten, die dreimal hintereinander auf einem beschleunigenden Rotarod getestet werden $(3,3 \mathrm{U} / \mathrm{min}$ bis 12 $\mathrm{U} / \mathrm{min}$ innerhalb von $2 \mathrm{~min}$ ) zeigen keine motorischen Defizite.

Herausforderung (Tag2): Bei höheren Beschleunigungsraten $(4.1 \mathrm{U} / \mathrm{min}$ bis $41 \mathrm{U} / \mathrm{min}$ innerhalb von $6 \mathrm{~min}$ ) und fünf aufeinander folgende Testdurchläufen entwickeln Mutanten starke motorische Defizite. D, 5 Monate alte Mutanten zeigen signifikant schlechteres Balanciervermögen.E, 5 Monate alte Mutanten auf einer erhöhten Gitterplattform zeigen signifikant mehr Vorder- und Hinterpfotenfehltritte als Kontrollen. 


\section{Diskussion}

In vivo und in vitro konnten bisher zahlreiche molekulare Programme und Mechanismen zur Steuerung früher Phasen der Axo- und Denritogenese sowie zahlreiche Wachstumsfaktoren, Zell-Adhäsionssysteme und zellintrinsische Signaltransduktionswege zur Steuerung der axonalen Navigation und synaptischen Zielfindung beschrieben werden.

Auf zellintrinsischer transkriptioneller Ebene sind bisher nur wenige Effektoren bekannt, die diese Prozesse beeinflussen. Hierzu zählen u. a. die bHLH-Proteine NEX und NDRF, die die Exekution zellintrinsischer Programme zur Spezifizierung thalamokortikaler und neokortikale Projektionen von Langstreckenprojektionsneuronen des Vorderhirns vermitteln.

Transkriptionelle Regulationsmechanismen zur Steuerung der Axo- und Synaptogenese sowie axonalen Navigation und Zielfindung zerebellärer inhibitorischer Interneurone hingegen sind bisher weitestgehend unbekannt.

Im Rahmen dieser Arbeit sollte analysiert werden, ob die kortikale axonale Spezifizierungsfunktion von NDRF auch in dessen zerebellärer Hauptexpressionsdomäne, den Körner-, Korb- und Sternzellen konserviert ist.

Zudem sollte analysiert werden, ob der NDRF-Verlust in Körner-, Korb- und Sternzellen sekundäre Effekte in deren Zielzellen (Purkinje-Zellen) nach sich zieht und inwieweit sich diese in potentiellen motorischen Defiziten niederschlagen.

\subsection{Rückkreuzung}

Die von Olson et al., (2001) generierten NDRF-Nullmutanten litten ab P 14 unter einem Wachstumsblock und zeigten Verhaltensauffälligkeiten, wie Krämpfe und Ataxien, die zum Tode der meisten Tiere um P 21 führten. Dies schloss Analysen während adulter Altersstadien aus. Im Rahmen dieser Arbeit wurde dagegen der letale Phänotyp von NDRF-Nullmutanten durch Rückkreuzung auf einen anderen genetischen Hintergrund umgangen.

Nur in wenigen Fällen, sind phänotypische Veränderungen ausschließlich auf Mutationen des ursächlichen Locus zurück zu führen, wesentlich häufiger werden sie durch eine Einzelmutation ausgelöst, aber stark durch den Genotyp anderer Loci moduliert (MONTAGUTELLI, 2000).

Zum Beispiel führt die Mutation des PLP-Gens (proteolipid protein) der rumpshaker-Mutante auf $\mathrm{C} 3 \mathrm{H}$-genetischem Hintergrund zu milder Dysmyelinisierung ohne die Überlebensspanne der Tiere zu beeinflussen, während ein C57BL/6-genetischer Stammeshintergrund bei dieser Mutation zu Anfallsleiden und Tod um P 30 führt (Al-Saktawi et al., 2003). 
Wird das mit NDRF stark verwandte NeuroD-Gen auf einem C57BL6-genetischen Hintergrund inaktiviert, sterben die meisten Tiere perinatal an Diabetes, wohingegen durch Rückkreuzung auf einen Sv129 genetischen Hintergrund eine Überlebensrate der Tiere von $60-70 \%$ bis in adulte Altersstadien erreicht werden kann (Lee et al., 2000).

Da NDRF in vitro die endokrine Differenzierung induziert, in vivo stark im embryonalen Pankreas exprimiert ist und hier, wie NeuroD, unter der Kontrolle von Neurogenin3 steht (Gasa et al., 2008) könnte auch bei NDRF-Nullmutanten Diabetes als Grund perinataler Letalität in Frage kommen. Basierend auf dieser Annahme und dem von Lee et al., (2000) erfolgreich angewendeten Rückkreuzungsansatz wurden im Rahmen dieser Arbeit NDRFNullmutanten ebenfalls auf einen SV129-genetischen Stammeshintergrund zurückgekreuzt.

Tatsächlich konnte so der letale Phänotyp NDRF-nullmutanter Mäuse umgangen werden, was eine Analyse an höheren Altersstadien erlaubte.

\subsection{Die Funktion von NDRF in zerebellären Körnerzellen}

\subsubsection{NDRF sichert das Überleben von Körnerzellen während früher Entwicklungsphasen}

NDRF besitzt eine essentielle Funktion als Regulator des Zellzyklus und als Initiator neuronaler Differenzierung (Sugimoto et al., 2009). Darüber hinaus konnte von Olson et al., (2001) gezeigt werden, dass NDRF essentiell für das Überleben zerebellärer Körnerzellen ist. Viele Körnerzellen der von Olson et al., (2001) analysierten NDRF-nullmutanten Tiere gingen innerhalb der ersten drei postnatalen Wochen apoptotisch unter (mit einem Höhepunkt an P 19), was zu einer reduzierten Dicke der zerebellären Körnerzellschicht bei diesen Tiere führte. Bei den im Rahmen dieser Arbeit analysierten Tieren wurde bestätigt, dass NDRF das Überleben von Körnerzellen sichert. An P 5 und P 10 starben in der Mutante eindeutig Körnerzellen apoptotisch, zum Ende der dritten postnatalen Woche war jedoch keine Apoptose mehr detektierbar.

Die verschieden starke Auswirkung des NDRF-Verlusts auf das frühe Absterben zerebellärer Körnerzellen bei den Tieren von Olson et al., (2001) verglichen mit den in dieser Arbeit analysierten Mutanten ist sehr wahrscheinlich auf Effekte des unterschiedlichen genetischen Hintergrundes zurück zu führen.

\subsubsection{NDRF besitzt in vivo keine essentielle Funktion als transkriptioneller Regulator der Dendrito- Axo- und Synaptogenese zerebellärer Körnerzellen}

Transkriptionelle Kontrolle spielt hochwahrscheinlich eine Schlüsselrolle für die axonale Elongation, Navigation und Zielfindung (Polleux et al., 2007). Trotz intensiver Bemühungen 
konnten bisher jedoch nur wenige transkriptionelle Mechanismen zur Steuerung des Axonwachstums eindeutig identifiziert werden.

Einer dieser Mechanismen wird beispielsweise über den stark in Körnerzellen exprimierten APC (anaphase promoting complex) vermitelt. In postmitotischen Neuronen stimulieren APC und dessen Co-Aktivatorproteine CDH1 (cadherin) und CDC20 (cell devision cycle 20) die Degradation des TF SNON (KKI-related novel gene isoform; Konishi et al., 2004; Stegmüller et al., 2006). Inaktivierung von CDH1 in vivo beschleunigt das Axonwachstum, während die Reduktion der SNON-Expression zu verringertem Axonwachtsum führt. Diese und weitere Ergebnisse deuten auf eine zentrale Rolle des TF SNON als transkriptioneller Regulator des Axonwachstums hin (Stegmüller et al., 2006, 2008; Polleux et al., 2007; Ikeuchi et al., 2009; Polleux und Snider, 2010).

Zusätzlich zu SNON wurde NDRF als weiterer transkriptioneller Schlüsselregulator der Axonentwicklung in zerebellären Körnerzellen vorgestellt (Yang et al., 2009)). Yang et al., (2009) schlossen aus in vitro Beobachtungen, dass die Bildung von Parallelfaser-Präsynpasen über NDRF mittels des CDC20-APC (cell divison cycle 20-anaphase promoting complex) reguliert wird. Sie postulierten, dass der CDC20-APC präsynaptische Differenzierung durch die Degradation von Proteinen vermittelt, die hemmend auf die Synapsenentwicklung wirken. So bindet NDRF an die destruction box 8, ein Erkennungsmotiv von CDC20, und könnte einen geeigneten Kandidaten für den CDC20-APC zur Regulation der Synapsenentwicklung darstellen. In den Studien von Yang et al., (2009) führte ein CDC20-Verlust in primären Körnerzellkulturen zu erhöhten NDRF-Leveln und NDRF-Verlust zu einer erhöhten Anzahl von Parallelfasersynapsen, sodass der Schluss nahe lag, dass NDRF ein Zielprotein des CDC20-APC und Inhibitor der Synapsenentwicklung sei.

Diese in vitro Daten stehen jedoch in starkem Widerspruch zu den im Rahmen dieser Arbeit in vivo gewonnen Resultaten.

Durch die Analyse adulter NDRF-nullmutanter Mäuse konnte in dieser Arbeit zunächst gezeigt werden, dass Körnerzellen, die eine frühe Differenzierungsverzögerung (nach Verlust von NDRF) überlebten und nicht apoptotisch zugrunde gingen, funktionell in das zerebelläre Netzwerk integriert wurden. So konnte auf histologischem und immunhistochemischen Wege nachgewiesen werden, dass die Körnerzellen der Mutanten über normal entwickelte Dendriten mit klauenförmigen Endfüßchen (Telodenria) und T-förmige Axone (Parallelfasern) verfügten.

Darüber hinaus bestätigten elektronenmikroskopische Analysen, dass die ParallelfaserPurkinje-Zellsynapsen der NDRF-Nullmutanten in normaler Anzahl vorhanden und 
morphologisch unauffällig waren. Mittels elektrophysiologischer Analyse konnte abschließend nachgewiesen werden, dass diese Synapsen in Mutanten normale Werte für die paired pulse fascilitation als $\mathrm{Maß}$ synaptischer Kurzzeitplastizität zeigten, somit also unbeeinträchtigt und voll funktional vorlagen.

Die gesamte Bandbreite der im Rahmen dieser Arbeit angewendeten Analysemethoden, zeigte keinen Einfluss eines Verlustes von NDRF auf die Parallelfaser-Purkinje-Zellsynapsen, weder auf morphologischem noch funktionellem Niveau. Es ist also davon auszugehen, dass in der in vivo Situation NDRF keine essentielle Funktion in der Entwicklung und im Erhalt dieser Synapsen zukommt.

\subsubsection{Partielle Redundanz der bHLH-Proteine NeuroD und NDRF in zerebellären Körnerzellen}

Die weitgehende Unauffälligkeit derjenigen Körnerzellen die den Verlust von NDRF überleben und korrekt in das Netzwerk der Körnerzellschicht integriert wurden, könnte mit einer funktionellen Kompensation durch den, mit NDRF eng verwandten, bHLHTranskriptionsfaktor NeuroD erklärt werden. Gerade bei entwicklungsrelevanten Genen kann genetische und funktionelle Redundanz zu evolutionsbiologischen Selektionsvorteilen führen (Nowak et al., 1997) und ist bereits für viele Gene und ihre Produkte beschrieben worden (Hummler et al., 1994; Kume et al., 2000; Reichelt et al., 2001; Keith et al., 2001; Mills et al., 2001).

Wurde zusätzlich zum inaktivierten NDRF-Gen auch NeuroD konditional in postmitotischen, postmigratorischen Körnerzellen inaktiviert, kam es zu stark erhöhter Apoptose zerebellärer Körnerzellen und reduzierter zerebellärer Größe auch noch an P 21. Wurde jedoch nur ein Allel von NeuroD zusätzlich zu NDRF inaktiviert, so entsprach der Phänotyp dem der NDRFEinzelmutante. Ein Allel von NeuroD reichte also aus, um die Apoptose von Körnerzellen an und nach P 21 zu verhindern.

Eine Grundvorrausetzung für funktionelle Redundanz zwischen NeuroD und NDRF wäre, dass diese beiden Gene auch räumlich und zeitlich stark überlappend in zerebellären Körnerzellen exprimiert sind. Eine solche Koexpression von NeuroD und NDRF in zerebellären Körnerzellen liegt tatsächlich vor, wie mit Hilfe von in situ Hybridisierungen an P 10 gezeigt werden konnte (Schwab et al., 1998a).

Zusammengefasst deuten diese Resultate auf eine hochgradige funktionelle Redundanz von NeuroD und NDRF in postmitotischen, postmigratorischen zerebellären Körnerzellen hin. Innerhalb dieser NeuroD Subfamilie kann jedoch keine vollkommene Redundanz vorliegen, da sowohl NeuroD- als auch NDRF-nullmutante Mäuse verschiedene Gehirndefekte 
aufweisen, die offensichtlich nicht durch Expression der anderen beiden Familienmitglieder kompensiert werden können (Schwab et al., 1998c; Miyata et al., 1999; Liu et al., 2000; Olson et al., 2001).

\subsection{Die Funktion von NDRF in zerebellären Interneuronen}

\subsubsection{NDRF reguliert die terminale Differenzierung von Interneuronen der Molekularschicht}

Das gesamte Repertoir GABA-erger Interneurone des zerebellären Kortex und der TZK geht ab E13 aus einer Population Nestin-, Nephrin-, PTF1a- und PAX2-positiver Progenitoren der Ventrikularzone (VZ) hervor (Hoshino et al., 2005; Hoshino, 2006a; Pascual et al., 2007; Mizuhara et al., 2010). Weiterhin sind die proneuronalen bHLH-Transkriptionsfaktoren MASH1, NGN1 und NGN2 ab E 11,5 in der VZ detektierbar (Zordan et al., 2008). Sie zeigen zum Teil überlappende, zum Teil exklusive Expressionsdomänen untereinander sowie mit dem ab E 13,5 exprimierten PAX2 (Silbereis et al., 2009). Beginnende NDRF-Expression ist ebenfalls an E 13,5 im ventralen Bereich der embryonalen VZ detektierbar (Allen Brain Atlas). Zurzeit ist noch unklar, ob diese Gene als frühe spezifische Marker SubHerkunftsdomänen von Purkinje-Zell- und Interneuron-Progenitoren definieren (Zordan et al., 2008).

Da NDRF als Inhibitor von MASH1 nachgewiesen werden konnte und MASH1 seinerseits die Exekution eines GABA-ergen Zellschicksals initiiert (Zordan et al., 2008; Roybon et al., 2010), wäre es möglich, dass bei den im Rahmen dieser Arbeit analysierten NDRFdefizienten Tiere ein Ungleichgewicht der frühen Expression von NDRF, NGN2 und MASH1 zu einer Fehlprogrammierung und Absterben interneuronaler Vorläufer führt.

Da die Anzahl und Verteilung PAX2-positiver interneuronaler Progenitoren in der WS von Mutanten verglichen mit Kontrollen unverändert war, konnte dies allerdings ausgeschlossen werden.

Unter normalen Umständen beginnen die interneuronalen Progenitoren der WS um P 0 den basalen interneuronalen Marker GAD1 zu exprimieren (Simat et al., 2007). Sie wandern durch die IKS und erreichen ihre Position in der oberen Hälfte (Sternzellen) bzw. in der unteren Hälfte der MS (Korbzellen) bis P 21. Beide Interneuronenpopulationen exprimieren zu diesem Zeitpunkt den reifen interneuronalen Marker Parvalbumin und haben jegliche Expression unreifer Marker, wie PAX2, verloren (Schwaller et al., 2002; Simat et al., 2007). Dendrito- Axo- und Synaptogenese sind vollständig abgeschlossen.

Das Fehlen von transkriptioneller Regulation durch NDRF hatte jedoch gravierende Folgen für die Exekution dieses terminalen interneuronalen Differenzierungsprogrammes. So zeigten 
MS-IN in NDRF-Nullmutanten einen zellintrinsischen Differenzierungsblock der sich u. a. in stark verzögerter Expression von GAD1 sowie nahezu unveränderter Expression des unreifen Markers PAX2 bis zum Alter von über 6 Monaten äußerte.

Diese, durch den NDRF-Verlust hervorgerufenen, terminalen Differenzierungsdefizite waren, wie bei Körnerzellen, durch verstärkte Apoptose der MS-IN an P 5 und P 10 in der Molekularschicht gekennzeichnet. Im Gegensatz zu Körnerzellen führte das apoptotische Absterben der MS-IN-Vorläufer zu einer um etwa 2/3 reduzierten Dichte reifer MS-IN in Mutanten.

Die ebenfalls aus dem Pool, durch die WS wandernder, PAX2-positiver Progenitoren hervorgehenden Golgi-Zellen der Körnerzellschicht exprimieren kein NDRF und waren daher vom NDRF-Verlust nicht betroffen.

Zusammengefasst beeinflusst das Fehlen von NDRF also nicht die frühen Schritte der Entwicklung von MS-IN, wie Progenitorengeneration und -migration, sondern führt zu spezifischen Defekten in deren terminaler Differenzierung.

Im Gegensatz zu Körnerzellen, in denen der NDRF-Verlust eine transiente Differenzierungsverzögerung bewirkt, die die meisten Körnerzellen überwinden können (Körnerzellen in adulten NDRF-Nullmutanten exprimieren alle typischen Reifemarker) führt fehlende NDRF-Expression in MS-IN $\mathrm{zu}$ einem weitreichenden, konstanten Differenzierungsblock.

Interessanter Weise wurde ein ähnlicher Effekt für das mit NDRF hochgradig verwandte bHLH-Protein NeuroD in Interneuronen des olfaktorischen Bulbus beobachtet. Hier führte die Inaktivierung von NeuroD mittels kombinierter RNAi- und Elektroporationsstrategie (Boutin et al., 2008) zur Beeinträchtigung terminaler Differenzierungsschritte periglomerulärer Interneurone, bei nicht betroffener Generation und Migration von deren Progenitoren (Boutin et al., 2010).

\subsubsection{NDRF als transkriptioneller Regulator der Axonentwicklung in Korbzellen}

Stern- und Korbzellen wurden lange Zeit als zwei genetisch indifferente Zellpopulationen angesehen, die sich lediglich aufgrund ihrer Position und ihres Innervierungsmusters unterscheiden.

So wurde die enge Verwandtschaft der beiden Zellpopulationen durch Transplantationsexperimente mit GABA-ergen, PAX2-positiven MS-IN-Progenitoren unterstrichen (Leto et al., 2009). Diese zeigten, dass die Entscheidung, ob sich MS-IN 
Progenitoren zu Korb- oder Sternzellen entwickeln, gänzlich abhängig von extrazellulären Signalen der jeweiligen Zieldomäne ist (Leto et al., 2009).

Trotz dieser engen Verwandtschaft wurden vor kurzem die wenigen, bisher bekannten, innerhalb der Molekularschicht korbzellspezifisch exprimierten Gene, durch Analysen auf Basis der öffentlichen Genexpressionsdatenbank „The Allen Brain Atlas“, um über 20 zusätzliche Kandidaten erweitert. Zu diesen gehören z.B. PENK1 (Proenkephalin1), CHST1 (arbohydrate sulfotransferase 1) und GRM8 (glutamate receptor metabotropic 8) (Schilling und Oberdick, 2009).

Mit NDRF wurde im Rahmen dieser Arbeit ein Kandidatengen identifiziert, das zwar in Stern- und Korbzellen gleichermaßen exprimiert ist, deren terminale Differenzierung aber in unterschiedlichem Masse beeinflusst.

So entwickelten die überlebenden Sternzellen NDRF-defizienter Mäuse normale Dendriten, Axone und synaptische Kontakte. Korbzellen in NDRF-Nullmutanten zeigten ebenfalls eine unbeeinträchtigte Dendritenentwicklung, im Gegensatz zu Sternzellen aber eine stark retardierte Ausprägung translobularer Axone und gänzlich fehlende funktionelle PinceauSynapsen an P 25 und P 75.

Diese Beobachtung ist gerade vor dem Hintergrund der phylogenetischen Entwicklung der beiden Interneuronenpopulationen interessant, da viele Analysen dafür sprechen, dass Korbzellen evolutionsgeschichtlich aus spezialisierten Sternzellen hervorgegangen und somit phylogenetisch jünger sind.

Die Evolution vom Sternzell- hin zum zusätzlichen Korbzellsystem vollzog sich dabei innerhalb verschiedener Klassen von Wirbeltieren (Vertebrata) parallel. So besitzen tiefer in der Molekularschicht gelegene Sternzellen von niederen Reptilien meist wenige somatische Kontakte und stellen damit Korbzellvorläufer dar. In höher entwickelten Reptilienklassen, wie Echsen (Lacertilia) oder Leguanartigen (Iguania), finden sich schon zahlreiche korbförmige synaptische Plexus (Altman und Bayer, 1997). Amphibien (Amphibia) als stammesgeschichtlich älteste Klasse der Landwirbeltiere (Tetrapoda), besitzten ebenfalls noch keine Korbzellen, während Säugetiere (Mammalia) und Vögel (Aves) hoch spezialisierte Korbzellen mit korbförmigen synaptischen Strukturen aufweisen. Auch innerhalb der Fische (Pisces) ist dieser phylogenetische Sprung zu beobachten (review in Llinás, 1969).

Die erhöhte Komplexität und Größe des Zerebellums und die gesteigerte Anzahl von Purkinje-Zellen und Parallelfaser-Transmissionen in höher entwickelten Arten, ziehen einen erhöhten Bedarf transverser bzw. translobularer Purkinje-Zellinhibition nach sich. In einfacheren Arten mit kleinen Zerebelli, wie etwa den Amphibien, war dieser ausreichend 
durch inhibitorische, peridendritische Sternzellsynapsen gedeckt. In höher entwickelten Arten genügte die Inhibition auf dendritischem Level aber nicht mehr, sodass ein Entwicklungsdruck hin zu potenteren, die MS über lange Distanzen durchlaufenden, inhibitorischen Efferenzen mit perisomatischen Purkinje-Zellsynapsen entstand, der in den hoch entwickelten Korbzellen z. B. von Vögeln und Säugetieren seine Entsprechung fand.

So führte die Entwicklung hoch spezialisierter translobularer Korbzellaxone hochwahrscheinlich auch zu einem gesteigerten Bedarf zusätzlicher zellintrinsischer transkriptioneller Regulationsmechanismen des Axonwachstums.

Mit NDRF konnte im Rahmen dieser Arbeit ein solcher zentraler transkriptioneller Regulator des Axonwachstums von Korbzellen identifiziert werden.

Gerade vor dem Hintergrund, dass zentrale Mechanismen axonaler Zielfindung und Entwicklung funktioneller Korbzellsynapsen auf postsynaptischer Seite schon detailliert beschrieben werden konnten (Ango et al., 2004a), stellt die Identifikation zellintrinsischer Mechanismen zur Steuerung der Korbzellaxonentwicklung einen wichtigen Schritt dar, um den Gesamtprozess der Ausbildung der hoch organisierten inhibitorischen KorbzellEfferenzen auf Purkinje-Zellen zu verstehen.

Grundsätzlich sind in diesem Zusammenhang zwei Szenarien vorstellbar und zu unterscheiden.

Die Ausprägung eines axonalen Vorläufers unter Inhibition des Auswachsens übriger Neuriten (Polarisierung) wird in neuronalen Progenitoren in vivo meist zu Beginn und während deren Migration initiiert (Polleux et al., 2007; Polleux und Snider, 2010). So wäre es zum einen möglich, dass sich fehlende transkriptionelle Kontrolle durch NDRF in NDRFNullmutanten schon früh negativ auf die Polarisierung migrierender Korbzellprogenitoren auswirkt und so die anschließende translobulare Elongation und Zielfindung des Axons gestört wird.

Eine solche polarisierungsrelevante Funktion konnte z.B. für FOXO-(forkhead box $)$ Transkriptionsfaktoren im Zusammenspiel mit der Proteinkinase PAK1 (p21/CDC42/RAC1activated kinase 1) in zerebellären Körnerzellen und hippocampalen Neuronen beschrieben werden. FOXO-TF und PAK1 agieren hier als Komponenten eines zellintrinsischen transkriptionellen Signaltransduktionsweges, denen eine zentrale Rolle bei der Herstellung neuronaler Polarität zukommt (de la Torre-Ubieta et al., 2010). So führte die Inaktivierung von FOXO TF an P 3 beispielsweise zu Verlust und Desorientierung von Körnerzellaxonen an $\mathrm{P} 8$ sowie zu stark verlängerten sekundären neuronalen Fortsätzen, insgesamt also zu 
einem stark gestörten morphologischen Gleichgewicht zwischen Axon- und Dendritenentwicklung.

Verglichen mit dem Potential von FOXO-TF schon das initiale Polarisierungsgeschehen neuronaler Progenitoren auf transkriptionellem Niveau zu regulieren, besitzt NDRF sehr wahrscheinlich keinen Einfluss auf die Polarisierung von Korbzellvorläufern.

Korbzellen adulter NDRF-defizienter Tiere verfügen über ein ausgewogenes morphologisches Gleichgewicht zwischen dendritischem und basalem axonalen Kompartiment.

Basierend auf der Annahme, dass Störungen des Polarisierungsmechanismus zu einem beeinträchtigten axo-denritischen morphologischen Gleichgewicht führen würden, ist es also eher unwahrscheinlich, dass NDRF schon frühe polarisierungsrelevante Aspekte der Korbzellentwicklung reguliert.

Die unbeeinträchtigte konservierte Basalmorphologie, vor allem jedoch die Charakteristik der axonalen Entwicklungsstörungen NDRF-defizienter Korbzellen deuten auf ein zweites Szenario hin, in dem NDRF erst spätere Aspekte der Axonentwicklung transkriptionell kontrolliert. Dies wäre konsistent mit der zuvor im Vorderhirn beobachteten Funktion von NDRF als Schlüsselregulator der axonalen Zielfindung und Faszikulation thalamo- und neokortikaler Projektionsneurone (Ince-Dunn et al., 2006).

Während Korbzellprogenitoren ihre finale Position inner-/oberhalb der PS erreichen (ab P 5) elongieren sie ihr Axon, das Kontakt mit der jeweils benachbarten Purkinje-Zelle aufnimmt. Von diesem Kontaktpunkt aus entspringen Kollateralen, die einem auf der PurkinjeZelloberfläche präsentierten, Neurofascin186-Gradienten folgen (Kontakt-Attraktion). Dieser Gradient steuert die weitere Extension der Kollateralen indem er als Wachstumssubstrat und direktionales instruktives Signal fungiert.

Auf dem Purkinje-Zell Soma liegt Neurofascin186 in mono- oder dimerer Form vor und vermittelt die Kollateralen-Extension über niederaffine Zelladhäsionskräfte. An der PurkinjeZell-AIS hingegen führt die Assoziation von Neurofscin186 mit multivalentem Ankyrin 3 und ß4-Spectrin zu mehrfach verknüpften, oligomeren Neurofscin186-Formen und somit zu hochaffinen Zelladhäsionskräften. Diese vermitteln schließlich die Ausprägung des dichten terminalen synaptischen Plexus aus den Axon-Kollateralen.

In ANK3-Nullmutanten liegt Neurofascin186 auf der gesamten Purkinje-Zelloberfläche, an der Purkinje-Zell-AIS sowie ektopisch entlang des Purkinje-Zell-Axons in ungekoppelter, niederaffiner Form vor. Hier wachsen die Axon-Kollateralen entlang des niederaffinen Neurofascin186 Wachstumssubstrates und bilden keine Pinceau-Synapsen. Zusätzlich folgen und verzweigen Sie sich präzise entlang ektopisch Neurofascins186-Domänen. 
Um zu überprüfen, ob der axonale Defizit von Korbzellen NDRF-defizienter Mäuse durch sekundäre Defekte an der Purkinje-Zell-Postsynapse begründet war, wurde im Rahmen dieser Arbeit ANK3 in Kontrollen und Mutanten immunhistochemisch detektiert. Die normale Verteilung von ANK3 an der Purkinje-Zell-AIS von Mutanten sprach dafür, dass die axonalen Defizite tatsächlich durch korbzellintrinsische Ursachen begründet waren. Im Rahmen der dreidimensionalen morphometrischen Rekonstruktion immunhistochemisch detektierter Korbzellaxone wurde zudem deutlich, dass NDRF-defiziente Korbzellen über ein Axon mit normalen Grundmorphologie, d. h. einem primären axonalen Fortsatz mit mehreren Kollateralen, verfügten. Diese Beobachtung sprach dafür, dass transkriptioneller Kontrolle durch NDRF für die Ausbildung eines primären Korbzellaxons per se sowie die grundsätzliche Fähigkeit, Kollateralen zu entwickeln abdingbar ist.

Im Gegensatz zu ANK3-Nullmutanten, in denen die Entwicklung der primären axonalen Korbzellfortsätze und deren initiale Kontaktaufnahme mit benachbarten Purkinje-Zelle nicht gestört war, gingen die Korbzellaxone der NDRF-Nullmutanten überhaupt keine Kontakte mit benachbarten Purkinje-Zellen ein. Sie wuchsen gänzlich „orientierungslos“ innerhalb der Molekularschicht umher, bildeten zum Teil um $360^{\circ}$ gebogene Schlingen und gänzlich desorientierte Kollateralen.

Diese Beobachtungen sprachen dafür, dass in NDRF-defizienten Korbzellen zellintrinsische Defizite solcher Strukturen und Mechanismen vorliegen, die unter normalen Umständen die gerichtete Navigation und initiale Kontaktaufnahme von Korbzell-Axonen vermitteln.

Die Interaktion zwischen extrazellulären Effektoren und zellintrinsischen Mechanismen wird zumeist durch mehrere Superfamilien von Zelladhäsionsmolekülen (CAMs) und Zelloberflächenrezeptoren vermittelt.

Über diese werden komplexe intrazelluläre Signaltransduktionskaskaden in Gang gesetzt, die die Axonentwicklung über bestimmte zytologische Hauptprozesse beeinflussen, $\mathrm{zu}$ denen $\mathrm{u}$. a. die Modifikation der Aktinfilament-Dynamik und Microtubuli-Formation sowie die lokale Anreicherung von Signalmolekülen zählen.

Die Exekution und Modifikation spezifischer transkriptioneller Programme spielt hierbei sehr wahrscheinlich eine essentielle Rolle. Eine Funktion von NDRF könnte daher darin bestehen, solche transkriptionellen Programme zu regulieren.

Zerebelläre Korbzellen wurden bisher nur in sehr geringem Masse genetisch charakterisiert. So sind auf der Ebene von Rezeptoren, intrazellulären Signaltransduktionskomponenten jeweils nur sehr wenige korbzellexklusive Kandidaten bekannt. An dieser Stelle wären 
beispielsweise weitere Analysen zur Identifikation potentieller Interaktionspartner des L1 CAMs Neurofascin186 auf Korbzellen und daran gekoppelter Signaltransduktionswege nötig. Solange in diesem Bereich keine detaillierteren Untersuchungen erfolgen, können potentielle Ansatzpunkte von NDRF in der transkriptionellen Maschinerie zur Steuerung der Korbzellaxonentwicklung lediglich spekulativ diskutiert werden.

\subsection{Motorische Defizite bei fehlender synaptischer Korbzelltransmission}

Studien zu motorischem Lernen fokussierten sich in der Vergangenheit hauptsächlich auf die Rolle von Plastizität bei exzitatorischen Synapsen, die Projektionsneurone kontaktieren.

Im Zerebellum konzentrierte man sich dabei hauptsächlich auf plastische Veränderungen an Parallelfaser-Purkinje-Zellsynapsen, die durch gleichzeitige Aktivierung von Parallelfasern und Kletterfasern erzeugt werden (Marr, 1969). Diese Co-Aktivierung führt zu einer

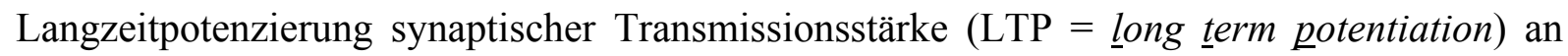
Parallelfasern, einer Form von synaptischer Plastizität, deren molekulare Basis detailliert beschrieben werden konnte und eine zentrale Rolle für Zerebellum-spezifische Funktionen motorischen Lernens einnimmt (De Zeeuw et al., 1998; Hansel et al., 2006; Steuber et al., 2007).

Alle immunhistochemischen, elektronenmikroskopischen und elektrophysiologischen Befunde sprechen dafür, dass die Parallelfaser-Purkinje-Zellsynapse in NDRF-Nullmutanten normal entwickelt ist. Die Werte für die PPF (paired pulse fascilitation), einem Maß für synaptische Kurzzeitplastizität (Maruki et al., 2001), waren in Mutanten vergleichbar mit Kontrollen. Auch die exzitatorische synaptische Transmission durch Kletterfasern war in Mutanten normal entwickelt, wie elektrophysiologische Untersuchungen zeigten. Insgesamt sprechen diese Resultate dafür, dass die beobachteten Defizite motorischen Lernens nicht durch gestörte synaptische Parallelfaser-Purkinje-Zelltransmission bedingt waren.

Im Rahmen dieser Arbeit wurden Zerebellum-spezifische Aspekte motorischen Lernens u. a. mit Hilfe des Rotarod-Tests analysiert.

Das Laufen auf der sich drehenden Rotarod-Trommel forderte von den Versuchstieren hierbei die schnelle und präzise Wiederholung einer Serie gleichförmiger Bewegungen.

Den Purkinje-Zellen des Zerebellums kommt bei der Vermittlung dieses motorischen Ablaufs eine essentielle Bedeutung zu. Ihre Spontanaktivität besitzt einen Frequenzbereich von 10 $100 \mathrm{HZ}$ und stellt eine wichtige nichtsynaptische Grundeigenschaft dar (Thach, 1968; Häusser and Clark, 1997; Nam and Hockberger, 1997; Raman and Bean, 1999). 
Veränderungen dieser Spontanaktivitätsfrequenz durch veränderten inhibitorischen (Korbund Sternzellen) oder exzitatorischen (Parallel- und Kletterfasern) synaptischen input führt zu veränderter synaptischer Transmission auf die TZK, was eine weitere Basis motorischen Lernens darstellt (Häusser und Clark, 1997; Kim und Thompson, 1997; Hesslow und Ivarsson, 1994)

Laut Nolan et al., (2003) ist hierbei vor allem die nichtsynaptische integrative Eigenschaft von Purkinje-Zellen von Bedeutung, die wiederum von ihrer Fähigkeit abhängt, von vorausgegangenen Aktivitätsmustern (,activation history“) schnell $\mathrm{zu}$ normalem Membranpotential und Spontanfrequenz zurück zu finden.

Die Phasen repetetiver Muskelkontraktion und -relaxation während sukzessiver Bewegungsabläufe ist auf Ebene der Purkinje-Zellen durch repetetive stille Perioden der spontanen Feuerrate gekennzeichnet (Thach, 1968).

In Studien an HCN1-knockouts (hyperpolarization-activated cyclic nucleotide regulated nonselective cation channel 1) konnten Nolan et al., (2003) zeigen, dass dieser Kanal das integrative Potential von Purkinje-Zellen stabilisiert und damit gewährleistet, dass ihre input/output-Funktion unabhängig vom vorherigen Verlauf ihrer Aktivierung ist.

Die Autoren postulieren, dass diese nichtsynaptische integrative Funktion von HCN1 auf Purkinje-Zellen wichtig für die Dekodierung von input-Signalen ist und es darüber ermöglicht wird, dass synaptische Plastizität korrekten Einfluss auf die motorischen Fähigkeiten der Versuchstiere hat. Interessanter Weise beobachteten die Autoren in Tieren mit deletiertem HCN1 die gleichen Defizite motorischer Fähigkeiten, wie bei den im Rahmen dieser Arbeit analysierten NDRF-Nullmutanten mit gestörter Korbzell-Transmission auf Purkinje-Zellen. So waren die HCN1-, wie auch NDRF Nullmutanten, bei geringer Rotationsgeschwindigkeit $\mathrm{zu}$ motorischem Lernen auf dem Rotarod in der Lage, während dies bei etwas höheren Rotationsgeschwindigkeiten nicht mehr der Fall war.

Die Autoren postulieren, dass HCN1-defiziente Purkinje-Zellen nicht fähig sind, synaptischen input nach stillen Phasen der Spontanaktivität in korrekte output-Muster zu überführen, die für die korrekte Generierung motorischer Abläufe nötig wären. Nach diesem Model sind die kurzen Intervalle innerhalb sukzessiver hochfrequenter Bewegungen $\mathrm{zu}$ kurz für die Wiederherstellung der integrativen Eigenschaften von Purkinje-Zellen.

Längere Intervalle zwischen den Phasen sukzessiver Bewegungen genügen hingegen, um die integrativen Eigenschaften der Purkinje-Zellen wiederherzustellen. Diese Annahme ist zunächst plausibel, die später aufgedeckte präferentielle Lokalisation von HCN1 auf Korbzellaxonen (Luján et al., 2005b) spricht jedoch dafür, dass die von Nolan et al., (2003) 
observierten Defizite hauptsächlich durch beeinträchtigte synaptische Korbzelltransmission hervor gerufen wurden. Da bei den im Rahmen dieser Arbeit analysierten NDRFNullmutanten synaptische Korbzelltransmission gänzlich fehlt und die beobachteten Defizite motorischen Lernens denen der HCN1-Nullmutanten sehr ähnlich sind, ist es wahrscheinlich, dass auch der durch HCN1-Defiziens ausgelöste Defekt motorischen Lernens hauptsächlich durch Störung synaptischer Korbzelltransmission und nicht ausschließlich durch gestörte integrative Potentiale von Purkinje-Zellen vermittelt wurde. Gestützt wird diese Hypothese durch Analysen von Wulff et al., (2009), die erstmals die genaue Funktion von MS-IN für verschiedene Aspekte des motorischen Lernens analysierten. Für die Analysen von Wulff et al., (2009) wurden Mäuse generiert, in denen GABRG2 (GABA므 receptor 22 subunit) selektiv auf Purkinje-Zellen inaktiviert war, was den kompletten Verlust GABA-erger inhibitorischer synaptischer Transmission von MS-IN auf Purkinje-Zellen nach sich zog.

Dies führte zum Verlust der Phasen-Adaptation und Aktivitätserhöhung von Purkinje-Zellen.

Es konnte gezeigt werden, dass MS-IN das Aktivitätsmuster von Purkinje-Zellen modulieren und darüber die Induktion von Plastizität in Neuronen der Vestibularis- und tiefen zerebellären Kerne vermitteln Wulff et al., (2009). Interessanter Weise führte auch hier fehlende synaptische Transmission durch MS-IN nicht zum kompletten Verlust, sondern lediglich zu stark beeinträchtigtem motorischem Lernvermögen.

Im Gegensatz zu den konditionalen GABRG2-Mutanten, fehlt bei NDRF-Nullmutanten hauptsächlich die inhibitorische synaptische Transmission durch Korbzellen, da die verbliebenen Sternzellen noch funktionale peridendritische Synapsen bilden. Der verbliebene Sternzell-input genügt jedoch nicht, trotz des ansonsten hohen Kompensationsvermögens des zerebellären Kortex (Wulff et al., 2009), für den Verlust des Korbzell-inputs zu kompensieren, was die essentielle Rolle dieser synaptischen Transmission für motorisches Lernen unterstreicht. Insgesamt stärken die Studien von Nolan et al., (2003) und Wulff et al., (2009) sowie die in dieser Arbeit beobachteten Ergebnisse die Hypothese, dass basale motorische Fähigkeiten, sowie motorisches Lernen unter wenig anspruchsvollen Bedingungen nicht von synaptischer Purkinje-Zell-Inhibition durch Korbzellen abhängig ist. Bei schneller, hochfrequenter und repetetiver motorischer Beanspruchung ist Purkinje-Zell-Inhibition durch Korbzellen zur Gewährleistung korrekten motorischen Lernens unabdingbar.

Weiter untermauert wird diese Beobachtung durch die Tatsache, dass GABA-erge Interneurone per se synaptische Plastizität generieren können und dadurch die „Rechenleistung“ (computational capacity) ihrer Mikroschaltkreise erhöhen (Smith und Otis, 2005; Kullmann und Lamsa, 2007; Scelfo et al., 2008). Gerade GABA-erge MS-IN haben ein 
hohes Potential zur Erzeugung synaptischer Plastizität, sowohl auf synaptischem Eingangsals auch Ausgangsniveau (Kano et al., 1992; Jörntell und Ekerot, 2002; Duguid und Smart, 2004; Mittmann et al., 2005; Smith und Otis, 2005; Scelfo et al., 2008).

Leider konnte im Rahmen dieser Arbeit nicht ausgeschlossen werden, dass durch den NDRFVerlust hervor gerufene Defekte des Vorderhirns Einfluss auf die motorischen Fähigkeiten der NDRF-Nullmutanten haben (Lin et al., 2005; Ince-Dunn et al., 2006)

Weitere Experimente, z.B. mit konditionalen NDRF-Mutanten, wären an dieser Stelle nötig, um zu untersuchen, inwieweit der Defekt im motorischen Lernens tatsächlich auf fehlende inhibitorische synaptische Transmission durch Korbzellen zurück geführt werden kann.

\subsection{Neuropathologische Veränderungen durch gestörte GABA- erge synaptische Transmission im Zerebellum}

Im Rahmen dieser Arbeit konnte gezeigt werden, dass der Verlust von NDRF zu kompletter Abwesenheit inhibitorischer synaptischer Transmission von Korbzellen auf Purkinje-Zellen führt. Die Beeinträchtigung dieser essentiellen Purkinje-Zell-Inhibition stellt auch einen diskutierten Teilaspekt der Pathophysiologie menschlicher Nervenkrankheiten, wie Schizophrenie und essentiellem Tremor dar.

Mehrere Untersuchungen der letzten zehn Jahre sprechen dafür, dass Schizophrenie u. a. durch eine gestörte synaptische Architektur des Zerebellums hervor gerufen werden kann. Detailiertere post mortem Analysen der Zerebelli von Schizophrenie-Patienten konnten zeigen, dass die mRNA-Level von GAD1 und GAD2 in Purkinje-, Golgi-, Stern- und Korbzellen herunter reguliert waren (Bullock et al., 2008). In Golgi-, Stern- und Korbzellen war zusätzlich die Expression von GAT-1 ( $\underline{G A B A}$ transporter-1)-Transkripten herunter reguliert. Die Hypothese gestörter inhibitorischer zerebellärer Synapsenformation wird untermauert durch bei Schizophrenie-Patienten nachgewiesene reduzierte Expressionslevel von SNAP-25 (synaptosomal-associated protein 25), eines synaptischen Proteins, dass das Andocken synaptischer Vesikel reguliert (Mukaetova-Ladinska et al., 2002).

Es existieren keine Hinweise darauf, dass bHLH-TF der NeuroD-Familie einen direkten Einfluss auf die Pathophysiologie von Shizophrenie haben, jedoch spiegelt die im Rahmen dieser Arbeit analysierte NDRF-Nullmutante den Teilaspekt reduzierter zerebellärer kortikaler Inhibition bei Schizophrenie wider. Somit könnte die NDRF-Nullmutante evtl. heran gezogen werden, um die Ursachen der motorischen Anteile des Symptomkatalogs bei Schizophrenie zu untersuchen. Das Gleiche gilt für die menschliche Nervenkrankheit essentieller Tremor (ET), die alleinstehend auftritt, in 60\% der Fälle autosomal-dominant vererbt wird und deren Haupterkrankungsalter zwischen dem 2. und 6. Lebensjahrzehnt liegt. 
Bei vielen ET-Patienten liegen morphologisch anormale (,haarige“) Pinceau-Synapsen vor, die zu gestörter Purkinje-Zell-Inhibition führen, was vermutlich zur Symptomatik dieses Haltetremors beiträgt (Erickson-Davis et al., 2010). Als sekundäre Anzeichen gestörter Inhibition durch Korbzellen entwickeln Purkinje-Zellen von ET-Patienten axonale Schwellungen. Auch hier gibt es keine experimentellen Anhaltspunkte dafür, dass bHLH-TF der NeuroD-Familie einen direkten Einfluss auf die Pathophysiologie des ET haben, doch könnte die im Rahmen dieser Arbeit analysierte NDRF-Nullmutante den Teilaspekt reduzierter zerebellärer kortikaler Inhibition bei ET widerspiegeln und z. B. für zerebellumspezifische Verhaltenstests heran gezogen werden.

Trotz der Tatsache, dass gestörte zerebelläre Inhibition zur Pathophysiologie mehrerer menschlicher Nervenkrankheiten beiträgt, sind die vor allem später in der Entwicklung stattfindenden Entwicklungsschritte des zerebellären GABA-ergen Systems bisher relativ wenig erforscht. Im Rahmen dieser Arbeit konnten diesbezüglich neue Erkenntnisse gewonnen werden. NDRF konnte als essentieller transkriptioneller Regulator mit Einfluss auf die terminale Differenzierung von Korb- und Sternzellen sowie auf die Axo- und Synaptogenese von Korbzellen charakterisiert werden. Diese Beobachtung liefert erste Einblicke in die transkriptionellen Regulationsmechanismen terminaler Entwicklungsphasen zerebellärer kortikaler Interneurone und somit wichtige Erkenntnisse zum Verständnis der Entwicklung des zerebellären GABA-ergen Gesamtsystems. 


\section{Material}

\subsection{Chemikalien}

Alle im Folgenden nicht bezeichneten Standardlaborchemikalien und Verbrauchsmaterialien, wurden von handelsüblichen Firmen wie Amersham Biosciences (Freiburg), Boehringer Ingelheim (Ingelheim), Roche (Indianapolis, USA), Carl Roth (Karlsruhe), Serva (Heidelberg), BD Falcon (Heidelberg), Eppendorf (Hamburg), Riedel de Haen (Hannover), Merck (Darmstadt), Sigma (Taufkirchen), BioRad (München), Invitrogen (Karlsruhe), VWR (Darmstadt) bezogen.

Acrylamid (30\%)

Agarose

Ammoniumacetat

Ampicillin

Aqua Poly Mount (Einbettmedium)

AraC (Cytosine B-D-arabinofuranoside)

Azur II

B27 Supplement 50x

beta-Mercaptoethanol

Bleinitrat

BME (basal medium eagle)

BSA (bovines Serumalbumin)

CapSure Macro LCM Caps

Chloroform

Combitips und Tubes (verschiedene Größen)

DAPI (4,6-diamidino-2-phenylindol)

Dinatriumhydrogenphosphat

DMEM BioWhittaker,

DNAseI

EDTA

Ethanol (100\%)

Ethidiumbromid

Eukitt (Einbettmedium)

Falconröhrchen, Größe: 15 ml, $50 \mathrm{ml}$

FCS (fötales Kälberserum)

Formaldehyd
Gerbu Trading

Cambrex

Merck

Merck

Polyscience

Sigma

Merck

Gibco

Sigma

Merck

Gibco

Sigma

Molecular Devices

Merck

Eppendorf

Boehringer

Merck

Cambrex

Roche

Sigma-Aldrich

Fluka

Sigma

Kindler GmbH

BD Falcon

PAM

Merck 
Formvar

Gentamicin

Glutamax ${ }^{\circledR} 100 \mathrm{x}$

Glutaraldehyd

Haemalaun

HBSS

Immumount (Einbettmedium)

Isopropanol

Kaliumdihydrogenphosphat

Magermilchpulver

Methylenblau

Natriumchlorid $(\mathrm{NaCl})$

Natriumdihydrogenphosphat

Osmiumtetroxid

Paraformaldehyd (PFA)

Pferdeserum (HS)

Propylenoxid

Proteinase-Hemmer Tabletten (Complete, Mini)

RNAlater $^{\circledR}$, RNA stabilization reagent

Schiff's Reagenz

$\mathrm{SYBR}^{\circledR}$ Green PCR Master Mix

Tris(hydroxymethyl)aminomethanhydrochlorid

Triton X-100

Trypsin

Trypsin-EDTA

Uranylacetat

Xylol

Ziegenserum

Zitronensäure

$\beta$ - Mercaptoethanol

\subsection{Radiochemikalien}

$\alpha\left[{ }^{32} \mathrm{P}\right]-\mathrm{dCTP}(3000 \mathrm{Ci} / \mathrm{mmol}, 250 \mathrm{mCi} / \mathrm{ml})$
Plano

Sigma

Gibco

Merck

Merck

Gibco

Shandon

Merck

Merck

Naturaflor Töpfer

Merck

Merck

Merck

Roth

Serva

Sigma

Serva

Roche

Ambion

Merck

Applied Biosystems

Merck

Serva

Gibco

Sigma

Merck

Merck

Gibco

Merck

Sigma

Amersham Pharmacia

Menzel/Marienfeld

Whatman

Sarasotas 
Histobond Adhäsions-Objektträger

Hybond TM-NX Membran

Hybridisierungsröhren

Hybridisierungsröhren

Loch Platten (96-iger)

PAP-Pen

PCR-Microtiterplatten

PCR-Microtiterplatten -Folien

Pipetten-Spitzen

Polypropylen Röhrchen (15 ml)

Reaktionsgefäße $(0,5 \mathrm{ml}, 1,5 \mathrm{ml}, 2,0 \mathrm{ml})$
Marienfeld

Amersham

Biometra

Hybaid

Applied Biosystems

Dako Cytomation

Abgene

Abgene

Gilson/ART Molecular

Bioproducts

BD Falcon

Eppendorf

Agilent Technologies

Diatome

Kappa

Jenoptik

Axon-Instruments

Zeiss, Leo

IBI

BioRad

Intas

Affymetrix

Mikrom

Leica

Biometra

Warner Instruments

Sartorius

Zeiss

Leica

Olympus

Zeiss

Leica

AEG 
PCR-Maschine Trio Thermoblock

PCR-Versiegler „Combi Thermosealer“

Perestaltikpumpe SR70

Phosphoimager (Molecular Dynamics 400E)

Photometer (Ultraspec 3000)

Pipetten (Pipetman ${ }^{\circledR}$ )

Pipetus Akku

Reinstwasseranlagen

Rotarod Verhaltenstestgerät ENV-575M

Schlittenmikrotom HM400

Spannungsgerät PowerPac HC

Szintillationszähler

Thermomixer

Trimm-Fräse (für Eponblöcke)

Ultramikrotom RM 2155

Ultra-Turrax Polytron PT3000

UV-Illuminator (Stratalinker 2400)

Verstärker Multiclamp 700B (Elektrophysiologie)

Vibratom Vibroslicer VT1200S

Vortexer Genie 2

Zentrifugen: Tischzentrifuge mini

Tischzentrifuge Biofuge pico

Kühlzentrifuge Optima TLX

7500 Fast Real-time PCR System
Biometra

Advanced Biotechnologies

Heraeus

Fuji

Pharmacia

Gilson

Hirschmann

Sartorius

Med. Associates Inc.

Mikrom

Bio-Rad

LKB-Wallac

Eppendorf

Reichert

Leica

Kinematika AG

Stratagene

Axon Instruments

Leica Instruments

Bender \& Hobein AG

Roth

Heraeus

Beckmann

Applied Biosystems

\subsection{Lösungen und Puffer}

\subsubsection{Lösungen für die Immunhistochemie}

\section{Citratpuffer}

Stammlösung A: 0,1 M Zitronensäure

Stammlösung B: 0,1 M Natriumzitrat

Gebrauchslösung (0,01 M, pH 6)

Stammlösung A

$9 \mathrm{ml}$

Stammlösung B

$41 \mathrm{ml}$ 
$\mathrm{H}_{2} \mathrm{O}_{\text {dd }}$ ad

$500 \mathrm{ml}$

\section{Trispuffer}

Stammlösung $(0,5 \mathrm{M}, \mathrm{pH} 7,6)$

TRIS(hydroxymethyl)-aminomethan 60,75 g

in $500 \mathrm{ml}$ aqua bidest lösen, mit $1 \mathrm{M} \mathrm{HCl}$ auf $\mathrm{pH}$ 7,6 einstellen und mit $\mathrm{H}_{2} \mathrm{O}_{\mathrm{dd}}$ auf $1000 \mathrm{ml}$ auffüllen.

\section{Gebrauchslösung (0,05 M, pH 7,6)}

Stammlösung $100 \mathrm{ml}$

$\mathrm{NaCl} 9 \mathrm{~g}$

mit $\mathrm{H}_{2} \mathrm{O}_{\text {dd }}$ auf $1000 \mathrm{ml}$ auffüllen.

Trispuffer $+2 \%$ Milchpulver $(1000 \mathrm{ml})$

Trispuffer Gebrauchslösung $1000 \mathrm{ml}$

Magermilchpulver $20 \mathrm{~g}$

Über einen Faltenfilter abfiltrieren.

\section{Phosphatpuffer (Sörensen)}

Stammlösung A: 0,2 M Natriumdihydrogenphosphat

Stammlösung B: 0,2 M Dinatriumhydrogenphosphat

\section{Gebrauchslösung (0,1 M, pH 7,4)}

Stammlösung A

$20 \mathrm{ml}$

Stammlösung B

$80 \mathrm{ml}$

$\mathrm{H}_{2} \mathrm{O}_{\mathrm{dd}}$

$100 \mathrm{ml}$

\section{PBS/BSA}

Phosphatpuffer Stammlösung A

$20 \mathrm{ml}$

Phosphatpuffer Stammlösung B

$80 \mathrm{ml}$

$\mathrm{NaCl}$

$1,8 \mathrm{~g}$

BSA

$1,0 \mathrm{~g}$

$\mathrm{H}_{2} \mathrm{O}_{\mathrm{dd}}$

$100 \mathrm{ml}$

Fixierungslösung für Immunhistochemie

(1000 ml)

Phosphatpuffer Stammlösung A

$100 \mathrm{ml}$

Phosphatpuffer Stammlösung B

$400 \mathrm{ml}$ 
37 \% Paraformaldehyd, abfiltriert durch zwei

Faltenfilter

$100 \mathrm{ml}$

aqua bidest

$400 \mathrm{ml}$

\section{Scotts Lösung}

Kaliumhydrogencarbonat

$2 \mathrm{~g}$

Magnesiumsulfat

$20 \mathrm{~g}$

$\mathrm{H}_{2} \mathrm{O}_{\text {dd }}$ ad.

$1000 \mathrm{ml}$.

\subsubsection{Lösungen für in-situ Hybridisierungen}

\section{Hybridisierungs Puffer}

$50 \%$ Formamid

$2 \%$ Blockierungsreagenz

$5 \mathrm{x}$ SSC depc

$0,02 \%$ SDS

$0,10 \%$ Sarcosyl

steril filtrieren, bei $-20{ }^{\circ} \mathrm{C}$ aufbewahren

10x Maleinsäure Puffer

1 M Maleinsäure

$75 \mathrm{~g} / \mathrm{l} \mathrm{NaOH}$

$1,5 \mathrm{M} \mathrm{NaCl}$

mit $10 \mathrm{M} \mathrm{NaOH}$ auf $\mathrm{pH}$ 7,5 bringen, steril filtrieren

\section{BCIP-Stammlösung}

$50 \mathrm{mg} / \mathrm{ml}$ in $100 \% \mathrm{DMF}$

bei $-20{ }^{\circ} \mathrm{C}$ lagern

\section{NBT-Stammlösung}

$75 \mathrm{mg} / \mathrm{ml}$ in $70 \% \mathrm{DMF}$

bei $-20{ }^{\circ} \mathrm{C}$ lagern

\section{Färbepuffer}

$100 \mathrm{mM}$ TrisCl pH 9.5

$100 \mathrm{mM} \mathrm{NaCl}$

$50 \mathrm{mM} \mathrm{MgCl}{ }_{2}$ 
$20 \times$ SSC depc

$3 \mathrm{M} \mathrm{NaCl}$

$0,3 \mathrm{M}$ NaCitrat

mit $1 \mathrm{M} \mathrm{HCl}$ auf $\mathrm{pH} 7$ bringen

1,5 ml DEPC dazu, ü. N. bei $37^{\circ} \mathrm{C}$ inkubieren, autoklavieren

TE-Puffer

$10 \mathrm{mM}$ TrisCl pH 7.5

1 mM EDTA

\subsection{Lösungen für Northern-Blot Analyse}

SSC (20 x,1000 ml)

$\mathrm{NaCl}$

$3,0 \mathrm{M}$

Natriumcitrat

$0,3 \mathrm{M}$

DEPC- $\mathrm{H}_{2} \mathrm{O}$

$\mathrm{H}_{2} \mathrm{O}$

$1000 \mathrm{ml}$

DEPC

$1 \mathrm{ml}$

Über Nacht bei $37^{\circ} \mathrm{C}$ stehenlassen und anschließend autoklavieren

Methylenblau-Färbelösung

$(100 \mathrm{ml})$

Methylenblau

$2 \mathrm{mg}(2 \%)$

auf $100 \mathrm{ml} \mathrm{mit} \mathrm{H}_{2} \mathrm{O}_{\text {dd }}$ auffüllen

RNA-Gelpuffer (10x,1000 ml)

MOPS

$41,2 \mathrm{~g}(0,2 \mathrm{M})$

Natriumacetat $(100 \mathrm{mM})$

$800 \mathrm{ml}(80 \mathrm{mM})$

pH 7 mit $2 \mathrm{M} \mathrm{NaOH}$ einstellen

EDTA (0,5 M,pH 8)

$20 \mathrm{ml}(10 \mathrm{mM})$

auf $1000 \mathrm{ml}$ mit $\mathrm{H}_{2} \mathrm{O}$-DEPC auffüllen

RNA-Gelpuffer Gebrauchslösung (1x, 1000 ml)

RNA-Gelpuffer(10 x)

$100 \mathrm{ml}$

Formaldehyd (37\%)

$175 \mathrm{ml}$

auf $1000 \mathrm{ml}$ mit $\mathrm{H}_{2} \mathrm{O}$-DEPC auffüllen 
RNA-Probenpuffer (2 x)

RNA-Gelpuffer $(10 \mathrm{x}) \quad 50 \mu 1$

Glyzerin $\quad 300 \mu 1$

Formaldehyd (37\%) $\quad 50 \mu 1$

Formamid $\quad 50 \mu 1$

Bromphenolblau $\quad 0,25 \%$

nach RNA-Zugabe, 5 min auf $65^{\circ} \mathrm{C}$ erhitzen

Northern-Hybridisierungspuffer $(20 \mathrm{ml})$

Denhardts-Reagenz (100 x) $1 \mathrm{ml}(5 \mathrm{x})$

$\operatorname{SSC}(20 \mathrm{x}) \quad 4 \mathrm{ml}(4 \mathrm{x})$

Formamid $\quad 10 \mathrm{ml}(50 \%)$

$\operatorname{SDS}(10 \%) \quad 2 \mathrm{ml}(1 \%)$

$\mathrm{H}_{2} \mathrm{O}$-DEPC $3 \mathrm{ml}$

10 min bei $65^{\circ} \mathrm{C}$ erhitzen

Heringssperma ssDNA $(2 \mathrm{mg} / \mathrm{ml}) \quad 1 \mathrm{ml}(0,1 \mathrm{mg} / \mathrm{ml})$

Vor der Zugabe der Heringsspermien-DNA diese 5 min bei $95{ }^{\circ} \mathrm{C}$ denaturieren.

\subsubsection{Spezielle PCR-Lösungen}

Soriano PCR-Puffer (5 x)

Substanz

$1 \mathrm{M}$ Ammoniumsulphat

1 M Tris, $\mathrm{pH} \mathrm{8,8}$

1 M Magnesiumdichlorid

$\beta$-Mercaptoethanol

0,5 M EDTA, $\mathrm{pH} 8$

Aqua dest

Gesamtvolumen
Menge

$4,15 \mathrm{ml}$

$16,75 \mathrm{ml}$

$1,68 \mathrm{ml}$

$87,5 \mu 1$

$3,35 \mu 1$

$27,33 \mathrm{ml}$

$50 \mathrm{ml}$

\section{Endkonzentration}

$83 \mathrm{mM}$

$335 \mathrm{mM}$

$33,5 \mathrm{mM}$

$25 \mathrm{mM}$

$33,5 \mathrm{mM}$

\subsubsection{Lösungen für die Elektronenmikroskopie}

Fixativ für 500 ml; pH 7,5 (nach Schultz \& Karlsson, 1965)

Natriumdihydrogenphosphat $\mathrm{x}_{2} \mathrm{O}$

$0,9 \mathrm{~g}$

Dinatriumhydrogenphosphat $\mathrm{x} 2 \mathrm{H}_{2} \mathrm{O}$

$7,75 \mathrm{~g}$

Natriumchlorid 
Lösen in dd $\mathrm{H} 2 \mathrm{O}$

ad $250 \mathrm{ml}$

Glutaraldehyd $25 \%$

$50 \mathrm{ml}$

Paraformaldehyd $10 \%$ (kochen; mit 6 - 10 Tropfen $1 \mathrm{M} \mathrm{NAOH}$

$$
\text { Klären; abkühlen lassen) }
$$

$200 \mathrm{ml}$ (f.c.: $4 \%$ )

(Lösungen langsam mischen und steril filtrieren)

Färbelösung für Semi-Dünnschnitte (Richardson, 1969)

Methylenblau-Lösung: 1\% Methylenblau in 1\% wässriger Boraxlösung

Azur-II-Lösung: $\quad 1 \%$ Azur II in $\mathrm{H} 2 \mathrm{O}$

Im Verhältnis von 1:1 mischen und filtriert benutzen.

Eponmischung nach Luft, 1961 (für 47,1 ml)

Glycidether 100

$21,4 \mathrm{ml}$

DDSA

$14,4 \mathrm{ml}$

MNA

$11,3 \mathrm{ml}$

10min rühren lassen

DMP-30

$0,84 \mathrm{ml}$

20min rühren lassen

\subsubsection{Lösungen für die Elektrophysiologie}

\section{Lösung für Vibratom:}

$75 \mathrm{mM} \mathrm{NaCl}$

2,5 $\mathrm{mM} \mathrm{KCl}$

$0,5 \mathrm{mM} \mathrm{CaCl}_{2}$,

$7 \mathrm{mM} \mathrm{MgCl}_{2}$

$1,25 \mathrm{mM} \mathrm{NaH}_{2} \mathrm{PO}_{4}$

$26 \mathrm{mM} \mathrm{NaHCO}_{2}$

25 mM Glukose

$75 \mathrm{mM}$ Sucrose

begast mit $95 \% \mathrm{O}_{2} / 5 \% \mathrm{CO}_{2}$

Spülmedium während elektrophysiologischer Aufnahmen:

$125 \mathrm{mM} \mathrm{NaCl}$

$2.5 \mathrm{mM} \mathrm{KCl}$

$2.5 \mathrm{mM} \mathrm{CaCl}_{2}$, 
1,3 $\mathrm{mM} \mathrm{MgCl}_{2}$

$26,2 \mathrm{mM} \mathrm{NaH}_{2} \mathrm{PO}_{4}$

$1 \mathrm{mM} \mathrm{NaHCO}_{2}$

$11 \mathrm{mM}$ Glukose

\subsubsection{Aufnahme von EPSCs}

Zugabe von

$100 \mu \mathrm{M}$ Picrotoxin

Zur Aufnahme von Kletterfaser-EPSCs weitere Zugabe von 0,6 - 0,8 $\mu \mathrm{M}$ NBQX (2,3-dioxo6-nitro-1,2,3,4-tetrahydrobenzo[f]quinoxalin-7-sulfonamid)

Pipettenlösung:

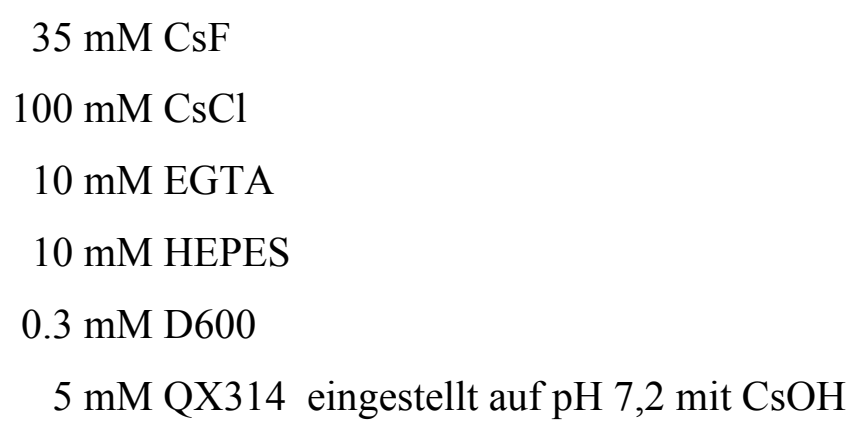

\subsubsection{Aufnahme von IPSCs}

Zugabe von

$5 \mu \mathrm{M}(\mathrm{NBQX})$

0,5 $\mu \mathrm{M}$ Tetrodotoxin

Pipettenlösung für Purkinje-Zell-mIPSCs:

$120 \mathrm{mM}$ CsGlu

$15 \mathrm{mM} \mathrm{CsCl}$

$8 \mathrm{mM} \mathrm{NaCl}$

0,2 mM EGTA

$10 \mathrm{mM}$ HEPES

$2 \mathrm{mM}$ Mg-ATP

0.3 mM Na-GTP eingestellt auf PH 7,3 mit CsOH

\section{Pipettenlösung für Sternzell-mIPSCs:}

$150 \mathrm{mM} \mathrm{CsCl}$ 


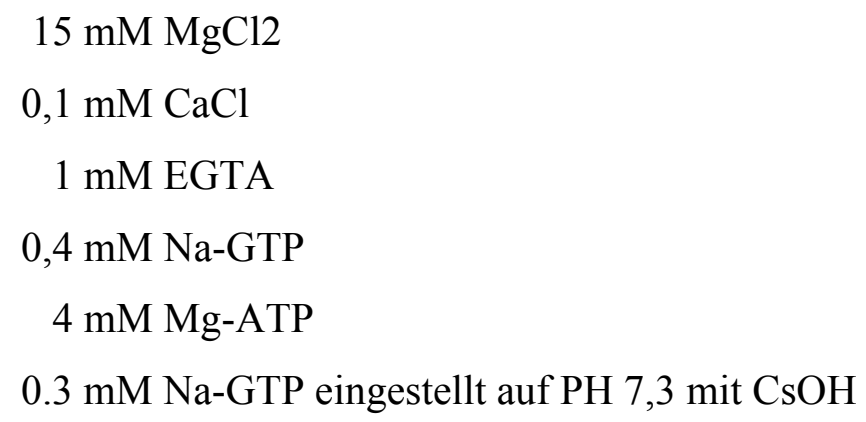

\subsubsection{Weitere Lösungen und Puffer}

\section{PBS (10 x)}

$\mathrm{NaCl}$

$100 \mathrm{~g}$

$\mathrm{KCl}$

$\mathrm{Na}_{2} \mathrm{HPO}_{4} \times 2 \mathrm{H}_{2} \mathrm{O}$

$\mathrm{KH}_{2} \mathrm{PO}_{4}$

in $900 \mathrm{ml} \mathrm{H} \mathrm{O}_{\text {dd }}$ lösen, $\mathrm{pH}$ mit $1 \mathrm{M} \mathrm{NaOH}$ auf 7,2 einstellen, mit $\mathrm{H}_{2} \mathrm{O}_{\text {dd }}$ auf $1000 \mathrm{ml}$ auffüllen

TAE (50 x)

Tris-Base

$242 \mathrm{~g}$

Eisessig $57,1 \mathrm{ml}$

EDTA $(0,5 \mathrm{M}, \mathrm{pH} 8)$

$100 \mathrm{ml}$

$\mathrm{H}_{2} \mathrm{O}_{\text {dd }}$ ad $1000 \mathrm{ml}$.

\subsection{Antikörper}

\subsubsection{Primärantikörper}

\begin{tabular}{|l|c|c|c|}
\hline Antikörper-Typ & Hersteller-Firma & Kat. Nr. & Verdünnung \\
\hline $\begin{array}{l}\text { Kaninchen anti-ANK3 } \\
\text { (polyklonal) }\end{array}$ & Santa Cruz & sc-12719 & $1: 50$ \\
\hline $\begin{array}{l}\text { Kaninchen anti-CALB } \\
\text { (polyklonal) }\end{array}$ & Swant & CB-38a & $1: 1000$ \\
\hline $\begin{array}{l}\text { Kaninchen anti-CALR } \\
\text { (polyklonal) }\end{array}$ & Millipore & AB5054 & $1: 1000$ \\
\hline $\begin{array}{l}\text { Kaninchen anti-HCN1 } \\
\text { (polyklonal) }\end{array}$ & Biomol & SA-597 & $1: 200$ \\
\hline Kaninchen anti & upstate & $06-868$ & $1: 500$ \\
\hline
\end{tabular}




\begin{tabular}{|c|c|c|c|}
\hline GABRA1 (polyklonal) & & & \\
\hline $\begin{array}{l}\text { Kaninchen anti- } \\
\text { GABRA } 6 \text { (polyklonal) }\end{array}$ & Millipore & AB5610 & $1: 500$ \\
\hline $\begin{array}{l}\text { Maus anti-GAD1 } \\
\text { (monoklonal) }\end{array}$ & Millipore & MAB5406 & $1: 1000$ \\
\hline $\begin{array}{l}\text { Kaninchen anti-GAD2 } \\
\text { (polyklonal) }\end{array}$ & Millipore & AB5082 & $1: 1000$ \\
\hline $\begin{array}{l}\text { Maus anti-MAP2 } \\
\text { (monoklonal) }\end{array}$ & Chemicon & MAB3418 & $1: 800$ \\
\hline $\begin{array}{l}\text { Kaninchen anti-NEFH } \\
\text { (polyklonal) }\end{array}$ & Sigma & G9264 & $1: 200$ \\
\hline $\begin{array}{l}\text { Maus anti-PVALB } \\
\text { (monoklonal) }\end{array}$ & Sigma & P3088 & $1: 1000$ \\
\hline $\begin{array}{l}\text { Kaninchen anti- } \\
\text { PVALB (polyklonal) }\end{array}$ & Swant & PV-28 & $1: 1000$ \\
\hline $\begin{array}{l}\text { Kaninchen anti-PAX2 } \\
\text { (polyklonal) }\end{array}$ & Zymed & $71-6000$ & $1: 250$ \\
\hline $\begin{array}{l}\text { Maus anti-PSD95 } \\
\text { (monoklonal) }\end{array}$ & ABR & MA1-046 & $1: 400$ \\
\hline $\begin{array}{l}\text { Meerschweinchen anti- } \\
\text { VGLUT1 } \\
\text { (polyklonal) }\end{array}$ & Millipore & AB5905 & $1: 5000$ \\
\hline
\end{tabular}

\subsubsection{Sekundärantikörper}

\begin{tabular}{|c|c|c|c|}
\hline Antiköper-Typ & Hersteller-Firma & Kat. Nr. & Verdünnung \\
\hline $\begin{array}{l}\text { Cy3-gekoppelter } \\
\text { Antikörper (Affe } \\
\text { anti } \\
\text { Meerschweinchen) }\end{array}$ & Millipore & AP193C & $1: 1000$ \\
\hline $\begin{array}{l}\text { Cy2-gekoppelter } \\
\text { Antikörper (Ziege } \\
\text { anti Maus) }\end{array}$ & Jackson Immuno R. L & $111-225-003$ & $1: 200$ \\
\hline Cy3-gekoppelter & Jackson Immuno R. L. & $111-165-003$ & $1: 2000$ \\
\hline
\end{tabular}


Antikörper (Ziege anti Kaninchen)

\subsection{Oligonukleotide}

\subsubsection{Primer zur Genotypisierung der $\mathrm{MACC}^{\mathrm{Cre}}$ - Mauslinie}

Die Primer wurden in der Sequenzierabteilung des Max-Planck-Instituts synthetisiert.

\begin{tabular}{|l|l|l|}
\hline Name & Nukleotid-Sequenz 5' -> 3' & Länge (bp) \\
\hline MACC s & TAG AGC ATT AGG GTG GGA G & 19 \\
\hline MACC as & TGC CGC CTT TGC AGG TGT GTC TTA C & 25 \\
\hline
\end{tabular}

\subsubsection{Primer zur Genotypisierung der NeuroD-flox - Mauslinie}

\begin{tabular}{|l|l|l|}
\hline Name & Nukleotid-Sequenz 5' -> 3' & Länge (bp) \\
\hline KO $\beta 2.2 . a s$ & TGA CAG AGC CCA GAT GTA & 18 \\
\hline ND I s & GTT TTT GTG AGT TGG GAG TG & 20 \\
\hline ND 6.2.as & AGG ATT ACA AAC AAG ATT AC & 20 \\
\hline
\end{tabular}

\subsubsection{Primer zur Genotypisierung der NDRF mutanten Mauslinie}

\begin{tabular}{|l|l|l|}
\hline Name & Nukleotid-Sequenz 5' -> 3' & Länge (bp) \\
\hline NDRF s & TGG GCT CTC TCG GAG ATC T & 19 \\
\hline NDRF as & CTG TTG GGA GGT GGG GAG AG & 20 \\
\hline KO neo & ATT GTC TGT TGT GCC CAG TG & 20 \\
\hline
\end{tabular}

\subsubsection{Primer für die RT-PCR}

Primer für die RT-PCR wurden mit Hilfe des Roche Universal ProbeLibrary Assay Design Centers entworfen:

\begin{tabular}{|l|l|l|}
\hline Name & Nukleotid-Sequenz 5' -> 3' & Länge (bp) \\
\hline $\begin{array}{l}\text { Topoisomerase } \\
1(\mathrm{TOP} 1) \mathrm{s}\end{array}$ & AATGAGAGGGGACAGCAAAC & 20 \\
\hline $\begin{array}{l}\text { Topoisomerase } \\
1(\mathrm{TOP} 1) \text { as }\end{array}$ & CCTTGTCTGTGGCCTTCG & 18 \\
\hline NDRF s & CCTCTCCCCTTGACTCCTCT & 20 \\
\hline NDRF as & GAACAGGCGGGTCAGCAT & 18 \\
\hline
\end{tabular}

\subsection{Größenmarker}

Name

Basenpaare

$\underline{\text { Hersteller }}$ 
$\phi X 174 x H a e$ III $\quad 1353,1078,872,603,310,281,271, \quad$ NEB

234, 194, 118, 72

$1 \mathrm{~kb}$ Ladder $\quad 10000,8000,6000,5000,4000,3500, \quad$ Fermentas

$3000,2500,1500,1000,750,500,250$

Es wurden jeweils $500 \mathrm{ng}(5-10 \mu \mathrm{l})$ eingesetzt.

\subsection{Reaktionskomplettausstattungen}

Prime-It-II ${ }^{\circledR}$-Kit

QIAamp Tissue Kit

RNeasyTM Total RNA

SUPERSCRIPTTM-Kit

TRIzOL ${ }^{\circledR}$ Reagent

Invisorb Spin Tissue Mini Kit (256)

FD Rapid GolgiStain ${ }^{\mathrm{TM}}$ Kit

\author{
Stratagene \\ Qiagen \\ Miniprep-Kit Qiagen \\ GIBCOBRL \\ GIBCOBRL \\ Invitek \\ FD NeuroTechnologies
}

\subsection{Genetisch veränderte Tiere}

Tiere der NeuroD-flox x MACC-Cre - Linie mit gefloxtem Exon 2 des NeuroD Gens und Cre-Rekombinase unter Kontrolle des Promotors der GABA(A) $\alpha 6$ Rezeptor Untereinheit auf gemischtem genetischem C57/B16 x DBA/2 Hintergrund.

NDRF-/- Mäuse mit inaktiviertem NDRF Gen auf einem Sv129 Stammeshintergrund.

\subsection{Hard- und Software}

Die vorliegende Arbeit wurde auf einem Notebook „Latitude E 6500“ der Firma Dell mit dem Betriebssystem Windows XP Professionell V. 2002 (Microsoft) angefertigt. Die Digitalisierung fluoreszensmikroskopischer Bilder erfolgte durch die Digital-Kamera des Mikroskops DM RXA (Leica) unter Verwendung des Programmes ImageJ V. 1.43. (open source) Konfokalmikroskopische erzeugte Bilder wurden mittels des Programmes LSM Image Browser V. 4.0.0.157 (Zeiss) geöffnet und bearbeitet. Die weitere Bildbearbeitung wurde mit den Programmen Photoshop CS 3.0 (Adobe Systems), Adobe Illustrater CS 3.0. (Adobe Systems) und ImageJ V. 1.43 durchgeführt. PCR-Fotos und Northern-Blots wurden mit dem Scanner Duoscan T 1200 (AGFA) digitalisiert. Statistische Auswertungen von Messdaten erfolgte unter Verwendung der Programme Excel 2003 (Microsoft), sowie GraphPad Prism V. 5.01 (GraphPad Software). Literaturrecherchen wurden mit Hilfe des Internetservice des National Center for Biotechnology Information (Internetadresse: http://www.ncbi.nlm.nih.gov/) sowie unter Verwendung des online-Katalogs des Max- 
Planck-Instituts für experimentelle Medizin durchgeführt. Elektrophysiologische Daten wurden mit dem Programm Clampex (Molecular Devices) digitalisiert und mittels der Programme Axograph X (AxoGraph Scientific) und Microsoft Excel 2003 (Microsoft) bearbeitet. RT-PCR-Daten wurden statistisch mit dem Programm qBase V.1.3.5 (Center for Medical Genetics) und Microsoft Excel 2003 (Microsoft) ausgewertet. 


\section{Methoden}

\subsection{Histologische und immunhistochemische Methoden}

\subsubsection{Ganzkörperfixierung von Mäusen durch Perfusion}

Zunächst wurden die Tiere mit 2,5 \%igem Avertin $(0,2 \mathrm{ml} / 10$ g Körpergewicht) intraperitonial anästhesiert. Danach wurde der Brustkorb der Maus geöffnet, das Herz frei präpariert, eine Perfusionskanüle in die linke Herzkammer eingeführt und ein Schnitt im rechten Vorhof gesetzt. Die Fixationslösung wurde mittels einer Peristaltikpumpe (Heraeus SR70, Flußrate 0,2 - 0,5 ml/s) in die Kanüle gepumpt. Zum Ausspülen des Blutes wurde zunächst mit $30 \mathrm{ml}$ HBSS perfundiert, gefolgt von 4 \%igem, in Sörensenpuffer $(\mathrm{pH} 7,4)$ gepuffertem Paraformaldehyd. Der Kopf der Tiere wurde entfernt, die Schädelkalotte wurde eröffnet, das fixierte Gehirn wurde frei präpariert und bei $4{ }^{\circ} \mathrm{C}$ für $1-2 \mathrm{~h}$ in der Fixierungsslösung nachfixiert. Gelagert wurden die Gewebe bei $4{ }^{\circ} \mathrm{C}$ in $1 \mathrm{x}$ PBS-Puffer.

\subsubsection{Herstellung von Paraffinschnitten für die Lichtmikroskopie}

Die präparierten, Paraformaldehyd-fixierten Gehirne wurden unter Verwendung eines Gewebeinfiltrationsautomaten (MICROM HMP 110) paraffiniert und an einer ParaffinAusgießstation (MICROM AP 280) eingebettet. $5 \mu \mathrm{m}$ dicke Schnitte wurden an einem Schlittenmikrotom (MICROM HM 400) aus den Paraffinblöcken gewonnen, die zunächst auf $37^{\circ} \mathrm{C}$ warmen Wasser geglättet, dann auf Objektträger aufgezogen und über Nacht bei $37^{\circ} \mathrm{C}$ getrocknet wurden. Die Einbettung erfolgte nach folgendem Schema:

Reagenz

EtOH $50 \%$

EtOH 70\%

$\mathrm{EtOH} 70 \%$

EtOH 96\%

EtOH 96\%

EtOH 100\%

EtOH 100\%

Isopropanol

Xylol

Xylol

Paraffin

Paraffin

\section{Dauer}

$1 \mathrm{~h}$

$2 \mathrm{~h}$

$2 \mathrm{~h}$

$1 \mathrm{~h}$

$1 \mathrm{~h}$

$1 \mathrm{~h}$

$1 \mathrm{~h}$

$1 \mathrm{~h}$

$2 \mathrm{~h}$

$2 \mathrm{~h}$

$2 \mathrm{~h}$

$2 \mathrm{~h}$ 


\subsubsection{Herstellung von Vibratomschnitten für die Lichtmikroskopie}

Die Zerebelli der fixierten Gehirne wurden entfernt, in 4 \%ige Agarose eingebettet und an einem Vibratom (Leica VT1000s) in eisgekühltem 1x PBS-Puffer geschnitten. Die $60 \mu \mathrm{m}$ dicken Schnitte wurden in 24iger Lochplatten überführt, die ebenfalls mit eisgekühltem 1x PBS-Puffer befüllt waren. Für immunhistochemische Analysen wurden die Schnitte bei $4^{\circ} \mathrm{C}$ für maximal 1 Woche in 1x PBS-Puffer gelagert.

\subsubsection{Herstellung von Kryostatschnitten}

Die auf $-80{ }^{\circ} \mathrm{C}$ gelagerten Zerebelli wurden vor dem Schneiden $1 \mathrm{~h}$ lang in der Schneidekammer des Kryostaten (Leica) gelagert, um deren Temperatur der Kammertemperatur von $-20{ }^{\circ} \mathrm{C}$ anzupassen. Für In-Situ Hybridisierungen wurden $14 \mu \mathrm{m}$ dicke Schnitte angefertigt und direkt mit einem auf Raumtemperatur erwärmten Objektträger aufgenommen. Für Golgi-Silberimprägnierungen wurden $50 \mu \mathrm{m}$ dicke Schnitte angefertigt und mittels eines Pinsels in eine mit Reinstwasser gefüllte Sammel-Schale überführt. Hier konnten die frei schwimmenden Schnitte auf Adhäsions-Objektträger (Histobond) aufgezogen werden.

\subsubsection{Semidünn- und Ultradünnschnitte für die Elektronenmikroskopie}

Die mittels Karlsson \& Schulz Fixationslösung fixierten Zerebelli wurde präpariert und in mehrere sagittale Scheiben zertrennt, die dann in 1 x PBS-Puffer gespült wurden. Nach Überführung dieser Scheiben in die Kunststofförbchen des Gewebe-Infiltrationsautomaten "Lynxel" (Visions BioSystems Inc.), erfolgte die Einbettung in Epon nach folgendem Einbettschema:

\section{Reagenz}

Sörensen-Puffer

2\% OsO4 in Puffer (s.o.)

A. dest.

A. dest.

A. dest.

$30 \%$ Ethanol

$50 \%$ Ethanol

$70 \%$ Ethanol

$90 \%$ Ethanol

$100 \%$ Ethanol

$100 \%$ Ethanol
Dauer

$15 \mathrm{~min}$

$4 \mathrm{~h}$

$20 \mathrm{~min}$

$20 \mathrm{~min}$

$20 \mathrm{~min}$

$30 \mathrm{~min}$

$30 \mathrm{~min}$

$30 \mathrm{~min}$

$30 \mathrm{~min}$

$15 \mathrm{~min}$

$15 \mathrm{~min}$

\section{Temperatur}

$4{ }^{\circ} \mathrm{C}$

$4{ }^{\circ} \mathrm{C}$

RT

RT

RT

RT

RT

RT

RT

RT

RT 
$100 \%$ Ethanol

$100 \%$ Ethanol

Propylenoxid

Propylenoxid

Propylenoxid

Propylenoxid/ Epon 2 : 1

Propylenoxid/ Epon 1 : 1

Propylenoxid/ Epon 1 : 2

Epon rein
15 min

RT

$15 \mathrm{~min}$

RT

$15 \mathrm{~min}$

RT

$15 \mathrm{~min}$

RT

$15 \mathrm{~min}$

RT

$2 \mathrm{~h}$

RT

$2 \mathrm{~h}$

RT

$4 \mathrm{~h}$

RT

$4 \mathrm{~h}$

RT

Die so infiltrierten Proben wurden auf je einen Tropfen Epon gelegt, über die dann eine mit Epon gefüllte Gelatine-Kapsel-Hälfte gestülpt wurde. Die so vorbereiteten Proben wurden über einen Zeitraum von $24 \mathrm{~h}$ bei $60{ }^{\circ} \mathrm{C}$ polymerisiert. Die Gelatine-Kapseln wurden durch Erhitzen in einem Wasserbad gelöst. Die gehärteten Eponblöcke wurden mit einer Fräse (Reichert) getrimmt, sodass hiernach zunächst Semidünnschnitte $(0,5 \mu \mathrm{m})$ und nach einem weiteren Trimmvorgang, Ultradünnschnitte $(50 \mathrm{~nm})$ mit Hilfe eines Ultramikrotoms (Leica) angefertigt werden konnten.

\subsubsection{Immunhistochemische Analyse auf Paraffinschnitten}

\subsubsection{HE-Immunhistochemie}

Für die Hämatoxylin/Eosin-IHC (Hämalaun/Eosin) wurden Paraffinschnitte zunächst entparaffiniert, indem sie für $2 \times 10$ min in Xylol und je $2 \times 2$ min in $100 \%, 96 \%$ und $70 \%$ EtOH inkubiert wurden. Anschließend wurden die Schnitte zweimal mit $\mathrm{H}_{2} \mathrm{O}$ gespült und für 10min in saurem Hämalaun gefärbt. Die Entfärbung erfolgte in $\mathrm{H}_{2} \mathrm{O}$ und $\mathrm{HCl} / \mathrm{EtOH}$. Zur Bläuung wurden die Schnitte 10 min lang in Scotts-Lösung getaucht. Zur anschließenden Rotfärbung wurden die Schnitte $5 \mathrm{~min}$ in alkalisches Eosin überführt. Zuletzt wurden die Paraffinschnitte in $\mathrm{H}_{2} \mathrm{O}$ gespült und $1 \mathrm{~min}$ in $50 \%, 1 \mathrm{~min}$ in $70 \%, 2 \times 1 \mathrm{~min}$ in $80 \%$ und $2 \mathrm{x}$ $5 \mathrm{~min}$ in $100 \% \mathrm{EtOH}$ dehydriert. Um die Schnitte einzudecken, wurden sie für 3 x 5 min in Xylol inkubiert und mit Eukitt eingedeckt. Hämalaun ist ein pH-veränderter Hämatoxylin Farbstoff. Dieser ist acidophil und färbt das Chromatin der Zellkerne blau, während Eosin das Zytoplasma und den Golgikomplex rot anfärbt.

\subsubsection{Fluoreszente Immunhistochemie auf Paraffinschnitten}

Die $5 \mu \mathrm{m}$ dicken Paraffinschnitte wurden zunächst über eine absteigende Alkoholreihe entparaffiniert. Die Schnitte wurden dann $5 \mathrm{~min}$ in Citratpuffer inkubiert und anschließend $3 \mathrm{x}$ 
5min in Citratpuffer gekocht (Mikrowelle; 650W). Nach dem Abkühlen wurden die Schnitte 5 min in Tris-Puffer mit $2 \%$ Milchpulver gespült und mit einem PAP-Pen ${ }^{\circledR}$ (Dako Cytomation) umrandet. Um unspezifische Hintergrundfärbung zu minimieren, wurden die Schnitte nun bei RT in 1 : 5 verdünntem, inaktivierten Ziegenserum (200 $\mu$ l Ziegenserum + $800 \mu \mathrm{l}$ PBS/BSA) inkubiert. Nach etwa 10 min wurde das Ziegenserum abgegossen und der in PBS/BSA verdünnte primäre Antikörper für 12 Stunden bei $4{ }^{\circ} \mathrm{C}$ appliziert. Nach dieser Inkubation wurden die Schnitte dreimal für je 5 min mit Tris-Puffer $(+2 \%$ Milchpuffer $)$ gespült. Danach wurde der Sekundärantikörper für eine Stunde bei Raumtemperatur auf die Schnitte gegeben. Es folgten wieder drei Waschschritte in Tris-Puffer mit $2 \%$ Milchpulver und die Applikation von DAPI-Lösung $(0,5 \mu \mathrm{g} / \mathrm{ml})$ zur Darstellung der Kerne. Nach erneutem Waschen mit Tris-Puffer wurden die Schnitte mit Immo-Mount (Shandon) eingedeckt.

\subsubsection{Immunhistochemische Analyse auf Vibratomschnitten}

$50 \mu \mathrm{m}$ dicke Vibratomschnitte wurden zunächst bei RT für 30 min in $0.4 \%$ Triton- X100/PBS $(500 \mu \mathrm{l} / \mathrm{Schnitt})$ permeabilisiert, anschließend $30 \mathrm{~min}$ in $0.4 \% \mathrm{HS}, 0.2 \%$ Triton- X100/PBS $(500 \mu 1 / \mathrm{Schnitt})$ blockiert und über Nacht bei $4{ }^{\circ} \mathrm{C}$ mit in $1 \%$ Pferdeserum, $0.05 \%$ TritonX100/PBS verdünnten Antikörpern inkubiert (300 - $500 \mu \mathrm{l} / \mathrm{Schnitt).} \mathrm{Nachdem} \mathrm{die} \mathrm{Schnitte}$ zweimal $15 \mathrm{~min}$ in PBS gewaschen wurden, erfolgte die Inkubation mit einem speziesspezifischen Sekundärantikörper für $2 \mathrm{~h}$ bei RT, im Dunkeln. Zur Darstellung der Kerne wurde nach Ablauf der Inkubationszeit für 5 min eine DAPI-Lösung $(0,5 \mu \mathrm{g} / \mathrm{ml}$ in 1,5 \% HS/PBS) auf die Schnitte. Danach wurden diese zweimal 15 min in PBS gewaschen und in ein Wasserbad überführt, um sie auf einen Objektträger aufzuziehen und in Aqua Poly Mount ${ }^{\circledR}$ einzudecken.

\subsubsection{Methylen-Azur II-Färbung (Richardson, 1969) von Semidünnschnitten}

Semidünnschnitte wurden mit einer Methylenblau- und Azur II-Lösung (1:1) gefärbt, die für 1 - 2 min auf die Schnitte gegeben und danach mit destilliertem Wasser abgespült wurde. Danach wurden die Schnitte mit Hilfe einer $60{ }^{\circ} \mathrm{C}$ warmen Heizplatte getrocknet und mit Eukitt $^{\circledR}$ eingedeckt.

Die so gefärbten Semidünnschnitte dienten als Orientierungshilfe, um die Eponblöcke auf die gewünschten Regionen zur weiteren Herstellung von Ultradünnschnitten trimmen zu können.

\subsubsection{Kontrastierung von Ultradünnschnitten}

Die 50nm dicken Ultradünnschnitte befanden sich auf mit Formvar ${ }^{\circledR}$ befilmten Grids und 
wurden zur Kontrastierung unter Lichtausschluss für 35 - 38 min auf einen Tropfen 4 \%ige Uranylacetatlösung gegeben, danach in aqua bidest gespült und anschließend für weitere 15 18 min auf einen Tropfen Bleicitrat überführt. Nach der Durchführung weiterer Waschschritte mit aqua bidest wurden die Grids mit den darauf befindlichen Ultradünnschnitten getrocknet konnten in das Elektronenmikroskop EM109 (Zeiss) geschleust und aufgenommen werden.

\subsubsection{Golgi-Färbung}

Zur Anfärbung zerebellärer Körnerzellen sowie Korb- und Sternzellen wurde das „FD Rapid GolgiStain ${ }^{\mathrm{TM}} \mathrm{Kit}^{\text {“ }}$ der Firma FD NeuroTechnologies verwendet. Es wurde nach HerstellerAngaben verwendet bis auf folgende Abweichungen: Anstatt, wie im Handbuch beschrieben, die Kryostatschnitte der imprägnierten Zerebelli auf Adhäsions-Objektträger zu überführen und in einem Exikator über Nacht zu trocknen, wurden die Schnitte in eine mit Wasser befüllte Petri-Schale überführt. Alle weiteren Färbe- und Entwässerungsschritte erfolgten, wie im Handbuch vermerkt, jedoch schwammen die Schnitte dabei frei in den jeweiligen Lösungen (free floating-Methode), statt schon auf Objektträgern fixiert $\mathrm{zu}$ sein. Die Einbettung der Schnitte erfolgte mit Eukitt ${ }^{\circledR}$.

\subsubsection{TUNEL-Färbung}

Die Darstellung von Apoptose auf Paraffinschnitte erfolgte mit dem DeadEndTM Colometric TUNEL System (Promega) nach den Angaben des Herstellers.

\subsubsection{Morphometrische Analysen}

Die zerebelläre Größe, Zell- und Synapsendichte wurden auf jeweils 2 bis 5 zerebellären Sagittalschnitten von je 3 Tieren pro Genotyp mit Hilfe des Programmes ImageJ durchgeführt. Die Dichte der Molekularschicht- und Körnerzellschichtinterneurone sowie die Purkinje-Zellanzahl wurden immer in Lobulus 5 des Zerebellums bestimmt.

Zur Bestimmung der Körnerzelldichte wurden $0,024 \mathrm{~mm}^{2}$ große, Methylenblau-gefärbte Bereiche der Körnerzellschicht ausgezählt. Die Dichte der Parallelfasersynapsen wurde auf 50nm dicken Ultradünnschnitten in einem $100 \mu \mathrm{m}^{2}$ großen Bereich der Molekularschicht ermittelt.

Individuelle Korbzellen wurden in $50 \mu \mathrm{m}$ dicken Vibratomschnitten von je 2 Kontrollen und 3 Mutanten (10 Schnitte/Tier) mit Hilfe eines Konfokalmikroskops (Zeiss LSM510) visualisiert. Um einen großen Teil der Dendriten identifizierter Korbzellen aufzunehmen, wurden $165 \mu \mathrm{m}$ x $165 \mu \mathrm{m}$ breite und $12 \mu \mathrm{m}$ tiefe konfokale Bilderstapel (z-stacks) in der translobularen Ebene angefertigt (insgesamt 40 Bilder pro Stapel). Diese Bilderstapel wurden 
in das Programm Neuromantic V.1.6.3 (Darren R. Myatt) eingespeist und dienten hier der dreidimensionalen Rekonstruktion von Korbzelldendriten- und Axonen.

\section{2 mRNA-Detektion mittels In-Situ Hybridisierung}

In-situ Hybridisierungen (ISH) wurden mit nicht-radioaktiv markierten RNA Sonden auf 14 $\mu \mathrm{m}$ Kryostatschnitten (s. 5.1.4) unter RNAse freien Bedingungen durchgeführt.

\subsubsection{Sondenherstellung}

Die Sequenz der ISH-Sonden ist exakt komplementär zu den zu detektierenden mRNAs. Die Synthese der ISH-Sonden erfolgte durch RNA-Polymerasen, welche an zwei verschiedene, die DNA-Matrize flankierende RNA-Polymerase-Promotoren binden.

\subsubsection{Restriktionsverdau zur Linearisierung der Plasmide}

Pro Plasmid wurden 5 - $10 \mu \mathrm{g}$ mit $20 \mathrm{U}$ des entsprechenden Enzyms in einem $100 \mu \mathrm{l}$ Ansatz für $2 \mathrm{~h}$ verdaut. Anschließend wurde die linearisierte DNA mittels Gelelektrophorese aufgetrennt und aufgereinigt.

\subsubsection{In vitro Transkription zur Sondenmarkierung}

Um die RNA-Sonden zu markieren wurde bei der Synthese ein Nukleotid-Mix verwendet, der an UTP gekoppeltes Digoxigenin enthielt. Die Standardreaktionen fanden in einem Volumen von $20 \mu \mathrm{l}$ statt in folgenden Reaktionsansatz statt:

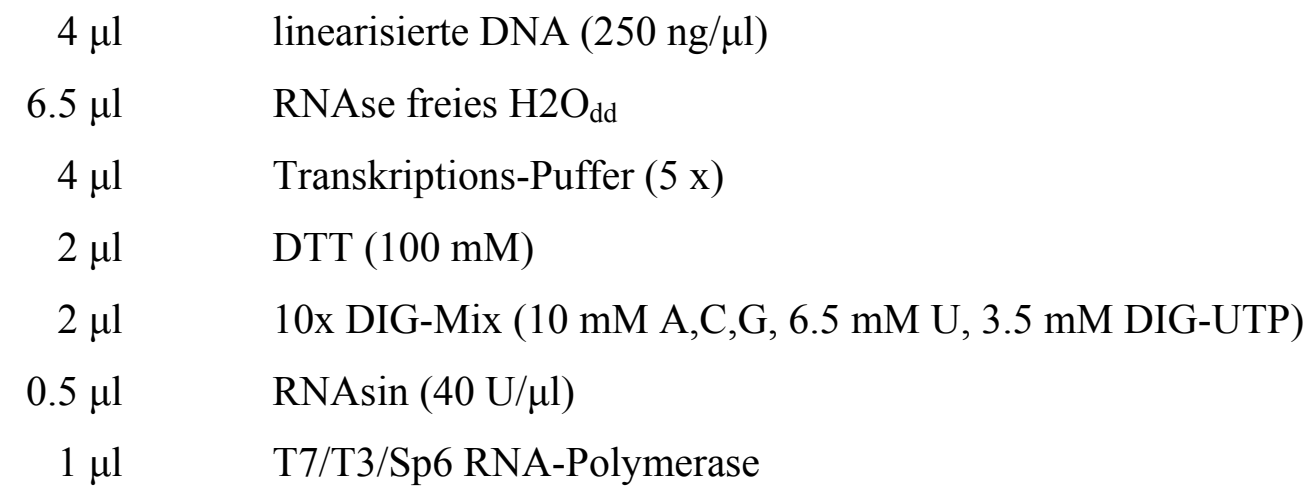

Nach einer Inkubationszeit von $2 \mathrm{~h}$ bei $37^{\circ} \mathrm{C}$ wurde die Reaktion durch die Zugabe von $2 \mu 1$ RQ1-DNAse abgestoppt und für weitere $15 \mathrm{~min}$ bei $37{ }^{\circ} \mathrm{C}$ inkubiert. Zur Inhibierung der DNAse wurde $1 \mu \mathrm{l} \quad 0.5 \mathrm{M}$ EDTA pH 8 zugegeben. Anschließend wurde $1 \mu \mathrm{l}$ des Reaktionsansatzes mit $2 \mu \mathrm{l}$ RNA-Probenpuffer und $12 \mu \mathrm{l}$ RNAse-freiem $\mathrm{H}_{2} \mathrm{O}_{\text {dd }}$ versetzt und die RNA durch eine Inkubation von 1 min bei $95{ }^{\circ} \mathrm{C}$ denaturiert. Die Abkühlung des Reaktionsanstzes erfolgte auf Eis und die weitere Analyse der RNA-Sonde wurde auf einem $1,5 \%$ Agarosegel durchgeführt. 


\subsubsection{Hydrolyse der cRNA}

Zur Verkürzung einiger Sonden auf 200 bp wurde eine alkalische Hydrolyse durchgeführt. Dafür wurde der in vitro Transkriptions-Ansatz auf Eis mit $73 \mu \mathrm{H}_{2} \mathrm{O}_{\mathrm{dd}}$ aufgefüllt und $5 \mu \mathrm{l} 2$ $\mathrm{M} \mathrm{NaOH}$ (f.c. 0,1 M NaOH) zugegeben. Mit Hilfe folgender Formel wurde die Dauer der alkalischen Hydrolyse bestimmt:

$\mathrm{t}[\mathrm{min}]=\mathrm{LS}-\mathrm{LE} / \mathrm{K} \times \mathrm{LS} \times \mathrm{LE}$

mit $\quad \mathrm{K}=0.1101 \mathrm{~kb} / \mathrm{min}$

$\mathrm{LS}=$ Anfangslänge in $\mathrm{kb}$

$\mathrm{LE}=$ Endlänge in $\mathrm{kb}$ (normalerweise $0,2 \mathrm{~kb}$ )

Durch die Zugabe von $5 \mu 12 \mathrm{M} \mathrm{HCl}$ wurde die Reaktion abgestoppt und neutralisiert.

\subsubsection{Aufreinigung der RNA-Sonden}

Nach der in vitro Transkription bzw. der Hydrolyse wurden die RNA-Sonden aufgereinigt und von nicht eingebauten Nukleotiden getrennt. Dafür wurden zwei verschiedene Methoden angewendet. Bei der ersten erfolgte die Aufreinigung mittels Gelfiltration. Die Sonden wurden mit Bio-Gel P30 Säulen (BioRad) nach Herstellerangabe von allen Nukleotiden bis zu 30 Basen getrennt. Das Volumen nicht hydrolysierter Sonden wurde dafür mit RNAse freiem $\mathrm{H}_{2} \mathrm{O}_{\mathrm{dd}}$ auf $50 \mu \mathrm{l}$ aufgefüllt. Bei der zweiten Methode erfolgte die Aufreinigung mittels Ethanolfällung. Hierfür wurde der Reaktionsansatz der in vitro Transkription mit RNAse freiem $\mathrm{H}_{2} \mathrm{O}_{\mathrm{dd}}$ auf $100 \mu \mathrm{l}$ aufgefüllt und $10 \mu \mathrm{l} 3 \mathrm{M}$ Natriumacetat (pH 5.2) sowie $1 \mu \mathrm{l}$ Pellet Paint zugegeben und gemischt. Danach wurde $330 \mu \mathrm{l} 100 \%$ EtOH zugegeben, erneut gemischt und der Ansatz anschließend bei $-20{ }^{\circ} \mathrm{C}$ für $1-2 \mathrm{~h}$ inkubiert. Nach Zentrifugation bei $13.000 \mathrm{U} / \mathrm{min}$ für $20 \mathrm{~min}$ wurde das RNA-Pellet mit $80 \% \mathrm{EtOH}$ gewaschen und nach dem Lufttrocknen in $50 \mu \mathrm{l}$ RNAse freiem $\mathrm{H}_{2} \mathrm{O}_{\mathrm{dd}}$ resuspendiert. Die Lagerung der Sonden erfolgte verdünnt in Hybridisierungspuffer $(1: 20)$ bei $-20^{\circ} \mathrm{C}$.

\subsubsection{Chromogene in-situ Hybridisierung (CISH)}

Zur Durchführung der CISH wurden RNAse freie Lösungen und RNAse freie, verschließbare Glasküvetten verwendet. Die Kryostatschnitte wurden $20 \mathrm{~min}$ bei RT aufgetaut, $5 \mathrm{~min}$ in PBS gewaschen und anschließend acetyliert. Dazu wurde $5 \mathrm{~min}$ in $0.1 \mathrm{M}$ Triethanolamin, dann 10 min in frisch angesetzter Acetylierungslösung $(200 \mathrm{ml} 0.1 \mathrm{M}$ Triethanolamin, $500 \mu \mathrm{l}$ Essigsäureanhydrid) inkubiert und schließlich dreimal $5 \mathrm{~min}$ in PBS gewaschen. Die

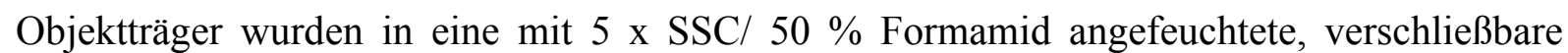


Kammer gelegt. Zum Blockieren unspezifischer Bindungsstellen wurde mit $300 \mu 1$ Hybridisierungspuffer $1-2 \mathrm{~h}$ bei RT prähybridisiert. Nach Entfernen des Hybridisierungspuffers wurde 100 - $200 \mu \mathrm{l}$ der in Hybridisierungspuffer verdünnten Sonden (ca. 100 ng cRNA) auf die Schnitte gegeben. Die Objektträger wurden mit Parafilm abgedeckt und zur Hybridisierung über Nacht bei $65{ }^{\circ} \mathrm{C}$ in der angefeuchteten Kammer inkubiert. Anschließend wurden die Schnitte in Glasküvetten bei RT zweimal für 10 min in 2x SSC, zweimal für 10 min bei $68^{\circ} \mathrm{C}$ in vorgewärmten $0,2 \times$ SSC und dann bei RT 5 min in 0,2 x SSC gewaschen, um nicht gebundene RNA-Sonden zu entfernen. Die Schnitte wurden 5 min in Maleinsäurepuffer äquilibriert und 1 bei RT in Maleinsäurepuffer mit 1\% Milchpulver geblockt. Die Antikörperinkubation zur Detektion der markierten RNA:RNA-Hybride erfolgte erneut in einer angefeuchten Kammer. Der AP-gekoppelte anti-dig Antikörper wurde 1 : 2000 in Maleinsäurepuffer inkl. 1\% Milchpulver verdünnt und für eine Stunde bei RT inkubiert. Anschließend wurde zweimal $30 \mathrm{~min}$ in Maleinsäure Puffer gewaschen und 5 min im Färbepuffer äquilibriert. Die Schnitte wurden in frisch angesetzter Färbelösung (60 ml Färbepuffer, $270 \mu 1$ NBT-Stammlösung, $210 \mu 1$ BCIP-Stammlösung) in einer Standküvette im Dunkeln inkubiert bis die gewünschte Signalstärke erreicht war (2 - 24 h). Die Reaktion wurde mittels TE abgestoppt, die Schnitte mit Kaisers Glyceringelatine eingedeckt und bei 4 ${ }^{\circ} \mathrm{C}$ im Dunkeln gelagert.

\subsection{Molekularbiologische Methoden}

\subsubsection{Präparation von genomischer DNA aus Mausschwanzgeweben}

Genomische DNA (bis $50 \mu \mathrm{g}$ ) für Routine-PCR-Analysen wurde aus Schwanzbiopsiematerial (ca. 0,5 cm) mit der Reaktionskomplettausstattung Invisorb ${ }^{\circledR}$ Spin Tissue Mini Kit (256) (Invitek) nach Herstellerangaben gewonnen. Die Lagerung der genomischen DNA erfolgte bei $4{ }^{\circ} \mathrm{C}$. Für PCR-Analysen wurden 1 - $5 \mu \mathrm{l}$ (aus $200 \mu \mathrm{l}$ Gesamteluat) eingesetzt.

\subsubsection{Präparation von Gesamt-RNA aus dem Zerebellum der Maus}

Zur Präparation zerebellärer Gesamt-RNA wurde die Reaktionskomplettausstattung „RNeasy ${ }^{\mathrm{TM}}$ Total Miniprep-Kit“ (Qiagen) benutzt. Die Zerebelli wurden mit Hilfe eines Ultraturrax in QIAzol Lyse-Puffer (Qiagen) homogenisiert. Die weiteren Präparationsschritte erfolgten nach Herstellerangaben. Die gewonnene RNA-Lösung wurden sofort in flüssigem Stickstoff schock gefroren und bei $-80^{\circ} \mathrm{C}$ gelagert. 


\title{
5.3.3 Konzentrationsbestimmung von Nukleinsäuren mittels Photometer
}

DNA -bzw. RNA-Konzentrationen wurden mit Hilfe eines Spektralphotometers durch Messung der optischen Dichte bestimmt. Nach Verdünnung der Lösung (1 : 100) wurde die Absorption der Lösung bei $260 \mathrm{~nm}$ in einer Quarzküvette bestimmt. Für dsDNA entspricht eine $\mathrm{OD}_{260}=1$ einer Konzentration von $50 \mu \mathrm{g} / \mathrm{ml}$; für RNA-Lösungen und ssDNA $40 \mu \mathrm{g} / \mathrm{ml}$. Durch Messung der Absorption bei $280 \mathrm{~nm}$ konnte der Verunreinigungsgrad der Lösung bestimmt werden, wobei ein Wert von 1,5-2,0 für das Verhältnis $\mathrm{OD}_{260: 280}$ eine wenig verunreinigte Lösung anzeigt. Desweiteren wurden RNA-Konzentrationen mit Hilfe eines elektrophoretisch arbeitenden Agilent-Bioanalyzers 2100 nach Hersteller-Angaben spezifiziert.

\subsubsection{Die Polymerase-Kettenreaktion}

Für die Polymerasekettenreaktion wurde eine Reaktionskomplettausstattung von Sigma (RedTaq) verwendet. Das Reaktionsprinzip basiert auf zwei spezifischen Oligonukleotiden, sogenannten Primern, die an komplementäre Bereiche denaturierter DNA binden. Die hitzestabile DNA-Polymerase aus dem Bakterium Thermus aquaticus (Taq-Polymerase) verdoppelt anschließend die molare Menge der eingesetzten Matrizen-DNA in jedem Zyklus. Standardansätze für die Genotypisierung von Mäusen hatten ein Reaktionsvolumen von $20 \mu 1$.

$\begin{array}{lr}\text { Standardreaktion: } & \\ \text { Matrizen-DNA } & 1,0 \mu \mathrm{l} \\ \text { 10 x PCR-Puffer } & 2,0 \mu \mathrm{l} \\ \text { dNTPs (je Nukleotid 2,5 mM) } & 2,0 \mu \mathrm{l} \\ \text { 5'-Primer }\left(10 \times 10^{6} \mathrm{M}\right) & 0,5 \mu \mathrm{l} \\ \text { 3'-Primer }\left(10 \times 10^{6} \mathrm{M}\right) & 0,5 \mu \mathrm{l} \\ \text { RedTaq-Polymerase } & 1,0 \mu \mathrm{l} \\ \mathrm{H}_{2} \mathrm{O}_{\mathrm{dd}} & 13 \mu \mathrm{l}\end{array}$

Das Standard-Amplifikationsprotokoll enthielt 36 Zyklen:

\author{
3 min $95^{\circ} \mathrm{C}$ Denaturierung \\ 30 sek $56{ }^{\circ} \mathrm{C}$ Anlagerung der Primer (Zyklus) \\ 90 sek $72^{\circ} \mathrm{C}$ Extension (Zyklus) \\ 60 sek $95^{\circ} \mathrm{C}$ Denaturierung (Zyklus) \\ 60 sek $56^{\circ} \mathrm{C}$ Schlussanlagerung
}


10 min $72{ }^{\circ} \mathrm{C}$ Schluss-Extension

Dieses Standard PCR-Protokoll wurde durch Modifikation der Anlagerungs-Temperaturen und Dauer der einzelnen Zyklusphasen für die jeweils verwendeten Primer optimiert.

Aufgrund der Unzugänglichkeit des genomischen NDRF Locus wurde für die Polymerasekettenreaktion nicht das Standardprotokoll sondern folgende Modifikation verwendet. Der entsprechende Reaktionspuffer (Soriano) ist unter 4.5.4 beschrieben.

$\underline{\text { Reaktionsansatz: }}$

Substanz

DNA, ca. $200 \mathrm{ng} / \mu \mathrm{g}$

Primer: NDRFsense, $50 \mathrm{pmol} / \mu \mathrm{l}$

Primer: revNEOsense, $50 \mathrm{pmol} / \mu \mathrm{l}$

Primer: NDRFantisense, $50 \mathrm{pmol} / \mu 1$

dNTP, 10 mmol ges.

DMSO

BSA, $10 \mathrm{mg} / \mathrm{ml}$

Soriano PCR Puffer, 5x

Taq Polymerase, $1 \mathrm{U} / \mu \mathrm{l}$

$\mathrm{H}_{2} \mathrm{O}_{\mathrm{dd}}$
Menge

$2,0 \mu \mathrm{l}$

$0,1 \mu \mathrm{l}$

$0,1 \mu \mathrm{l}$

$0,1 \mu 1$

$1,0 \mu 1$

$2,5 \mu 1$

$0,2 \mu 1$

$5,0 \mu \mathrm{l}$

$0,1 \mu \mathrm{l}$

$8,9 \mu 1$

\subsubsection{Agarose-Gelelektrophorese von DNA}

Zur Auftrennung von DNA-Fragmenten zwischen 0,5 und 2 kb Größe wurden 1,5-2\%-ige Agarosegele verwendet. Hierzu wurde die Agarose in 1x TAE-Puffer aufgekocht, gelöst und nach Zusatz von Ethidiumbromid (f.c. $1 \mu \mathrm{g} / \mathrm{ml}$ ) in eine Gelform gegossen. Verschiedene Kunststoffkämme sorgten für die Aussparung der Geltaschen bei Erstarrung der Agarose. Das ausgehärtete Gel wurde in eine Flachgelkammer gelegt und mit 1x TAE-Laufpuffer bedeckt. In Abhängigkeit von der Größe der Gelkammer und der Agarosekonzentration betrug die angelegte Spannung zwischen 70 und $180 \mathrm{~V}$ (5 - $10 \mathrm{~V} / \mathrm{cm})$. Durch die Interkalation des Ethidiumbromids in die DNA konnte diese nach erfolgter Elektrophorese auf einem UVIlluminator visualisiert und fotografiert werden. Als Größenmarker diente 0,5 $\mu \mathrm{g}$ GeneRuler $1 \mathrm{~kb}$ DNA Ladder (Fermentas).

\subsubsection{Denaturierende Formaldehyd-Agarose-Gelelektrophorese von RNA}

RNA wurde in formaldehydhaltigen, $1 \%$ igen Agarosegelen aufgetrennt. Dazu wurde $1 \mathrm{~g}$ Agarose in 82,5 $\mathrm{ml} \mathrm{1x} \mathrm{RB}$ aufgekocht und nach Abkühlen 17,5 ml $37 \%$ (12,3 M) 
Formaldehyd zugegeben (f.c. 2,2 M). RNA-Proben (3 - $10 \mu \mathrm{g}$ ) wurden mit 1 Vol. RNALadepuffer $(2 \mathrm{x})$ versetzt, für $5 \mathrm{~min}$ bei $65^{\circ} \mathrm{C}$ denaturiert und auf das Gel geladen. Die Elektrophorese erfolgte bei $120 \mathrm{~V}$ für 2 - 3 h in 1 x RB (+ Formaldehyd, f.c. 2,2 M).

\subsubsection{Northern-Blot-Analyse}

Nach Auftrennung der zerebellären Gesamt-RNA über ein 1\%iges Formaldehyd-Agarosegel erfolgte der Transfer auf eine Nylonmembran (Hybond ${ }^{\mathrm{TM}}-\mathrm{N}$ ) nach Herstellerangaben und nach Standardverfahren. Vor dem Transfer wurde zur Größenbestimmung ein fluoreszierendes Lineal zusammen mit dem Gel fotografiert. Die RNA wurde durch UVBestrahlung (120 mJ) kovalent an die Membran gebunden. Die Membran wurde für 10 min in einer Methylenblaulösung geschwenkt, um ribosomale RNA anzufärben und den Transfer zu kontrollieren. Vorhybridisierung $\left(20 \mathrm{~min}\right.$ bei $42{ }^{\circ} \mathrm{C}$ ) und Hybridisierung (über Nacht bei $42^{\circ} \mathrm{C}$ ) erfolgten in $10 \mathrm{ml}$ Hybridisierungspuffer in einer Hybridisierungsröhre (Biometra). Die Hybridisierung erfolgte durch Zugabe von $10^{6} \mathrm{cpm} / \mathrm{ml}$ einer durch "random prime labeling" radioaktiv markierten DNA-Sonde. Die Membran wurde mit aufsteigender Stringenz in 10 min-Intervallen gewaschen $\left(60-70^{\circ} \mathrm{C} ; 2 \times \mathrm{SSC} / 0,5 \% \mathrm{SDS}\right.$ bis $\left.0.1 \times \mathrm{SSC} / 0,1 \% \mathrm{SDS}\right)$ und anschließend für $1-3 \mathrm{~h}$ auf eine "Phosphoimager"-Platte gelegt. Hybridisierungssignale wurden mit einem "Phosphoimager" aufgenommen, mit dem Programm „McBas2.0“ bearbeitet und quantifiziert. Die Exposition auf Röntgenfilm erfolgte mit einer Verstärkerfolie bei $-80{ }^{\circ} \mathrm{C}$ für $6-72 \mathrm{~h}$.

\subsubsection{Radioaktive Markierung von DNA-Fragmenten}

Die radioaktive Markierung von DNA-Fragmenten mit $\alpha\left[{ }^{32} \mathrm{P}\right]$-dCTP erfolgte mittels der Reaktionskomplettausstattung "Prime-It-II ${ }^{\circledR}$ "-Kit (Stratagene) nach Angaben des Herstellers. 25 ng eines Gel-aufgereinigten DNA-Fragments wurden hierfür eingesetzt. Nicht eingebaute Nukleotide wurden nach der Reaktion über eine chromatographische Gelfiltration mit Hilfe von „Bio-Spin 30“ (Biorad) Säulen abgetrennt. Die spezifischen Aktivität wurde von $1 \mu 1$ des Ansatzes im Szintillator bestimmt. Vor der Hybridisierung wurde die DNA-Sonde durch Aufkochen für 10 min denaturiert.

\subsection{Eletrophysiologische Methoden}

\subsubsection{Gewebepräparation}

Es wurden sagittale oder parasagittale zerebelläre Schnitte von NDRF-Nullmutanten oder heterozygoten Kontrollen zwischen P 15 und P 19 angefertigt. Der Kopf der Tiere wurde entfernt, das Zerebellum wurde zügig heraus präpariert, in die mit Eisgekühlter 
Schneidelösung (siehe 4.5.6) gefüllte Wanne eines Vibratoms geklebt und mit einem 4\%igen Agarblock gestützt. $300 \mu \mathrm{m}$ dicke zerebelläre Schnitte wurden vor den elektrophysiologischen Aufnahmen für 30 Minuten in $37{ }^{\circ} \mathrm{C}$ warmer Schneidelösung inkubiert. Zur Detektion von Parallel- und Kletterfaser-EPSCs und Purkinje- und SternzellmIPSCs wurden die unter 4.5.6 aufgeführten Aufnahme- und Pipettenlösungen verwendet.

\subsubsection{Elektrophysiologische Messungen}

Es wurden Whole-cell-Aufnahmen von zuvor optisch identifiziert Zellen angefertigt. Dies geschah mittels eines Gradienten-Kontrast-Systems (Dodt et al., 2002) unter Verwendung eines inversen Mikroskops (Olympus BX51Wl) mit einem 60 x Wasser-Immersionsobjektiv. Purkinje-Zellen waren voltage-clamped (Spannungsklemmtechnik) bei - $60 \mathrm{mV}$. Pipetten wurden aus Blei enthaltenden Glaskapillaren gezogen und hatten einen Widerstand von 1,0 bis 1,5 M $\Omega$. Der Serienwiderstand (Rs) betrug stets weniger als $5 \mathrm{M} \Omega$ (meistens weniger als 3 $\mathrm{M} \Omega$ ) und wurde zu über $80 \%$ kompensiert. Serienwiderstände bei Sternzellaufnahmen betrugen unter $25 \mathrm{M} \Omega$ und wurden nicht kompensiert. Die Pipettenlösung zur Aufnahme von EPSCs und mIPSCs enthielten die unter 4.5.6 aufgeführten Substanzen. Kletter- und Parallelfasern wurden mit Glaskapillaren stimuliert, die mit extrazellulärer Lösung gefüllt waren (2-10 V, 20-200 $\mu \mathrm{s})$. EPSCs und mIPSCs wurden mittels eines Verstärkers (MultiClamp 700B; Axon Instruments) aufgenommen, bei 2 - $4 \mathrm{kHz}$ gefiltert und bei $20-50$ $\mathrm{kHz}$ digitalisiert. Alle Experimente wurden bei $30-33{ }^{\circ} \mathrm{C}$ durchgeführt.

\subsection{Verhaltenstests}

\subsubsection{Rotarod}

\subsubsection{Aufbau der Versuchsapparatur}

Zur Überprüfung des motorischen Lernvermögens der Versuchstiere wurde der konstant rotierende und beschleunigte Rotarod (Med Associates Inc.) verwendet. Das Gerät besteht aus einer waagerechten Lauftrommel, die durch Kunststoff-Scheiben in fünf $11 \mathrm{~cm}$ breite Abschnitte unterteilt ist. Unterhalb der Lauf-Kammern befanden sich Kunststoffplatten, die mit einer digitalen Stopp-Uhr in Verbindung standen. Sie wurden zu Beginn jedes Durchganges angehoben und die Stoppuhr dadurch in Gang gesetzt. Fiel eine Maus von der drehenden Laufstange, so wurde die Zeit durch die Bewegung der Kunststoffplatte gestoppt.

\subsubsection{Zeitliche Parameter und Intervalle}

Zur Überprüfung der motorischen Ausdauer der Tiere wurden je 4 Kontrollen, und 5 Mutanten bei 5 U/min getestet. Zur Überprüfung des motorischen Lernvermögens wurden am 
ersten Tag 32 Kontrollen, und 24 Mutanten dreimal hintereinander auf der beschleunigten Lauftrommel (3,3 - $12 \mathrm{U} / \mathrm{min})$ getestet (Habituation). Am darauf folgenden Tag wurden diese Tiere fünfmal hintereinander bei 4,1 - $41 \mathrm{U} / \mathrm{min}$ getestet (Herausforderung). Die Pausen zwischen den einzelnen Durchgängen betrugen jeweils 10 min.

\subsubsection{Bar-Test}

Um das grundsätzliche Balanciervermögen der Tiere $(\mathrm{n}=6$ Kontrollen und 8 Mutanten) $\mathrm{zu}$ überprüfen wurden diese dreimal hintereinander auf eine runde Stange (,bar $\left.{ }^{66}\right)$ mit 1,8 cm Durchmesser gesetzt und die Zeit gestoppt, bis sie herunter fielen. Die Maximalzeit, wurde auf eine Minute festgelegt und die Pausen zwischen den einzelnen Durchgängen betrugen jeweils $10 \mathrm{~min}$.

\subsubsection{Fehltritt-Test}

Um weitere koordinative Fähigkeiten der Mutanten $(n=8)$ und Kontrollen $(n=4) \mathrm{zu}$ bestimmen wurden diese dreimal hintereinander für drei Minuten auf ein erhöhtes 30 x $30 \mathrm{~cm}$ großes Gitter mit 1,5 cm Gitterlochgröße gesetzt und die Anzahl der Vorder- und Hinterpfotenfehltritte bestimmt, die die Tiere beim Explorieren der Plattform zeigten. Die Pausen zwischen den einzelnen Durchgängen betrugen jeweils 10 min.

\subsubsection{Statistische Analysen}

Statistische Unterschiede wurden mit Hilfe des ungepaarten zweiseitigen Student schen tTests ananlysiert und als signifikant betrachtet, sobald $\mathrm{p}$ kleiner 0,05 war. 


\section{Zusammenfassung}

Der zerebelläre Kortex besteht aus drei Hauptzelltypen, GABA-ergen Purkinje-Zellen (PZ), glutamatergen Körnerzellen (KZ) und verschiedenen Subtypen von zumeist GABA-ergen Interneuronen (IN), zu denen die Korb und Sternzellen der Molekularschicht sowie die Interneurone der Körnerzellschicht (KS-IN) gehören.

Eine zentrale Aufgabe bei der Erforschung neuronaler Entwicklung ist die Identifizierung von Mechanismen, die die Spezifikation, Migration und terminale Differenzierung verschiedener Neuronentypen koordinieren. Die große Zahl geeigneter, natürlich vorkommender Mausmutanten sowie die Vielzahl bekannter, spezifischer Marker hat $\mathrm{zu}$ einem breiten Verständnis der Entwicklung zerebellärer KZ und PZ geführt. Neben weiteren, sind basiche Helix-loop-HelixTranskriptionsfaktoren (bHLH-TF), wie MATH1 und NeuroD für die Generation und das Überleben von $\mathrm{KZ}$ von essenzieller Bedeutung, ohne dabei die Entwicklung von PZ oder IN zu beeinflussen.

Die Entwicklung und Funktion GABA-erger zerebellärer IN ist bisher wesentlich weniger erforscht. Die wenigen, bisher bekannten Mausmutanten mit Entwicklungsdefekten in zerebellären IN führten hauptsächlich zur Identifikation von Transkriptionsfaktoren (MASH1, PTF1a, NGN2), die eher für die Determinierung eines GABA-ergen Zellschicksals und während der Migration von IN eine Rolle spielen, als für spätere, spezifische Differenzierungsstadien.

Der bHLH-TF NDRF wird in postmitotischen Körner-, Stern- und Korbzellen exprimiert. Zur Analyse seiner Funktion für die Entwicklung des Zerebellums wurde NDRF mittels homologer Rekombination in embryonischen Stammzellen inaktiviert. Durch den Tod einiger KZ-Progenitoren, war die Dicke der zerebellären Körnerzellschicht in NDRF-Nullmutanten leicht reduziert. Trotzdem verlief die Entwicklung und Integration der KZ, die den Übergang vom späten Progenitorenstadium zur differenzierten KZ überlebten, in Abwesenheit von NDRF normal, was vermutlich mit einer kompensatorischen Funktion von NeuroD zu begründen ist.

Im Gegensatz dazu waren die inhibitorischen IN der zerebellären Molekularschicht schwer und konstant betroffen. Ihre Anzahl war auf 31,4 \% verglichen mit Kontrollen reduziert und die Expression interneuronaler Marker war verzögert (GAD1), bzw. fehlte nahezu komplett (Parvalbumin). Begleitet wurden diese Expressionsdefizite durch stark verlängerte Expression des frühen, unreifen Differenzierungsmarkers PAX2. Die dendritische Morphologie von Korb- und Sternzellen war während aller Entwicklungsphasen normal. Bezüglich der Axo- und Synaptogenese gab es aber große Unterschiede zwischen Korb- und Sternzellen.

Während die Verteilung funktionaler, GAD2-positiver Sternzellsynapsen auf Purkinje-Zellen in Mutanten an P 25 normal war, waren Korbzellaxone deformiert und desorientiert und PinceauSynapsen fehlten gänzlich. An P 75 lagen die Korbzellaxone immer noch deformiert in der Molekularschicht vor, ohne funktionale Synapsen mit PZ zu bilden.

Fehlende Inhibition von PZ durch Korbzellen in NDRF-Nullmutanten war von starken Defiziten im motorischen Lernen begleitet, ohne die grundlegenden motorischen Fähigkeiten der Tiere zu beeinflussen.

Zusammengefasst implizieren diese Resultate eine wichtige Rolle für NDRF in der terminalen Differenzierung zerebellärer Molekularschicht-IN, vor allem aber für Korbzellen, da hier der NDRF-Verlust zu schweren Defiziten in der Axo- und Synaptogenese führte. 


\section{Literaturverzeichnis}

Abremski K, Hoess R, Sternberg N (1983) Studies on the properties of P1 site-specific recombination: evidence for topologically unlinked products following recombination. Cell 32:1301-1311

Abremski K, Wierzbicki A, Frommer B, Hoess RH (1986) Bacteriophage P1 Cre-loxP sitespecific recombination. Site-specific DNA topoisomerase activity of the Cre recombination protein. J. Biol. Chem 261:391-396

Adler CE, Fetter RD, Bargmann CI (2006) UNC-6/Netrin induces neuronal asymmetry and defines the site of axon formation. Nat. Neurosci 9:511-518

Ahmad I (1995) Mash-1 is expressed during ROD photoreceptor differentiation and binds an E-box, E(opsin)-1 in the rat opsin gene. Brain Res. Dev. Brain Res 90:184-189

Airaksinen MS, Eilers J, Garaschuk O, Thoenen H, Konnerth A, Meyer M (1997) Ataxia and altered dendritic calcium signaling in mice carrying a targeted null mutation of the calbindin D28k gene. Proc. Natl. Acad. Sci. U.S.A 94:1488-1493

Aizawa H, Hu S, Bobb K, Balakrishnan K, Ince G, Gurevich I, Cowan M, Ghosh A (2004) Dendrite development regulated by CREST, a calcium-regulated transcriptional activator. Science 303:197-202

Akazawa C, Ishibashi M, Shimizu C, Nakanishi S, Kageyama R (1995) A mammalian helix-loop-helix factor structurally related to the product of Drosophila proneural gene atonal is a positive transcriptional regulator expressed in the developing nervous system. J. Biol. Chem 270:8730-8738

Alessi DR, James SR, Downes CP, Holmes AB, Gaffney PR, Reese CB, Cohen P (1997) Characterization of a 3-phosphoinositide-dependent protein kinase which phosphorylates and activates protein kinase Balpha. Curr. Biol 7:261-269

Al-Saktawi K, McLaughlin M, Klugmann M, Schneider A, Barrie JA, McCulloch MC, Montague P, Kirkham D, Nave K, Griffiths IR (2003) Genetic background determines phenotypic severity of the Plp rumpshaker mutation. J. Neurosci. Res 72:12-24

Altman J (1972) Postnatal development of the cerebellar cortex in the rat. II. Phases in the maturation of Purkinje cells and of the molecular layer. J. Comp. Neurol 145:399-463

Altman J, Bayer SA (1978) Prenatal development of the cerebellar system in the rat. I. Cytogenesis and histogenesis of the deep nuclei and the cortex of the cerebellum. J. Comp. Neurol 179:23-48

Altman J, Bayer SA (1985a) Embryonic development of the rat cerebellum. I. Delineation of the cerebellar primordium and early cell movements. J. Comp. Neurol 231:1-26

Altman J, Bayer SA (1985b) Embryonic development of the rat cerebellum. III. Regional differences in the time of origin, migration, and settling of Purkinje cells. J. Comp. Neurol 231:42-65 
Altman J, Bayer SA (1985c) Embryonic development of the rat cerebellum. III. Regional differences in the time of origin, migration, and settling of Purkinje cells. J. Comp. Neurol 231:42-65

Altman J (1972a) Postnatal development of the cerebellar cortex in the rat. II. Phases in the maturation of Purkinje cells and of the molecular layer. The Journal of Comparative Neurology 145:399-463

Altman J (1972b) Postnatal development of the cerebellar cortex in the rat. I. The external germinal layer and the transitional molecular layer. The Journal of Comparative Neurology 145:353-397

Altman, J. and Bayer, S. A. (1997). Development of the Cerebellar System: In Relation to its Evolution, Structure and Functions. New York: CRC press.

Ango F, di Cristo G, Higashiyama H, Bennett V, Wu P, Huang ZJ (2004a) Ankyrin-based subcellular gradient of neurofascin, an immunoglobulin family protein, directs GABAergic innervation at purkinje axon initial segment. Cell 119:257-272

Ango F, di Cristo G, Higashiyama H, Bennett V, Wu P, Huang Z (2004b) Ankyrin-Based Subcellular Gradient of Neurofascin, an Immunoglobulin Family Protein, Directs GABAergic Innervation at Purkinje Axon Initial Segment. Cell 119:257-272

Ango F, Wu C, Van der Want JJ, Wu P, Schachner M, Huang ZJ (2008a) Bergmann glia and the recognition molecule CHL1 organize GABAergic axons and direct innervation of Purkinje cell dendrites. PLoS Biol 6:e103

Ango F, Wu C, Van der Want JJ, Wu P, Schachner M, Huang ZJ (2008b) Bergmann Glia and the Recognition Molecule CHL1 Organize GABAergic Axons and Direct Innervation of Purkinje Cell Dendrites. PLoS Biol 6:e103

Arber S, Ladle DR, Lin JH, Frank E, Jessell TM (2000) ETS gene Er81 controls the formation of functional connections between group Ia sensory afferents and motor neurons. Cell 101:485-498

Arimura N, Kaibuchi K (2007) Neuronal polarity: from extracellular signals to intracellular mechanisms. Nat. Rev. Neurosci 8:194-205

Arimura N, Menager C, Fukata Y, Kaibuchi K (2004) Role of CRMP-2 in neuronal polarity. J. Neurobiol 58:34-47

Arlotta P, Molyneaux BJ, Chen J, Inoue J, Kominami R, Macklis JD (2005) Neuronal subtype-specific genes that control corticospinal motor neuron development in vivo. Neuron 45:207-221

Armengol JA, Sotelo C (1991) Early dendritic development of Purkinje cells in the rat cerebellum. A light and electron microscopic study using axonal tracing in 'in vitro' slices. Brain Res. Dev. Brain Res 64:95-114

Armstrong CL, Hawkes R (2000) Pattern formation in the cerebellar cortex. Biochem. Cell 


\section{Biol 78:551-562}

Armstrong CL, Krueger-Naug AM, Currie RW, Hawkes R (2001) Expression of heat-shock protein Hsp25 in mouse Purkinje cells during development reveals novel features of cerebellar compartmentation. J. Comp. Neurol 429:7-21

Arroyo EJ, Scherer SS (2000) On the molecular architecture of myelinated fibers. Histochemistry and Cell Biology 113:1-18

Atchley WR, Fitch WM (1997) A natural classification of the basic helix-loop-helix class of transcription factors. Proc. Natl. Acad. Sci. U.S.A 94:5172-5176

Ballabh P, Braun A, Nedergaard M (2004) The blood-brain barrier: an overview: structure, regulation, and clinical implications. Neurobiol. Dis 16:1-13

Bartholomä A, Nave KA (1994) NEX-1: a novel brain-specific helix-loop-helix protein with autoregulation and sustained expression in mature cortical neurons. Mech. Dev 48:217228

Basilico C, Moscatelli D (1992) The FGF family of growth factors and oncogenes. Adv. Cancer Res 59:115-165

Baumann N, Pham-Dinh D (2001) Biology of Oligodendrocyte and Myelin in the Mammalian Central Nervous System. Physiol. Rev. 81:871-927

Bellosta P, Costa M, Lin DA, Basilico C (1995) The receptor tyrosine kinase ARK mediates cell aggregation by homophilic binding. Mol. Cell. Biol 15:614-625

Ben-Arie N, Bellen HJ, Armstrong DL, McCall AE, Gordadze PR, Guo Q, Matzuk MM, Zoghbi HY (1997a) Math1 is essential for genesis of cerebellar granule neurons. Nature 390:169-172

Ben-Arie N, Bellen HJ, Armstrong DL, McCall AE, Gordadze PR, Guo Q, Matzuk MM, Zoghbi HY (1997b) Math1 is essential for genesis of cerebellar granule neurons. Nature 390:169-172

Bessis A, Salmon AM, Zoli M, Le Novère N, Picciotto M, Changeux JP (1995) Promoter elements conferring neuron-specific expression of the beta 2-subunit of the neuronal nicotinic acetylcholine receptor studied in vitro and in transgenic mice. Neuroscience 69:807-819

Biederer T, Sara Y, Mozhayeva M, Atasoy D, Liu X, Kavalali ET, Südhof TC (2002) SynCAM, a synaptic adhesion molecule that drives synapse assembly. Science 297:15251531

Bixby JL, Harris WA (1991) Molecular mechanisms of axon growth and guidance. Annu. Rev. Cell Biol 7:117-159

Bobik M, Ellisman MH, Rudy B, Martone ME (2004) Potassium channel subunit Kv3.2 and the water channel aquaporin-4 are selectively localized to cerebellar pinceau. Brain Res 1026:168-178 
Boutin C, Diestel S, Desoeuvre A, Tiveron M, Cremer H (2008) Efficient in vivo electroporation of the postnatal rodent forebrain. PLoS ONE 3:e1883

Boutin C, Hardt O, de Chevigny A, Coré N, Goebbels S, Seidenfaden R, Bosio A, Cremer H (2010) NeuroD1 induces terminal neuronal differentiation in olfactory neurogenesis. Proc. Natl. Acad. Sci. U.S.A 107:1201-1206

Bradford D, Cole SJ, Cooper HM (2009) Netrin-1: diversity in development. Int. J. Biochem. Cell Biol 41:487-493

Bradke F, Dotti CG (2000) Establishment of neuronal polarity: lessons from cultured hippocampal neurons. Current Opinion in Neurobiology 10:574-581

Bradley A, Evans M, Kaufman MH, Robertson E (1984) Formation of germ-line chimaeras from embryo-derived teratocarcinoma cell lines. Nature 309:255-256

Brand M, Heisenberg CP, Jiang YJ, Beuchle D, Lun K, Furutani-Seiki M, Granato M, Haffter P, Hammerschmidt M, Kane DA, Kelsh RN, Mullins MC, Odenthal J, van Eeden FJ, Nüsslein-Volhard C (1996) Mutations in zebrafish genes affecting the formation of the boundary between midbrain and hindbrain. Development 123:179-190

Brand S, Dahl AL, Mugnaini E (1976) The length of parallel fibers in the cat cerebellar cortex. An experimental light and electron microscopic study. Exp Brain Res 26:39-58

Broccoli V, Boncinelli E, Wurst W (1999) The caudal limit of Otx2 expression positions the isthmic organizer. Nature 401:164-168

Brose N (1999) Synaptic cell adhesion proteins and synaptogenesis in the mammalian central nervous system. Naturwissenschaften 86:516-524

Bruce-Keller AJ (1999) Microglial-neuronal interactions in synaptic damage and recovery. J. Neurosci. Res 58:191-201

Buchstaller A, Kunz S, Berger P, Kunz B, Ziegler U, Rader C, Sonderegger P (1996) Cell adhesion molecules $\mathrm{NgCAM}$ and axonin-1 form heterodimers in the neuronal membrane and cooperate in neurite outgrowth promotion. J. Cell Biol 135:1593-1607

Buhl DL, Harris KD, Hormuzdi SG, Monyer H, Buzsáki G (2003) Selective impairment of hippocampal gamma oscillations in connexin-36 knock-out mouse in vivo. J. Neurosci 23:1013-1018

Bullock WM, Cardon K, Bustillo J, Roberts RC, Perrone-Bizzozero NI (2008) Altered Expression of Genes Involved in GABAergic Transmission and Neuromodulation of Granule Cell Activity in the Cerebellum of Schizophrenia Patients. Am J Psychiatry 165:1594-1603

Buskin JN, Hauschka SD (1989) Identification of a myocyte nuclear factor that binds to the muscle-specific enhancer of the mouse muscle creatine kinase gene. Mol. Cell. Biol 9:26272640

Cabrera CV, Alonso MC (1991) Transcriptional activation by heterodimers of the achaetescute and daughterless gene products of Drosophila. EMBO J 10:2965-2973 
Campos-Ortega JA (1993) Mechanisms of early neurogenesis in Drosophila melanogaster. J. Neurobiol 24:1305-1327

Cardin JA, Carlén M, Meletis K, Knoblich U, Zhang F, Deisseroth K, Tsai L, Moore CI (2009) Driving fast-spiking cells induces gamma rhythm and controls sensory responses. Nature 459:663-667

Caviness VS, Frost DO (1980) Tangential organization of thalamic projections to the neocortex in the mouse. J. Comp. Neurol 194:335-367

Chae JH, Stein GH, Lee JE (2004) NeuroD: the predicted and the surprising. Mol. Cells $18: 271-288$

Chan SS, Zheng H, Su MW, Wilk R, Killeen MT, Hedgecock EM, Culotti JG (1996) UNC40, a C. elegans homolog of DCC (Deleted in Colorectal Cancer), is required in motile cells responding to UNC-6 netrin cues. Cell 87:187-195

Chan-Palay V, Palay SL (1971) The synapse en marron between golgi II neurons and mossy fibers in the rat's cerebellar cortex. Z Anat Entwicklungsgesch 133:274-287

Chan-Palay V, Palay SL (1972) The stellate cells of the rat's cerebellar cortex. Z Anat Entwicklungsgesch 136:224-248

Charych EI, Akum BF, Goldberg JS, Jörnsten RJ, Rongo C, Zheng JQ, Firestein BL (2006) Activity-independent regulation of dendrite patterning by postsynaptic density protein PSD95. J. Neurosci 26:10164-10176

Chen B, Schaevitz LR, McConnell SK (2005a) Fezl regulates the differentiation and axon targeting of layer 5 subcortical projection neurons in cerebral cortex. Proc. Natl. Acad. Sci. U.S.A 102:17184-17189

Chen J, Rasin M, Kwan KY, Sestan N (2005b) Zfp312 is required for subcortical axonal projections and dendritic morphology of deep-layer pyramidal neurons of the cerebral cortex. Proc. Natl. Acad. Sci. U.S.A 102:17792-17797

Cheung WT, Richards DE, Rogers JH (1993) Calcium binding by chick calretinin and rat calbindin D28k synthesised in bacteria. Eur. J. Biochem 215:401-410

Chi CL, Martinez S, Wurst W, Martin GR (2003) The isthmic organizer signal FGF8 is required for cell survival in the prospective midbrain and cerebellum. Development 130:26332644

Chih B, Engelman H, Scheiffele P (2005) Control of excitatory and inhibitory synapse formation by neuroligins. Science 307:1324-1328

Cobos I, Borello U, Rubenstein JL (2007) Dlx Transcription Factors Promote Migration through Repression of Axon and Dendrite Growth. Neuron 54:873-888

Cobos I, Calcagnotto ME, Vilaythong AJ, Thwin MT, Noebels JL, Baraban SC, Rubenstein JLR (2005) Mice lacking Dlx1 show subtype-specific loss of interneurons, reduced 
inhibition and epilepsy. Nat. Neurosci 8:1059-1068

Cowan CR, Hyman AA (2004) Asymmetric cell division in C. elegans: cortical polarity and spindle positioning. Annu. Rev. Cell Dev. Biol 20:427-453

Craig AM, Banker G (1994a) Neuronal polarity. Annu. Rev. Neurosci 17:267-310

Craig AM, Banker G (1994b) Neuronal polarity. Annu. Rev. Neurosci 17:267-310

Crandall JE, Caviness VS (1984) Thalamocortical connections in newborn mice. J. Comp. Neurol 228:542-556

Crossley PH, Martinez S, Martin GR (1996) Midbrain development induced by FGF8 in the chick embryo. Nature 380:66-68

Cui W, Allen ND, Skynner M, Gusterson B, Clark AJ (2001) Inducible ablation of astrocytes shows that these cells are required for neuronal survival in the adult brain. Glia $34: 272-282$

Cunningham BA, Hemperly JJ, Murray BA, Prediger EA, Brackenbury R, Edelman GM (1987) Neural cell adhesion molecule: structure, immunoglobulin-like domains, cell surface modulation, and alternative RNA splicing. Science 236:799-806

Da Silva JS, Hasegawa T, Miyagi T, Dotti CG, Abad-Rodriguez J (2005) Asymmetric membrane ganglioside sialidase activity specifies axonal fate. Nat. Neurosci 8:606-615

Dalva MB, Takasu MA, Lin MZ, Shamah SM, Hu L, Gale NW, Greenberg ME (2000) EphB receptors interact with NMDA receptors and regulate excitatory synapse formation. Cell 103:945-956

De Zeeuw CI, Hansel C, Bian F, Koekkoek SK, van Alphen AM, Linden DJ, Oberdick J (1998) Expression of a Protein Kinase C Inhibitor in Purkinje Cells Blocks Cerebellar LTD and Adaptation of the Vestibulo-Ocular Reflex. Neuron 20:495-508

Dieudonne S (1998) Submillisecond kinetics and low efficacy of parallel fibre-Golgi cell synaptic currents in the rat cerebellum. J. Physiol. (Lond.) 510 ( Pt 3):845-866

Dodt H, Eder M, Schierloh A, Zieglgänsberger W (2002) Infrared-guided laser stimulation of neurons in brain slices. Sci. STKE 2002:p12

Dotti CG, Sullivan CA, Banker GA (1988) The establishment of polarity by hippocampal neurons in culture. J. Neurosci 8:1454-1468

Dotti CG, Poo M (2003) Neuronal polarization: building fences for molecular segregation. Nat. Cell Biol 5:591-594

Duguid IC, Smart TG (2004) Retrograde activation of presynaptic NMDA receptors enhances GABA release at cerebellar interneuron-Purkinje cell synapses. Nat Neurosci 7:525533

Dumoulin A, Triller A, Dieudonné S (2001) IPSC kinetics at identified GABAergic and 
mixed GABAergic and glycinergic synapses onto cerebellar Golgi cells. J. Neurosci 21:60456057

Edwards MA, Yamamoto M, Caviness VS (1990) Organization of radial glia and related cells in the developing murine CNS. An analysis based upon a new monoclonal antibody marker. Neuroscience 36:121-144

Elkins T, Zinn K, McAllister L, Hoffmann FM, Goodman CS (1990) Genetic analysis of a Drosophila neural cell adhesion molecule: interaction of fasciclin I and Abelson tyrosine kinase mutations. Cell 60:565-575

Ellis HM, Spann DR, Posakony JW (1990) extramacrochaetae, a negative regulator of sensory organ development in Drosophila, defines a new class of helix-loop-helix proteins. Cell 61:27-38

ElShamy WM, Linnarsson S, Lee KF, Jaenisch R, Ernfors P (1996) Prenatal and postnatal requirements of NT-3 for sympathetic neuroblast survival and innervation of specific targets. Development 122:491-500

Englund C, Kowalczyk T, Daza RAM, Dagan A, Lau C, Rose MF, Hevner RF (2006) Unipolar brush cells of the cerebellum are produced in the rhombic lip and migrate through developing white matter. J. Neurosci 26:9184-9195

Erickson-Davis CR, Faust PL, Vonsattel JG, Gupta S, Honig LS, Louis ED (2010) "Hairy baskets" associated with degenerative Purkinje cell changes in essential tremor. J. Neuropathol. Exp. Neurol 69:262-271

Esch T, Lemmon V, Banker G (1999) Local presentation of substrate molecules directs axon specification by cultured hippocampal neurons. J. Neurosci 19:6417-6426

Evans MJ (2001) The cultural mouse. Nat. Med 7:1081-1083

Evans MJ, Kaufman MH (1981) Establishment in culture of pluripotential cells from mouse embryos. Nature 292:154-156

Fabre S, Reymond N, Cocchi F, Menotti L, Dubreuil P, Campadelli-Fiume G, Lopez M (2002) Prominent role of the Ig-like V domain in trans-interactions of nectins. Nectin3 and nectin 4 bind to the predicted C-C'-C"-D beta-strands of the nectin1 V domain. J. Biol. Chem 277:27006-27013

Falconer D.S. (1951) Two new mutations, trembler and reeler, with neurological action in the house mouse. J. Genet. 50, 192-201

Fiala JC, Feinberg M, Popov V, Harris KM (1998) Synaptogenesis via dendritic filopodia in developing hippocampal area CA1. J. Neurosci 18:8900-8911

Flanagan JG, Vanderhaeghen P (1998) The ephrins and Eph receptors in neural development. Annu. Rev. Neurosci 21:309-345

Franco M, Tamagnone L (2008) Tyrosine phosphorylation in semaphorin signalling: shifting into overdrive. EMBO Rep 9:865-871 
Fredette B, Rutishauser U, Landmesser L (1993) Regulation and activity-dependence of Ncadherin, NCAM isoforms, and polysialic acid on chick myotubes during development. J. Cell Biol 123:1867-1888

Gasa R, Mrejen C, Lynn FC, Skewes-Cox P, Sanchez L, Yang KY, Lin C, Gomis R, German MS (2008) Induction of pancreatic islet cell differentiation by the neurogenin-neuroD cascade. Differentiation 76:381-391

Gillespie C, Sherman DL, Fleetwood-Walker SM, Cottrell DF, Tait S, Garry EM, Wallace VC, Ure J, Griffiths IR, Smith A (2000) Peripheral Demyelination and Neuropathic Pain Behavior in Periaxin-Deficient Mice. Neuron 26:523-531

Glassmann A, Topka S, Wang-Eckardt L, Anders S, Weisheit G, Endl E, Zimmer A, Schilling K (2009) Basic molecular fingerprinting of immature cerebellar cortical inhibitory interneurons and their precursors. Neuroscience 159:69-82

Goebbels S, Bode U, Pieper A, Funfschilling U, Schwab MH, Nave K (2005) Cre/loxPmediated inactivation of the bHLH transcription factor gene NeuroD/BETA2. genesis 42:247252

Goldowitz D, Hamre K (1998) The cells and molecules that make a cerebellum. Trends Neurosci 21:375-382

Goldowitz D, Smeyne RJ (1995) Tune into the weaver channel. Nat. Genet 11:107-109

Goold RG, Owen R, Gordon-Weeks PR (1999) Glycogen synthase kinase 3beta phosphorylation of microtubule-associated protein $1 \mathrm{~B}$ regulates the stability of microtubules in growth cones. J. Cell. Sci 112 ( Pt 19):3373-3384

Gordon-Weeks PR, Fischer I (2000) MAP1B expression and microtubule stability in growing and regenerating axons. Microsc. Res. Tech 48:63-74

Goshima Y, Nakamura F, Strittmatter P, Strittmatter SM (1995) Collapsin-induced growth cone collapse mediated by an intracellular protein related to UNC-33. Nature 376:509-514

Govek E, Newey SE, Van Aelst L (2005) The role of the Rho GTPases in neuronal development. Genes Dev 19:1-49

Gradwohl G, Fode C, Guillemot F (1996) Restricted expression of a novel murine atonalrelated bHLH protein in undifferentiated neural precursors. Dev. Biol 180:227-241

Graf ER, Zhang X, Jin S, Linhoff MW, Craig AM (2004) Neurexins induce differentiation of GABA and glutamate postsynaptic specializations via neuroligins. Cell 119:1013-1026

Grant AL, Jones A, Thomas KL, Wisden W (1996) Characterization of the rat hippocalcin gene: the 5' flanking region directs expression to the hippocampus. Neuroscience 75:10991115

Greenblatt J (1997) RNA polymerase II holoenzyme and transcriptional regulation. Curr. Opin. Cell Biol 9:310-319 
Grumet M, Friedlander DR, Edelman GM (1993) Evidence for the binding of Ng-CAM to laminin. Cell Adhes. Commun 1:177-190

Gu H, Marth JD, Orban PC, Mossmann H, Rajewsky K (1994) Deletion of a DNA polymerase beta gene segment in $\mathrm{T}$ cells using cell type-specific gene targeting. Science 265:103-106

Guillemot F, Joyner AL (1993) Dynamic expression of the murine Achaete-Scute homologue Mash-1 in the developing nervous system. Mech. Dev 42:171-185

Guthrie S (1996) Patterning the hindbrain. Curr. Opin. Neurobiol 6:41-48

Gupton SL und Gertler FB (2007) Filopodia: the fingers that do the walking Sci STKE. 21, (400):re5.

Habener JF, Kemp DM, Thomas MK (2005) Minireview: transcriptional regulation in pancreatic development. Endocrinology 146:1025-1034

Haiech J, Derancourt J, Pechère JF, Demaille JG (1979) Magnesium and calcium binding to parvalbumins: evidence for differences between parvalbumins and an explanation of their relaxing function. Biochemistry 18:2752-2758

Hama H, Hara C, Yamaguchi K, Miyawaki A (2004) PKC signaling mediates global enhancement of excitatory synaptogenesis in neurons triggered by local contact with astrocytes. Neuron 41:405-415

Hamburgh M. (1960) Observations on the neuropathology of „Reeler“, a neurological mutation in the mouse. Experimentia 16, 460

Hamilton DL, Abremski K (1984) Site-specific recombination by the bacteriophage P1 loxCre system. Cre-mediated synapsis of two lox sites. J. Mol. Biol 178:481-486

Hámori J, Szentágothai J (1966) Participation of Golgi neuron processes in the cerebellar glomeruli: an electron microscope study. Exp Brain Res 2:35-48

Hansel C, de Jeu M, Belmeguenai A, Houtman SH, Buitendijk GH, Andreev D, De Zeeuw CI, Elgersma Y (2006) [alpha]CaMKII Is Essential for Cerebellar LTD and Motor Learning. Neuron 51:835-843

Harris R, Sabatelli LM, Seeger MA (1996) Guidance cues at the Drosophila CNS midline: identification and characterization of two Drosophila Netrin/UNC-6 homologs. Neuron $17: 217-228$

Hart AH, Reventar R, Bernstein A (2000) Genetic analysis of ETS genes in C. elegans. Oncogene 19:6400-6408

Hartline DK, Colman DR (2007) Rapid conduction and the evolution of giant axons and myelinated fibers. Curr. Biol 17:R29-35

Hashimoto K, Kano M (2005) Postnatal development and synapse elimination of climbing 
fiber to Purkinje cell projection in the cerebellum. Neurosci. Res 53:221-228

Hatten ME (1999) Central nervous system neuronal migration. Annu. Rev. Neurosci 22:511-539

Hatten ME, Heintz N (1995) Mechanisms of neural patterning and specification in the developing cerebellum. Annu. Rev. Neurosci 18:385-408

Hatten ME, Alder J, Zimmerman K, Heintz N (1997) Genes involved in cerebellar cell specification and differentiation. Current Opinion in Neurobiology 7:40-47

Häusser M, Clark BA (1997) Tonic synaptic inhibition modulates neuronal output pattern and spatiotemporal synaptic integration. Neuron 19:665-678

Heck D, Sultan F (2002) Cerebellar structure and function: making sense of parallel fibers. Hum Mov Sci 21:411-421

Hedgecock EM, Culotti JG, Hall DH (1990) The unc-5, unc-6, and unc-40 genes guide circumferential migrations of pioneer axons and mesodermal cells on the epidermis in $\mathrm{C}$. elegans. Neuron 4:61-85

Hedgecock EM, Culotti JG, Hall DH, Stern BD (1987) Genetics of cell and axon migrations in Caenorhabditis elegans. Development 100:365-382

Hesslow G, Ivarsson M (1994) Suppression of cerebellar Purkinje cells during conditioned responses in ferrets. Neuroreport 5:649-652

Hidalgo-Sánchez M, Simeone A, Alvarado-Mallart RM (1999) Fgf8 and Gbx2 induction concomitant with Otx2 repression is correlated with midbrain-hindbrain fate of caudal prosencephalon. Development 126:3191-3203

Hilliard MA, Bargmann CI (2006) Wnt signals and frizzled activity orient anterior-posterior axon outgrowth in C. elegans. Dev. Cell 10:379-390

Hirano S, Suzuki ST, Redies C (2003) The cadherin superfamily in neural development: diversity, function and interaction with other molecules. Front. Biosci 8:d306-355

Hirata T, Suda Y, Nakao K, Narimatsu M, Hirano T, Hibi M (2004) Zinc finger gene fezlike functions in the formation of subplate neurons and thalamocortical axons. Dev. Dyn 230:546-556

Höhl-Abrahão JC, Creutzfeldt OD (1991) Topographical mapping of the thalamocortical projections in rodents and comparison with that in primates. Exp Brain Res 87:283-294

Hong K, Hinck L, Nishiyama M, Poo MM, Tessier-Lavigne M, Stein E (1999) A ligandgated association between cytoplasmic domains of UNC5 and DCC family receptors converts netrin-induced growth cone attraction to repulsion. Cell 97:927-941

Hoogenraad CC, Milstein AD, Ethell IM, Henkemeyer M, Sheng M (2005) GRIP1 controls dendrite morphogenesis by regulating EphB receptor trafficking. Nat. Neurosci 8:906-915 
Horiguchi K, Hanada T, Fukui Y, Chishti AH (2006) Transport of PIP3 by GAKIN, a kinesin-3 family protein, regulates neuronal cell polarity. J. Cell Biol 174:425-436

Hormuzdi SG, Pais I, LeBeau FE, Towers SK, Rozov A, Buhl EH, Whittington MA, Monyer $\mathrm{H}$ (2001) Impaired electrical signaling disrupts gamma frequency oscillations in connexin 36-deficient mice. Neuron 31:487-495

Hoshino M (2006a) Molecular machinery governing GABAergic neuron specification in the cerebellum. The Cerebellum 5:193-198

Hoshino M (2006b) Molecular machinery governing GABAergic neuron specification in the cerebellum. The Cerebellum 5:193-198

Hoshino M, Nakamura S, Mori K, Kawauchi T, Terao M, Nishimura YV, Fukuda A, Fuse T, Matsuo N, Sone M, Watanabe M, Bito H, Terashima T, Wright CVE, Kawaguchi Y, Nakao K, Nabeshima Y (2005) Ptfla, a bHLH transcriptional gene, defines GABAergic neuronal fates in cerebellum. Neuron 47:201-213

Hoyle GW, Mercer EH, Palmiter RD, Brinster RL (1993) Expression of NGF in sympathetic neurons leads to excessive axon outgrowth from ganglia but decreased terminal innervation within tissues. Neuron 10:1019-1034

Hummler E, Cole TJ, Blendy JA, Ganss R, Aguzzi A, Schmid W, Beermann F, Schütz G (1994) Targeted mutation of the CREB gene: compensation within the CREB/ATF family of transcription factors. Proc. Natl. Acad. Sci. U.S.A 91:5647-5651

Hurov JB, Watkins JL, Piwnica-Worms H (2004) Atypical PKC phosphorylates PAR-1 kinases to regulate localization and activity. Curr. Biol 14:736-741

Hynes RO, Lander AD (1992) Contact and adhesive specificities in the associations, migrations, and targeting of cells and axons. Cell 68:303-322

Ichtchenko K, Hata Y, Nguyen T, Ullrich B, Missler M, Moomaw C, Südhof TC (1995) Neuroligin 1: a splice site-specific ligand for beta-neurexins. Cell 81:435-443

Iijima M, Huang YE, Devreotes P (2002) Temporal and spatial regulation of chemotaxis. Dev. Cell 3:469-478

Ikeuchi Y, Stegmüller J, Netherton S, Huynh MA, Masu M, Frank D, Bonni S, Bonni A (2009) A SnoN-Ccd1 pathway promotes axonal morphogenesis in the mammalian brain. J. Neurosci 29:4312-4321

Inagaki N, Chihara K, Arimura N, Ménager C, Kawano Y, Matsuo N, Nishimura T, Amano M, Kaibuchi K (2001) CRMP-2 induces axons in cultured hippocampal neurons. Nat. Neurosci 4:781-782

Ince-Dunn G, Hall BJ, Hu S, Ripley B, Huganir RL, Olson JM, Tapscott SJ, Ghosh A (2006) Regulation of thalamocortical patterning and synaptic maturation by NeuroD2. Neuron 49:683-695

Inouye M, Murakami U (1980a) Temporal and spatial patterns of Purkinje cell formation in 
the mouse cerebellum. J. Comp. Neurol 194:499-503

Inouye M, Murakami U (1980b) Temporal and spatial patterns of Purkinje cell formation in the mouse cerebellum. J. Comp. Neurol 194:499-503

Ishii N, Wadsworth WG, Stern BD, Culotti JG, Hedgecock EM (1992) UNC-6, a lamininrelated protein, guides cell and pioneer axon migrations in C. elegans. Neuron 9:873-881

Ito M (1984) The modifiable neuronal network of the cerebellum. Jpn. J. Physiol 34:781792

Jan YN, Jan LY (1993) HLH proteins, fly neurogenesis, and vertebrate myogenesis. Cell $75: 827-830$

Jarman AP, Grau Y, Jan LY, Jan YN (1993) atonal is a proneural gene that directs chordotonal organ formation in the Drosophila peripheral nervous system. Cell 73:1307-1321

Jessell TM, Sanes JR (2000) Development. The decade of the developing brain. Curr. Opin. Neurobiol 10:599-611

Jessen KR, Mirsky R, Salzer J (2008) Introduction. Schwann cell biology. Glia 56:14791480

Jiang H, Guo W, Liang X, Rao Y (2005) Both the establishment and the maintenance of neuronal polarity require active mechanisms: critical roles of GSK-3beta and its upstream regulators. Cell 120:123-135

Johnson CP, Fujimoto I, Rutishauser U, Leckband DE (2005) Direct evidence that neural cell adhesion molecule (NCAM) polysialylation increases intermembrane repulsion and abrogates adhesion. J. Biol. Chem 280:137-145

Johnson JE, Birren SJ, Anderson DJ (1990) Two rat homologues of Drosophila achaetescute specifically expressed in neuronal precursors. Nature 346:858-861

Jones SB, Lu HY, Lu Q (2004) Abl tyrosine kinase promotes dendrogenesis by inducing actin cytoskeletal rearrangements in cooperation with Rho family small GTPases in hippocampal neurons. J. Neurosci 24:8510-8521

Jörntell H, Ekerot C (2002) Reciprocal Bidirectional Plasticity of Parallel Fiber Receptive Fields in Cerebellar Purkinje Cells and Their Afferent Interneurons. Neuron 34:797-806

Jouet M, Rosenthal A, MacFarlane J, Kenwrick S, Donnai D (1993) A missense mutation confirms the L1 defect in X-linked hydrocephalus (HSAS). Nat. Genet 4:331

Joyner AL (1996) Engrailed, Wnt and Pax genes regulate midbrain--hindbrain development Trends Genet. 12(1):15-20

Joyner AL, Liu A, Millet S (2000) Otx2, Gbx2 and Fgf8 interact to position and maintain a mid-hindbrain organizer. Curr. Opin. Cell Biol 12:736-741

Kalinichenko SG, Okhotin VE (2005) Unipolar brush cells--a new type of excitatory 
interneuron in the cerebellar cortex and cochlear nuclei of the brainstem. Neurosci. Behav. Physiol 35:21-36

Kano M, Rexhausen U, Dreessen J, Konnerth A (1992) Synaptic excitation produces a longlasting rebound potentiation of inhibitory synaptic signals in cerebellar Purkinje cells. Nature 356:601-604

Kaprielian Z, Patterson PH (1994) The molecular basis of retinotectal topography. Bioessays 16:1-11

Karam SD, Kim YS, Bothwell M (2001) Granule cells migrate within raphes in the developing cerebellum: an evolutionarily conserved morphogenic event. J. Comp. Neurol 440:127-135

Kashani AH, Qiu Z, Jurata L, Lee S, Pfaff S, Goebbels S, Nave K, Ghosh A (2006) Calcium activation of the LMO4 transcription complex and its role in the patterning of thalamocortical connections. J. Neurosci 26:8398-8408

Kater SB, Rehder V (1995) The sensory-motor role of growth cone filopodia. Curr. Opin. Neurobiol 5:68-74

Katz MJ, Lasek RJ, Silver J (1983) Ontophyletics of the nervous system: development of the corpus callosum and evolution of axon tracts. Proc. Natl. Acad. Sci. U.S.A 80:5936-5940

Kawano Y, Yoshimura T, Tsuboi D, Kawabata S, Kaneko-Kawano T, Shirataki H, Takenawa T, Kaibuchi K (2005) CRMP-2 is involved in kinesin-1-dependent transport of the Sra1/WAVE1 complex and axon formation. Mol. Cell. Biol 25:9920-9935

Keino-Masu K, Masu M, Hinck L, Leonardo ED, Chan SS, Culotti JG, Tessier-Lavigne M (1996) Deleted in Colorectal Cancer (DCC) encodes a netrin receptor. Cell 87:175-185

Keith B, Adelman DM, Simon MC (2001) Targeted mutation of the murine arylhydrocarbon receptor nuclear translocator 2 (Arnt2) gene reveals partial redundancy with Arnt. Proc. Natl. Acad. Sci. U.S.A 98:6692-6697

Kennedy TE, Serafini T, de la Torre JR, Tessier-Lavigne M (1994) Netrins are diffusible chemotropic factors for commissural axons in the embryonic spinal cord. Cell 78:425-435

Kim JJ, Thompson RF (1997) Cerebellar circuits and synaptic mechanisms involved in classical eyeblink conditioning. Trends in Neurosciences 20:177-181

Kimura T, Watanabe H, Iwamatsu A, Kaibuchi K (2005) Tubulin and CRMP-2 complex is transported via Kinesin-1. J. Neurochem 93:1371-1382

Kiss JZ, Muller D (2001) Contribution of the neural cell adhesion molecule to neuronal and synaptic plasticity. Rev Neurosci 12:297-310

KLEINSMITH LJ, PIERCE GB (1964) MULTIPOTENTIALITY OF SINGLE EMBRYONAL CARCINOMA CELLS. Cancer Res 24:1544-1551

Kolodziej PA, Timpe LC, Mitchell KJ, Fried SR, Goodman CS, Jan LY, Jan YN (1996) 
frazzled encodes a Drosophila member of the DCC immunoglobulin subfamily and is required for CNS and motor axon guidance. Cell 87:197-204

Konishi Y, Stegmüller J, Matsuda T, Bonni S, Bonni A (2004) Cdh1-APC controls axonal growth and patterning in the mammalian brain. Science 303:1026-1030

Krantz DE, Zipursky SL (1990) Drosophila chaoptin, a member of the leucine-rich repeat family, is a photoreceptor cell-specific adhesion molecule. EMBO J 9:1969-1977

Kuehn MR, Bradley A, Robertson EJ, Evans MJ (1987) A potential animal model for Lesch-Nyhan syndrome through introduction of HPRT mutations into mice. Nature 326:295298

Kuhn TB, Stoeckli ET, Condrau MA, Rathjen FG, Sonderegger P (1991) Neurite outgrowth on immobilized axonin-1 is mediated by a heterophilic interaction with L1(G4). J. Cell Biol $115: 1113-1126$

Kullmann DM, Lamsa KP (2007) Long-term synaptic plasticity in hippocampal interneurons. Nat Rev Neurosci 8:687-699

Kume H, Maruyama K, Tomita T, Iwatsubo T, Saido TC, Obata K (1996) Molecular cloning of a novel basic helix-loop-helix protein from the rat brain. Biochem. Biophys. Res. Commun 219:526-530

Kume T, Deng K, Hogan BL (2000) Minimal phenotype of mice homozygous for a null mutation in the forkhead/winged helix gene, Mf2. Mol. Cell. Biol 20:1419-1425

Kusakabe M, Nishida E (2004) The polarity-inducing kinase Par-1 controls Xenopus gastrulation in cooperation with 14-3-3 and aPKC. EMBO J 23:4190-4201

Lainé J, Axelrad H (1998) Lugaro cells target basket and stellate cells in the cerebellar cortex. Neuroreport 9:2399-2403

Lalonde R (1987a) Motor abnormalities in weaver mutant mice. Exp Brain Res 65:479-481

Lalonde R (1987b) Motor abnormalities in staggerer mutant mice. Exp Brain Res 68:417420

Larouche M, Che PM, Hawkes R (2006) Neurogranin expression identifies a novel array of Purkinje cell parasagittal stripes during mouse cerebellar development. J. Comp. Neurol 494:215-227

Larouche M, Hawkes R (2006) From clusters to stripes: the developmental origins of adult cerebellar compartmentation. Cerebellum 5:77-88

Larramendi LM, Lemkey-Johnston N (1970) The distribution of recurrent Purkinje collateral synapses in the mouse cerebellar cortex: an electron microscopic study. J. Comp. Neurol 138:451-459

Lawson L, Perry V, Dri P, Gordon S (1990) Heterogeneity in the distribution and morphology of microglia in the normal adult mouse brain. Neuroscience 39:151-170 
Leclerc N, Gravel C, Hawkes R (1988) Development of parasagittal zonation in the rat cerebellar cortex: MabQ113 antigenic bands are created postnatally by the suppression of antigen expression in a subset of Purkinje cells. J. Comp. Neurol 273:399-420

Lee JE, Hollenberg SM, Snider L, Turner DL, Lipnick N, Weintraub H (1995) Conversion of Xenopus ectoderm into neurons by NeuroD, a basic helix-loop-helix protein. Science 268:836-844

Lee JK, Cho JH, Hwang WS, Lee YD, Reu DS, Suh-Kim H (2000) Expression of neuroD/BETA2 in mitotic and postmitotic neuronal cells during the development of nervous system. Dev. Dyn 217:361-367

Lee KJ, Mendelsohn M, Jessell TM (1998) Neuronal patterning by BMPs: a requirement for GDF7 in the generation of a discrete class of commissural interneurons in the mouse spinal cord. Genes Dev 12:3394-3407

Lee SH, Schwaller B, Neher E (2000) Kinetics of Ca2+ binding to parvalbumin in bovine chromaffin cells: implications for $[\mathrm{Ca} 2+]$ transients of neuronal dendrites. J. Physiol. (Lond.) 525 Pt 2:419-432

Lee SM, Danielian PS, Fritzsch B, McMahon AP (1997) Evidence that FGF8 signalling from the midbrain-hindbrain junction regulates growth and polarity in the developing midbrain. Development 124:959-969

Lemke G (1988) Unwrapping the genes of myelin. Neuron 1:535-543

Leto K, Bartolini A, Rossi F (2008) Development of cerebellar GABAergic interneurons: origin and shaping of the "minibrain" local connections. Cerebellum 7:523-529

Leto K, Bartolini A, Yanagawa Y, Obata K, Magrassi L, Schilling K, Rossi F (2009) Laminar fate and phenotype specification of cerebellar GABAergic interneurons. J. Neurosci 29:7079-7091

Leto K, Carletti B, Williams IM, Magrassi L, Rossi F (2006) Different types of cerebellar GABAergic interneurons originate from a common pool of multipotent progenitor cells. J. Neurosci 26:11682-11694

Lewandoski M (2001) Conditional control of gene expression in the mouse. Nat. Rev. Genet 2:743-755

Li JY, Joyner AL (2001) Otx2 and Gbx2 are required for refinement and not induction of mid-hindbrain gene expression. Development 128:4979-4991

Lin C, Hansen S, Wang Z, Storm DR, Tapscott SJ, Olson JM (2005) The dosage of the neuroD2 transcription factor regulates amygdala development and emotional learning. Proc. Natl. Acad. Sci. U.S.A 102:14877-14882

Lin JH, Saito T, Anderson DJ, Lance-Jones C, Jessell TM, Arber S (1998) Functionally related motor neuron pool and muscle sensory afferent subtypes defined by coordinate ETS gene expression. Cell 95:393-407 
Liu A, Joyner AL (2001a) Early anterior/posterior patterning of the midbrain and cerebellum. Annu. Rev. Neurosci 24:869-896

Liu A, Joyner AL (2001b) EN and GBX2 play essential roles downstream of FGF8 in patterning the mouse mid/hindbrain region. Development 128:181-191

Liu A, Losos K, Joyner AL (1999) FGF8 can activate Gbx2 and transform regions of the rostral mouse brain into a hindbrain fate. Development 126:4827-4838

Liu M, Pleasure SJ, Collins AE, Noebels JL, Naya FJ, Tsai M, Lowenstein DH (2000) Loss of BETA2/NeuroD leads to malformation of the dentate gyrus and epilepsy. Proceedings of the National Academy of Sciences of the United States of America 97:865-870

Livet J, Sigrist M, Stroebel S, De Paola V, Price SR, Henderson CE, Jessell TM, Arber S (2002) ETS gene Pea3 controls the central position and terminal arborization of specific motor neuron pools. Neuron 35:877-892

Llinás, R. (1969). Neurobiology of Cerebellar Evolution and Development. Proceedings of the First International Symposium of the Institute for Biomedical Research, American Medical Association/Education \& Research Foundation Chicago

Lossi L, Merighi A (2003) In vivo cellular and molecular mechanisms of neuronal apoptosis in the mammalian CNS. Prog. Neurobiol 69:287-312

Luckner R, Obst-Pernberg K, Hirano S, Suzuki ST, Redies C (2001) Granule cell raphes in the developing mouse cerebellum. Cell Tissue Res 303:159-172

Luján R, Albasanz JL, Shigemoto R, Juiz JM (2005a) Preferential localization of the hyperpolarization-activated cyclic nucleotide-gated cation channel subunit HCN1 in basket cell terminals of the rat cerebellum. European Journal of Neuroscience 21:2073-2082

Luján R, Albasanz JL, Shigemoto R, Juiz JM (2005b) Preferential localization of the hyperpolarization-activated cyclic nucleotide-gated cation channel subunit HCN1 in basket cell terminals of the rat cerebellum. Eur. J. Neurosci 21:2073-2082

Ma Q, Kintner C, Anderson DJ (1996a) Identification of neurogenin, a vertebrate neuronal determination gene. Cell 87:43-52

Ma Q, Kintner C, Anderson DJ (1996b) Identification of neurogenin, a vertebrate neuronal determination gene. Cell 87:43-52

Machold R, Fishell G (2005) Math1 is expressed in temporally discrete pools of cerebellar rhombic-lip neural progenitors. Neuron 48:17-24

Maricich SM, Herrup K (1999) Pax-2 expression defines a subset of GABAergic interneurons and their precursors in the developing murine cerebellum. J. Neurobiol 41:281294

Marr D. (1969) A theory of cerebellar cortex. J Physiol. 202(2):437-70

Martin GR, Evans MJ (1975) Differentiation of clonal lines of teratocarcinoma cells: 
formation of embryoid bodies in vitro. Proc. Natl. Acad. Sci. U.S.A 72:1441-1445

Martinez S, Crossley PH, Cobos I, Rubenstein JL, Martin GR (1999) FGF8 induces formation of an ectopic isthmic organizer and isthmocerebellar development via a repressive effect on Otx2 expression. Development 126:1189-1200

Martinez-Rico C, Pincet F, Perez E, Thiery JP, Shimizu K, Takai Y, Dufour S (2005) Separation force measurements reveal different types of modulation of E-cadherin-based adhesion by nectin-1 and -3. J. Biol. Chem 280:4753-4760

Maruki K, Izaki Y, Nomura M, Yamauchi T (2001) Differences in paired-pulse facilitation and long-term potentiation between dorsal and ventral CA1 regions in anesthetized rats. Hippocampus 11:655-661

Mason CA, Christakos S, Catalano SM (1990a) Early climbing fiber interactions with Purkinje cells in the postnatal mouse cerebellum. J. Comp. Neurol 297:77-90

Mason CA, Christakos S, Catalano SM (1990b) Early climbing fiber interactions with Purkinje cells in the postnatal mouse cerebellum. J. Comp. Neurol 297:77-90

McCormick MB, Tamimi RM, Snider L, Asakura A, Bergstrom D, Tapscott SJ (1996) NeuroD2 and neuroD3: distinct expression patterns and transcriptional activation potentials within the neuroD gene family. Mol. Cell. Biol 16:5792-5800

McCrea RA, Bishop GA, Kitai ST (1976) Intracellular staining of Purkinje cells and their axons with horseradish peroxidase. Brain Res 118:132-136

McFarlane S, Cornel E, Amaya E, Holt CE (1996) Inhibition of FGF receptor activity in retinal ganglion cell axons causes errors in target recognition. Neuron 17:245-254

McFarlane S, McNeill L, Holt CE (1995) FGF signaling and target recognition in the developing Xenopus visual system. Neuron 15:1017-1028

McMahon AP, Bradley A (1990) The Wnt-1 (int-1) proto-oncogene is required for development of a large region of the mouse brain. Cell 62:1073-1085

Ménager C, Arimura N, Fukata Y, Kaibuchi K (2004) PIP3 is involved in neuronal polarization and axon formation. J. Neurochem 89:109-118

Meier G. \& Hoag W. G. (1962) The neuropathology of „reeler“, a neuromuscular mutation in mice. J. Neuropathol.-Exp. Neurol. 21: 649-654

Meyer RL (1998) Roger Sperry and his chemoaffinity hypothesis. Neuropsychologia 36:957-980

Meyers EN, Lewandoski M, Martin GR (1998) An Fgf8 mutant allelic series generated by Cre- and Flp-mediated recombination. Nat. Genet 18:136-141

Mihrshahi R (2006) The corpus callosum as an evolutionary innovation. J. Exp. Zool. B Mol. Dev. Evol 306:8-17 
Millen KJ, Millonig JH, Wingate RJ, Alder J, Hatten ME (1999) Neurogenetics of the cerebellar system. J. Child Neurol 14:574-581; discussion 581-582

Miller FD, Kaplan DR (2003) Signaling mechanisms underlying dendrite formation. Curr. Opin. Neurobiol 13:391-398

Millet S, Bloch-Gallego E, Simeone A, Alvarado-Mallart RM (1996) The caudal limit of Otx2 gene expression as a marker of the midbrain/hindbrain boundary: a study using in situ hybridisation and chick/quail homotopic grafts. Development 122:3785-3797

Mills M, Yang N, Weinberger R, Vander Woude DL, Beggs AH, Easteal S, North K (2001) Differential expression of the actin-binding proteins, alpha-actinin-2 and -3 , in different species: implications for the evolution of functional redundancy. Hum. Mol. Genet 10:13351346

Minaki Y, Nakatani T, Mizuhara E, Inoue T, Ono Y (2008) Identification of a novel transcriptional corepressor, Corl2, as a cerebellar Purkinje cell-selective marker. Gene Expr. Patterns 8:418-423

Mintz B, Illmensee K (1975) Normal genetically mosaic mice produced from malignant teratocarcinoma cells. Proc. Natl. Acad. Sci. U.S.A 72:3585-3589

Missler M, Fernandez-Chacon R, Südhof TC (1998) The making of neurexins. J. Neurochem 71:1339-1347

Mitchell KJ, Doyle JL, Serafini T, Kennedy TE, Tessier-Lavigne M, Goodman CS, Dickson BJ (1996) Genetic analysis of Netrin genes in Drosophila: Netrins guide CNS commissural axons and peripheral motor axons. Neuron 17:203-215

Mittmann W, Koch U, Häusser M (2005) Feed-forward inhibition shapes the spike output of cerebellar Purkinje cells. J Physiol 563:369-378

Miyata T, Maeda T, Lee JE (1999) NeuroD is required for differentiation of the granule cells in the cerebellum and hippocampus. Genes Dev 13:1647-1652

Miyata T, Nakajima K, Mikoshiba K, Ogawa M (1997) Regulation of Purkinje cell alignment by reelin as revealed with CR-50 antibody. J. Neurosci 17:3599-3609

Mizuhara E, Minaki Y, Nakatani T, Kumai M, Inoue T, Muguruma K, Sasai Y, Ono Y (2010) Purkinje cells originate from cerebellar ventricular zone progenitors positive for Neph3 and E-cadherin. Dev. Biol 338:202-214

Mizuhara E, Nakatani T, Minaki Y, Sakamoto Y, Ono Y (2005) Corl1, a novel neuronal lineage-specific transcriptional corepressor for the homeodomain transcription factor Lbx1. J. Biol. Chem 280:3645-3655

Molyneaux BJ, Arlotta P, Hirata T, Hibi M, Macklis JD (2005) Fezl is required for the birth and specification of corticospinal motor neurons. Neuron 47:817-831

MONTAGUTELLI X (2000) Effect of the Genetic Background on the Phenotype of Mouse Mutations. J Am Soc Nephrol 11:S101-105 
Morales D, Hatten ME (2006) Molecular markers of neuronal progenitors in the embryonic cerebellar anlage. J. Neurosci 26:12226-12236

Morara S, van der Want JJ, de Weerd H, Provini L, Rosina A (2001) Ultrastructural analysis of climbing fiber-Purkinje cell synaptogenesis in the rat cerebellum. Neuroscience 108:655-671

Mugnaini E, Floris A, Wright-Goss M (1994) Extraordinary synapses of the unipolar brush cell: an electron microscopic study in the rat cerebellum. Synapse 16:284-311

Mugnaini E, Forstronen PF (1967) Ultrastructural studies on the cerebellar histogenesis. I. Differentiation of granule cells and development of glomeruli in the chick embryo. Z Zellforsch Mikrosk Anat 77:115-143

Mukaetova-Ladinska EB, Hurt J, Honer WG, Harrington CR, Wischik CM (2002) Loss of synaptic but not cytoskeletal proteins in the cerebellum of chronic schizophrenics. Neuroscience Letters 317:161-165

Nakajima K.[1], Kohsaka S.[1] (2004) Microglia:Neuroprotective and Neurotrophic Cells in the Central Nervous System. Current Drug Targets - Cardiovascular \& Hematological Disorders 4:65-84

Nakamura H, Katahira T, Matsunaga E, Sato T (2005) Isthmus organizer for midbrain and hindbrain development. Brain Res. Brain Res. Rev 49:120-126

Nam SC, Hockberger (1997) Analysis of spontaneous electrical activity in cerebellar Purkinje cells acutely isolated from postnatal rats. PEJ Neurobiol. 33(1):18-32

Naya FJ, Huang HP, Qiu Y, Mutoh H, DeMayo FJ, Leiter AB, Tsai MJ (1997) Diabetes, defective pancreatic morphogenesis, and abnormal enteroendocrine differentiation in BETA2/neuroD-deficient mice. Genes Dev 11:2323-2334

Naya FJ, Stellrecht CM, Tsai MJ (1995) Tissue-specific regulation of the insulin gene by a novel basic helix-loop-helix transcription factor. Genes Dev 9:1009-1019

Negishi M, Oinuma I, Katoh H (2005) R-ras as a key player for signaling pathway of plexins. Mol. Neurobiol 32:217-222

Nishida K, Hoshino M, Kawaguchi Y, Murakami F (2010) Ptfla Directly Controls Expression of Immunoglobulin Superfamily Molecules Nephrin and Neph3 in the Developing Central Nervous System. Journal of Biological Chemistry 285:373-380

Nishimura T, Fukata Y, Kato K, Yamaguchi T, Matsuura Y, Kamiguchi H, Kaibuchi K (2003) CRMP-2 regulates polarized Numb-mediated endocytosis for axon growth. Nat. Cell Biol 5:819-826

Nishimura T, Kato K, Yamaguchi T, Fukata Y, Ohno S, Kaibuchi K (2004) Role of the PAR-3-KIF3 complex in the establishment of neuronal polarity. Nat. Cell Biol 6:328-334

Nolan MF, Malleret G, Lee KH, Gibbs E, Dudman JT, Santoro B, Yin D, Thompson RF, 
Siegelbaum SA, Kandel ER, Morozov A (2003) The Hyperpolarization-Activated HCN1 Channel Is Important for Motor Learning and Neuronal Integration by Cerebellar Purkinje Cells. Cell 115:551-564

Nose A, Mahajan VB, Goodman CS (1992) Connectin: a homophilic cell adhesion molecule expressed on a subset of muscles and the motoneurons that innervate them in Drosophila. Cell 70:553-567

Nowak MA, Boerlijst MC, Cooke J, Smith JM (1997) Evolution of genetic redundancy. Nature 388:167-171

Oellers N, Dehio M, Knust E (1994) bHLH proteins encoded by the Enhancer of split complex of Drosophila negatively interfere with transcriptional activation mediated by proneural genes. Mol. Gen. Genet 244:465-473

Olson JM, Asakura A, Snider L, Hawkes R, Strand A, Stoeck J, Hallahan A, Pritchard J, Tapscott SJ (2001) NeuroD2 Is Necessary for Development and Survival of Central Nervous System Neurons. Developmental Biology 234:174-187

Oppenheim RW, Prevette D, Yin QW, Collins F, MacDonald J (1991) Control of embryonic motoneuron survival in vivo by ciliary neurotrophic factor. Science 251:16161618

Pascual M, Abasolo I, Mingorance-Le Meur A, Martínez A, Del Rio JA, Wright CVE, Real FX, Soriano E (2007) Cerebellar GABAergic progenitors adopt an external granule cell-like phenotype in the absence of Ptfla transcription factor expression. Proc. Natl. Acad. Sci. U.S.A 104:5193-5198

Pasterkamp RJ, Giger RJ (2009) Semaphorin function in neural plasticity and disease. Curr. Opin. Neurobiol 19:263-274

Patil N, Cox DR, Bhat D, Faham M, Myers RM, Peterson AS (1995) A potassium channel mutation in weaver mice implicates membrane excitability in granule cell differentiation. Nat. Genet 11:126-129

Pepitoni S, Wood IC, Buckley NJ (1997) Structure of the m1 muscarinic acetylcholine receptor gene and its promoter. J. Biol. Chem 272:17112-17117

Piccolo S, Sasai Y, Lu B, De Robertis EM (1996) Dorsoventral patterning in Xenopus: inhibition of ventral signals by direct binding of chordin to BMP-4. Cell 86:589-598

Pichitpornchai C, Rawson JA, Rees S (1994) Morphology of parallel fibres in the cerebellar cortex of the rat: an experimental light and electron microscopic study with biocytin. J. Comp. Neurol 342:206-220

Pimenta AF, Zhukareva V, Barbe MF, Reinoso BS, Grimley C, Henzel W, Fischer I, Levitt P (1995) The limbic system-associated membrane protein is an Ig superfamily member that mediates selective neuronal growth and axon targeting. Neuron 15:287-297

Polleux F, Snider W (2010) Initiating and growing an axon. Cold Spring Harb Perspect Biol 2:a001925 
Polleux F, Ince-Dunn G, Ghosh A (2007) Transcriptional regulation of vertebrate axon guidance and synapse formation. Nat. Rev. Neurosci 8:331-340

Pouzat C, Hestrin S (1997) Developmental regulation of basket/stellate cell-->Purkinje cell synapses in the cerebellum. J. Neurosci 17:9104-9112

Prasad BC, Clark SG (2006) Wnt signaling establishes anteroposterior neuronal polarity and requires retromer in C. elegans. Development 133:1757-1766

Quitsch A, Berhörster K, Liew CW, Richter D, Kreienkamp H (2005) Postsynaptic shank antagonizes dendrite branching induced by the leucine-rich repeat protein Densin-180. J. Neurosci 25:479-487

Rakic P (1973) Kinetics of proliferation and latency between final cell division and onset of differentiation of cerebellar stellate and basket neurons. J. Comp. Neurol 147:523-546

Ramaswamy S, McBride JL, Han I, Berry-Kravis EM, Zhou L, Herzog CD, Gasmi M, Bartus RT, Kordower JH (2009) Intrastriatal CERE-120 (AAV-Neurturin) protects striatal and cortical neurons and delays motor deficits in a transgenic mouse model of Huntington's disease. Neurobiol. Dis 34:40-50

Raman IM, Bean BP. (1999) Properties of sodium currents and action potential firing in isolated cerebellar Purkinje neurons. Ann N Y Acad Sci. 30;868:93-6

Ramon \& Cajal S. (1890b) Sur le fibres nerveuses de la cauche granuleuse du cervelet et sur l’ évolution de éléments cérébelleux. Int. Monatschr. Anat. Physiol. 7, 447-468

Ramón \& Cajal, S. (1909 - 1911) Histologie du Systeme Nerveux de '1 Homme et des Vertébrés, 2 vols. Azoulay L. (trans.). Reprinted by Institituto Ramón y Cajal del C.S.I.C., Madrid, 1952-1955

Ramón \& Cajal, S. (1929) Étude sur la neurogenése de quelques vertébrés. Guth L. (trans.) Studies on Vertebrate Neurogenesis. Thomas, Springfield, Ill., 1960

Redies C, Luckner R, Arndt K (2002) Granule cell raphes in the cerebellar cortex of chicken and mouse. Brain Res. Bull 57:341-343

Reichelt J, Büssow H, Grund C, Magin TM (2001) Formation of a normal epidermis supported by increased stability of keratins 5 and 14 in keratin 10 null mice. Mol. Biol. Cell $12: 1557-1568$

Reifers F, Böhli H, Walsh EC, Crossley PH, Stainier DY, Brand M (1998) Fgf8 is mutated in zebrafish acerebellar (ace) mutants and is required for maintenance of midbrain-hindbrain boundary development and somitogenesis. Development 125:2381-2395

Rhinn M, Dierich A, Le Meur M, Ang S (1999) Cell autonomous and non-cell autonomous functions of Otx2 in patterning the rostral brain. Development 126:4295-4304

Rhinn M, Dierich A, Shawlot W, Behringer RR, Le Meur M, Ang SL (1998) Sequential roles for Otx2 in visceral endoderm and neuroectoderm for forebrain and midbrain induction 
and specification. Development 125:845-856

Rice DS, Curran T (2001) Role of the reelin signaling pathway in central nervous system development. Annu. Rev. Neurosci 24:1005-1039

Robertson E, Bradley A, Kuehn M, Evans M (1986) Germ-line transmission of genes introduced into cultured pluripotential cells by retroviral vector. Nature 323:445-448

Roybon L, Mastracci TL, Ribeiro D, Sussel L, Brundin P, Li J (2010) GABAergic differentiation induced by Mash1 is compromised by the bHLH proteins Neurogenin2, NeuroD1, and NeuroD2. Cereb. Cortex 20:1234-1244

Rubenstein JL (1998) Development of the cerebral cortex: V. Transcription factors and brain development Am Acad Child Adolesc Psychiatry. 37(5):561-2.

Ruthazer ES, Cline HT (2004) Insights into activity-dependent map formation from the retinotectal system: a middle-of-the-brain perspective. J. Neurobiol 59:134-146

Rutishauser U (1989) N-cadherin: a cell adhesion molecule in neural development. Trends Neurosci 12:275-276

Saito Y, Murakami F, Song WJ, Okawa K, Shimono K, Katsumaru H (1992) Developing corticorubral axons of the cat form synapses on filopodial dendritic protrusions. Neurosci. Lett 147:81-84

Sakisaka T, Takai Y (2004) Biology and pathology of nectins and nectin-like molecules. Curr. Opin. Cell Biol 16:513-521

Sasai Y, Lu B, Steinbeisser H, Geissert D, Gont LK, De Robertis EM (1994) Xenopus chordin: a novel dorsalizing factor activated by organizer-specific homeobox genes. Cell 79:779-790

Sato T, Araki I, Nakamura H (2001) Inductive signal and tissue responsiveness defining the tectum and the cerebellum. Development 128:2461-2469

Sauer B, Henderson N (1988) Site-specific DNA recombination in mammalian cells by the Cre recombinase of bacteriophage P1. Proc. Natl. Acad. Sci. U.S.A 85:5166-5170

Scelfo B, Sacchetti B, Strata P (2008) Learning-related long-term potentiation of inhibitory synapses in the cerebellar cortex. Proceedings of the National Academy of Sciences 105:769774

Schilling K (2000) Lineage, development and morphogenesis of cerebellar interneurons. Prog. Brain Res 124:51-68

Schilling K, Oberdick $\mathrm{J}$ The Treasury of the Commons: Making Use of Public Gene Expression Resources to Better Characterize the Molecular Diversity of Inhibitory Interneurons in the Cerebellar Cortex. The Cerebellum Available at: http://dx.doi.org/10.1007/s12311-009-0124-6 [Zugegriffen November 12, 2009].

Schmid C, Schwarz V, Hutter H (2006) AST-1, a novel ETS-box transcription factor, 
controls axon guidance and pharynx development in C. elegans. Dev. Biol 293:403-413

Schmidt H, Stiefel KM, Racay P, Schwaller B, Eilers J (2003) Mutational analysis of dendritic $\mathrm{Ca} 2+$ kinetics in rodent Purkinje cells: role of parvalbumin and calbindin D28k. J. Physiol. (Lond.) 551:13-32

Schüller U, Kho AT, Zhao Q, Ma Q, Rowitch DH (2006) Cerebellar 'transcriptome' reveals cell-type and stage-specific expression during postnatal development and tumorigenesis. Mol. Cell. Neurosci 33:247-259

Schwab MH, Druffel-Augustin S, Gass P, Jung M, Klugmann M, Bartholomae A, Rossner MJ, Nave KA (1998a) Neuronal basic helix-loop-helix proteins (NEX, neuroD, NDRF): spatiotemporal expression and targeted disruption of the NEX gene in transgenic mice. J. Neurosci 18:1408-1418

Schwab MH, Druffel-Augustin S, Gass P, Jung M, Klugmann M, Bartholomae A, Rossner MJ, Nave KA (1998b) Neuronal basic helix-loop-helix proteins (NEX, neuroD, NDRF): spatiotemporal expression and targeted disruption of the NEX gene in transgenic mice. J. Neurosci 18:1408-1418

Schwab MH, Druffel-Augustin S, Gass P, Jung M, Klugmann M, Bartholomae A, Rossner MJ, Nave K (1998c) Neuronal Basic Helix-Loop-Helix Proteins (NEX, neuroD, NDRF): Spatiotemporal Expression and Targeted Disruption of the NEX Gene in Transgenic Mice. J. Neurosci. 18:1408-1418

Schwaller B, Meyer M, Schiffmann S (2002) 'New' functions for 'old' proteins: The role of the calcium-binding proteins calbindin D-28k, calretinin and parvalbumin, in cerebellar physiology. Studies with knockout mice. The Cerebellum 1:241-258

Schwamborn JC, Püschel AW (2004) The sequential activity of the GTPases Rap1B and Cdc42 determines neuronal polarity. Nat. Neurosci 7:923-929

Scicolone G, Ortalli AL, Carri NG (2009) Key roles of Ephs and ephrins in retinotectal topographic map formation. Brain Res. Bull 79:227-247

Scott EK, Luo L (2001) How do dendrites take their shape? Nat. Neurosci 4:359-365

Seibt J, Schuurmans C, Gradwhol G, Dehay C, Vanderhaeghen P, Guillemot F, Polleux F (2003) Neurogenin2 specifies the connectivity of thalamic neurons by controlling axon responsiveness to intermediate target cues. Neuron 39:439-452

Serafini T, Kennedy TE, Galko MJ, Mirzayan C, Jessell TM, Tessier-Lavigne M (1994) The netrins define a family of axon outgrowth-promoting proteins homologous to $\mathrm{C}$. elegans UNC-6. Cell 78:409-424

Sharrocks AD (2001) The ETS-domain transcription factor family. Nat Rev Mol Cell Biol 2:827-837

Shen K, Bargmann CI (2003) The immunoglobulin superfamily protein SYG-1 determines the location of specific synapses in C. elegans. Cell 112:619-630 
Shen K, Fetter RD, Bargmann CI (2004) Synaptic specificity is generated by the synaptic guidepost protein SYG-2 and its receptor, SYG-1. Cell 116:869-881

Sherman DL, Brophy PJ (2005) Mechanisms of axon ensheathment and myelin growth. Nat. Rev. Neurosci 6:683-690

Shi S, Jan LY, Jan Y (2003a) Hippocampal neuronal polarity specified by spatially localized $\mathrm{mPar3/mPar6}$ and PI 3-kinase activity. Cell 112:63-75

Shi S, Jan LY, Jan Y (2003b) Hippocampal neuronal polarity specified by spatially localized $\mathrm{mPar} 3 / \mathrm{mPar} 6$ and PI 3-kinase activity. Cell 112:63-75

Shimizu C, Akazawa C, Nakanishi S, Kageyama R (1995) MATH-2, a mammalian helixloop-helix factor structurally related to the product of Drosophila proneural gene atonal, is specifically expressed in the nervous system. Eur. J. Biochem 229:239-248

Silbereis J, Cheng E, Ganat YM, Ment LR, Vaccarino FM (2009) Precursors with glial fibrillary acidic protein promoter activity transiently generate GABA interneurons in the postnatal cerebellum. Stem Cells 27:1152-1163

Simat M, Ambrosetti L, Lardi-Studler B, Fritschy J (2007) GABAergic synaptogenesis marks the onset of differentiation of basket and stellate cells in mouse cerebellum. Eur. J. Neurosci 26:2239-2256

Simeone A (2000) Positioning the isthmic organizer where Otx2 and Gbx2meet. Trends Genet 16:237-240

Simeone A, Puelles E, Acampora D (2002) The Otx family. Curr. Opin. Genet. Dev 12:409415

Skaper SD, Moore SE, Walsh FS (2001) Cell signalling cascades regulating neuronal growth-promoting and inhibitory cues. Prog. Neurobiol 65:593-608

Smith SL, Otis TS (2005) Pattern-dependent, simultaneous plasticity differentially transforms the input-output relationship of a feedforward circuit. Proceedings of the National Academy of Sciences of the United States of America 102:14901-14906

Smithies O, Gregg RG, Boggs SS, Koralewski MA, Kucherlapati RS (1985) Insertion of DNA sequences into the human chromosomal beta-globin locus by homologous recombination. Nature 317:230-234

Snow PM, Zinn K, Harrelson AL, McAllister L, Schilling J, Bastiani MJ, Makk G, Goodman CS (1988) Characterization and cloning of fasciclin I and fasciclin II glycoproteins in the grasshopper. Proc. Natl. Acad. Sci. U.S.A 85:5291-5295

Sohal VS, Zhang F, Yizhar O, Deisseroth K (2009) Parvalbumin neurons and gamma rhythms enhance cortical circuit performance. Nature 459:698-702

Solbach S, Celio MR (1991) Ontogeny of the calcium binding protein parvalbumin in the rat nervous system. Anat. Embryol 184:103-124 
Sommer L, Ma Q, Anderson DJ (1996a) neurogenins, a novel family of atonal-related bHLH transcription factors, are putative mammalian neuronal determination genes that reveal progenitor cell heterogeneity in the developing CNS and PNS. Mol. Cell. Neurosci 8:221-241

Sommer L, Ma Q, Anderson DJ (1996b) neurogenins, a novel family of atonal-related bHLH transcription factors, are putative mammalian neuronal determination genes that reveal progenitor cell heterogeneity in the developing CNS and PNS. Mol. Cell. Neurosci 8:221-241

Sorokin SP, Hoyt RF, Blunt DG, McNelly NA (1992) Macrophage development: II. Early ontogeny of macrophage populations in brain, liver, and lungs of rat embryos as revealed by a lectin marker. Anat. Rec 232:527-550

SPERRY RW (1963) CHEMOAFFINITY IN THE ORDERLY GROWTH OF NERVE FIBER PATTERNS AND CONNECTIONS. Proc. Natl. Acad. Sci. U.S.A 50:703-710

Stegmüller J, Huynh MA, Yuan Z, Konishi Y, Bonni A (2008) TGFbeta-Smad2 signaling regulates the Cdh1-APC/SnoN pathway of axonal morphogenesis. J. Neurosci 28:1961-1969

Stegmüller J, Konishi Y, Huynh MA, Yuan Z, Dibacco S, Bonni A (2006) Cell-intrinsic regulation of axonal morphogenesis by the Cdh1-APC target SnoN. Neuron 50:389-400

Sternberg N, Hamilton D (1981) Bacteriophage P1 site-specific recombination. I. Recombination between loxP sites. J. Mol. Biol 150:467-486

Steuber V, Mittmann W, Hoebeek FE, Silver RA, De Zeeuw CI, Häusser M, De Schutter E (2007) Cerebellar LTD and Pattern Recognition by Purkinje Cells. Neuron 54:121-136

Sugimoto Y, Furuno T, Nakanishi M (2009) Effect of NeuroD2 expression on neuronal differentiation in mouse embryonic stem cells. Cell Biol. Int 33:174-179

Suzuki A, Hirata M, Kamimura K, Maniwa R, Yamanaka T, Mizuno K, Kishikawa M, Hirose H, Amano Y, Izumi N, Miwa Y, Ohno S (2004) aPKC acts upstream of PAR-1b in both the establishment and maintenance of mammalian epithelial polarity. Curr. Biol 14:1425-1435

Takasu MA, Dalva MB, Zigmond RE, Greenberg ME (2002) Modulation of NMDA receptor-dependent calcium influx and gene expression through EphB receptors. Science 295:491-495

Takebayashi K, Takahashi S, Yokota C, Tsuda H, Nakanishi S, Asashima M, Kageyama R (1997) Conversion of ectoderm into a neural fate by ATH-3, a vertebrate basic helix-loophelix gene homologous to Drosophila proneural gene atonal. EMBO J 16:384-395

Takeichi M (2007) The cadherin superfamily in neuronal connections and interactions. Nat. Rev. Neurosci 8:11-20

Tamai I, Tsuji A (2000) Transporter-mediated permeation of drugs across the blood-brain barrier. J Pharm Sci 89:1371-1388

Tessier-Lavigne M, Goodman CS (1996) The Molecular Biology of Axon Guidance. Science 274:1123-1133 
Thach WT (1968) Discharge of Purkinje and cerebellar nuclear neurons during rapidly alternating arm movements in the monkey. J. Neurophysiol 31:785-797

Thomas KR, Folger KR, Capecchi MR (1986) High frequency targeting of genes to specific sites in the mammalian genome. Cell 44:419-428

Togashi H, Sakisaka T, Takai Y (2009) Cell adhesion molecules in the central nervous system. Cell Adh Migr 3 Available at: http://www.ncbi.nlm.nih.gov/pubmed/19372758 [Zugegriffen Mai 1, 2010].

de la Torre-Ubieta L, Gaudillière B, Yang Y, Ikeuchi Y, Yamada T, DiBacco S, Stegmüller J, Schüller U, Salih DA, Rowitch D, Brunet A, Bonni A (2010) A FOXO-Pak1 transcriptional pathway controls neuronal polarity. Genes Dev 24:799-813

Traub RD, Whittington MA, Colling SB, Buzsáki G, Jefferys JG (1996) Analysis of gamma rhythms in the rat hippocampus in vitro and in vivo. J. Physiol. (Lond.) 493 ( Pt 2):471-484

Trivedi N, Marsh P, Goold RG, Wood-Kaczmar A, Gordon-Weeks PR (2005) Glycogen synthase kinase-3beta phosphorylation of MAP1B at Ser1260 and Thr1265 is spatially restricted to growing axons. J. Cell. Sci 118:993-1005

Tsien JZ, Chen DF, Gerber D, Tom C, Mercer EH, Anderson DJ, Mayford M, Kandel ER, Tonegawa S (1996) Subregion- and cell type-restricted gene knockout in mouse brain. Cell $87: 1317-1326$

Uittenbogaard M, Chiaramello A (2000) Differential expression patterns of the basic helixloop-helix transcription factors during aging of the murine brain. Neurosci. Lett 280:95-98

Ushkaryov YA, Petrenko AG, Geppert M, Südhof TC (1992) Neurexins: synaptic cell surface proteins related to the alpha-latrotoxin receptor and laminin. Science 257:50-56

Van Aelst L, Cline HT (2004) Rho GTPases and activity-dependent dendrite development. Curr. Opin. Neurobiol 14:297-304

Van Duyne GD (2001) A structural view of cre-loxp site-specific recombination. Annu Rev Biophys Biomol Struct 30:87-104

Vannucci SJ, Maher F, Simpson IA (1997) Glucose transporter proteins in brain: Delivery of glucose to neurons and glia. Glia 21:2-21

Varoqueaux F, Aramuni G, Rawson RL, Mohrmann R, Missler M, Gottmann K, Zhang W, Südhof TC, Brose N (2006) Neuroligins determine synapse maturation and function. Neuron 51:741-754

Vessey JP, Karra D (2007) More than just synaptic building blocks: scaffolding proteins of the post-synaptic density regulate dendritic patterning. J. Neurochem 102:324-332

Voronova A, Baltimore D (1990) Mutations that disrupt DNA binding and dimer formation in the E47 helix-loop-helix protein map to distinct domains. Proc. Natl. Acad. Sci. U.S.A $87: 4722-4726$ 
Vos BP, Maex R, Volny-Luraghi A, De Schutter E (1999) Parallel fibers synchronize spontaneous activity in cerebellar Golgi cells. J. Neurosci 19:RC6

Wacker I, Schwarz V, Hedgecock EM, Hutter H (2003) zag-1, a Zn-finger homeodomain transcription factor controlling neuronal differentiation and axon outgrowth in C. elegans. Development 130:3795-3805

Wadsworth WG, Bhatt H, Hedgecock EM (1996) Neuroglia and pioneer neurons express UNC-6 to provide global and local netrin cues for guiding migrations in C. elegans. Neuron $16: 35-46$

Walsh FS, Doherty P (1997) Neural cell adhesion molecules of the immunoglobulin superfamily: role in axon growth and guidance. Annu. Rev. Cell Dev. Biol 13:425-456

Wang VY, Rose MF, Zoghbi HY (2005) Math1 expression redefines the rhombic lip derivatives and reveals novel lineages within the brainstem and cerebellum. Neuron 48:31-43

Weisheit G, Gliem M, Endl E, Pfeffer PL, Busslinger M, Schilling K (2006) Postnatal development of the murine cerebellar cortex: formation and early dispersal of basket, stellate and Golgi neurons. Eur. J. Neurosci 24:466-478

Wheelock MJ, Johnson KR (2003) Cadherins as modulators of cellular phenotype. Annu. Rev. Cell Dev. Biol 19:207-235

Whelan J, Cordle SR, Henderson E, Weil PA, Stein R (1990) Identification of a pancreatic beta-cell insulin gene transcription factor that binds to and appears to activate cell-typespecific expression: its possible relationship to other cellular factors that bind to a common insulin gene sequence. Mol. Cell. Biol 10:1564-1572

Wulff P, Schonewille M, Renzi M, Viltono L, Sassoe-Pognetto M, Badura A, Gao Z, Hoebeek FE, van Dorp S, Wisden W, Farrant M, De Zeeuw CI (2009) Synaptic inhibition of Purkinje cells mediates consolidation of vestibulo-cerebellar motor learning. Nat Neurosci 12:1042-1049

Wurst W, Bally-Cuif L (2001) Neural plate patterning: upstream and downstream of the isthmic organizer. Nat. Rev. Neurosci 2:99-108

Yagi T, Takeichi M (2000) Cadherin superfamily genes: functions, genomic organization, and neurologic diversity. Genes Dev 14:1169-1180

Yamada M, Ohnishi H, Sano SI, Nakatani A, Ikeuchi T, Hatanaka H (1997) Insulin receptor substrate (IRS)-1 and IRS-2 are tyrosine-phosphorylated and associated with phosphatidylinositol 3-kinase in response to brain-derived neurotrophic factor in cultured cerebral cortical neurons. J. Biol. Chem 272:30334-30339

Yamagata M, Weiner JA, Sanes JR (2002) Sidekicks: synaptic adhesion molecules that promote lamina-specific connectivity in the retina. Cell 110:649-660

Yamanaka H, Yanagawa Y, Obata K (2004) Development of stellate and basket cells and their apoptosis in mouse cerebellar cortex. Neuroscience Research 50:13-22 
Yan D, Guo L, Wang Y (2006) Requirement of dendritic Akt degradation by the ubiquitinproteasome system for neuronal polarity. J. Cell Biol 174:415-424

Yang Y, Kim AH, Yamada T, Wu B, Bilimoria PM, Ikeuchi Y, de la Iglesia N, Shen J, Bonni A (2009) A Cdc20-APC ubiquitin signaling pathway regulates presynaptic differentiation. Science 326:575-578

Yasumi M, Shimizu K, Honda T, Takeuchi M, Takai Y (2003) Role of each immunoglobulin-like loop of nectin for its cell-cell adhesion activity. Biochem. Biophys. Res. Commun 302:61-66

Yasunami M, Suzuki K, Maruyama H, Kawakami H, Nagai Y, Hagiwara M, Ohkubo H (1996) Molecular cloning and characterization of a cDNA encoding a novel basic helix-loophelix protein structurally related to Neuro-D/BHF1. Biochem. Biophys. Res. Commun 220:754-758

Ye W, Bouchard M, Stone D, Liu X, Vella F, Lee J, Nakamura H, Ang SL, Busslinger M, Rosenthal A (2001) Distinct regulators control the expression of the mid-hindbrain organizer signal FGF8. Nat. Neurosci 4:1175-1181

Yoshimura T, Arimura N, Kaibuchi K (2006) Molecular mechanisms of axon specification and neuronal disorders. Ann. N. Y. Acad. Sci 1086:116-125

Yuasa S, Kawamura K, Ono K, Yamakuni T, Takahashi Y (1991) Development and migration of Purkinje cells in the mouse cerebellar primordium. Anat. Embryol 184:195-212

Zervas M, Millet S, Ahn S, Joyner AL (2004) Cell behaviors and genetic lineages of the mesencephalon and rhombomere 1. Neuron 43:345-357

Zhang L, Goldman JE (1996) Developmental fates and migratory pathways of dividing progenitors in the postnatal rat cerebellum. J. Comp. Neurol 370:536-550

Zhai RG, Vardinon-Friedman H, Cases-Langhoff C, Becker B, Gundelfinger ED, Ziv NE, Garner CC (2001) Neuron 29(1):131-43

Zinn K, McAllister L, Goodman CS (1988) Sequence analysis and neuronal expression of fasciclin I in grasshopper and Drosophila. Cell 53:577-587

Zordan P, Croci L, Hawkes R, Consalez GG (2008) Comparative analysis of proneural gene expression in the embryonic cerebellum. Dev. Dyn 237:1726-1735

Zumbrunn J, Kinoshita K, Hyman AA, Näthke IS (2001) Binding of the adenomatous polyposis coli protein to microtubules increases microtubule stability and is regulated by GSK3 beta phosphorylation. Curr. Biol 11:44-49 


\section{Lebenslauf}

Vorname, Name: $\quad$ Alexander Pieper

Geburtsdatum: $\quad$ 11. März 1981

Geburtsort: $\quad$ Leipzig, Deutschland

Staatsangehörigkeit: deutsch

Ausbildung:

10/2006-09/2010 Promotion im Max-Planck-Institut für experimentelle Medizin in Göttingen, Abteilung Neurogenetik

Thema: "Untersuchung der Funktion des Kleinhirns mit Hilfe von Mausmutanten"

07/2006 - 09/2006 2-monatiges Forschungspraktikum im Bereich Chemieningenieurwesen im UNICAMP in Campinas (Sao Paulo, Brasilien)

Thema: „Entwicklung eines neuartigen Reaktors zur Extraktion mehrfach ungesättigter Fettsäuren aus Borretsch-Ö1““

08/2005 - 07/2006 Diplomarbeit im Max-Planck-Institut für experimentelle Medizin in Göttingen, Abteilung Neurogenetik

Thema: „Untersuchungen zur Funktion des basischen Helix-loopHelix-Transkriptionsfaktors NeuroD im Kleinhirn der Maus“

07/2005 Diplomprüfung Biologie

Hauptfach: Zoologie

Nebenfächer: Mikrobiologie; Botanik

04/2003 Vordiplomprüfung Biologie

Fächer: Chemie; Physik; Mikrobiologie; Botanik

10/2000 - 04/2005 Studium der Biologie an der Georg-August-Universität in Göttingen

10/2000 - 04/2005 Abiturprüfung in Burg bei Magdeburg

Publikationen:

Goebbels S, Bode U, Pieper A, Funfschilling U, Schwab MH, Nave KA, (2005) Cre/loxPmediated inactivation of the bHLH transcription factor gene NeuroD/BETA2. Genesis 42(4): 247-52. 


\section{Danksagung}

\section{Herzlicher Dank gilt}

meiner Betreuerin Dr. Sandra Goebbels, die mich stets unterstützt, gefördert und gefordert hat. Ich danke ihr für das Vertrauen, die eingeräumten Freiräume und den Rückhalt, um eigene Ideen innerhalb und jenseits des Projektes entwickeln und umsetzen zu können

meinem Anleiter Prof. Dr. Klaus-Armin Nave, der mich ebenfalls stets in meiner wissenschaftlichen Tätigkeit unterstützt hat und sich trotz vielseitiger wissenschaftlicher Verpflichtungen immer Zeit für konstruktive, positive und motivierende Gespräche nahm.

meinen Betreuern an der Biologischen Fakultät Prof. Dr. Nils Brose und Prof. Dr. Reinhold Hustert, die sich ebenfalls immer Zeit für mich nahmen und im Rahmen von Fortschrittsberichten und Gesprächen hilfreiche Anregungen zum Projekt gaben

Prof. Dr. André Fiala, Juniorprof. PD Dr. Ralph Heinrich und Dr. Judith Stegmüller für die Bereitschaft, sich meinem Prüfungsausschuss anzuschließen und die Flexibilität bei der Festsetzung des Disputationstermines

Assistent Prof. Dr. Jaques Wadiche und Dipl.-Biol. Stephanie Rudolph für die Durchführung elektrophysiologischer Experimente

Dr. Ingo Bormuth und M.Sc. Kuo Yan für die Durchführung zahlreicher in situ Hybridisierungen und die Beratung bei allen informatischen Fragestellungen

Dr. Sven Wichert ebenfalls für die Beratung bei informatischen Fragestellungen

Ulrike Bode für die langjährige Unterstützung, kompetente Beratung und Hilfe bei allen labortechnischen und experimentellen Fragestellungen

Anette Fahrenholz für die langjährige Unterstützung bei vielen histologischen und immunhistochemischen Analysen

Allen Mitarbeitern des Max-Planck-Instituts für Experimentelle Medizin für die ständige Hilfsbereitschaft und das Schaffen einer sehr angenehmen Arbeitsathmosphäre

Meinen Eltern, Großeltern und Svenja für Liebe. Rückhalt und kompromisslose Unterstützung jeder meiner Wege 